Portland State University

PDXScholar

1993

\title{
Evaluating the Effectiveness of Certain Metrics in Measuring the Quality of End User Documentation
}

\author{
Ronald Morrison \\ Portland State University
}

Follow this and additional works at: https://pdxscholar.library.pdx.edu/open_access_etds

Part of the Other Computer Sciences Commons

Let us know how access to this document benefits you.

\section{Recommended Citation}

Morrison, Ronald, "Evaluating the Effectiveness of Certain Metrics in Measuring the Quality of End User Documentation" (1993). Dissertations and Theses. Paper 1326.

https://doi.org/10.15760/etd.1325

This Dissertation is brought to you for free and open access. It has been accepted for inclusion in Dissertations and Theses by an authorized administrator of PDXScholar. Please contact us if we can make this document more accessible: pdxscholar@pdx.edu. 
EVALUATING THE EFFECTIVENESS OF CERTAIN IVIETRICS IN MEASURING THE QUALITY OF END USER DOCUMENTATION

\author{
by \\ RONALD MORRISON
}

A dissertation submitted in partial fulfillment of the requirements for the degree of

DOCTOR OF PHILOSOPHY

in

SYSTEMS SCIENCE: BUSINESS ADMINISTRATION

Portland State University

(C) 1993 
TO THE OFFICE OF GRADUATE STUDIES

The Members of the Committee approve the dissertation of Ronald Morrison presented August 3, 1993.
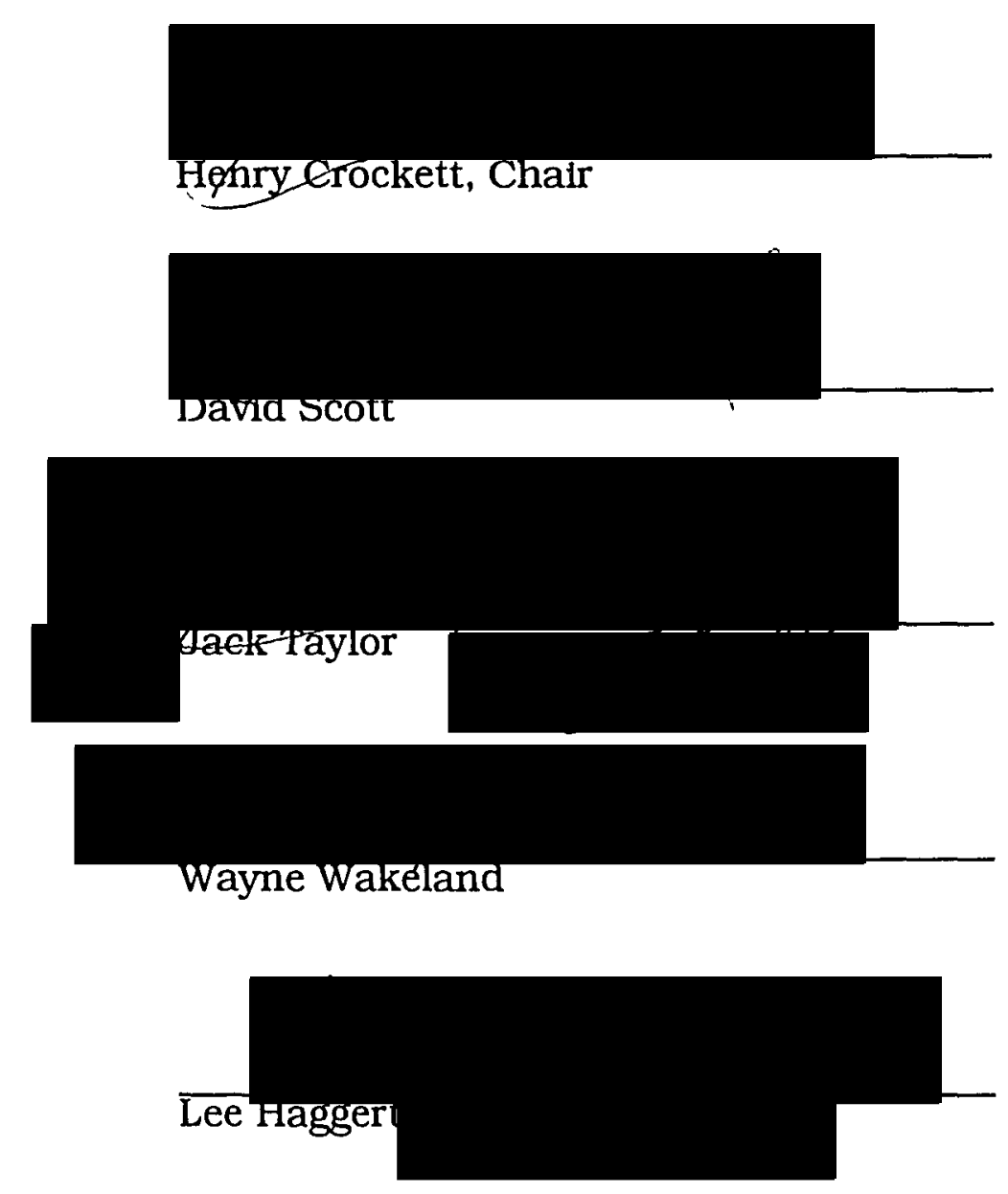

APPROVED:

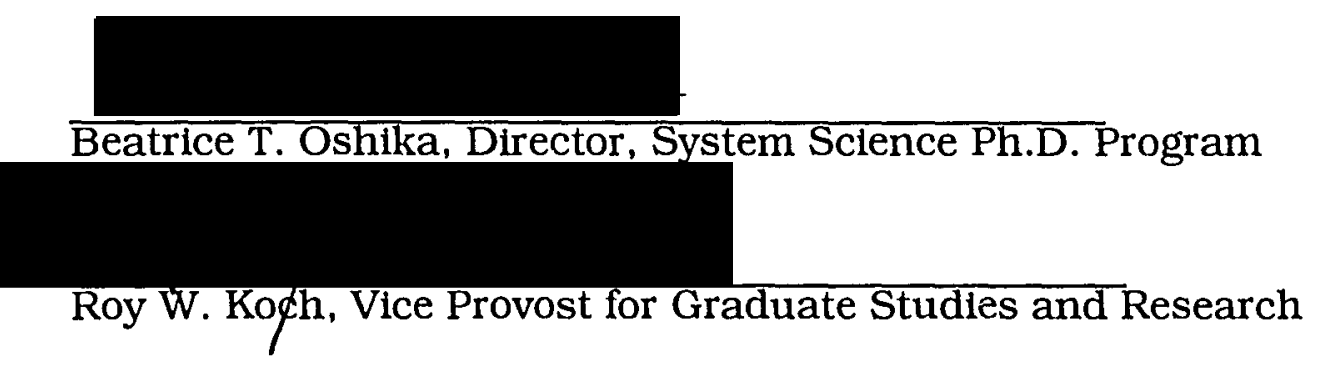


AN ABSTRACT OF THE DISSERTATION OF Ronald Morrison for the Doctor of Philosophy in Systems Science: Business Administration presented August 3, 1993.

Title: Evaluating the Effectiveness of Certain Metrics in Measuring the Quality of End User Documentation

APPROVED BY THE MEMEBERS OF THE DISSERTATION COMMITTEE

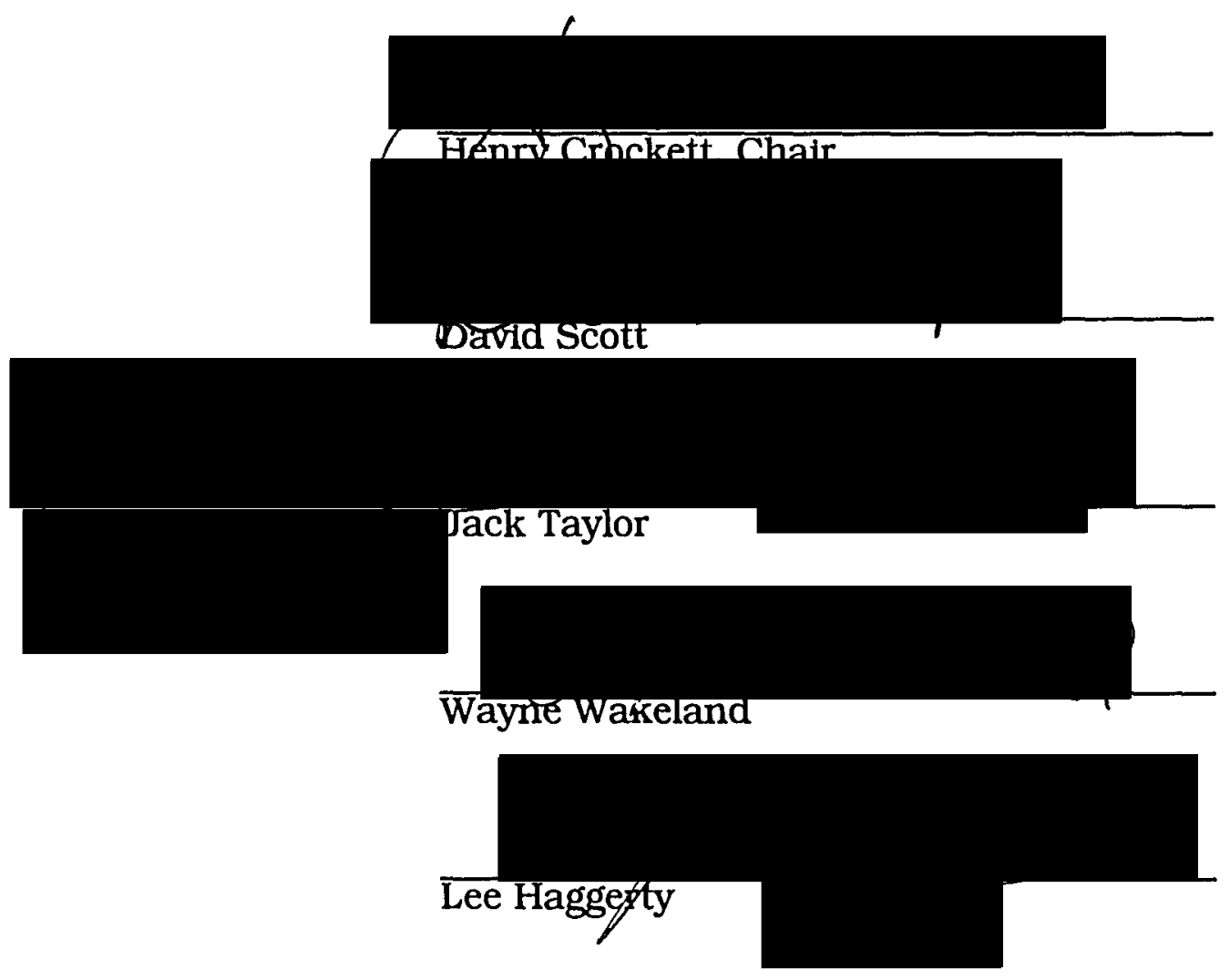

Traditional methods of evaluating quality in computer end user documentation have been subjective in nature, and have not been widely 
used in practice. Attempts to quantify quality and more narrowly define the essential features of quality have been limited -- leaving the issue of quality largely up to the writer of the user manual.

Quantifiable measures from the literature, especially Velotta (1992) and Brockman (1990), have been assembled into a set of uniformly weighted metrics for the measurement of document quality. This measure has been applied to the end user documentation of eighty-two personal computer packages. End user documentation is defined in terms of paper documents only. The research examined only those manuals that were titled "user guide," "training manual," "tutorial," or similar title. The research examined six categories of software: applications, graphics, utilities, spreadsheets, databases, and word processing.

Following the recommendation of Duffy (1985), a panel of experts was assembled and asked to evaluate several of the 82 end user manuals in order to determine what correlation exists between the set of metrics and the subjective opinion of experts.

The eighty-two documents in the sample were scored by the metrics using a convenient random sampling technique. This technique was selected based the consistency of the material in commercial software manuals and the methods of Velotta (1992). Data from the metrics suggest that there is little correlation between quality, category, price, page length, version number, and experience. On a scale of 0.0 to 1.0 , the minimum total score from the metrics was .2; the maximum score .83; the mean total score was .70 ; the median .697 with a standard deviation of .093 . The distribution is slightly skewed and leptokurtic 
(steeper than a normal curve). The metrics further suggest a declining score as the integration of sentences into chapters and chapters into the document progresses. Of the metrics two consistently had lower scores: those relating to the transition between sections of the document; and the reference tools provided.

Though not conclusive, the analysis of data from the panel of experts compared with the model results suggests only a moderate correlation. However, by varying the weighting scheme, it is possible to Improve model performance - essentially by "tuning" the model to match the sample data from the panelists. Further research would be required to verify if these weights have more global application. 


\section{ACKNOWLEDGMENTS}

I wish to thank the members of my dissertation committee (Henry Crockett, David Scott, Jack Taylor, Wayne Wakeland, and Lee Haggerty) for their support and their uncompensated time in helping me through my written examinations, oral examinations, and through the dissertation process. Without their support and time there would be no dissertation. I wish to thank the faculty and staff of the System Science Department for their efforts.

A special acknowledgment is appropriate to the software development firms listed in the Appendix, who provided evaluation copies of software for use in the research. Without their support of higher education and this dissertation in particular, universities would be unable to provide graduate level research to create a better trained workforce. I would hope everyone who reads this document will consider purchasing their products.

Finally, I would like to expressly thank the members of my family who supported me both financially and morally throughout my graduate study process, which went well beyond the single Masters degree started in 1988. Without their express approval and support none of this would have been possible given the long distances I had to commute and the large number of hours I wrre required to spend away from home. 
TABLE OF CONTENTS

PAGE

ACKNOWLEDGMENTS. . . . . . . . . . . . . . . II

LIST OF TABLES $\ldots \ldots \ldots \ldots \ldots \ldots \ldots \ldots$ vill

LIST OF FIGURES $\ldots \ldots \ldots \ldots \ldots \ldots \ldots \ldots \ldots$ ix

CHAPTER

I INTRODUCTION $\ldots \ldots \ldots \ldots \ldots \ldots \ldots \ldots \ldots \ldots$

Plan and Definitions. . . . . . . . . . . . . . . .

General Definition of Quality. . . . . . . . . . . . . .1

Definition of End User Manuals. . . . . . . . . . . . .

Two Critical Assumptions . . . . . . . . . . . . . .5

II REVIEW OF THE LITERATURE . . . . . . . . . . . 6

Computer Science Literature: The Human-

Computer Interface . . . . . . . . . . . . . .6

User Manuals: Experimental Studies. . . . . . . . . . . . .7

Computer Sclence Graphics Literature . . . . . . . . . . . 10

Technical Writing Literature and User

Documentation .......................11

Traditional Neglect . . . . . . . . . . . . . . . 11

Documentation guality . . . . . . . . . . . . . . 12

Graphic Elements in Documents. . . . . . . . . . . 13

Literature Regarding Measurement of Document

Quality . . . . . . . . . . . . . . . . . . . . . . 14

Measurement. . . . . . . . . . . . . . . . . . . . . 14

Readability. . . . . . . . . . . . . . . . . 16

Reference Aids Metrics . . . . . . . . . . . . . . 20

Graphical Metrics. . . . . . . . . . . . . . . . . . 22

Typographic Metrics . . . . . . . . . . . . . . . . 29

III THE PROPOSED MODEL . . . . . . . . . . . . . 32

Model Structure . . . . . . . . . . . . . . . . . 32 
Document (Level 1). . . . . . . . . . . . . . . . . . . . 34

Chapter and Paragraph (Level 2) . . . . . . . . . . .35

Sentence (Level 3). . . . . . . . . . . . . . . . . . . .37

Final Score . . . . . . . . . . . . . . . . . . . . . 40

Explanation of Example . . . . . . . . . . . . 40

IV RESEARCH METHODOLOGY . . . . . . . . . . . . . . . . . . 44

The Hypothesis and Overall Research Process . . . . . . . . .45

The Research Hypothesis $\ldots \ldots \ldots \ldots \ldots \ldots$

The Research Process. . . . . . . . . . . . . . . . . 45

Sampling Issues and the Scoring Process . . . . . . . . . 47

Selection of the Sample from a Given

Document . . . . . . . . . . . . . . . . . . 48

Selection of the Evaluation Platform ..........49

Selection of the Specific Software Packages . . . . . . . .53

Processing the User Manuals . . . . . . . . . . . . 53

Model Validity . . . . . . . . . . . . . . . . . . . 55

General Approach . . . . . . . . . . . . . . . . . 56

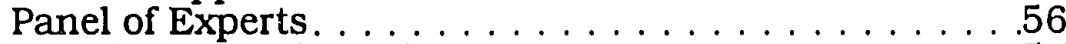

Initial Survey of Panel. . . . . . . . . . . . . . 57

Scoring of Documents by the Panel . . . . . . . . . . .58

Comparison of the Panel Scores to the Model . . . . . . . .59

Evaluation of the Consistency of the Model and

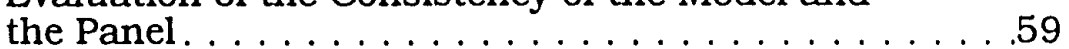

Testing of the Research Hypothesis . . . . . . . . 60

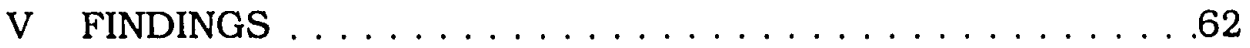

Analysis of the Model . . . . . . . . . . . . . . . . . .62

Data from the Model. . . . . . . . . . . . . . . . . .63

Levels and Categorles in the Model . . . . . . . . . . . 66

Internal Consistency of Samples . . . . . . . . . . . . . . .72

Statistical Analysis of the Model . . . . . . . . . . . . . . .74

Analysis of the ranelist Data $\ldots \ldots \ldots \ldots$. . . . . . . . .

Selection of the Panel of Experts . . . . . . . . . . . .82

Scoring by the Panel. . . . . . . . . . . . . . . . . 82

Data from the Panel of Experts . . . . . . . . . . . . . . .83

Internal Consistency of the Panel . . . . . . . . . 85

Statistical Analysis of the Panel of Experts . . . . . . 85

Analysis of the Model and Panelist Data . . . . . . . . . . 87

Statistical Tests of Hypothesis. . . . . . . . . . . .88 
Statistical Analysis of Combined Data . . . . . . . . . . 90

Factor Analysis . . . . . . . . . . . . . . 93

Observations. . . . . . . . . . . . . . . . . .98

Obtaining Evaluation Copies. . . . . . . . . . . . . . . 98

Volume of Material . . . . . . . . . . . . . . . . . . . . 999

Timing. . . . . . . . . . . . . . . . . . . .99

Formats. . . . . . . . . . . . . . . 100

Writing Styles. . . . . . . . . . . . . . . . . . . 100

Graphics ......................101

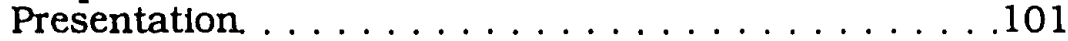

Style . . . . . . . . . . . . . . . . . . . 102

Training Aids . . . . . . . . . . . . . . . . . . 102

Reference Alds . . . . . . . . . . . . . . . . . 103

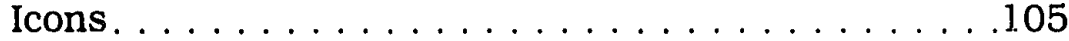

Product Depth . . . . . . . . . . . . . . . . 106

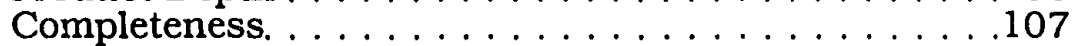

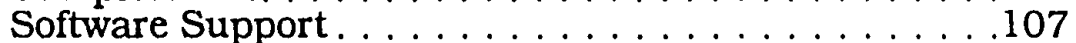

Descriptive Statistics . . . . . . . . . . . . . 108

VI CONCLUSIONS AND IMPLICATIONS . . . . . . . . . . . 109

Conclusions . . . . . . . . . . . . . . . . . 109

Potential Relationships That are More Complex

110

Intervening Variables . . . . . . . . . . . . . . . . 110

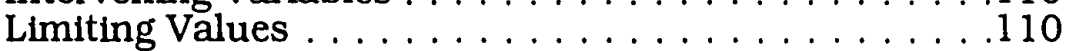

Implications of the Research. . . . . . . . . . .111

Indications for Future Research $\ldots \ldots \ldots \ldots \ldots 112$

Range of Samples. . . . . . . . . . . . . . . . . . . . . 112

Analysis of the Converse Model . . . . . . . . . .113

Improvement of the Model. . . . . . . . . . . . . .113

Time Series Analysis of Documentation . . . . . . . .114

Platform, Processor Studies

(MAC,UNIX,OS/2,MVS,DEC). . . . . . . . . . . . . . . .114

Research on Completeness and Development of

Metrics .........................114

Evaluation of Additional Materials. . . . . . . . . . 115

BIAS of Expert Judges . . . . . . . . . . . . . . . . . . . . 115

Development of End User Documents as a

Computer Semiotic Register . . . . . . . . . . . . . . 115

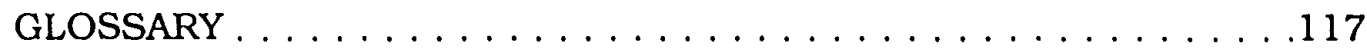

REFERENCES . . . . . . . . . . . . . . . . . . . . . . . . . . . 122 
APPENDIXES

A FIRMS WHO SENT EVALUATION COPIES . . . . . . . 130

B INSTRUCTIONS TO PANEL OF EXPERTS . . . . . . . . . 134

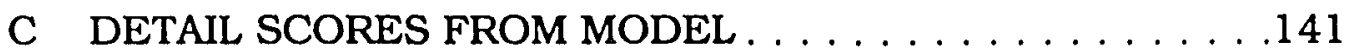

D DETAIL DATA FROM PANEL OF EXPERTS. . . . . . . . . . . 172

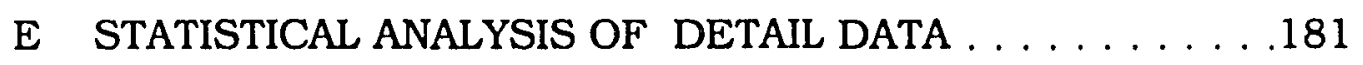




\section{LIST OF TABLES}

TABLE

PAGE

I Summary of Total Scores. . . . . . . . . . . . . . . . .74

II Summary of Document Level Statistics. . . . . . . . .76

III Summary of Chapter Level Statistics $\ldots \ldots \ldots \ldots \ldots \ldots .78$

IV Summary of Text Statistics. . . . . . . . . . 1

V Panelist Scoring Pattern . . . . . . . . . . .86

VI Sign Test Calculation. . . . . . . . . . 86

VII F Test of Data from Model and Experts . . . . . . . . .89

VIII T Test Paired Data from Model and Experts. . . . . . . .90

IX Correlation of Category Items $\ldots \ldots \ldots \ldots \ldots \ldots \ldots$

X Correlation of Experts and Document Levels . . . . . . . .92

XI Correlation of Expert Score and Variables . . . . . . .93 


\section{LIST OF FIGURES}

FIGURE

PAGE

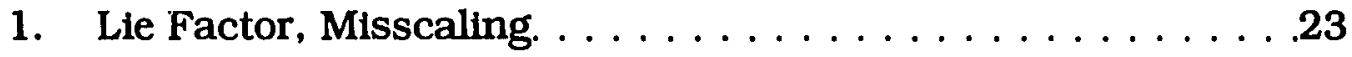

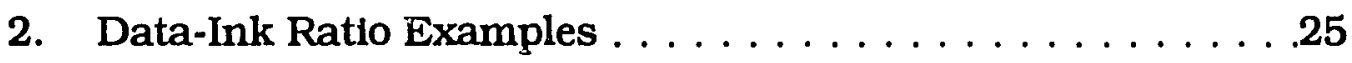

3. Ducks - Chart Junk, Vibrations, Grids, Bad Art. . . . . . 27

4. Computer Generated Duck. . . . . . . . . . . 28

5. Typographic Recommendations. . . . . . . . . . .30

6. Levels of Measurement in a Document . . . . . . . 33

7. The Model . . . . . . . . . . . . . . . . . 34

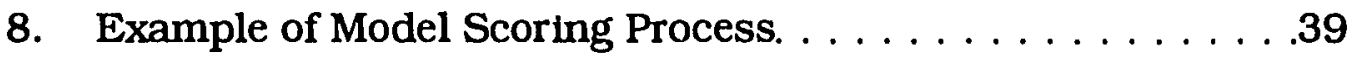

9. Flowchart of Research Process $\ldots \ldots \ldots \ldots \ldots \ldots \ldots$

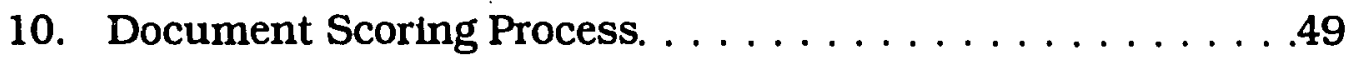

11. Plot of Total Model Score for Manual . . . . . . . . . . . .64

12. Plot of Model Score vs Retall Price $\ldots \ldots \ldots \ldots \ldots \ldots$

13. Plot of Model Score vs Numeric Category. . . . . . . . . . 66

14. Plot of Level vs Numeric Category. . . . . . . . . . . . .67 
15. Model Score by Application Category with Equal Weights . . . . . . . . . . . . . . 68

16. Score by Model Category with Variable Weights. . . . . . . .69

17. Sentence Level 3 Score vs Numeric Category. . . . . . . . . .70

18. Sentence Level 3 Score Weighted by Number of Variables . . . . . . . . . . . . . . . . 71

19. Frequency Distribution Document Level $1 \ldots \ldots \ldots$. . . . .76

20. Chapter Level 2 Frequency Distribution $\ldots \ldots \ldots \ldots \ldots 77$

21. Frequency Distribution of Sentence Level 3. . . . . . . . .79

22. Frequency Distribution of Text Scores . . . . . . . 80

23. Radar Plot of Expert Scores on Packages. . . . . . . . . . 84

24. Plot of Expert and Model Scores. . . . . . . . . . . . 88

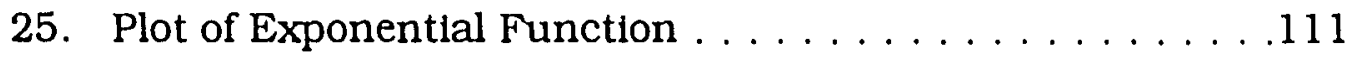




\section{CHAPTER I}

\section{INTRODUCTION}

\section{PLAN AND DEFINITIONS}

This dissertation explores the relationship between objective and subjective evaluation of document quality. Specifically, a number of quantitative measures are applied to end user documentation, referred to hereafter as user manuals, for a sample of popular computer programs. The resulting scores are compared to the evaluations of a panel of experts to determine the relationship between the metrics and expert judgment.

The journey begins by exploring the general definition of quality, defining user manuals, and specifying assumptions critical to the research.

\section{General Definition of Quality}

Each of us has a preconcelved notion of what quality means. Traditionally, we have held the notion that quality means "the best." In the context of this paper, expert opinion will be used to clarify quality into an operational term that can be measured and improved.

Quality is defined by Crosby (Oakland 1990 292-293) as conformance to specifications. Juran (Oakland 1990 292-293) defines quality in part as fitness for use or fitness for purpose. Recently, Juran has added "frecium from trouble." Further, quality is defined as doing 
things right the first time. That is, an organization seeks to eliminate waste and repetitive effort. Deming has described this as "a predictable degree of uniformity and dependability at low cost and suited to the market." (Oakland 1990 292-293)

From Juran's point of view, a quality product must be able to perform its function. This does not necessarily mean that the product is the best on the market.

Clearly these general definitions of quality are not sufficient to guide this research. As illustrated in the literature search that follows, user manual quality is defined implicitly via expert opinion and explicitly via a set of certain measures found in the literature search.

\section{Definition of End User Manuals}

User Manuals, sometimes called an instruction manuals, are the manual(s) accompanying the software that provide instructions on how to use the software and advice on how to improve one's skills. For the purposes of this study, only the documents that accompany the original computer software are considered. "Third party" books about software that do not accompany the software from the system developer are not considered in this study. It might be possible to conduct an entire research project on the topic of why after market books are published and who purchases them. This dissertation does not, however, address these questions.

If the instructions on how to use the software are imbedded in the computer programs themselves, they are called on-line help, on-line tutorials, on-line documentation, or Hypertext. In this case, the end user 
instructions will replace the software activities on the screen and multiple screens will be used to show information. For the purposes of this dissertation, on-line documents and other electronic media are not considered by ["definition"] to be user manuals because they do not support the following functions:

1. The user manual and the computer software must be capable of being viewed simultaneously without one blocking the view of the other. That is, the on-line help information cannot replace the computer software screens for even an instant, because the end user (customer) cannot view both at the same time and see the relation between the information and the software.

2. The user manual must be portable in that it can easily be moved from place to place and not require special equipment to view it. As such, the user manual is then restricted to physical forms such as books, magazines, posters, and the like.

3. The user manual must be able to be viewed by more than one person at a time. When asking for help and assistance, more than one person may read and voice an interpretation of the written words which may have different meanings depending upon the context in which they are used.

4. The user manual must have the capability of being viewed in more than one place at the same time so that the end user may cross reference information in several different 
places in order to better understand the information presented in the user manual. For example, a book can have a series of pages folded over to open the book to two passages at the same time.

An experiment by Dunsmore (1980) suggests that on-line documentation is not as effective as written documentation and is not as effective as minimal documentation as discussed later in the literature review. Given the advances in technology since 1980, it would be interesting to repeat Dunsmore's experiment to determine if the on-line documentation now available is more effective or has technology merely "glamorized" the interface. Unfortunately, it is beyond the scope of this research to answer this question.

Brockman (1990), Shneiderman (1987), and Gould et al. (1987) cite several studies indicating that paper documents can be read and understood more quickly than electronic media. In some cases electronic media creates more than a $25 \%$ penalty in reading speed. Mynatt, Leventhal, et. al (1992) suggest that a well designed Hypertext system may be better for answering questions, but their experiments have been inconclusive. Electrontc on-line help documents are popular because they "hide" the volume of information from the reader. As such, the reader will not be intimidated by the physical size of the document. Electronic documents are also more easily revised, and much cheaper to reproduce than paper documents.

Written user manuals are important because they: (1) represent the initial communication link between the application user and the 
software, (2) serve as the reference to look up procedures to use the software, and (3) serve as the initial training tool.

For the above cited reasons this research focuses on written user manuals.

\section{Two Critical Assumptions}

In this study it is assumed that: 1) the contents of the user manuals are accurate, and 2) that the document is complete. Complete means that the software developer included in the user manual all of the necessary information to use the application. The study of completeness is beyond the scope of this dissertation.

Chapter II revlews the pertinent literature where various quantitative measures of document quality are identified. Chapter III presents the proposed quantitative model used to score user manuals. Chapter IV describes the methodology used to test the model against expert opinion. Chapter V presents the results including general observations regarding data collection in the model, and the comparative analysis of the quantitative data of the model. Chapter VI concludes the exploratory study and identifies future areas of research. 


\section{CHAPTER II}

\section{REVIEW OF THE LITERATURE}

The literature pertinent to end user documentation includes computer science, technical writing, and literature on the measurement of document quality.

\section{COMPUTER SCIENCE LITERATURE: THE HUMAN-COMPUTER INTERFACE}

Covington (1985 165) states: "Documentation is arguably more Important than programming. After all the program becomes usable only through documentation."

Cooke (1984 64) has the following to say about documentation: "... Manuals are given out along with pencils and staplers. Making documentation as much a part of the working environment as other everyday tools helps improve productivity, increase employee loyalty, and create a positive working atmosphere."

Sohr (1983 286) has a different perspective on user manuals: "Software Manuals today are like the bicycle-assembly instructions of yesterday - those notorious documents responsible for unassembled bicycles left rusting away in basements everywhere."

The traditional approach of the software industry towards software documentation is described by Sohr (1983 286): "Lets face It, many software manuals are patchwork affairs thrown together at the last minute either by programmers or by technical writers who write too 
technically. Both assume that the user, given a few scraps of information, can figure out the rest."

These rather contradictory views suggest that there is clearly opportunity for improvement. This section will focus on experimental studies within the computer science field regarding user manuals followed by a few comments regarding graphics.

\section{User Manuals: Experimental Studies}

This section briefly reviews the results of eight relevant surveys by a variety of authors and organizations.

Roemer \& Chapanis (1982) found a correlation between the reading ability of the user and their performance, where as the complexity of the writing style was not correlated. Users, however, preferred the lowest level of complexity in documentation.

The Foss \& Rothman study (1982) suggests that user manuals organized around task performance using simple language increases the number of tasks performed, reduces time for each task, reduces commands for each task, and reduced number of help requests. Apriori design of documentation seems better than last minute haste.

A study of user manual organization (Rowland and Williams 1989) suggests that design, layout and other human factors can improve the quality of user manuals before they are created. In contrast, the Comstock and Clemens (1987) study, which focused on user satisfaction with respect to a small set of manuals, found that users liked small binders with tab dividers, page headers, lllustrations, and liked 
consistency in manual organization. They also like good use of examples, lllustrations, tables and highlighting.

Mayhew (1992) suggests the following guidelines for user manuals:

- Ease of Navigation

- Organize and label chapters and sections according to users goals

- Table of contents should provide high level overview.

- Index should have entries for both user goals and operation names.

- Separate different types of information and use a consistent visual clue for each

- Ease of Learning

- Provide foundation and build on it

- Teach in layers and in small independent units with dependent units of information

- Teach in a logical sequence, avold forward references.

- Provide complete information to do a task.

- Give examples

- Provide illustrations

- Make consistent use of spatial locational clues.

- Avoid abstract, formal notation

- Use visual, spatial representations and analogies

- Lead users to draw inferences

- Avold anthropomorphism (the attributing of human shape or characteristics to gods, objects, animals)

- Provide section on trouble shooting 
- Documentation should be consistent

- Ease of Reading

- Make use of white space

-Write at the fifth-grade reading level

- short simple sentences

- short familiar words

- short paragraphs

- active voice

- avoid negatives

- order instructions chronologically

- avold hyphenation

- do not right justify

- 50-55 characters per line or multiple columns

- Avoid unnecessary jargon

A 1982 Xerox survey and a 1986 Control Data survey by Hasslein found manuals to be software-oriented rather than function-oriented, did not have enough examples, and did not have enough reference aids.

A 1986 AT\&T External documentation survey found users wanted the following features:

- Easy to find reference alds recommended by users

- Easy to understand

- Complete, accurate, and up-to-date

- $81 / 2 \times 11$ page size preferences, (contradicted in the 1984 IBM survey)

- Good indexes Important

- Attractive screens, artwork, and drawings 
- Color was not important to a majority of respondents

A 1984 survey by Borland (regarding Microsoft Corporation documentation) found that end users wanted:

- Task oriented tutorials

- Screen illustrations

- Glossaries with terms

- Reference cards with conmmands and tasks

- Feature-oriented command index plus task-oriented command index

- Task-oriented organization

- "Phone book" type reference manual to describe all features

- Troubleshooting guides

A 1985 PC user group survey by Wilton (Brockman 1990 51) of what end users wanted vs what was delivered found:

- Manuals did not accommodate all users

- Tutorials helpful

- Illustrations insufficient

- Information hard to find

\section{Computer Science Graphics Literature}

The literature on graphics has been strongly focused on Cathode Ray Tube (CRT) images rather than the printed material used to document software. Scholtz, Young, and Olmsted (1992) discuss the aesthetic quality of interfaces with respect to graphics by using symmetry and balance, but do not provide any metrics to measure graphics in these terms. Tullis (1981) presents some research on 
comparing alphanumeric, graphic, and color information displays. He also presents mixed results on other studies that fall to offer any particular advantage of graphics over text. The results on color fall to define any significant advantage to color over black and white graphics.

\section{TECHNICAL WRITING LITERATURE AND USER DOCUMENTATION}

This section is divided into a discussion of the traditional neglect of user manuals by the writing field, a discussion of document quality, and comments regarding graphic elements in documents.

\section{Traditional Neglect}

In the past, user documentation has received very little emphasis, and that emphasis has been on the technology and jargon surrounding the information system itself. For example, Gray (1969) devoted almost 170 pages to documentation standards for computer systems but only 5 pages to user documentation. He argued that the user manual should be completed before system test, but should be delayed as long as possible to make it as accurate as possible. 1 Robinson (1973) devoted one page of his 100 page trade association guide on system development to the subject of user documentation. The majority of this page was a list indicating which portions of the information systems documentation should be copled into a separate booklet for the user, ignoring the educational level, training level, user focus, and other essential elements that are used by Brockman (1990).

1 It may well be that the traditional neglect and delay in producing documents has been in the interest of accuracy but nevertheless the final product always ends up being hastily completed. 
Crown (1992 13) argues that documentation fails because of user attitudes, management attitudes, and writer attitudes. Users can't find information, can't understand information, and are too lazy to look for information. Additional user problems are that the information is outdated, documentation is too long, and there are not enough copies. In addition, management is in a time squeeze, refuses to acknowledge value of documentation, falls to communicate, and is constrained by budget limitations. Also, writers have incomplete understanding of the system, value appearance over content issues, and value truth over clarity.

According to Weiss (1982 130):

"From the Earliest Days, programmers, analysts, and computer salespeople have been enjoined to think of the user, to be user oriented, to concentrate on the uses of the system and not the system itself. But these injunctions have largely failed.

Ironically, even though computer systems have been increasingly easier for ordinary people to use, computer documents have become more and more arcane. Computer professionals seem no more eager to speak and write in plain English than ever. In fact, with the tremendous growth in the industry, it is now possible for computer people to go for weeks at a time without having to communicate with a single 'civilian.' And their writing is generally among the most cryptic and dense of all the technical occupations."

\section{Documentation Quality}

Since the essence of end user documentation is to describe how to use the software, many of the concepts related to software quality will apply to the quality of user manuals. Boehm (1978) defines software quality in terms of eight areas:

1. Understandability

2. Completeness 
3. Conciseness

4. Portability

5. Consistency

6. Maintainability

7. Testability

8. Usability

Each of these areas of quality has a parallel in user manuals. The end user must be able to understand the terminology and concepts in the manual. The manual must be complete enough for the user to use the software and it must deliver the relevant concepts and instruction in a concise form the user can immediately grasp and follow. The user manual must be portable enough to be carried from place to place for assistance or study. The user document must be maintainable as the software is changed and as improved methods of writing are introduced. Finally, the user manual must be usable for its intended purpose.

\section{Graphic Elements in Documents}

According to Jonassen (1984) graphics serve 3 roles in documents: attentional, explicative, and retentional. He further reports on research by Pavio in 1975 that demonstrates pictures are remembered better than words. He asserts that while illustrations serve as "summary statements presented in graphic form," diagrams and charts do not create equal benefits for readers. Jonassen reports results from Goody (1977) suggesting that since no direct oral equivalents for charts exist, the mind therefore is required to analyze and process these items using special skills (abstraction, visualization, pattern recognition, 
etc.). Further elaboration by Wright in Jonassen (1984), suggest that design is a critical factor in determining whether or not charts and diagrams will be understood.

In his seminal works on graphic design, Tuft $(1983,1990)$ presents many examples of both good and poor graphic design elements and how they are used to create visual palettes of information that allow the transfer of multidimensional data in two dimensions. While Tuft's work provides notions of what good graphic design is, the literature does not indicate how Tuft's ideas might be quantified into metrics. This is discussed further in the following section.

\section{LITERATURE REGARDING MEASUREMENT OF DOCUMENT QUALITY}

This section is divided into measurement, readability, reference aids metrics, graphical metrics, and typographical metrics.

\section{Measurement}

This section considers three concepts: 1) relative importance of part of a document, 2) level of language, and 3) minimal vs complete or usable vs complete.

1) It seems likely that certain portions of an user manual are more "important" than others. Some research relative to computer program code suggests some applicability to the area of user manuals. Berns (1984) developed a list of point values and weights for measuring computer program maintainability and complexity.

2) Fitzsimmons (1978) and Halstead (1979) conducted research regarding the "level of a language" (difficulty level) and its volume 
(number of words) and how they relate to the difficulty of understanding. Halstead applied these concepts to a select group of abstracts from certain journals to determine if the relationship had some validity.

It has been argued that reading level, which is different than language level, does not impact understanding, Roemer and Chapnis (1986). Alan Boyd, quoted in Brockman (1990 94) stated of his firm's conversion of manuals from the Macintosh platform to IBM PC platform: "When we write the manual for the IBM PC version, we'll put in longer words."

3) Scholtz (1992) conducted tests comparing "minimal" manuals (those containing only the very basic information needed to operate the software) with traditional manuals (that included more complete information). The results indicate that the usability of a minimal manial and a traditional manual were the same. However, the tests involved performing basic tasks only, and did not involve using the manuals for reference, research, or testing the limits of the software. Thus it is possible that experienced users might consider a minimal manual to be too incomplete to be useful.

These results from Scholtz seem to indicate that document usability may not correspond to document quality, nor vice versa.

Carroll (1990) alludes to a sort of Heisenberg Uncertainty Principle that a document cannot be both complete and usable. A usable manual, therefore may lack certain elements essential to a quality document. Usabllity is a concept in the mind of the manual writer as well as the ultimate user of the software. Hopefully, there will be a very large 
overlap in meaning, but there may not be, as some documents suggest, [e.g. Brockman (1990 101), Carroll (1990 chap 4)].

\section{Readabillty}

Many measures of the understanding of printed material have been attempted in order to quantify the quality of printed documents in general. Scandinavian PC Systems (1987) produced software that measured the following characteristics of documents:

- Long words vs words per sentence

- Style: Simple, normal, narrative, foggy, wordy, elegant, difficult, pompous, complicated

- Percentage of long words per sentence

- Sentence length

- Consecutive short words

- Consecutive long words

- Word lengths

- Bricks - Words that are used repeatedly

- Mortar and Bricks: 400 most commonly used English words plus bricks

- Synonym list

- Sentence characteristics beginning to end

- Long words per sentence

- Sentence lengths

- General evaluation: focal point from ideal, variation, compliance with ideal, readabllity index, mortar percentage, short word sent percent. 
A popular index, the FOG index developed by Robert Gunning in the 1940s, (Weiss 1982 166) is:

$\mathrm{FOG}=(.4 \mathrm{x}$ \# of words $/$ \#of sentences $)+100 \mathrm{x}$ \# of words longer than 6 letters / \# of words in text)

A related measure the Readabllity index developed by Rudolf Flesch in the early 1950s, (Weiss 1982166 ) is similar to the FOG index except that the constant of .4 above has been dropped creating a measure that is roughly 2.5 times higher than the FOG index. The Readabllity index can be represented as:

$\mathrm{R}=$ average \# of words per sentence $+100 \times$ (Average \# of words per sentence / average \# of long words per sentence)

In a similar vein, the Flesch-Kincaid formula predicting grade level (GL) for grades 6 - 10 has been revised by the U.S. Military (DOD MIL-M$38784 \mathrm{~B})$, to require contractors to produce manuals to this metric for use by the Department of Defense (Rightwriter 1991 8-3), Weiss (1982 166):

$\mathrm{GL}=.39 \times$ average sentence length $+11.8 \times$ (average \# of syllables per word) -15.59

Another measure, the "Flesch formula", has been used by the insurance industry to measure for readability of insurance policies, Rightwriter (1991 8-3). It ranges from 0-100 and is calculated by:

$\mathrm{F}=206.8-1.015 \times$ (average sentence length) $-84.6 \times$ (average number of syllables per word).

As of 1979, Duffy (1985) reports over 100 different readabllity formulas. New ones are being created because the exdsting inventory does not correctly measure the desired variables. Duffy further reports 
"Existing readability formulas have come under considerable criticism because the predictor variables included in the formulas are not the underlying factors that cause variations in comprehension." Current software packages use many of the above formulas with some standardization on the Flesch-Kincaid formula.

Duffy further elaborates that readability measures fall to take into account motivation, comprehension and other factors. "because the formulas rely on a few simple properties of the completed text they do not provide a valid index of the many factors of document design that have impact on a document's usefulness." He suggests that experienced judges be used to determine document quality, but to date there have been no controlled studies to support the effectiveness of this approach.

NCR Corporation (Velotta 1992) has created a set of quality metrics that measure the following areas of a reference or task-oriented document:

- Noun strings

- Jargon

- Agency (agent of action, e.g. the user, the document, or the equipment)

- Goals for action

- Logical conditions

- Unnecessary references

- Cohesion at paragraph and section levels

- List consistency

- Text graphic Integration (captions, irrelevant graphics, misleading graphics) 
- Procedures (overall, steps for user action, graphics) for task oriented documents

- Multiple steps for task oriented documents

Task headings for task oriented documents

While this would appear to be a sufficiently detalled approach, what is lacking is how the text is integrated into an overall style of presentation. Jonassen (1984) states that how text is processed is tied to its function. He further states "the text itself should encourage the use of appropriate strategies - largely through the design features of the text Itself, 1.e., through display techniques." Jonassen (1984) further reports test results that indicate a $50 \%$ improvement in factual recall related directly to the display of the material. 2

"Increasingly it is being recognized that effective communication depends not only on the content of what is said, but on the way it is physically presented. Illegible or badly presented information can reduce the user's efficiency and may result in negative reactions to the information and its perceived source," argue Pat Wright (Brockman 1990 139). The NCR metric ignores many presentation alds. The rationale for this is that the metrics were designed for internal use only, where the typographic style and other elements are set as a matter of policy by the organization (Velotta 1992).

The NCR metrics also do not address the need for reference alds in user manuals.

The NCR metrics do attempt to quantify the relation between text and graphics using very basic measures, but they do not quantify the

2 These display factors are discussed later in this chapter. 
graphic content according to a set of metrics such as those based on the quality criteria developed by Tuft $(1983,1990)$ that are presented shortly in the Graphical Metrics section.

Despite these limitations, Duffy (1985) states that a structural analysis, such as that developed by Velotta, "may eventually provide useful information regarding general characteristics of effective documents."

\section{$\underline{\text { Reference Alds Metrics }}$}

Rowland and Williams (1989 394) state : "Efforts to steer the user to the correct book or chapter fail because the users ignore documentation models that violate their own schema and paradigms." This may suggest that metrics of quality may be impossible, but for the purposes of a majority of users, six measures might be considered.

(1) Overall Completeness - Brockman (1990) lists Pakin \& Associates quick reference aids test as a measurement of document quality. A document should have at least 9 of the following:

- Table of contents (two or more levels of detail)

- List of Illustrations / Figures or Tables (numbered and titled)

- Chapter table of contents (two or more levels of detall)

- Headings (two or more levels with organizational hierarchy clearly indicated)

- Figure Captions

- Tabs (titled)

- Error message appendix

- Glossary 
- Indexes

- Reference Card

The metric for this completeness measure might be the number of the above items present divided by 9 .

(2) Table of Contents - The quick test from Pakin \& Associates suggests the metric might be the number of chapters with less than 2 levels of headings compared to the total number of chapter entsies in the table of contents. The table of contents is similar to a road map and if the road map lacks sufficient detall to determine a path to the destination then it is insufficient.

(3) List of illustrations - The metric for this completeness measure might be the number of illustrations, figures or tables which are not listed, numbered or titled compared to the total number of lllustrations, figures and tables.

(4) Chapter Tabie of Contents and Headings - This metric might be similar to the table of contents metric. The number of chapters with tables of contents at two levels with clear headings using such typographic features as: bold face, italic, underline, indentation, type size, leading (line spacing),

(5) Glossary - Brockman (1990) suggests that the glossary should be $2 \%$ of the total number of pages in a document. Suggesting a metric providing a score of $100 \%$ for $2 \%$ or more pages and a lower score for less such as ratio of pages divided by $2 \%$. A second metric is the number of procedures described in the glossary divided by the number of glossary items. The result is then calculated as with Velotta (1992). 
(6) Indexes - Indexes may be organized word by word or letter by letter. While there is no "correct" way, recognizing which method is used can speed looking for a reference item. An average index will have 3 to 5 items per text page; while a technical, scholarly work, or encyclopedia may have 10 to 15 items per page of text; and a light index may have only one or two entries per page (Boston 1986). A simple method might be to compute the average number of entries per page of text and compare to an average of 5 entries per page. Any ratio over 1.00 would be rated as $100 \%$.

\section{Graphical Metrics}

As with the notion of quallity, everyone seems to have a traditional sense of what a quality graphic is but currently no metrics exist to quantify quality in graphics in user manuals. The NCR metrics, (Velotta 1992) contain some basic measures to relate the graphic to the text:

- Informative captions

- Irrelevant graphics

Inconsistent or misleading graphics

None of these measures quantify the actual quality of the graphic itself. The literature contains subjective material on quality but little on quantitative measures on graphical quality, (Scholtz 1992).

Based on the method employed by Velotta (1992), the measures take the following form:

- Lie Factors are due to misscaling graphic images by using more pictorial illustrations of data. Figure 1 from Tuft, (1983 57,76) illustrates 2 examples of the Lle Factor. 


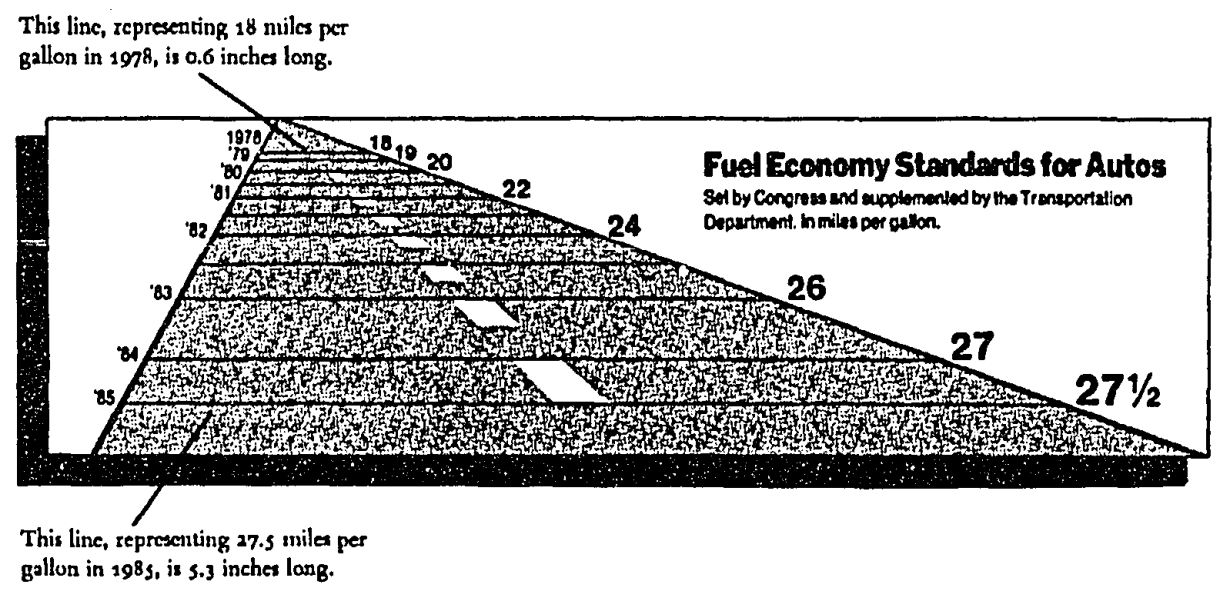

The ratio of 18 miles per gallon / 27 miles per gallon differs from .6 inches / 5.3 inches.

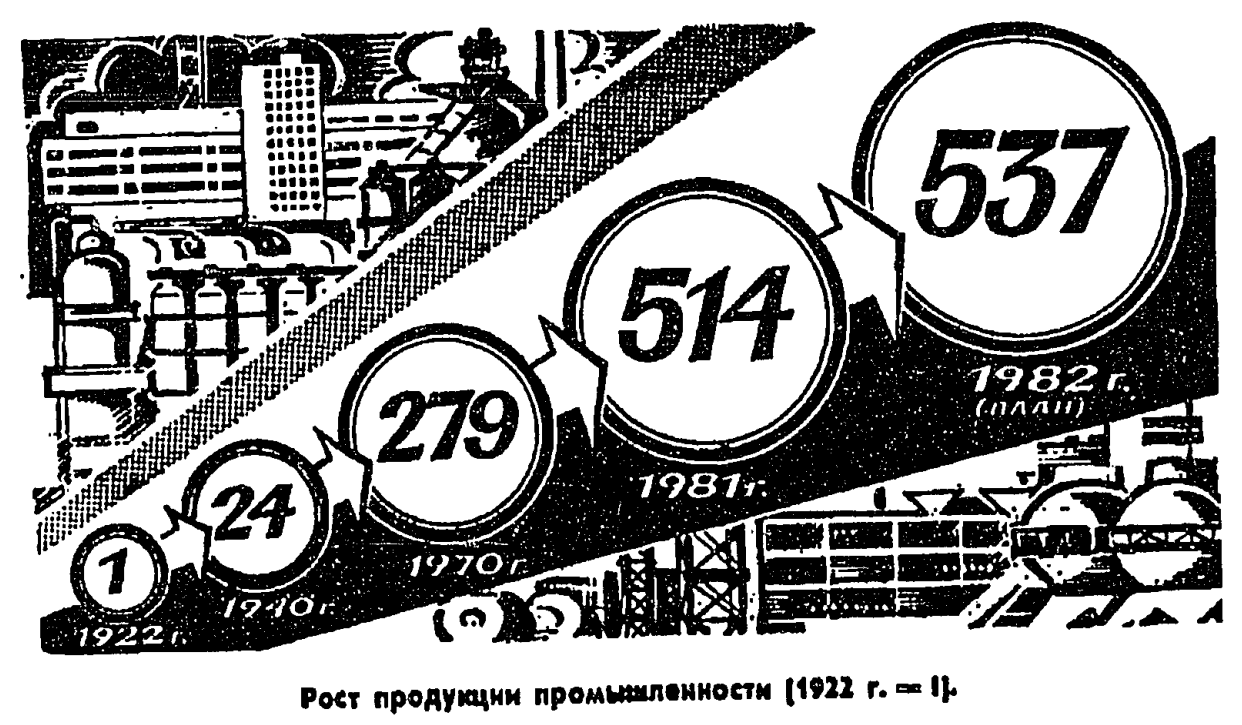

The areas of the circles are not in proportion to the magnitude of the numbers within.

Figure 1. Lie Factor, Misscaling.

The Lie Factor is computed by taking the size of the effect in the graphic divided by the size of the effect in the data. A ratio of 1 indicates true scaling. Lie factors greater than 
1 indicate overstating data; factors less than 1 indicate understating. Lie factors of 2 to 5 are not uncommon (Tuft, 1983). Lie factors can also occur in lllustrations such as screen layouts by misscaling certain portions of the illustration. The lie-factor measure would take the number of graphics with lie factors over 1 divided by the number of graphics in the document following the measures of Velotta, (1992)

- Dimensions, of course, are how the data is represented. Tuft (1983) suggests that the number of dimensions should not exceed the dimensions of the data. For example using a 3 dimensional graphic for data in one dimension causes distortion of the data and reduced understanding. The measure for dimensions would then be the number of graphics where the number of dimensions for the graphic exceeds the dimensions of the data.

- The Data-ink ratio (Tuft 1983) is the ratio of data ink to the total ink used to print the graphic. That is, on a simple graphic such as those in Figure 2 from Tuft (1983 94-95), the amount of ink used to display the data should exceed the amount of ink used for the reference areas. Another calculation is (1.0 - the proportion of a graphic that can be erased without loss of data information). 
The ratio of the data ink to the total ink in the upper left and right hide the data.

Most of the inis in this graphic is data-Ink (the dote and labels on the dlagonal) with perhaps $10-20$ percent nondata-Ink (the grid ticks and the frame)

$\checkmark$

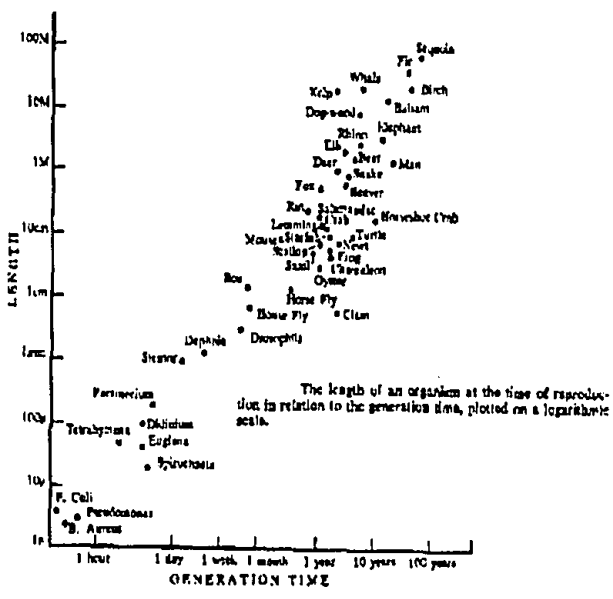

In this display with nearly all its ink devoted to matters other than data, the grid sea overwhelms the numbers (the falnt points scattered about the dlagonal):

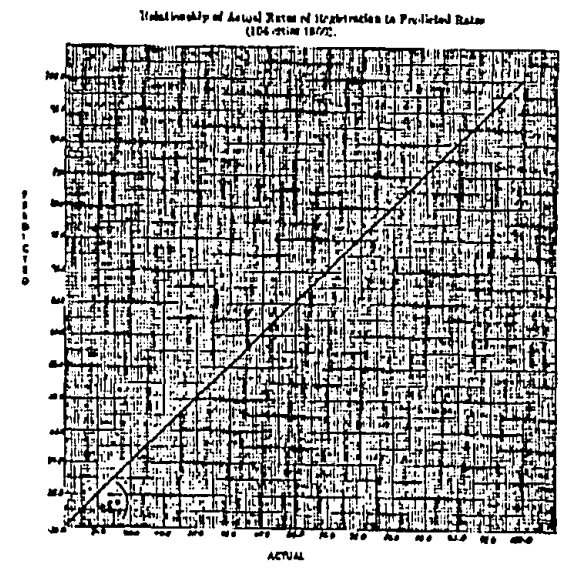

The same data is improved on the left then made unreadable again on the right

Another published verslon of the same data drove the share of data-Ink up to about .7, an improvement:

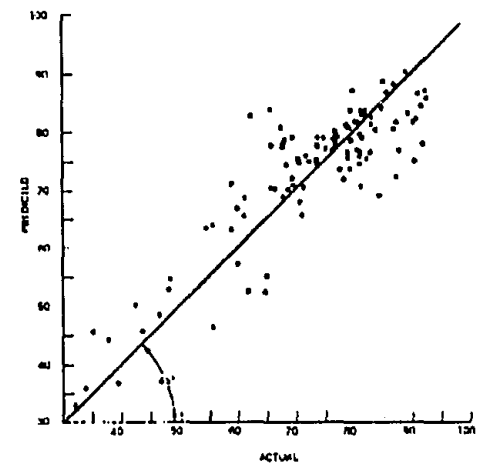

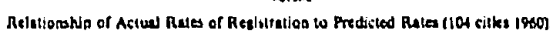

But a third reprint publication of the same flgure forgot to plot the points and simply retraced the grid lines form the original Including the excess strip of grid along the top and right margins. The resultung figure achleves a graphical absolute zero, a null data-Ink ratio:

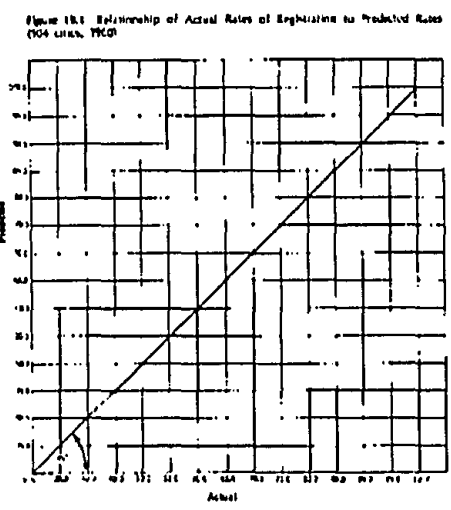

Figure 2. Data-Ink Ratio Examples. 
As the figures suggest there is a large portion of background that can be erased whlle clarifying the data and improving understanding. This concept can be further expanded to lllustrations by determining how much ink in the illustration is used to supply useless detail. The data-ink graphic measure would then be the number of graphics with data-ink ratios of less than $50 \%$ divided by the total number of graphics.

- The Duck (Tuft 1983 139) is composed of chart junk such as logos, vibrations, excess grids, unnecessary art, and other artifacts that distort and hide the understanding of graphic images. Figure 3 presents some examples of these art forms. The year end primary stock chart and the graphics below both suffer from Moire' vibration. which masks information. Moire' vibrations are patterns that seem to shimmer like a mirage in the desert to the eye. The wavy like patterns cause the eye to lose focus (for many people) on the critical detail of the chart; the patterns then obstruct the presentation of information rather than aid is it's presentation. Figure 3 presents two examples of this. 


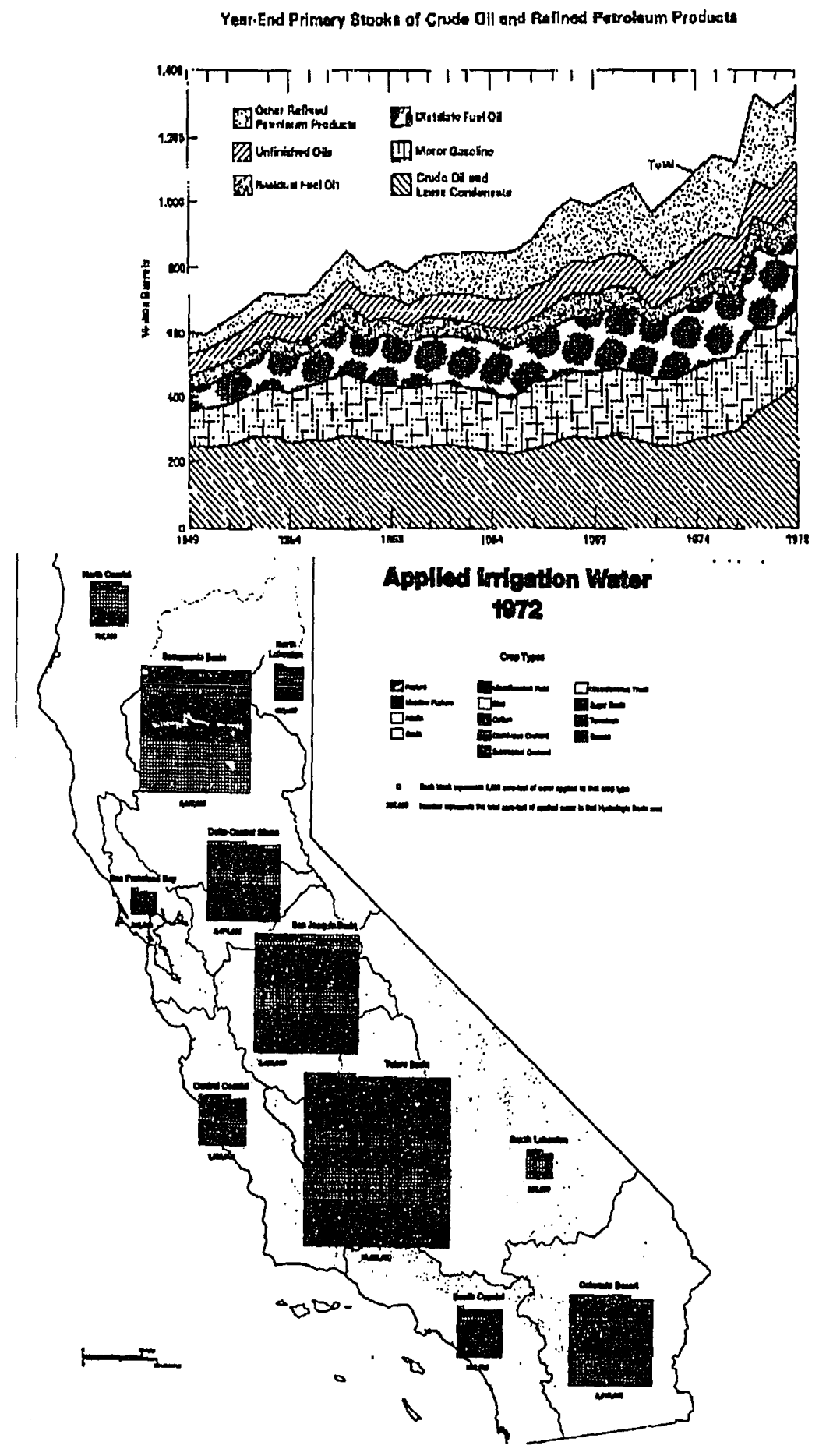

Figure 3. Ducks - Chart Junk, Vibrations, Grids, Bad Art. 
In the first example the number of patterns and the pattern itself distract the eye. The visual relationships of the chart require critical study -- reducing the value of the graphic. In the second example the state map of California is obstructed by the bands of data. The bands of data seem to shimmer in their patterns. The dark colors make visualizing the data more difficult.

The advent of computers and desktop graphics has made the creation of such bad graphics simple and easy. In many cases the computer software will assist in placing ducks before the writer. Figure 4 (Tuft 1983 120) provides an example of a computer generated duck from a software package such as Lotus 1-2-3.

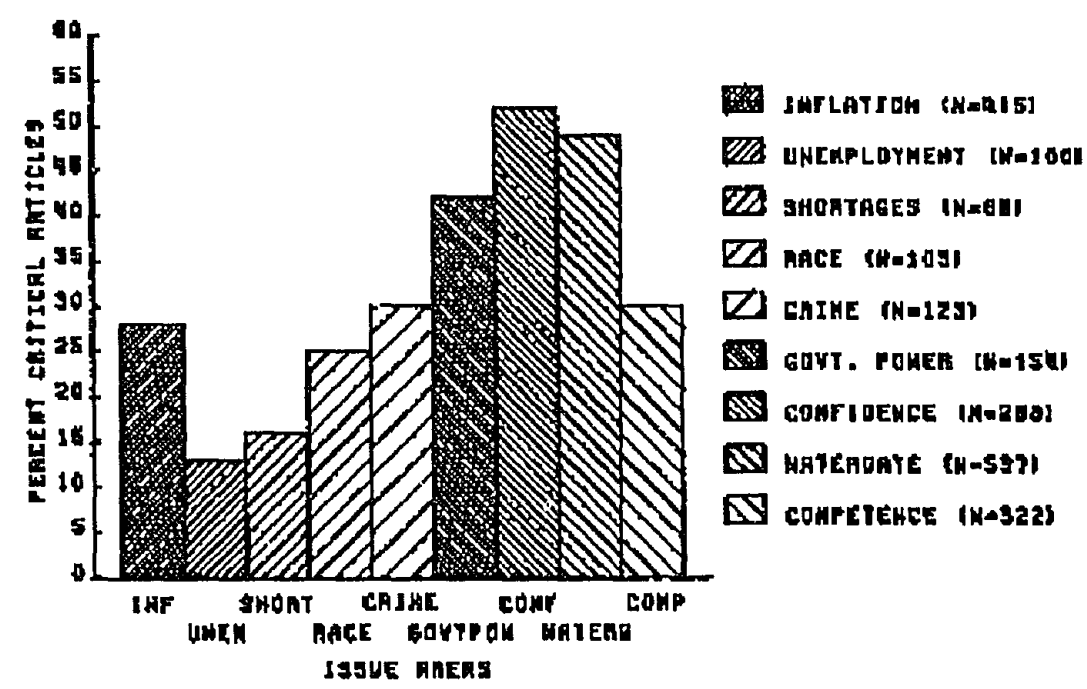

Figure 4. Computer Generated Duck. 
The figure suffers from the type style (all upper case computer line printer font), the random crosshatching patterns, the computer abbreviations of the categories, the moire' vibration, and the excessive scaling of the vertical axis showing more marks than data bars. Because of the combination of "software features" the entire graph becomes pop art rather than a graphic information device.

The duck measure would be the number of graphics with Ducks divided by the total number of graphic images in the document.

In the same manner as the total readabllity score developed by Velotta (1992), a total graphics score related to graphics can be obtained by subtracting each measure from 1.0 then averaging the entire set of graphics measures.

\section{Typographic Metrics}

Jonassen (1982) refers to typographic elements as textual display. He further discusses the notion that text and its display are jointly responsible for the potential of a book to be processed by a reader into knowledge. He states "The problem is that of selecting important Information from the text. . . Thus the more that important ideas . . . are embedded in a mass of secondary information, the more difficult they are to remember." 
Brockman (1990 140-141) has developed a set of typographic

recommendations, that appear to be suitable in view of the

\section{measurements in computer science experiments (Figure 5 )}

\begin{tabular}{|c|c|c|}
\hline Element & Definitions & Recommendations \\
\hline Typeface & $\begin{array}{l}\text { The look of the letters' } \\
\text { presentation on the paper } \\
\text { or the screen }\end{array}$ & $\begin{array}{l}\text { Use serifed type for } \\
\text { extended reading } \\
\text { purposes; chose an } \\
\text { appropriately toned } \\
\text { typeface; use typefaces } \\
\text { with a large x-height, } \\
\text { keep the number of } \\
\text { typefaces used to a } \\
\text { minimum }\end{array}$ \\
\hline Type Slze & $\begin{array}{l}\text { The vertical size of the } \\
\text { letters' (their point size) }\end{array}$ & $\begin{array}{l}\text { Use } 10 \text { or } 12 \text { point, but } \\
\text { be aware of typeface } \\
\text { variations }\end{array}$ \\
\hline Family Branch & $\begin{array}{l}\text { Within the letters' } \\
\text { typeface family letters can } \\
\text { be bolded, condensed, } \\
\text { outlined, shadowed, et.c. }\end{array}$ & $\begin{array}{l}\text { Minimize typeface shape } \\
\text { variations }\end{array}$ \\
\hline Letter Posture & $\begin{array}{l}\text { Within the letters } \\
\text { typeface family letters can } \\
\text { be roman (straight up } \\
\text { and down) or ltallc }\end{array}$ & $\begin{array}{l}\text { Use roman for extended } \\
\text { reading; use italic for rare } \\
\text { occaslons for contrast }\end{array}$ \\
\hline $\begin{array}{l}\text { Letter } \\
\text { Composition }\end{array}$ & $\begin{array}{l}\text { Within the letters' } \\
\text { typeface family letters can } \\
\text { be ALL UPPERCASE or a } \\
\text { mix of upper and lower } \\
\text { case }\end{array}$ & $\begin{array}{l}\text { Use a mixture of upper } \\
\text { and lower case }\end{array}$ \\
\hline Leading & $\begin{array}{l}\text { What we used to call } \\
\text { double space or single } \\
\text { space between lines }\end{array}$ & $\begin{array}{l}\text { Use } 1 \text { point lead on } \\
\text { paper; } 15 \% \text { of character } \\
\text { stroke width on-line }\end{array}$ \\
\hline Line Measure & $\begin{array}{l}\text { What we used to call the } \\
\text { width of lines on a page }\end{array}$ & $\begin{array}{l}\text { Keep line length between } \\
4.5 \text { inches and } 1.67 \\
\text { inches }\end{array}$ \\
\hline Appointment & $\begin{array}{l}\text { Decisions on column } \\
\text { Justification or } \\
\text { raggedness come within } \\
\text { this element }\end{array}$ & Use ragged right \\
\hline Word Spacing & Distance between words & $\begin{array}{l}\text { Use less space between } \\
\text { words than between lines }\end{array}$ \\
\hline Letter Spacing & Distance between letters & Use proportional Spacing \\
\hline $\begin{array}{l}\text { Rulers, leaders, } \\
\text { punctuation } \\
\text { marks, and } \\
\text { paragraph }\end{array}$ & & $\begin{array}{l}\text { Leave behind typewriter } \\
\text { practices and use proper } \\
\text { typesetting marks }\end{array}$ \\
\hline
\end{tabular}

Figure 5. Typographic Recommendations. 
These recommendations can be combined to create a single metric for typographic style. There are 11 elements of typographic style. The ratio of the total number followed to the total can then form a measure of the typographic quality of the document. While there may be some dispute about these recommendations, there is enough evidence from Brockman (1990) and others to suggest that this is a reasonable approach to this difficult problem. 


\section{CHAPTER III}

\section{THE PROPOSED MODEL}

The literature search has identified a variety of metrics that can be combined together to create a "model" of software document quality [Velotta (1992), Tuft (1983), and Brockman (1990)]. The challenge is to refine the model so that it can be efficiently applied and validate it.

This chapter presents such a model.

\section{MODEL STRUCTURE}

The metrics from the literature can be grouped into text, surrogate text (graphics), reference aids (ability to find items), and typographic presentation (the visual factors seen on the page). Each of the items is measured at different points in the integration of words into sentences, sentences into chapters, and chapters into the final document. These points of measurement are referred to as levels. The word "level" is used to signify a higher position in the integration of the document than the previous point. The model can be viewed as a table or matrix, with the various types of metrics grouped into columns, (category), and with rows representing the various levels (document, chapter, sentence) of a user manual to which each metric applies, referred to herein as the "level" of the measurement (see Figure 6). 


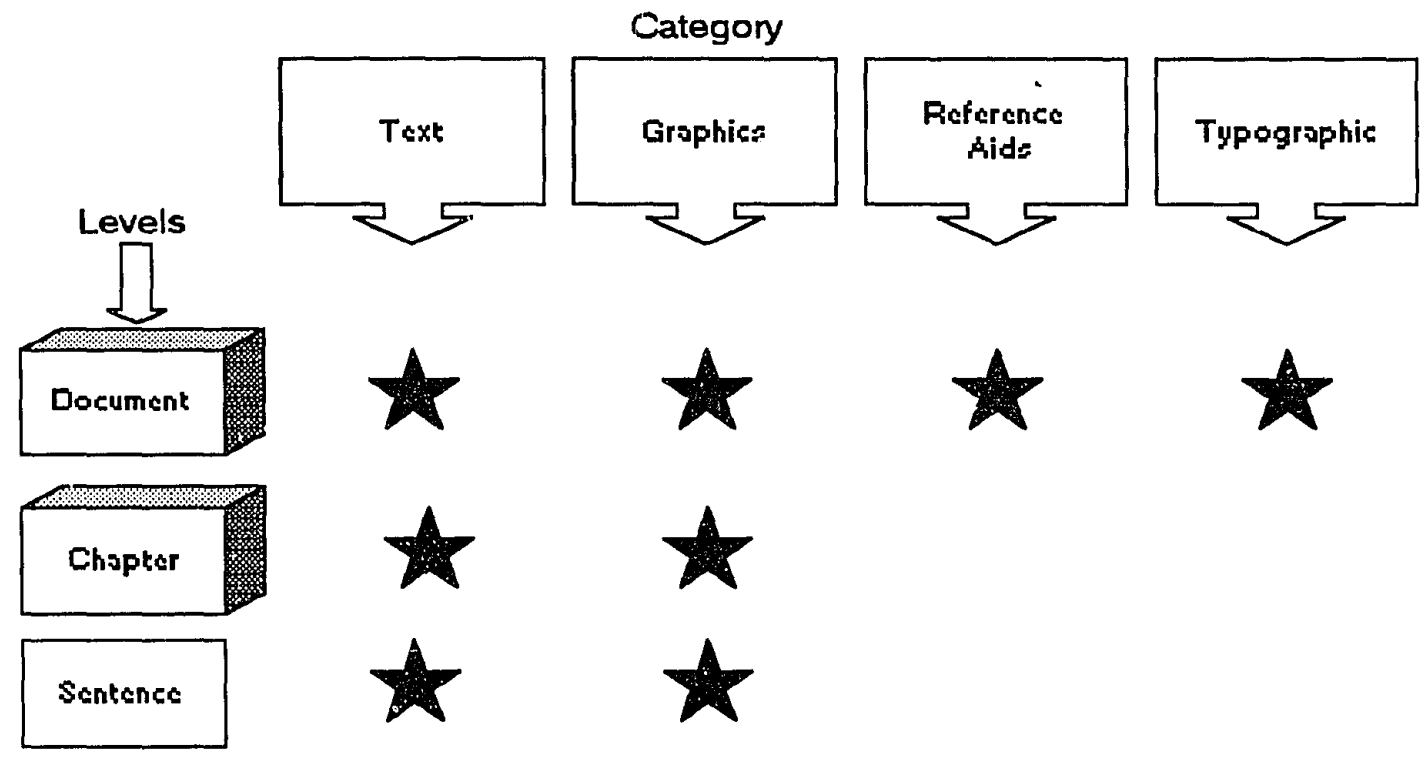

Figure 6. Levels of Measurement in a Document.

Figure 7 presents a more detailed summary of the model and is followed by a discussion of each measure. 3

3 Most of the textual measures and the calculation of those measures developed by Velotta is proprietary intellectual material loaned for the purpose of the dissertation by NCR Corporation. More detalled information can be obtained by contacting them directly. For that reason, the calculation details for many of the metric measures are not provided, although sufficient details are given so that the reader can develop a clear sense of how the model works. 
34

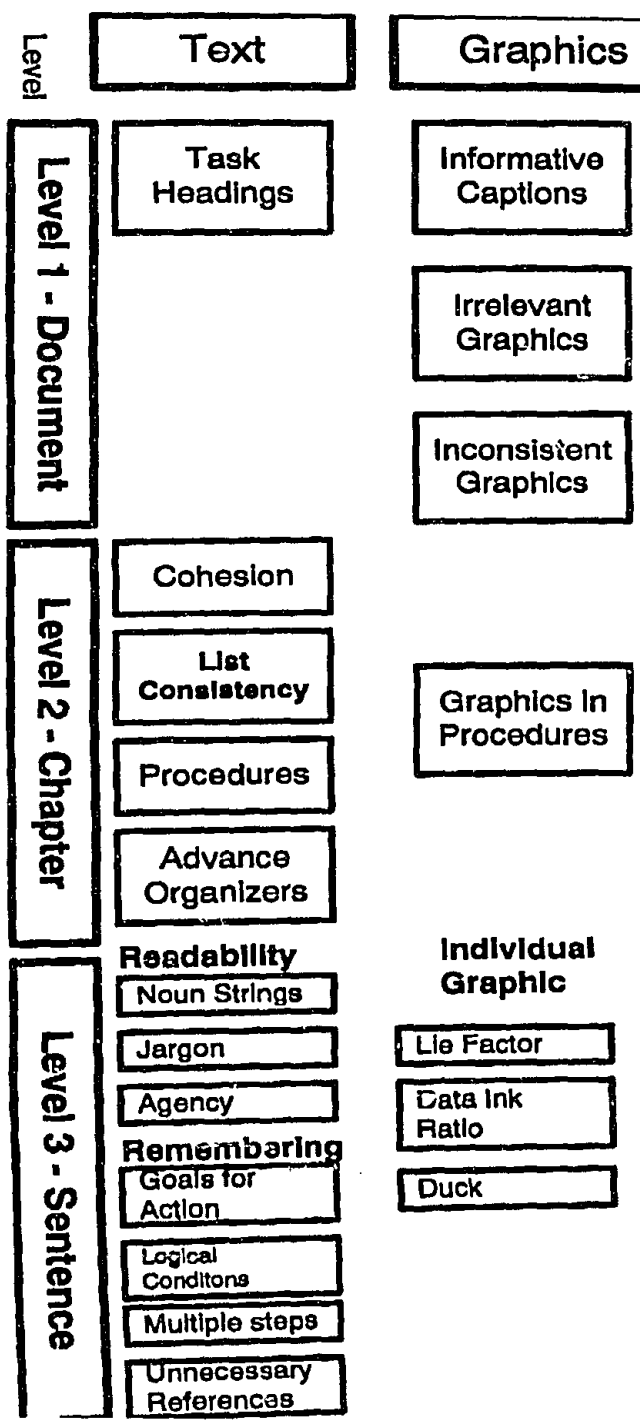

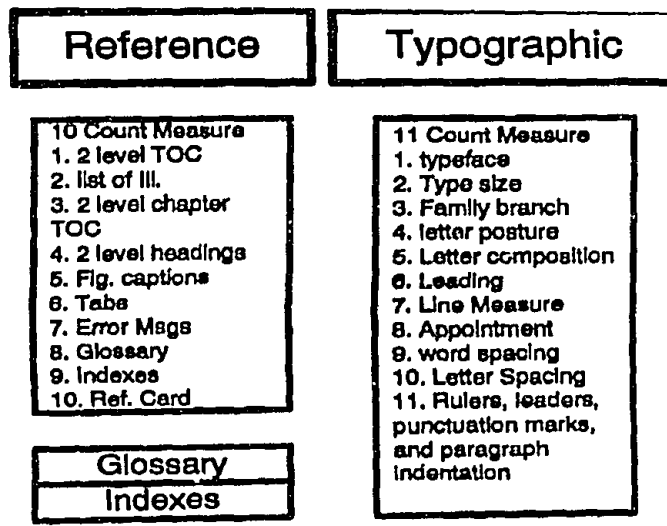

Figure 7. The Model.

\section{Document (Level 1)}

At the document level (Level 1 of Figure 7) there are several measures that make the user manual as a whole easier to use and understand. For example: 
Task Headings - In task-oriented manuals, headings that describe the task in the table of contents are easier to follow than those that leave the reader searching.

Captions below graphics provide clues as to why the graphic is in the text without requiring the reader to search through the text.

Irrelevant Graphics are graphics that provide no additional meaning to the text.

Inconsistent Graphics are graphics that fall in providing meaning to the text or reference material outside of the text material.

Reference Aids help the reader locate material within the document.

Glossaries are dictionaries of uncommon terms used in the manual.

Indexes list additional places in the text outside of the table of contents where information can be found.

Typographic Items evaluate the visual context that surrounds and presents the written material. These items make the material in the document easy to follow, easy to read, and help keep the reader's attention.

\section{Chapter and Paragraph (Level 2)}

The chapter level (Level 2 Figure 7 page 34) contains measures that indicate how well the sentences fit into an easy to follow sequence or 
pattern. The first four are text oriented and the fifth measure is graphics oriented.

Text-Oriented (Level 2). Chapter and Paragraph Level Cohesion measures determine how well sentences make up a unified thought pattern within the paragraph or section. For example, if a list of program steps begins without any statement of the purpose of the steps then the paragraph group does not follow a unified thought pattern. The reader is required to guess why the steps are there. Procedure Goals - Procedures are easier to follow if they begin with a statement of purpose or goal. Procedures are easier to understand if the steps are not buried in additional text that surrounds the steps necessary to accomplish the process. Procedures that have graphics often are better understood than those that have no visual clues to assist in following the text. Incomplete Lists are those that either miss or add items that the reader is not expecting.

Advance Organizers provide information regarding what follows, prepares the reader for future material, and provides guidance on how to follow the material.

Graphics-Oriented (Level 2). Graphics Used in Procedures counts if a one or more graphics are used as part of the procedure. 
Sentence (Level 3)

At the sentence level (Level 3 Figure 7 page 34) the model suggests certain key features of sentence construction that correspond to higher quality documents: Some of them measure the text itself.

Nounstrings are groups of nouns that refer to a construct such as File Open Dialog Box; the long string of nouns makes the construct difficult to read and refer to.

Jargon refers to words or groups of words that are outside the intended users vocabulary or words that are common in certain fields such as: Ford F150 5.8 liter Extended Cab Stepside Long Bed Pickup.

Agency is the concept of using certain constructs as subjects of sentences, that make the sentence meaningful and readily understood such as: Click the left mouse button. In the example, the intended subject of the sentence is you and is readily understood.

Goals for Action provides a direction for the action to go and provide the user with a notion of why the action is taking place. For example, "pull the handle on the slot machine to begin play." In this example, the reader understands what the consequence of pulling the handle will be.

Logical Conditions provide the reader with paths to follow in the document. For example, "If you want to play the slot machine, then insert a coin and pull the handle." 
Multiple Steps make the directions of procedures more difficult to follow. In the previous example, the reader was given two instructions in the same sentence.

Unnecessary References are references in the document that direct the reader to go some place else for small bits of information that could easily be placed in the text (and the reference omitted). For example, "See chapter 4 for instruction on how to click a mouse." The instructions in chapter 4 may be only one sentence.

The remaining three sentence level measures relate to the individual graphics in the user manual.

Lie Factors are due to misscaling in the graphic.

Data Ink Ratio refers to the amount of ink used to present the data vs the amount of ink used for other purposes. For example, an entire terminal screen display may be presented when only a small portion of the screen is relevant to the discussion in the text.

Ducks are graphics that are put in the user manual purely for ornamentation and flavor. Ducks add nothing to the meaning of the text or the material in the text and may not even in fact be relevant. For example, the addition of a row of dots to the top of each page adds nothing to the meaning of the text. 
Example of Metric Scoring Procen

\begin{tabular}{|c|c|c|c|c|c|}
\hline Itam & $\begin{array}{l}\text { cour } \\
0.01 .0\end{array}$ & Proosen & Count & $\begin{array}{l}\text { Denominator } \\
\text { of Retio }\end{array}$ & Uthinthon \\
\hline \multicolumn{6}{|l|}{ Docuntix } \\
\hline \multicolumn{6}{|l|}{$\div$} \\
\hline $\begin{array}{l}\text { Informattro } \\
\text { Captions }\end{array}$ & $\begin{array}{l}3 / 167 \\
0.02\end{array}$ & $\begin{array}{l}\text { In the entire document, count the } \\
\text { number of grephice with } \\
\text { informative ceptlone }\end{array}$ & $\begin{array}{l}\text { graphics } \\
\text { with } \\
\text { Informatt } \\
\text { e coptions } \\
3\end{array}$ & $\begin{array}{l}\text { number of } \\
\text { oraphto }\end{array}$ & $\begin{array}{l}\text { ratio of pumber o } \\
\text { grophics with } \\
\text { informattre } \\
\text { captiono/ total } \\
\text { number of } \\
\text { traphice }\end{array}$ \\
\hline \multicolumn{6}{|r|}{$1-1$} \\
\hline \multicolumn{6}{|l|}{$\cdot$} \\
\hline \multirow{2}{*}{\multicolumn{6}{|c|}{$\div$}} \\
\hline & & & & & \\
\hline \multicolumn{6}{|l|}{$\div$} \\
\hline Cloesary & $\begin{array}{c}12 / 6 \pi \\
\max 1.0 \\
1.0\end{array}$ & $\begin{array}{l}\text { In the entire document, count the } \\
\text { number of pades in the dosangy }\end{array}$ & $\begin{array}{l}\text { posary } \\
\text { papes } \\
12\end{array}$ & $\begin{array}{l}2 \% \text { of totel } \\
\text { page count } \\
300^{\circ} .02 \\
6\end{array}$ & $\begin{array}{l}\text { ratto of number of } \\
\text { doasary pares to } \\
2 \% \text { total page } \\
\text { count. Mridmum } \\
\text { of } 1.00\end{array}$ \\
\hline \multirow{2}{*}{\multicolumn{6}{|c|}{ 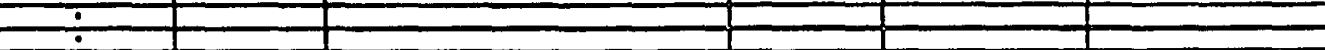 }} \\
\hline & & & & & \\
\hline \multicolumn{6}{|l|}{ crinis } \\
\hline \multirow{2}{*}{\multicolumn{6}{|c|}{$\div$}} \\
\hline & & & & & \\
\hline \multicolumn{3}{|l|}{$\div$} & \multicolumn{3}{|c|}{ - } \\
\hline $\begin{array}{l}\text { Procedural } \\
\text { Oraphica }\end{array}$ & $\begin{array}{l}4 / 6 \\
.687\end{array}$ & $\begin{array}{l}\text { From one of the two randoen } \\
\text { sumple chaptera, count the } \\
\text { number of procedures that have } \\
\text { graphlas to explatn procedure }\end{array}$ & $\begin{array}{c}\text { procedure } \\
\text { with } \\
\text { graphica } \\
4\end{array}$ & $\begin{array}{l}\text { number of } \\
\text { procedures }\end{array}$ & $\begin{array}{l}\text { ratso of number of } \\
\text { procedures with } \\
\text { graphes / number } \\
\text { of procedures in } \\
\text { enmple }\end{array}$ \\
\hline $\begin{array}{c}\text { Unt } \\
\text { Conaintency }\end{array}$ & $\begin{array}{l}1 \cdot 1 / 8 \\
.876\end{array}$ & $\begin{array}{l}\text { From ane } \alpha \text { the two random } \\
\text { numple chapters, count the } \\
\text { number of tmoondatent ints }\end{array}$ & $\begin{array}{c}\text { Inconelste } \\
\text { nt bitu } \\
1\end{array}$ & $\begin{array}{l}\text { total number of } \\
\text { Hitte in anmple } \\
\text { chapter } \\
\text { B }\end{array}$ & $\begin{array}{l}\text { 1-ratio of } \\
\text { Incondintent lints/ } \\
\text { total number of } \\
\text { unts in chapter. If } \\
\text { chupter bae no } \\
\text { usto then }-0.0001\end{array}$ \\
\hline \multicolumn{6}{|l|}{1} \\
\hline \multicolumn{6}{|l|}{ DrinteNCE } \\
\hline Noun 8trings & $\begin{array}{c}1+(21 / 808) \\
0.88\end{array}$ & $\begin{array}{l}\text { From the \& pares in ore of the } \\
\text { two random camples, count the } \\
\text { number } \alpha \text { words in noun strings } \\
\text { composed of } 9 \text { or more words }\end{array}$ & $\begin{array}{l}\text { noun } \\
\text { itring } \\
\text { count } \\
21\end{array}$ & word count & $\begin{array}{l}\text { 1. rntio of noun } \\
\text { sting word count } \\
\text { / totel worde to } \\
\text { cample }\end{array}$ \\
\hline \multicolumn{6}{|l|}{$\div$} \\
\hline \multicolumn{6}{|l|}{$\div$} \\
\hline \multicolumn{6}{|l|}{$\div$} \\
\hline \multirow{2}{*}{\multicolumn{6}{|c|}{$\div$}} \\
\hline & & & & & \\
\hline$\div$ & & & & & \\
\hline $\begin{array}{l}\text { Unrecensary } \\
\text { Referencen }\end{array}$ & $\begin{array}{c}1-(2 / 45) \\
0.86\end{array}$ & $\begin{array}{l}\text { From the } 4 \text { pages in one of the } \\
\text { two random samples, count the } \\
\text { number of references that are } \\
\text { unnecesary. }\end{array}$ & $\begin{array}{c}\text { unnecesia } \\
\text { y } \\
\text { reference } \\
\text { ount } \\
2 \\
\end{array}$ & $\begin{array}{l}\text { entence count } \\
\text { in eample }\end{array}$ & $\begin{array}{l}\text { 1-ratto of } \\
\text { unnecesury } \\
\text { reference count } \\
\text { / total number of } \\
\text { contenoses in } \\
\text { cample }\end{array}$ \\
\hline Total & .78 & $\begin{array}{l}\text { Uating the detall woores from each } \\
\text { metric }\end{array}$ & $\begin{array}{l}\text { metrle } \\
\text { ecore }\end{array}$ & & $\begin{array}{l}\text { comblne ttems into } \\
\text { total soore }\end{array}$ \\
\hline
\end{tabular}

Figure 8. Example of Model Scoring Process 
Final Score

When the elementary metrics items are combined together, as specified by Velotta, a score is computed that corresponds to the overall quality of the document. The inclividual scores of each metric provide measures of strength and weaknesses of various aspects of the document. The example that follows explains several of the metrics, including how they are measured and calculated. (Figure 8 and the explanation that follows it).

\section{Explanation of Example}

Figure 8 illustrates an example of the metric in use.

Document Level - (two of the eight document level measures are outlined below)

Informative Captions are the sentence like description below or above graphic examples that describe what the graphic relates to. In the entire document the total number of graphics that have such features are counted. Also the total number of graphics are counted. The score is formed by dividing the number of graphics with captions by the total number of graphics in the document. This forms a ratio score that is less than 1. If all of the graphics have informative captions then a perfect score of 1.0 is calculated. If none of the graphics have informative captions then the score calculated is zero $(0.0)$.

Glossaries are the area of the document where nontraditional terms are explained to assist the reader in 
understanding what technical terms or uncommon usage terms mean. In many normal documents the glossary is about $2 \%$ of the total number of pages in the manual. The number of pages of glossary terms are counted. The number of pages in the glossary is then divided by $2 \%$ times the number of pages to give a ratio. If the ratio is greater than 1 , the number 1.00 is used as a maximum. A document that has $2 \%$ or more of its total pages devoted to a glossary has a perfect score of 1.0. A document that has no glossary has a score of zero (0.0).

Chapter Level (two of the four chapter level measures are outlined below)

Graphics in Procedures are graphics that are associated with a procedure to provide a visual image of what is happening in the procedure. A procedure may have no graphics, one graphic or more than one graphic. The number of procedures in the sample chapter with at least one graphic is counted. The number of procedures with at least one graphic image is divided by the total number of procedures in the sample chapter to form a ratio that is less than 1 .

Incomplete Lists is a check to determine that all of the items in a list are present. If further explanation is provided of the items in the list then a check is made to determine that all of the items in the list are explained 
and that no additional items have been added. The number of inconsistent lists is formed by counting the number of lists in the chapter that are not complete. The measure is then one minus the ratio of inconsistent lists divided by the total number of lists in the sample chapter.

Sentence Level (two of the ten sentence level measures are outlined below)

Noun Strings are groups of nouns together that form a single logical noun term such as "Rubber Baby Buggy Bumpers." The string of nouns makes the item more difficult to remember and understand. In the sample pages selected from the chapters, the number of words in these terms that contain 3 or more nouns in a row are counted. A ratio is formed by dividing the resulting sum by the total number of words in the sample pages. The score is one minus the ratio computed above.

Unnecessary References require the reader to flip from one section of the book and back to understand a term that could be explained in the text without a forward of backward reference. The number of sentences containing an unnecessary reference are counted. The sum is divided by the total number of sentences in the sample pages from the chapter. The score is one minus the ratio formed above. 
Total Score - The total score is formed by combining the scores from the individual metrics into a composite measure for the document following the methods of Velotta (1992). Detailed examples of scoring can be obtained from NCR Corporation (Velotta 1992). 


\section{CHAPTER IV}

\section{RESEARCH METHODOLOGY}

In order to test the model developed in chapter III, it must be applied to an appropriate sample of user manuals and the results analyzed and compared to expert opinion.

Since the intent of the methods developed by Velotta is to measure the quality of a specific document over time, the proposed model may be able to measure relative improvement in quality, but not correspond well with the opinion of users and experts. As is the case with other measures such as the Flesch index and readability index, there is no guarantee that the score will actually reflect the quality of the document. In order for the model to have significant value, it must compare favorably with expert judgment, where the expert represents the collective experience of typical users.

This chapter is divided into three major sections. The first section deals with the research hypothesis and research design. The second section discusses sampling issues and the process of actually scoring documents using the model. The third section addresses the validity of the model. 
THE HYPOTHESIS AND OVERALL RESEARCH PROCESS

\section{The Research Hypothesis}

Quality in end user computer documents (user manuals) has several important dimensions. If the proposed model is able to capture a number of these dimensions, then it represents a meaningful contribution.

The basic hypothesis underlying this research then, is that the model outlined in Chapter III is able to measure the quality of user manuals.

$\mathrm{H}_{0}$ : There is no significant difference between the scores from panel of expert reviewers and the model.

$\mathrm{H}_{1}$ : There is a significant difference between the scores from the panel of experts and the model.

\section{The Research Process}

Figure 9 (Flowchart of Research Process) summarizes the process. Documents are scored by the model and also by the panel of experts. In order to facilitate comparison, The panel is asked to comment on the same randomly selected chapters that were scored using the model.

When scoring by both the model and the panel has been completed, the resulting data is tested for internal consistency. The data from the metric is tested using the Cronbach Alpha statistic, where a value greater than .5 indicates internal consistency. 


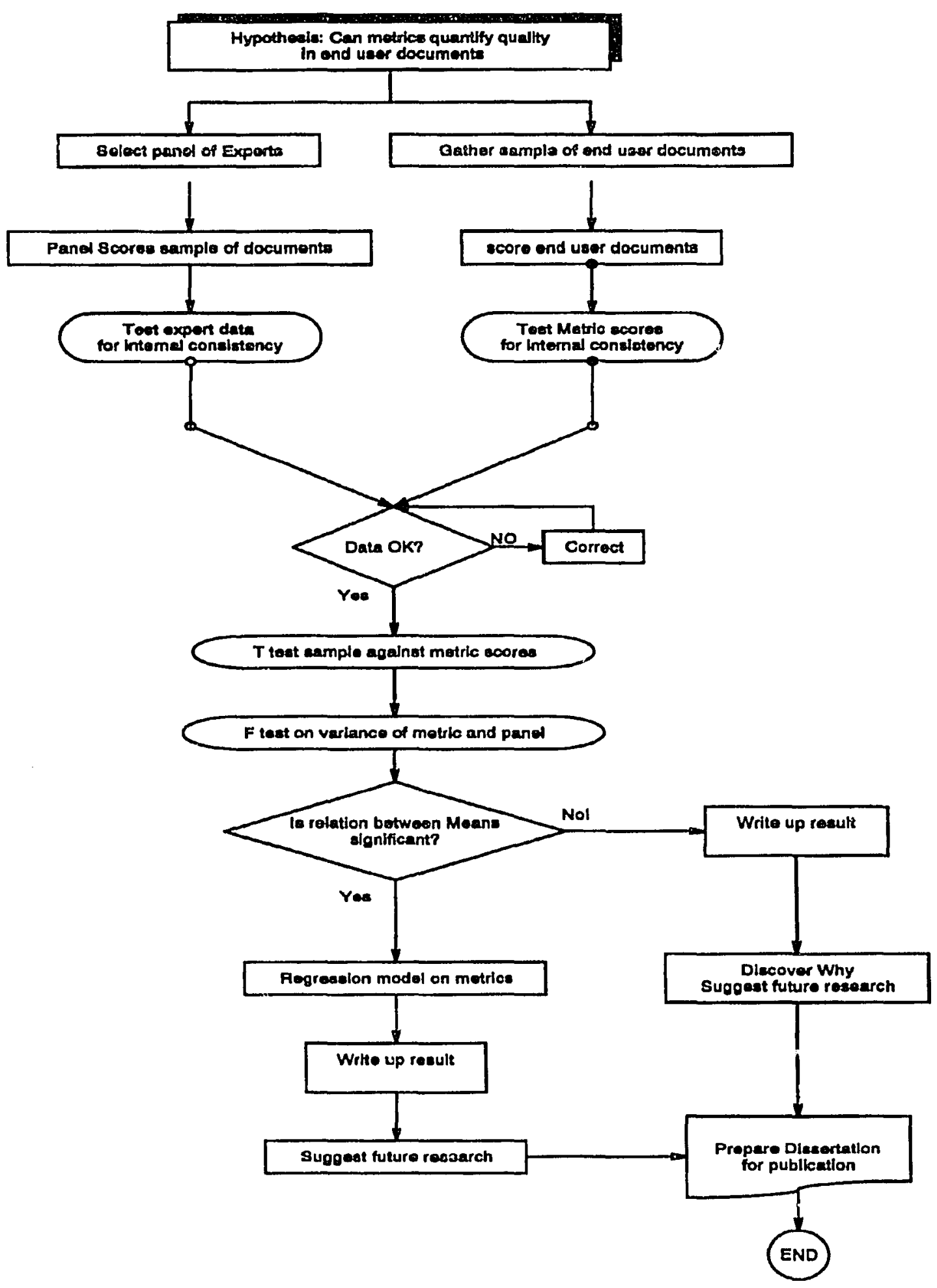

Figure 9. Flowchart of Research Process 
The data from the experts is tested for consistency using the Friedman Rank Test applied to the scores from different panelists for the same software package.

If the Chi Square statistic from the Friedman Rank indicate that the scores from the panel are from the same population, then further analysis is done (comparison to the model). If the data from the panel is not from the same population, this would signify that the experts are using different criteria for their evaluation. Thus, comparing them with the model will have very little value since the model does not allow for bias.

Any of the data from the model and from the panel of experts, that has passed the consistency tests is then analyzed to see if any correlation is present (using $\mathrm{T}$ and $\mathrm{F}$ tests). If the data from the experts has no relation to the model results then the study is ended with the discussion of the results.

If the data indicates a significant relationship, then additional tests will be performed as described later in this chapter. The study is then complete and the results are reported.

\section{SAMPLING ISSUES AND THE SCORING PROCESS}

In this section several sampling issues are discussed, including the method used to select a sample from a specific user manual, selection of the "evaluation" platform(s) (e.g. Windows vs. DOS vs. Macintosh) and the selection of the specific packages to be evaluated. The final section describes the scoring process. 
Selection of the Sample from a Given Document

One necessary underlying assumption of this research is that the user documents will be consistent enough that a random sample of chapters from the document will yield results that reflect the entire document. 4

The method of Velotta (1992) requires that a sample of two pages be taken randomly from each chapter in the document for scoring the sentence level metrics (Figure 7 page 34. For the chapter level metrics, Velotta suggests using two or three randomly selected chapters. This procedure creates better sampling at the sentence level than at the chapter level, because in a document with more than three chapters, more samples are taken at the sentence level. Also, the time required to count sentence level items becomes prohibitive as the number of documents is increased.

Thus, this research, the sentence level metrics (level 3 Figure 7 page 34) will be scored using 3-4 page samples from two randomly selected chapters. 5 The number of pages in the sample has been increased to account for the increased use of graphics in user manuals by the Microsoft Windows, Macintosh, and other platforms using a Graphical User Interface. The chapter level metrics will follow the method outlined by Velotta, but the samples will be limited to 20-30 pages to provide consistency of sample size. The document level metrics are 4 This follows from the belief that a company producing a shoddy product such as one with inconsistent user manuals, will not continue to survive in the market place. Companies offering higher quality products that are more consistent in their approach will survive, because buyers want consistency, e.g. McDonald's fast food.

5 This method varies slightly from the method used by Velotta, but was discussed with him and he concurs with this approach. 
applied to the entire document. Figure 10 summarizes the sampling and scoring process for a single document.

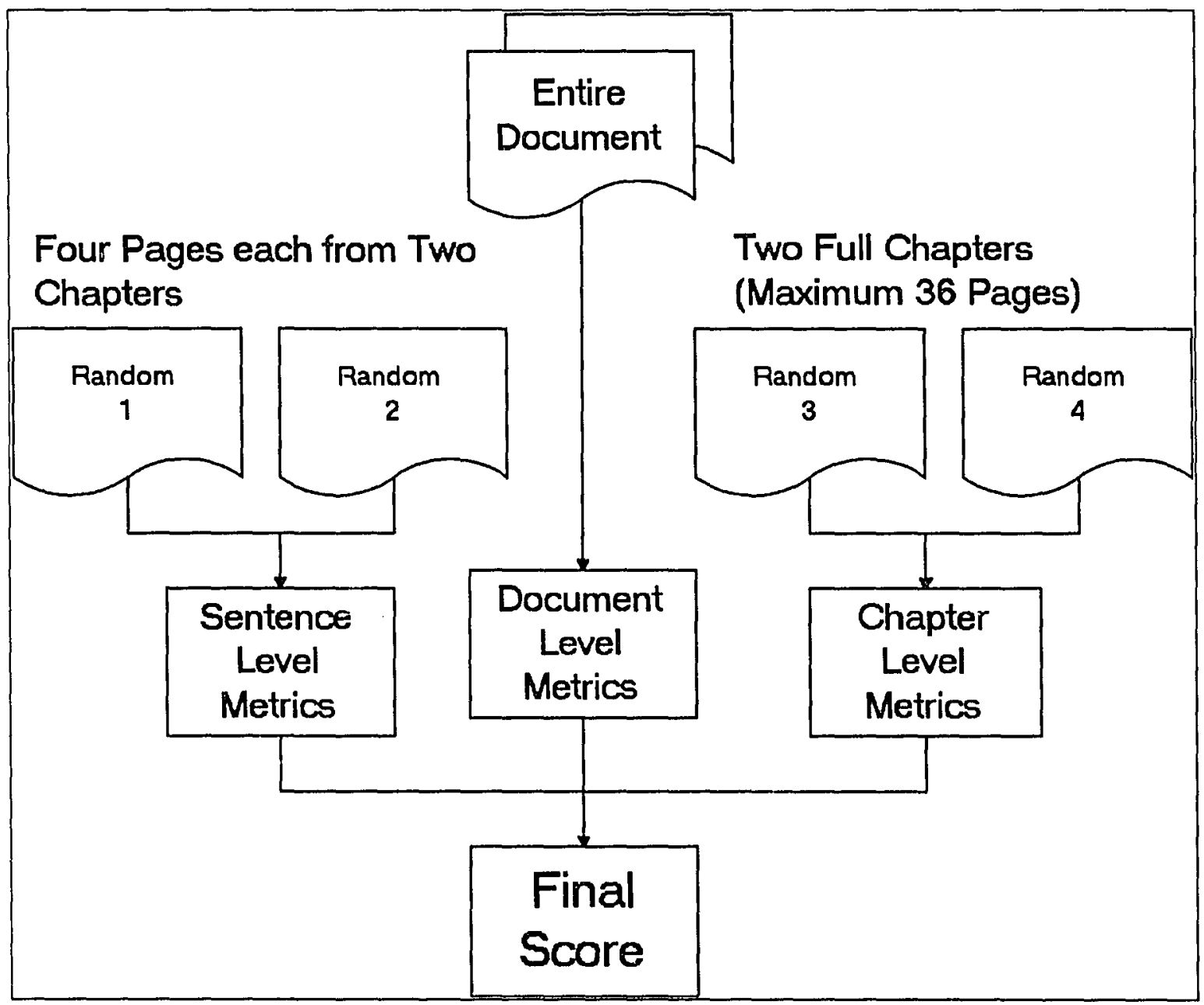

Figure 10. Document Scoring Process

Selection of the Evaluation Platform

The market forces in the personal computer software market have lead to the consolidation of products into several large software development houses. Some of the developers have offered many products in many different areas such as Microsoft, Lotus, and Borland. Other software developers such as Autodesk and Symantec have 
concentrated in certain product areas and have dominated the products in these areas. While there is a large number of software packages readily avallable to test the model, sample selection is done carefully to avoid a few major software developers from dominating the results of the research.

To provlde focus, the research has been restricted to packages that run under Microsoft Windows 3.1. the most recent user interface for the Intel processor-based PC platform. The implementation and success of Its Graphical User Interface (GUI) environment has lead to the creation of many software packages. This offers the opportunity to study the latest trends in software documentation, and still focus on one platform.

Windows 3.1 software packages can be divided into six major classifications. These classifications were selected from a cross section of advertising samples from industry trade publications. They are as follows:

1. Applications

- Accounting/Financial examples: ACCPAC, Peachtree Accounting for Windows, Quicken for Windows

- Personal Information Managers examples: IBM Current, Lotus Organizer, Daybook Plus

- Project Management Software examples: Microsoft Project, Timeline, Superproject

2. Drawing - CAD 
examples: AutoCAD, Microstation PC, DesignCAD, EasyCAD

- Graphics

examples: Zsoft PUBLISHERS Paintbrush, Corel

Draw, Image Star, Micrographics Designer

- Presentation Software

examples, Microsoft Powerpoint, Harvard Graphics for Windows, Freelance for Windows

3. Quantitative and Statistical

- Mathematical \& Statistical

examples: SAS for the PC, SPSS for WINDOWS, MathCAD, Mathematica

- Spreadsheets and Graphing

examples: Lotus 1-2-3 for Windows, Excel, Quattro Pro for Windows, What's Best, @Risk

4. Systems

- Database

examples: Foxpro, Paradox for Windows, Superbase 4 for Windows, Ask Sam for Windows, Atlas

Mapgraphics, Mapinfo

- Operating Systems \& Networks - entry level

examples: Windows, New Wave, Deskview386, Lantastic, Novell Lite, SCO Unix, Geoworks, System 7

5. Textual

- Desktop Publishing 
examples: Ventura Publisher for Windows,

Frameworks, Quark, Pagemaker

- Electronic Mail

examples: Lotus CC mall, Beyond Mall, Da Vincl eMall, Microsoft Mall

- Forms

examples: Delrina Perform, Formworks for Windows,

- Word Processing

examples: Microsoft Word for Windows, Aim Pro, Word Perfect for Windows, Rightwriter, Grammatik,

CA Textor

6. Utilities

- Communications

examples: Crosstalk for Windows, Procomm for

Windows, Winfax Pro, Mall, Laplink Pro, Mirror,

PC Anywhere, Carbon Copy

- Utilities

examples: Super PC Kwlk Power pack, Norton

Desktop, Printaplot, PC Tools, Mace, QEMM, 386Max, Xtree for Windows, Direct Access for Windows, QDos III

Within each classification, only one package from a specific software developer has been included. This eliminates the potential dominant influence of a specific software developer within a particular market niche. Further, the division of each major classification into two or more minor classifications prevent any one of the large software 
developers such as Microsoft, Lotus, or Borland from having a dominate influence on the research.

\section{Selection of the Specific Software Packages}

The population of avallable packages was created by mailing requests for evaluation coples to software developers in each of the categorles using the Windows Shopper's Guide, PC Products Monthly, MAC User, Byte, PC Magazine, and MAC World publications. The resulting sample packages that were sent by the contacted firms, plus those obtained from university sources, forms a convenient sample of 82 packages on which to conduct the research.

\section{Processing the User Manuais}

As software packages arrived in somewhat random order, they were first logged in a log book to list what packages were avallable to sample. The shipping boxes were then stored in a convenient, nonsequential order for evaluation.

An Excel spreadsheet was created to provide a table of random numbers for each package to be evaluated to determine which chapters to use. The random numbers had been generated through several random generation cycles.

Boxes were picked conveniently from the stack of unprocessed software packages and a document was selected that approximated one of the following titles:

User Manual

User's Guide

Tutorial 
Complete Reference Manual

Tutorial Manual

Training Manual

The procedure for processing each document was:

1. The general data concerning the price, title, version, page count chapter count, etc. were recorded.

2. The number of chapters counted in the table of contents was multiplied by each random number in the spreadsheet table to determine which four chapters would be scored. The round off error in the resulting product was used to avoid scoring the same chapter twice by either rounding up or down. If the random numbers and round off error were not sufficient then a nearby chapter was selected.

3. A four page sample was copied for each chapter of the first two chapters selected in step 2. The sample was selected conventently as follows: the sample for the first chapter usually was the first four pages, whereas the sample of the second chapter was selected by picking either the last four pages of the chapter or by selecting any major heading and copying four pages from that point.

4. The third and fourth chapters selected in step 2 were then copied in their entirety unless they exceeded 40 pages. If the chapter exceeded 40 pages then only the first 20 or so pages were used for the chapter level 2 scoring. The literature suggests that chapters should not exceed about 12 pages (Weiss 198250 ). This number refers to the 
concept of chunking information in manageable sizes for consumption by the reader. If the reader must spend a large amount of time reading a chapter, then it will probably not be read and understood at the first reading.

5. The first two chapters were then marked up and scored on the sentence level metrics.

6. The third and fourth chapters copled in step 4 were then scored for the chapter level metrics.

7. The data from the sample, is then scored using the formulas outlined in chapter III, including a total score for the document.

\section{MODEL VALIDITY}

First the general approach is summarized, followed by a discussion of how the panel was selected. The panelist's activities are then discussed, including an initial survey, and their scoring of the documents. Next is a discussion of how the scores from the panelists and the scores from the model are compared to determine if the subjective criteria of the panel (explained further shortly) and the objective criteria of the model are correlated. The method for determining the internal consistency of the panel's scores is also discussed. The final section addresses how the research hypothesis is tested. 


\section{General Approach}

Although it may be useful to have a model that provides a quantitative measure of the quality of the end user computer document, It is nevertheless necessary to determine if these metrics have any validity in the real world. In general, the notion of what is quality documentation has been a subjective evaluation by someone who is knowledgeable. This view is supported in the literature by Duffy (1985), who advocates the use of expert judges. To determine validity, a panel of experts has provided their underlying criteria for evaluation. Each expert has also evaluated a random sample of the scored packages. Their evaluations are compared to the scores provided by the model for those same documents to determine if the metrics are valid.

\section{$\underline{\text { Panel of Experts }}$}

The research uses experts as proxies for the opinions of users following the suggestions of Duffy (1985). Ideally, the panel would consist of typical users. However, there are substantial problems defining who the typical user is for any particular piece of software. Further research on this issue is needed. A further challenge would be to gather a sample from the population for each group of users for a particular piece of software. The third problem then would be to correlate the opinions of these user groups across application packages to determine the larger issues of quality in user manuals.

Consequently, a panel of six "experts" has been chosen. Three are active educators who teach end user application classes in word processing, spreadsheets, and other topics. One is active in the trade publications, and two work directly for major firms in the computer 
industry. Each expert has been asked to provide a list of criteria they would use to evaluate an user manual and the method they would use to score the document according to each criteria.

The rationale for selecting educators and revlewers is that: 1) they have experience in reviewing a large number of software packages and documents relating to those applications, such as aftermarket books and video materials; and 2) they work closely with students who are first time users of the software. The use of such a panel in effect condenses the experiences of end users through the training process. Two weaknesses of this method are that it: 1) emphasizes the experiences of users who are willing to pay for training and 2) assumes the personal biases of the experts will not have a detrimental influence. Since there was no compensation, material reward, or recognition, the effort of the panel members was limited to about 6 hours each in order to obtain the cooperation of enough experts to form the panel.

\section{Initial Survey of Panel}

Prior to scoring any software packages, the members of the panel of experts were sent surveys to determine if any of the panel members would be using any of the metrics or close approximations in their evaluations. The survey asked what they would lookd for as measures of quality and what methods the experts would use to score the quality of each of the categories in Figure 7. The data indicated that there is some overlap between the subjective expert evaluation criteria and the criteria used to develop the model. The responses included such phrases as:

"Step by step procedures" 
"Just enough info to do the job and no more."

"useful headings"

"Active voice",

"3rd person"

"indexes the way real people look for them"

"clear concise language"

"It should be obvious from the graphic what is being said."

The phrases do suggest a connection, but an entire research project could be constructed around what the phrases might mean in quantatative terms. This is beyond the scope of this research.

\section{Scoring of Documents by the Panel}

Each expert selected four to six documents from the list and evaluated them. Since the panel of experts is using subjective criteria to evaluate documents, the use of continuous ratio scores would probably not provide meaningful results. Thus, in order to provide a macro score of the quality of a user manual, the experts placed each document into one of the following four quartiles: .

D: The lower 25\% quartile, Below 70

C: The lower mid range quartile, 70-79

B: The Upper mid range quartile, 80-89

A: The upper quartile, 90-100

In addition, each document is ranked relative to other documents in the sample selected for evaluation by the expert. The panel member will complete a questionnaire evaluating: 1) the random chapters selected by the model, 2) the chapters chosen for scoring by the 
expert, 3) the absolute $A B C D$ scores (70-100) for text, graphics, reference aids, typographic representation, and 4) any additional scores chosen by the evaluator.

There is enough overlap in the selection of samples from the software scored by the model to determine if there is any correlation between judges for reliability. The instructions to the panel and the scoring material is listed in Appendix $B$.

\section{Comparison of the Panel Scores to the Model}

The scores from the panel of experts are correlated with the scores from the model to determine the association between the model and expert opinion. Further analysis indicates more exact and higher order relationships between the model and the panelists.

Both relative rankings and absolute scores are used to place each of the packages in a relative frame of reference. The metrics may have an upward or downward bias because the weighting of composite metric scores by the model may not be the same as the scoring logic used by the expert. Detalled scores have been requested in each main area (text, graphics, reference aids, typographic, other) to assist in isolating any such differences.

\section{Evaluation of the Consistency of the Model and the Panel}

Since all of the metric measures are ratio data scored on a scale of $0.00-1.00$, the individual scores at the sentence level (Level 3 Figure 7 page 34) and chapter level (Level 2 Figure 7 page 34) could be viewed as test questions on an exam with equal weight on each question. The exam has four parts. The statistics on the intercorrelations between the 
four parts can measured with a item statistic such as Cronbach's Alpha (Gullford 1954385 and Ferguson 1989 472). If the document is consistent, then the alpha statistic should suggest a reasonable measure of correlation between the four sample chapters.

The consistency of the data from different panelists can also be tested using Cronbach's Alpha. Other measures such as correlation may be used to determine if the data from the panel of experts is consistent. Since the panelists selected many of the same software packages for evaluation the Friedman Rank test [Ferguson (1989 443) SPSS (1992 384)] is used to determine if the quality measures used by the experts are from the same domain. That is, if the experts use similar measures, the sum of the ranks for the same package will tend to have means centered about multiples of some average rank. If the experts use widely diverging methods then the sum of the ranks for the same packages will tend to be the same, indicating a random pattern.

\section{Testing of the Research Hypothesis}

One set of sample data has been gathered through the application of the model to a large sample of user manuals. A second set of data has been gathered from the panel of experts via questionnaires. To test the research hypothesis, the means of the two sets of samples with different sample sizes can be tested using the $\mathrm{T}$ test modified by the BehrensFisher method for small sample sizes and unequal samples (Ferguson 1989 192). The $T$ test for paired samples (Ferguson 1989 203) can test the user manuals evaluated by both the model and the panel. The model has been applied to a sample size of 82 user manuals. The panel of 
experts constitutes a sample size of 23. These sample sizes can yleld a power of about .6-.7 [Cohen \& Cohen (1983 59-61, F.2), Rosenthall (1991 443)] and will detect a medium effect at the .05 level. Since this is an exploratory study, any significance would help validate the metrics and the ability to determine the size of the effect would be a bonus. If the $T$ test provides some support for the hypothesis, then the difference in variances of the two samples can be tested for significance using the $F$ test of variance (Ferguson 1989 203). If the null hypothesis is not rejected based on the initial statistical tests, the data will be input to the PC version of Systat, SPSS, or Statgraphics for further analysis.

If the results point to a significant relation between the two means then it is profitable to decompose the detail statistics to determine a more exact relationship between the variables and the notion of quality in user manuals. A significant relation between the metric and the evaluation of the panel of experts would suggest that certain metrics are more valuable than others. Using this assumption it would be profitable to run a regression model using the scores from the panel of experts as the dependent variable and the metrics as independent variables to determine what weighting the panel of experts placed on measures in certain areas. The knowledge gained from this exercise would be profitable in focusing future research. A second avenue of approach is to run an exploratory factor analysis to determine what quantitative measures are loading in what groups to suggest what factors may be present in the expert evaluations. The value of this exercise is to determine which of the variable from the model have the most value. 


\section{CHAPTER V}

\section{FINDINGS}

The previous four chapters have provided a basis for gathering data. There are definitions of what the relevant topics are. There is some body of literature that supported some further research into the defined topics. A proposed model of the process has been suggested. A method to gather the data for analysis has been proposed. This section deals with the analysis of the data that was collected using the model and was used by the panel of experts to evaluate the quality of the user manuals.

First, an analysis of the model data is presented, an analysis of the panelist data follows, and a comparison of the two data sets followed by some general observations completes the chapter. This chapter follows the flowchart presented in Figure 9 page 46.

\section{ANALYSIS OF THE MODEL}

First the distribution of the overall quality of the eighty two user manuals measured by the model and the relationship between quality measured by the model and price is examined. Next, the major components of quality measured by the model are examined to see graphically how these major components contribute to the overall measure of quality measured by the model. Following this analysis, the detailed components of each of the major components is examined separately in order to determine which specific elements of the 
documents that were scored exhibited the highest quality and which the least as measured by the model.

Following this analysis, issues of reliability of measures is undertaken. Because of the methods used in sampling chapters and sentences from user manuals to be scored, there are 4 different levels at which reliability measures may be assessed. The Sentence Level 3 samples from each of two chapters are examined. The chapter level 2 samples from two complete chapters are examined. The overall reliability of the sample user manual is discussed. Last. the reliability of the user manuals scored by the panel of experts in examined.

First a distribution of overall quality as measured by the model is discussed and the relationship between quality of user manuals and its software type, cost, is examined.

\section{Data from the Model}

The model measures 25 variables in the range of [0.00-1.00] and the Total Score of a document is the arithmetic mean of these 25 variables which assign equal weights to each of the variables. The data from the model is analyzed in terms of its groupings and components. The model is then compared to the four panelist scores. Finally, the model is tuned to the panelist data to explore the dimensions the panelists used in their expert evaluation.

The raw data collected from many of the software packages listed in Appendix A is presented in Appendix C. The data covers eighty two packages. In addition to the variables in the model several descriptive variables (price, version number, first date in user manual, application 
category) were examined graphically to look for any patterns in the data that might suggest a relationship between the descriptive variable and the score from the model.

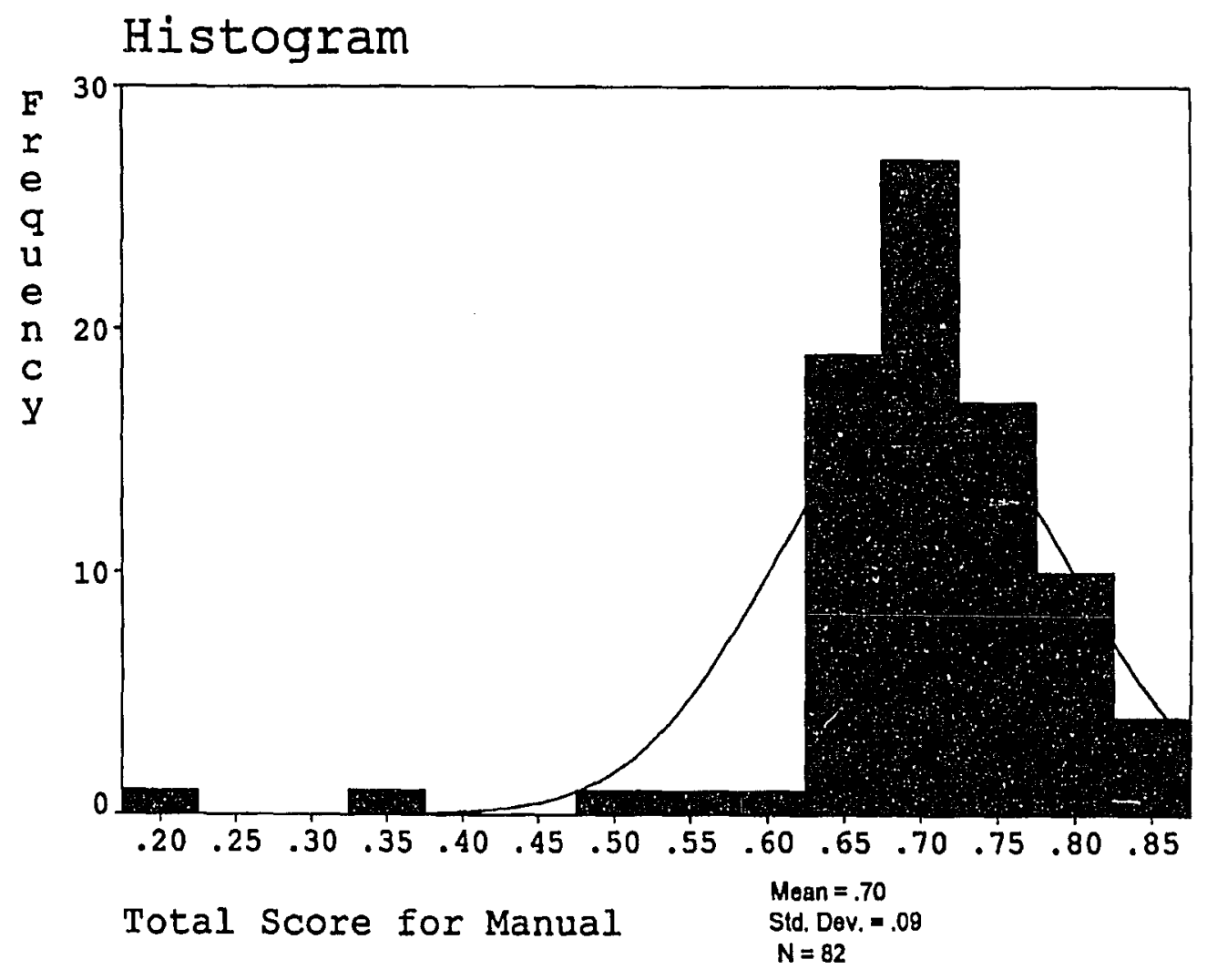

Figure 11. Plot of Total Model Score for Manual.

Figure 11 shows the frequency distribution for the total manual score with a normal curve plotted behind the histogram. On a scale from zero to one, the Total Scores from the model suggest a strong central tendency in the data, mean 0.70 variance 0.009 . eighty percent of the documents (66 out of 82) are within one standard deviation of the mean. This clustering means that the sample of documents are somewhat consistent and similar in nature. This is reasonable since the research 
focussed upon Windows software on a single hardware platform. A second issue is that the model total may not provide enough discrimination because no weighting has been applied to any of the Individual contributing variables of the model. That is, the averaging of less significant data may be masking more important data.

A plot of the total model score against the listed retall price of the software package suggested that the quality of the document in not correlated with the price of the software. (See Figure 12)

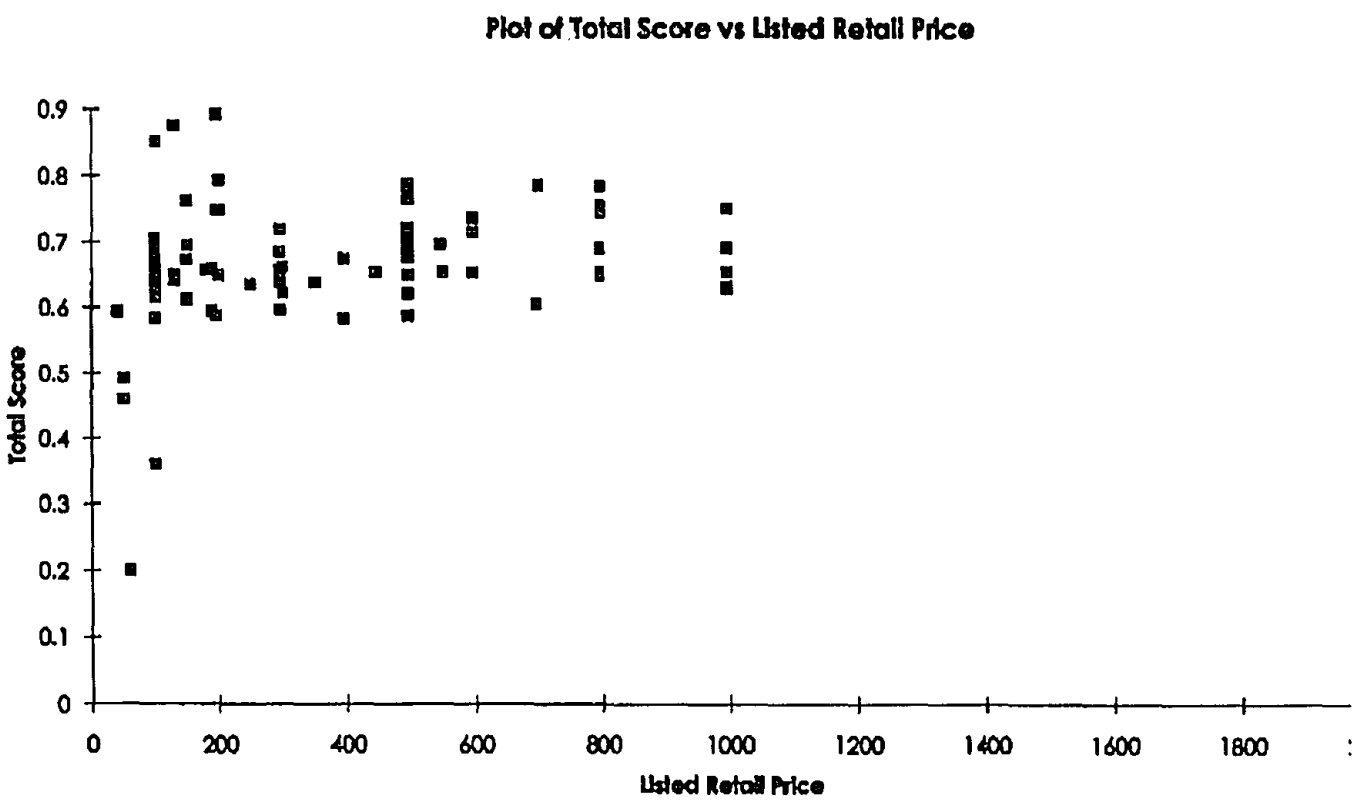

Figure 12. Plot of Model Score vs Retail Price.

This suggests that the amount of resources avallable may not Impact the end product. A similar plot of the total model score against the length of the end user document suggests that there in no relation between the length of the document and its quality. A plot (Figure 13) of the total model score against the major numeric software application 
categories (see the end of Appendix B for list) does not suggest that any particular application area is significantly better than any other. That is, there are similar high and low entries in all major groups.

Plot of Tolal Score ys Numertc Catogory

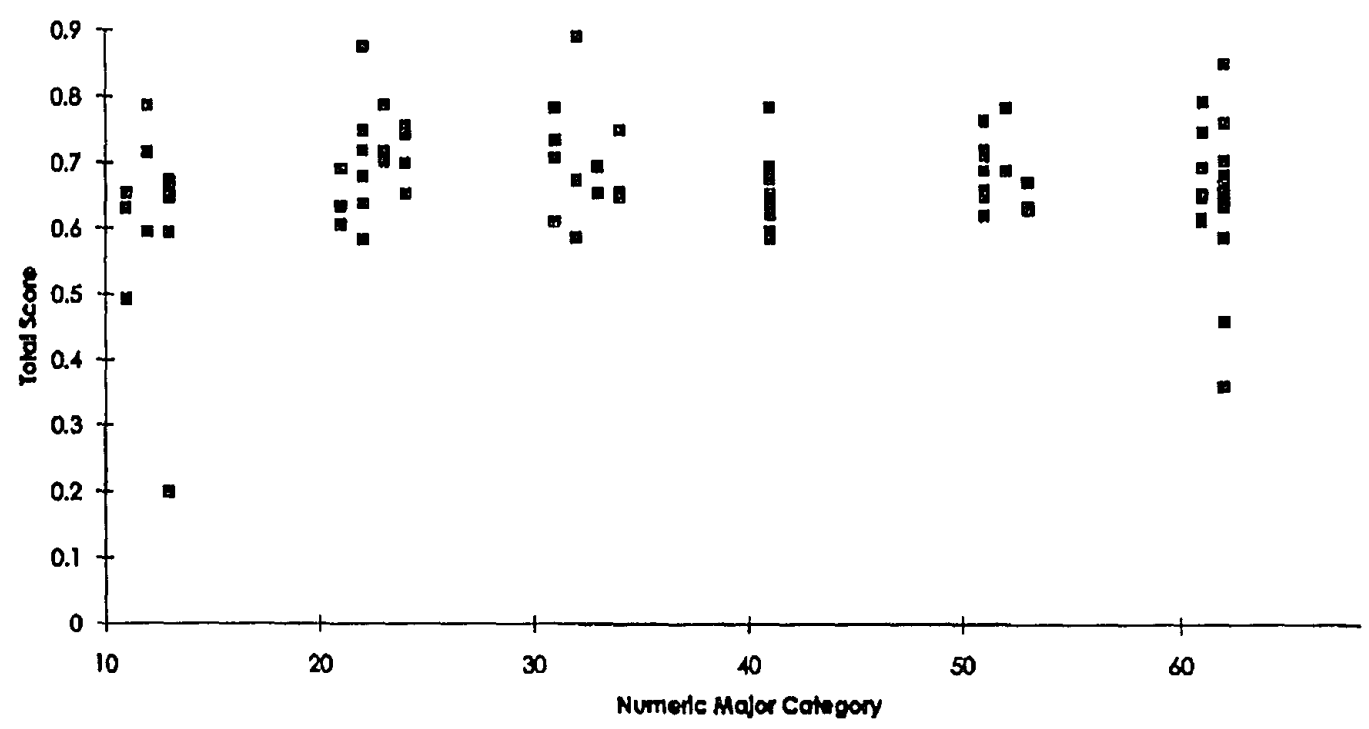

10-applications 20-drawing 30-quantitative 40- systems 50-textual 60-misc.

Figure 13. Plot of Model Score vs Numeric Category.

The descriptive data above and other data such as version number of the software and first year of publication did not suggest any visual relationships with quality as measured by the model.

Levels and Categories in the Model

A series of plots were made to determine if there were any apparent large difference in the proportion each level (Level $1,2,3$ of Figure 7 page 34) contributed in different software application classes. The plot of level scores vs numeric software application class (see Figure 
14) did show some differences (lower Document Level contribution, higher Sentence Level contribution), but did not suggest any obvious tendencies.

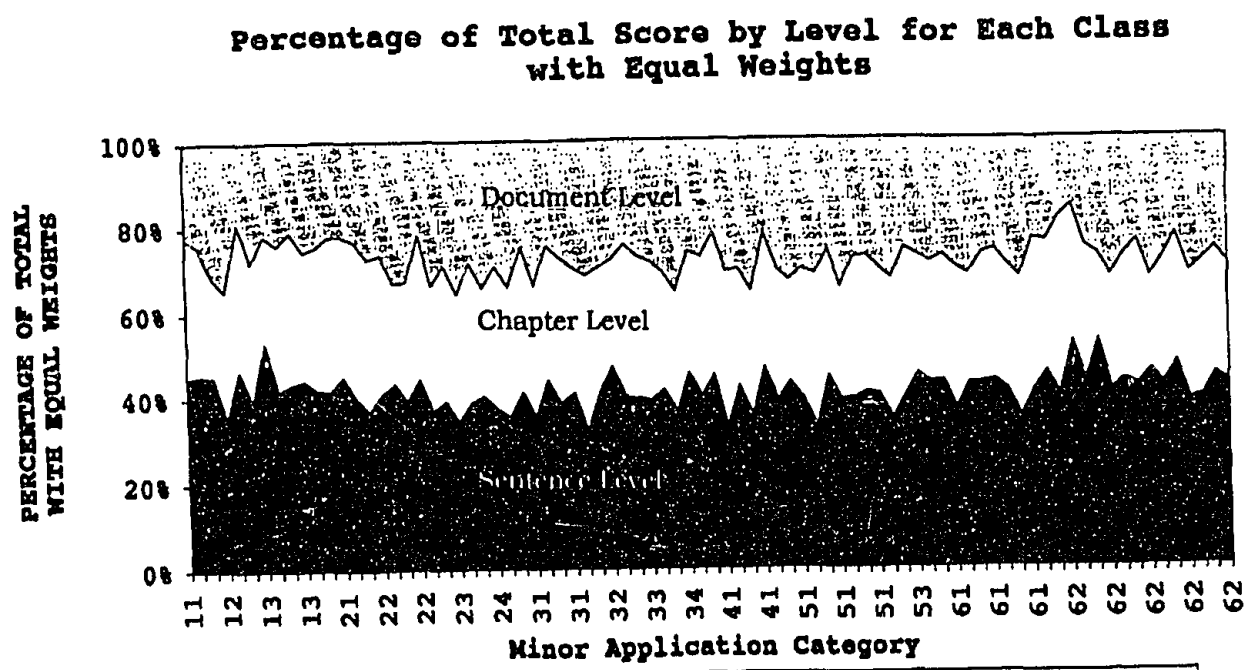

Sentence Level $3 \square$ Chapter Lovel 2 Document Level 1

\begin{tabular}{|l|}
\hline Minor Application Categories \\
\hline 11-accounting 12-project management 13-personal information managers \\
21-CAD 22-drawing 23-presentations 24-graphics \\
31-spreadsheets 32-addins 33-math 34-statistics \\
41-databases \\
51-word processing 52-desktop publishing 53-email \\
61-communications 62-utilities
\end{tabular}

Figure 14. Plot of Level vs Numeric Category.

A second plot weighting the level scores with the number of variables (Document Level 1 - 8 contributing variables, Chapter Level 2 7 contributing variables, Sentence Level 3 - 10 contributing variables) did not visually change the relationships. The proportions of the 
relationships, Document level $(8 / 25)$, Chapter Level $(7 / 25)$, and Sentence Level $(10 / 25)$ do not visually change the meaning of the data.

Using equal weights for the categories in Figure 7 page 34, the plot in Figure 15 suggests the typographic and graphics model categories predominate the model score.

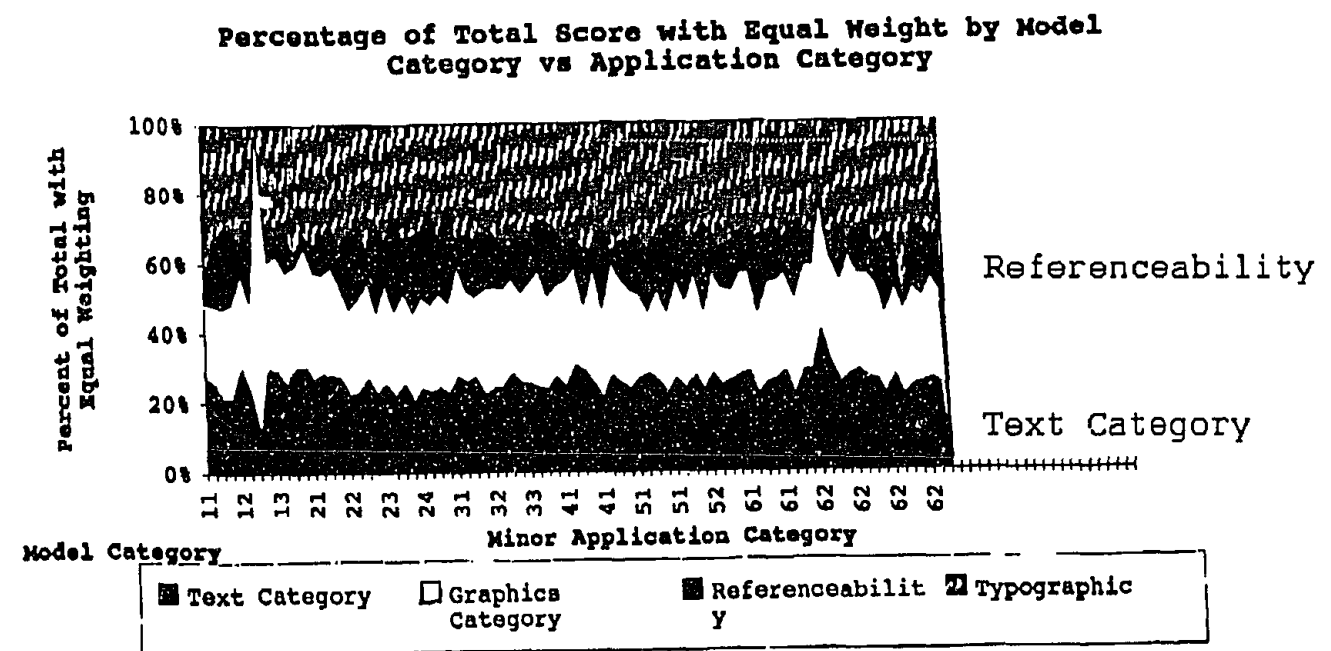

\begin{tabular}{|l|}
\hline Minor Application Categories \\
\hline 11-accounting 12-project management 13-personal information managers \\
21-CAD 22-drawing 23-presentations 24-graphlcs \\
31-gpreadsheets 32-adding 33-math 34-statistics \\
41-databases \\
51-word processing 52-desktop publishing 53-email \\
61-communications 62-utilities
\end{tabular}

Figure 15. Model Score by Application Category with Equal Weights.

If the plot is weighted by the number of variables in each level then the visual indication is that the Total Score is most heavily influenced by the text and graphics model categories (Figure 16). 


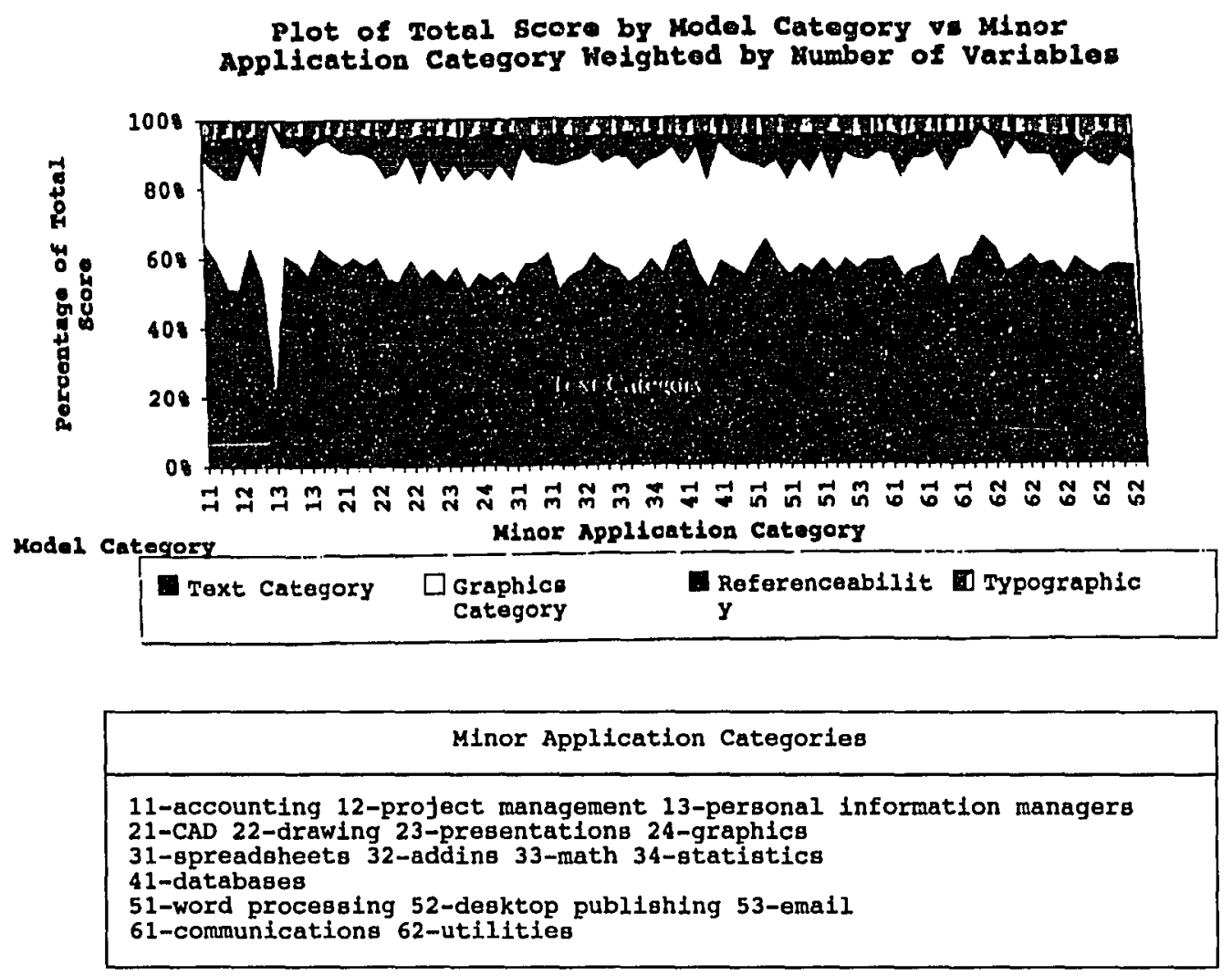

Figure 16. Score by Model Category with Variable Weights.

The plot of the composition of Sentence Level scores by category (see Figure 17) with equal weights for the text portion and the graphic portion suggested that the graphic portion of the measure is influencing the Sentence Level score. 


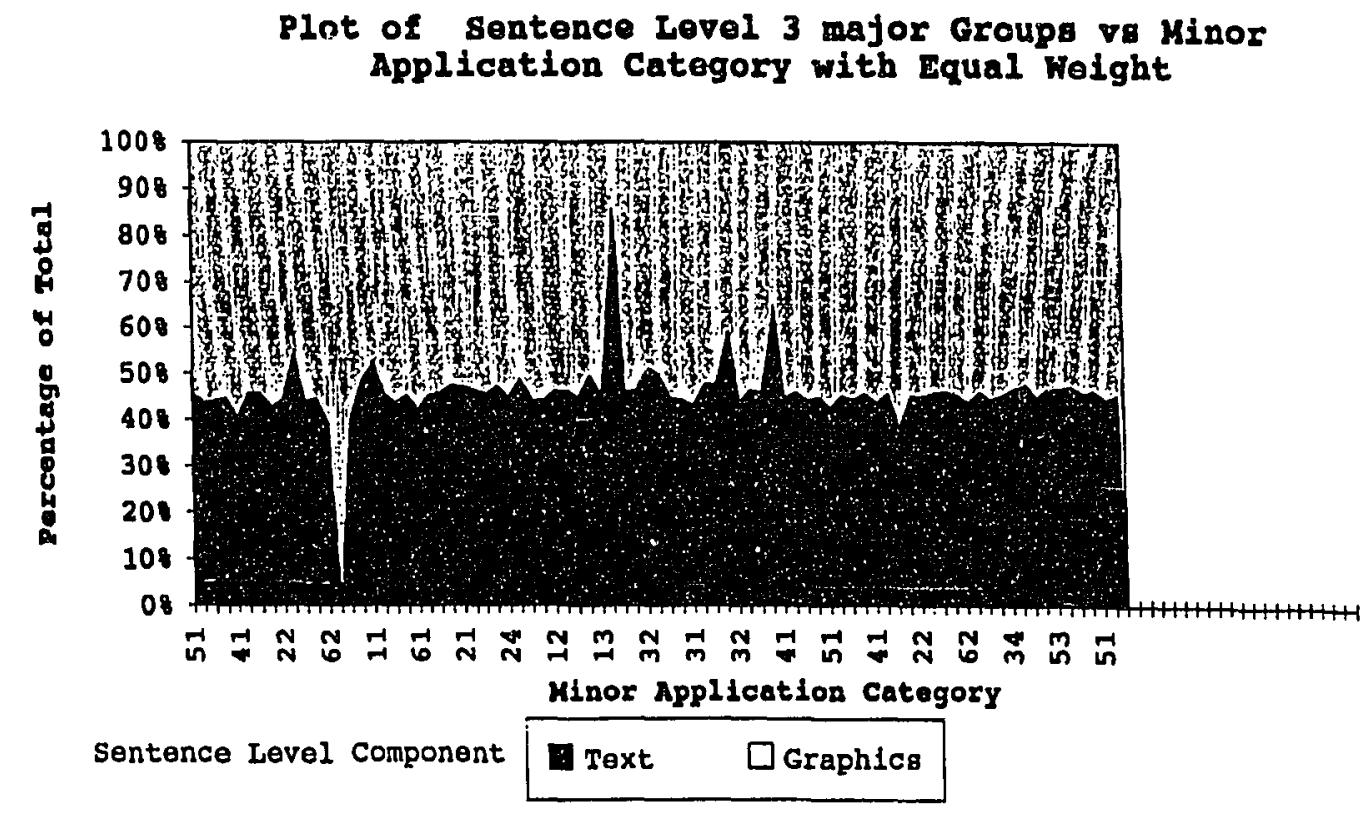

\begin{tabular}{|l|}
\hline Minor Application Categories \\
\hline 11-accounting 12-project management 13-personal information managers \\
21-CAD 22-drawing 23-presentations 24-graphics \\
31-spreadsheets 32-addins 33-math 34-statistica \\
41-databases \\
51-word processing 52-desktop publishing 53-email \\
61-communications 62-utilities \\
\hline
\end{tabular}

Figure 17. Sentence Level 3 Score vs Numeric Category.

If the same information is plotted using the number of variables as weighting then the text portion of the Sentence Level is the dominating feature (Figure 18) 


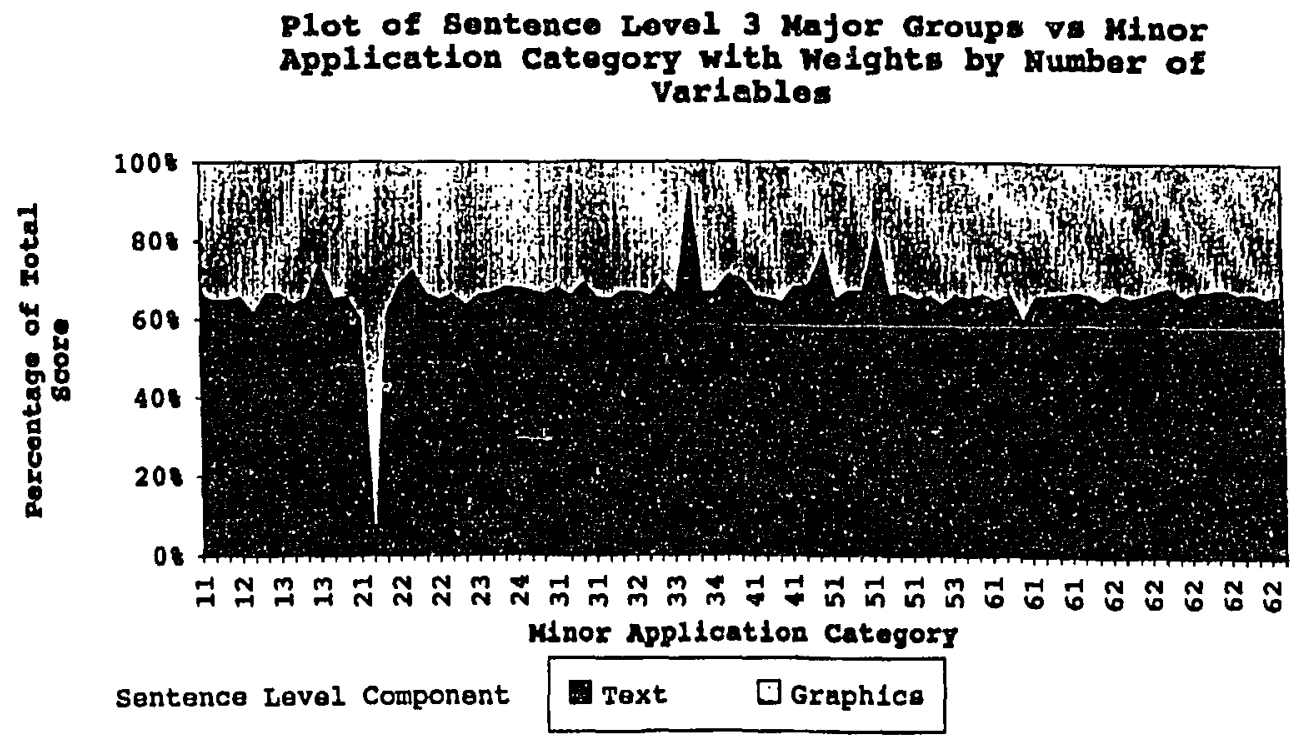

Minor Application Categories

11-accounting 12-project management 13-personal information managers

21-CAD 22-drawing 23-presentations 24-graphics

31-spreadsheets 32-adding 33-math 34-8tatistics

41-databases

51-word processing 52-desktop publishing 53-email

61-comunications 62-utilities

Figure 18. Sentence Level 3 Score Welghted by Number of Variables.

These flgures show that the method in which the total model score is formed from the contributing variables can influence the overall Total Score of the model. The Document level, Chapter Level, Sentence level contribution to the total model score may vary slightly from $1 / 3,1 / 3$, $1 / 3$ to $8 / 25,7 / 25,10 / 25$ respectively. The total score from the model formed by proportions based upon number of variables provides more emphasis to the Text category variables and less to typographic and referenceability categories. However, the text based contribution to the total model score did not show any overall relationship between application category and model score. 
Internal Consistency of Samples

The methodology described in figure 10 page 49 requires that samples from the user manual be taken to represent the document. This section examines the internal reliability of the overall samples and each of the two component samples (Chapter level and Sentence level). The Alpha Statistic provides a measure of internal consistency and the reliability of components. It is desirable to have the data reflect only the changes in conditions and not additional measurement error. That is, the component measures of the model should be internally consistent (Ferguson $1989466-472$ ). In considering the use of an alpha statistic to measure internal consistency, it is necessary to consider the context surrounding the research. In a normal situation, the alpha statistic is applied where there is a uniform test with uniform answers given to a group of subjects. Applying the analogy to the model scores across the sample chapters, may fall in practice. Although the test is uniform, each user manual can be expressly different. Therefore even though there is a standard method for grading, the same question is not being graded. In that sense, it is possible for there to be no correlation between samples and the alpha statistic would be zero. Any higher value of the statistic supports the notion of internal consistency. The Alpha statistic varies from 0.00 to 1.00 in the same manner as a correlation (Ferguson 1989 472). Any value over 0.5 is considered good at least there is more than chance association.

In the overall reliability test each of the variables sampled at the Sentence Level 3 of two random chapters and sampled at the Chapter Level 2 of the other two random chapters are used as items for 
computing the alpha statistic. This list (Appendix E) consists of 17 of the model variables sampled two times in each of four sample chapters for a total of 34 items. The variables are described in the next two paragraphs. All of the 17 items from the sampled chapters are used in the reliability test for an alpha is 0.8058 (Appendix E).

At the Sentence Level 3, the two chapter samples of 3-4 pages each consist of 10 of the model variables sampled twice for a total of 20 items. The alpha for this group is $\mathbf{0 . 8 2 7 8}$. The variables are: Agency - action, Agency - document, Agency - equipment, Agency - user, Goals for Action, Jargon, Logical Conditions, Multiple Steps, and Unnecessary References (See Figure 7 page 34).

On the two complete sampled chapters in each document seven variables from the Chapter Level 2 text group are sampled twice for a total of 14 items. The variables are: Advance Organizers, Paragraph Cohesion, Section Cohesion, List Consistency, Procedures with Goals, Graphics in Procedures, and User actions in Procedures. For the Chapter Level 2 scores (see Figure 7 page 34), the alpha is 0.6451 . The lower alpha on the sampled chapters reflected more variability in presentation options and writing styles of each software development organization than in the Sentence Level components. Also, the alpha statistic is sensitive to the number of items. The greater the number of items with other factors being constant the better the alpha statistic.

The total alpha statistic of .8058 is a good measure of internal consistency (Ferguson 1989 472). Therefore, taking the four random samples from each user manual provided representative data of the eighty two user manuals contained in the sample. Subjective 
evaluations of the panelists presented shortly provide further support for the internal consistency of the sampling method.

\section{Statistical Analysis of the Model}

This section examines each of the component groups of the model as well as the variables that comprise each group. Appendix $\mathrm{C}$ contains the summary statistical analysis of the model data. Figure 7 is shown again to assist in reading the following discussion of the model analysis.

Total Scores - the model total score, Figure 11 (page 64), histogram has a mean of 0.70 with a standard deviation of 0.09 . The distribution is not quite normal, but very close. The plot suggested that there is a threshold of acceptable commercial documentation that most documents in the sample tried to exceed.

Table I summarizes the data by descending level. The levels are not equally weighted, but the variables are, following the method of Velotta (1992).

\begin{tabular}{llll}
\multicolumn{5}{c}{ TABLE I } \\
SUMMARY & OF TOTAL SCORES \\
& & \\
model & Variables & mean & Std. dev. \\
\hline Document Level 1 & 8 & 0.58 & 0.14 \\
Chapter Level 2 & 7 & 0.64 & 0.12 \\
Sentence Level 3 & 10 & 0.84 & 0.09 \\
TotaL MODEL ScORE & 25 & 0.70 & 0.09
\end{tabular}

Document Level 1 Scores - The Document Level scores were skewed to the low quality end of the measure and had a wider variability; mean 0.58 with a standard deviation of 0.14 . 

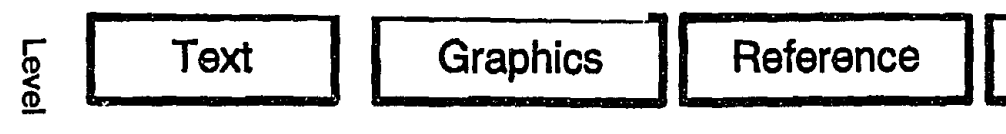

Typographic
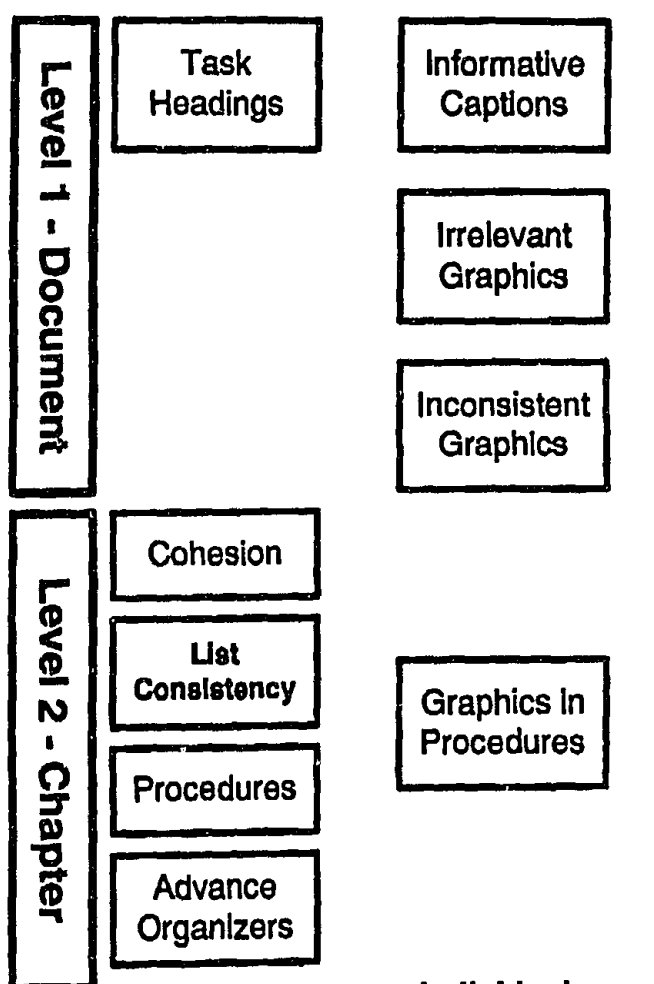

10 Count Measuro

1. 2 loved TOC

2. list of III.

3. 2 level chapter

TOC

4. 2 level headings

5. Fig. Ceptions

6. Tabs

7. Error Msgs

8. Clossary

O. Indexes

10. Ret. Card

Inconsistent
Graphics

\begin{tabular}{|c|}
\hline Glossary \\
\hline Indexes \\
\hline
\end{tabular}

11 Count Moasuro

1. typeface

2. Type stzo

3. Famlly branch

4. letter posture

5. Letter composition

6. Leading

7. Urie Measure

8. Appointment

8. word spacing

10. Lotter Spacing

11. Rulere, loadore,

punctuation marks,

and paragraph

Indentation

\section{Graphics in}

Procedures

Readabillity

Noun Strings

\section{Indlvidual}

Graphlc

Le Factor

Data Ink

Ratio

Goals or

Action

\section{Duck}

Logical

Conditons

Multiplo steps

Unñocessery

References

Figure 7. Duplicate Copy for Easy Reference. 
Figure 19 shows the frequency distribution for the Document Level with over half of the sample clustered around the mean.

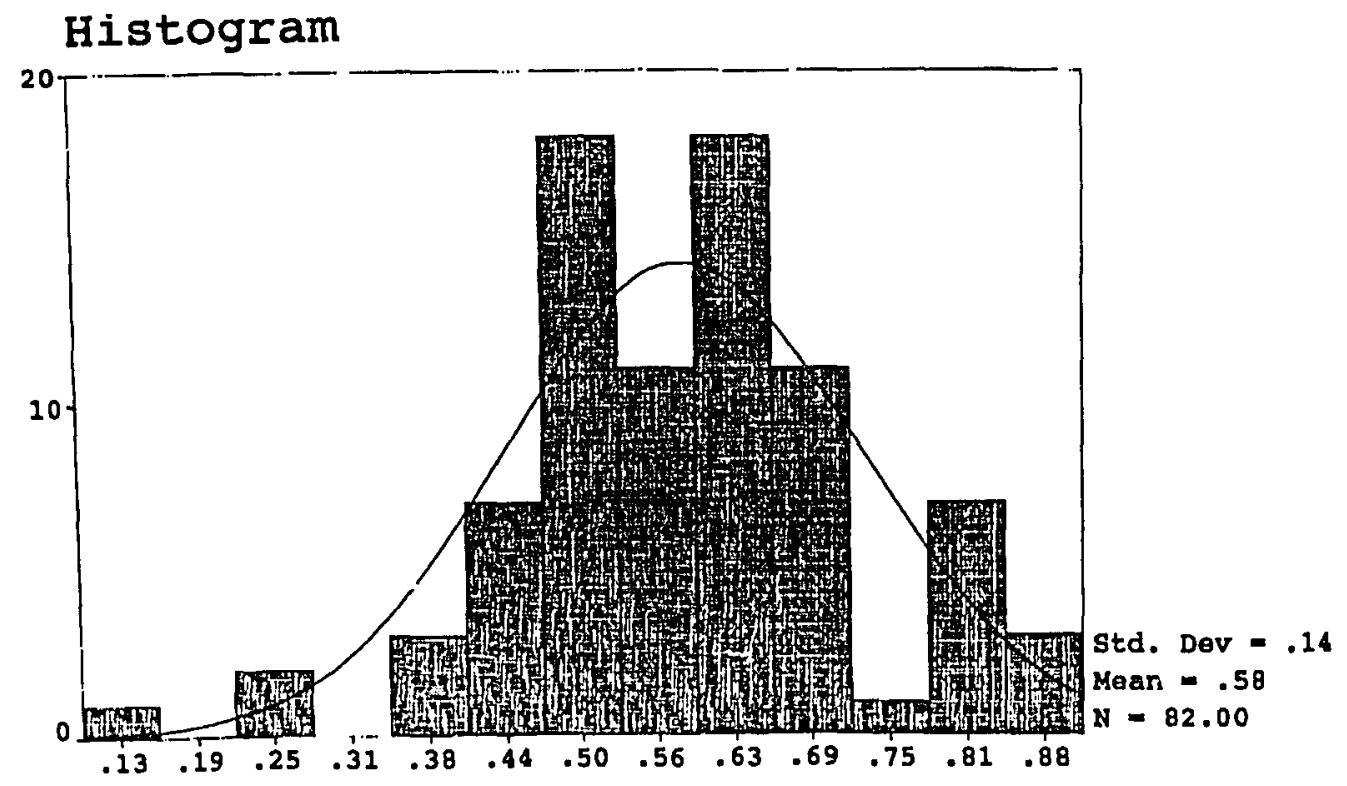

Figure 19. Frequency Distribution of the Document Level 1 Scores.

This might suggest some shortcomings at the Document Level (Level 1 Figure 7 page 75) to make the document more usable and easy to reference. For example, reference alds scored consistently low. This was reflected in the detall scores for the Document Level 1 variables, see Table II which are shown in descending mean order.

The glossary (mean 0.25) and informative captions (mean 0.23) showed the smallest means of the documents from the model. In most cases, there were no captions and no list of figures to find graphics. In many cases there was no glossary or it fell below $2 \%$ of the total number of pages in the user manual. 
TABLE II

SUMMARY OF DOCUMENT STATISTICS

\begin{tabular}{lll} 
model variable & mean & Std. dev. \\
\hline Inconsistent Graphics & 0.99 & 0.09 \\
Typographic & 0.89 & 0.14 \\
Irrelevant Graphics & 0.88 & 0.23 \\
Index to 5 per page & 0.57 & 0.33 \\
Reference Aids & 0.43 & 0.19 \\
Task headings & 0.43 & 0.25 \\
Glossary & 0.25 & 0.42 \\
Informative Captions & 0.23 & 0.38 \\
DocumENT LEVEL 1 & 0.58 & 0.20
\end{tabular}

Chapter Level 2 Scores - The Chapter Level (Level 2 Figure 7 page 75) mean score (0.64) and standard deviation (0.12) is more near the mean of the Total Score of 0.70 than the Sentence Level 3 score. The distribution (Figure 20) had more values occurring near the mean (more focused) than with the Document Level scores .

\section{Histogram}

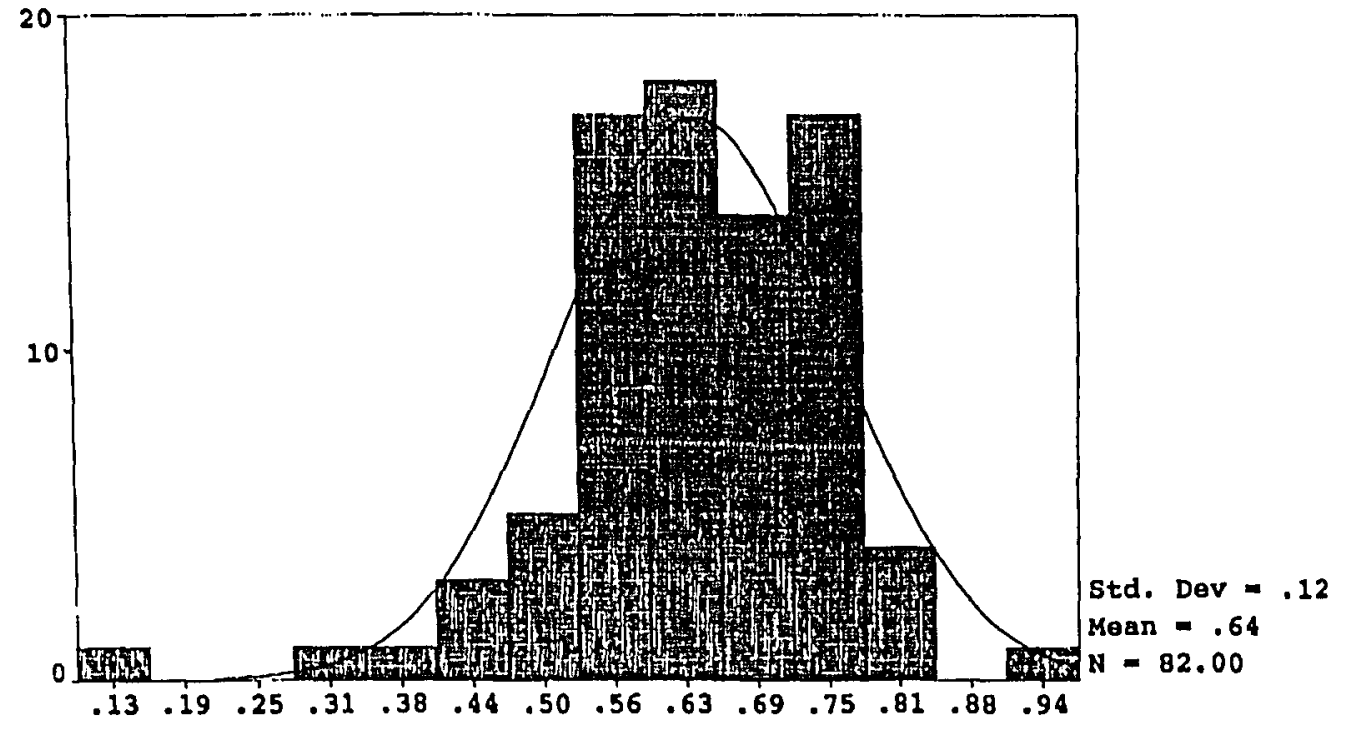

Figure 20. Frequency Distribution of Chapter Level 2 Scores. 
Several of the component variables at the Chapter Level (See Table III) showed a tendency for manual authors to focus on some aspects of the chapter while almost disregarding others.

TABLE III

SUMMARY OF CHAPTER LEVEL 2 STATISTICS

\begin{tabular}{lcc} 
model variable & mean & std. dev. \\
\hline Cohesion - section & 0.95 & 0.16 \\
Cohesion - paragraph & 0.92 & 0.20 \\
List Consistency & 0.92 & 0.20 \\
Goals in Procedures & 0.61 & 0.35 \\
Graphics in Procedures & 0.50 & 0.35 \\
Procedures - user action & 0.36 & 0.17 \\
Advance Organizers & 0.18 & 0.20 \\
CHAPTER LEVEL 2 TotaI & 0.64 & 0.12
\end{tabular}

The suggestion from Chapter Level was that there are too many sentences, without the user as the subject, in procedures (mean 0.36), not enough goal definition (mean 0.61), and not enough advance preparation of the material for the reader (mean 0.18). The question of procedures with graphics may be up for debate (mean 0.50). It is unclear if every procedure should have at least one graphic. This suggests that some modification of the model may be needed.

Sentence Level 3 Scores - The Sentence Level 3 scores (Figure 7 page 75) scores had a mean of 0.84 and standard deviation of 0.09 . Figure 21 shows a majority (62\%) of the observations within 0.035 of 0.88 . This shows a strongly central tendency of the Sentence Level 3 scores. 


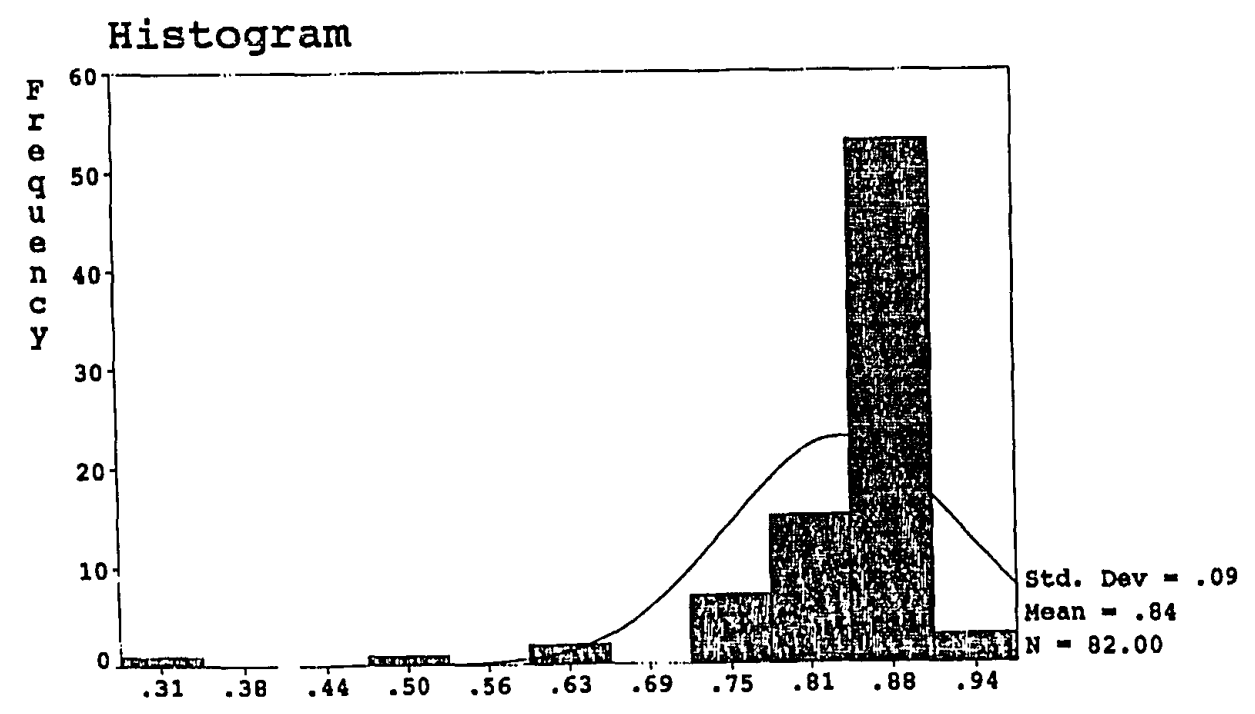

Figure 21. Frequency Distribution of Sentence Level 3 Scores.

The Sentence level is weighted by the graphics variables portion of the score (Lie Factors, Data-Ink Ratio, Ducks). The sharp rise at .88 suggested some feature of the text weighting the score. The frequency distribution (Figure 22 suggests a lower threshold most commercial user manuals try to meet.

The distribution of the Sentence Level 3 scores was influenced by the graphics component of the score (Figure 21) while the text scores (Figure (?)) suggested a narrow focus on the upper range. The graphics component variables of the model, Lie Factors (mean 0.96), Data-Ink (mean 0.97), Ducks (mean 0.88), provided a definite upward blas for the Sentence Level scores, Lecause of their generally higher scores (See Table 4) 


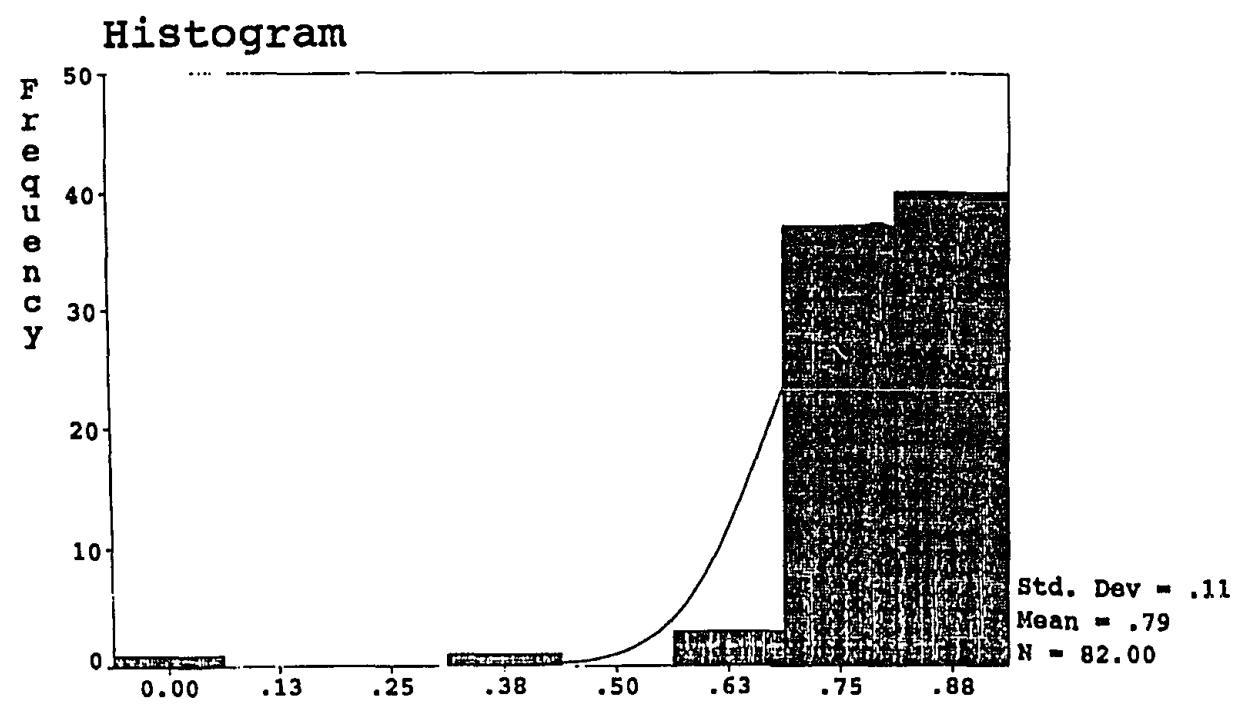

Figure 22. Frequency Distribution of Text Scores.

The text component of the Sentence Level score provided some data that suggest some work on the model may be needed to better form the component scores into the text portion of the sentence score. For example, the logical component scores low, but if it had a high score the text would be virtually unreadable and would be more like a complex program than a training aid. Table IV presents the Sentence Level 3 data in descending mean order on a scale from one (good) to zero (poor). The data suggests that the writers are seeking to obtain some threshold of minimum standards expressed in terms of the Sentence Level 3 text variables (See Figure 7 page 34). 
TABLE IV

SUMMARY OF SENTENCE LEVEL 3 STATISTICS

\begin{tabular}{lcc} 
model variable & mean & std. dev. \\
\hline Jargon & 0.98 & 0.12 \\
Unnecessary references & 0.97 & 0.12 \\
Data-ink & 0.97 & 0.11 \\
Lie Factors & 0.96 & 0.17 \\
Noun strings & 0.95 & 0.12 \\
Multiple steps & 0.94 & 0.14 \\
Ducks & 0.88 & 0.34 \\
Agency total score & 0.84 & 0.15 \\
Goals for action & 0.71 & 0.26 \\
Logical conditions & 0.16 & 0.08 \\
SENTENce LEvel 3 Total & 0.78 & 0.09
\end{tabular}

The data presented in this section suggests that the writers of software user manuals can meet certain minimum levels in the formation of sentence level text features represented by the model. As these features are integrated into higher level structures, the model suggests that the ability to achieve the same quality standard as the sentence text level measures declines. At the highest level of the user manual (Document Level 1) The integration of the material declines the most and the ability to find the higher quality material represented by the Sentence Level text measures is hampered by the lack of quality reference materials. At the Chapter Level the higher quality sentence level text material is buried in other material that discourages comprehension and learning. 


\section{ANALYSIS OF THE PANELIST DATA}

\section{Selection of the Panel of Experts}

The use of Expert judges as recommended by Duffy (1985) requires people with specialized skills, who can condense the experience of many users into a clear judgment of the issues involved in end user document quality. As such, these people usually have good paying jobs and are busy with their normal lives.

At the dissertation research level, there is no compensation system avallable to reward panelists for spending many hours of their time participating in research. While we would wish that everyone is willing to participate in such research projects, the practical reality is that no one wants to be bothered, because there is no reward mechanism either at the university level or where they are employed. In fact, the degree granting institution often does not even place emphasis on faculty participation in the process. Given this dismal set of conditions, it is extremely difficult to find people willing to invest their time in dissertation research.

Scoring by the Panel

The four panel members scored the documents using many of the same chapters as used for scoring the model. There were only a few Indications from the panel that any of the chapters scored with the model did not represent a uniform sampling of the document. While the criterla used by the panel were quite subjective, the panel in effect has validated the sampling method for the model (see Model validity section). 
All of the panel members selected more popular software packages due to access to the documents and personal preference. This overlap provided the means to test the internal consistency of the responses from the panel. The most popular packages scored by the panel were Microsoft Excel, Microsoft PowerPoint, and Microsoft Word for Windows. Since the identity of other panel members was generally unknown and panel members were scattered geographically, it can only be assumed that quality may play a part in their selections.

\section{Data from the Panel of Experts}

Four of the six panelists completed the scoring. One of the panelists scored only five packages; the remaining three scored six packages each. While each judge on the panel of experts was highly trained, each judge had a different personality, area of training, areas of interest, training and experience with different software packages, different impressions of software developers, different ideas of training, and other subjective differences that make the evaluation of each judge on the panel qualitatively different. Figure 23 shows a radar plot of the expert scores on several packages scaled from $0.00-1.00$. The plot Indicates the score that each panelist gave on the package on the line with the package number. For example, several experts scored Persuasion, package number 44 , at about 0.90 . Lines connect the scores to suggest the scoring pattern of the panelist. The data is summarized in Table V (page 86). On several packages the score is very close and on others there is some difference. 

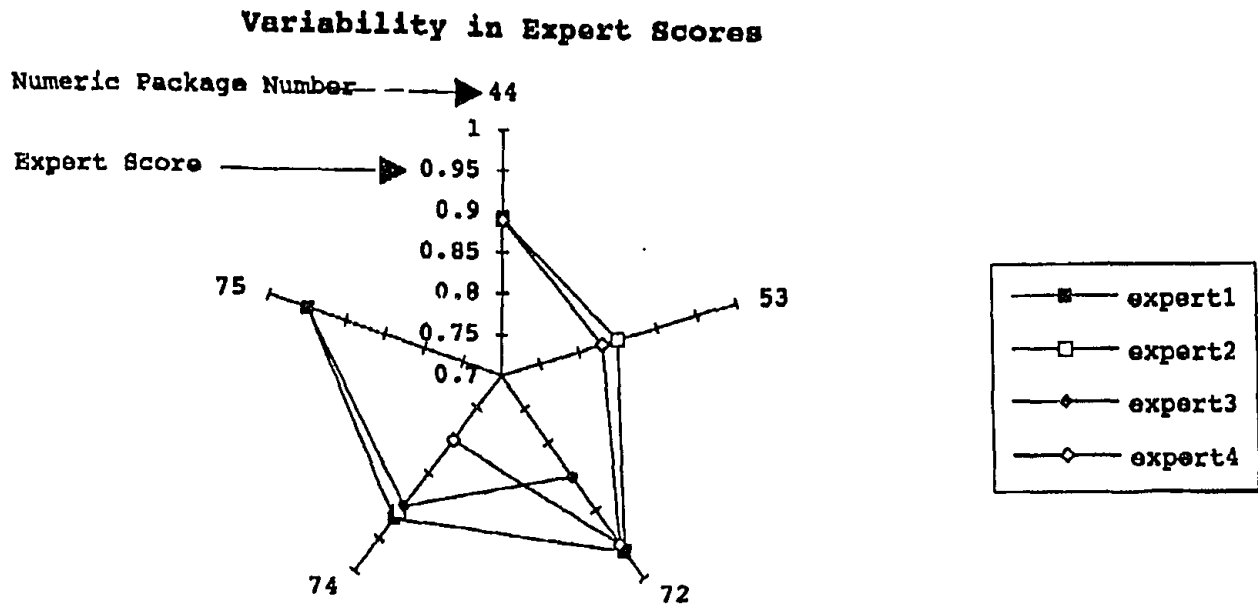

Nuneric Package Number

44-Perguasion 53-Paradox for windows 72-Word for พindow日 74-Excel 75Powerpoint

Figure 23. Radar Piot of Expert Scores on Packages.

The difference in scores of each of the panelists on a single package could be grouped into a variable called BIAS. The problem is that BIAS in expert judgments cannot be measured. Since the weights of each of the model variables in the expert judgment were not known, an equation cannot be exactly formulated. The BIAS is then hidden in weight differences, measurement error, and mathematical form. It is unknown if BIAS is additive or if it is a function of the other variables or a combination of both. It is also unknown how much it varies from expert to expert. At this point it was assumed to exist, but its influence should be the topic of further research, beyond this dissertation. 
Internal Consistency of the Panel

Several panel members chose the same packages to evaluate. In doing so, the panel provided a simple means to evaluate the internal consistency of their methods. For some packages such as Microsoft Excel the scores varied within 0.10 of each other, for Microsoft Powerpoint 0.0, for Microsoft Word for Windows 0.10, Persuasion 0.0, and for Paradox for Windows 0.02. This suggests that the panelists were very close in their scoring in most instances

In addition each panelist was asked to evaluate whether chapters selected for scoring by the model were representative of the remainder of the document. Only one chapter of the 92 chapters presented to the panelists was judged questionable (unsure if it was representative) by only one panelist.

Statistical Analysis of the Panel of Experts

The scores suggest a strong measure of internal consistency among the panelists, but it would be more comforting to have a statistical test to reinforce this visual notion. This section presents a test of the internal consistency of the quality scores from the panel. Two panelists scored Aldus Persuasion and three scored Paradox for Windows. The scoring pattern of the panelist created a situation where panelists did not score the same package. This created a matrix with many empty cells (Table V). 
TABLE V

PANELIST SCORING PATTERN

$\begin{array}{lllllc}\text { package } & \text { expert1 } & \text { expert2 } & \text { expert3 } & \text { expert4 } & \text { median } \\ \text { Word for Windows } & 0.96 & & 0.85 & 0.95 & 0.95 \\ \text { Excel } & 0.92 & 0.91 & 0.9 & 0.8 & 0.905 \\ \text { Eowerpoint } & 0.95 & & 0.95 & & 0.95 \\ \text { Persuasion } & & 0.89 & & 0.89 & 0.89 \\ \text { Paradox for Windows } & 0.85 & 0.85 & & 0.83 & 0.85\end{array}$

TABLE VI

SIGN TEST CALCULATION

$\begin{array}{llllll}\text { package } & \text { expert1 } & \text { expert2 } & \text { expert3 } & \text { expert4 } \\ \text { Word for Windows } & + & & - & - & \\ \text { Excel } & + & + & - & - & \\ \text { Powerpoint } & - & & - & - & \text { sum } \\ \text { Persuasion } & - & - & & - & 3 \\ \text { Paradox for Windows } & - & - & & & 11 \\ \text { Plus count } & 2 & 1 & & 4 & 14 \\ \text { Minus count } & 2 & 2 & 3 & 4 & \\ \text { Sum } & 4 & 3 & 3 & & \end{array}$

Detail Calculation

\begin{tabular}{|c|c|c|c|c|c|c|}
\hline & 0 & $\mathrm{E}$ & $0^{\wedge} 2 / E$ & $O-E$ & $(O-E)^{\wedge} 2$ & $(O-E)^{\wedge} 2 / E$ \\
\hline & 2 & 0.86 & 4.67 & 1.14 & $\frac{1}{1.31}$ & 1.52 \\
\hline & 1 & 0.64 & 1.56 & 0.36 & 0.13 & 0.20 \\
\hline & 0 & 0.64 & 0.00 & -0.64 & 0.41 & 0.64 \\
\hline & 0 & 0.86 & 0.00 & -0.86 & 0.73 & 0.86 \\
\hline & 2 & 3.14 & 1.27 & -1.14 & 1.31 & 0.42 \\
\hline & 2 & 2.36 & 1.70 & -0.36 & 0.13 & 0.05 \\
\hline & 3 & 2.36 & 3.82 & 0.64 & 0.41 & 0.18 \\
\hline & 4 & 3.14 & 5.09 & 0.86 & 0.73 & 0.23 \\
\hline sum & 14 & 14.00 & 18.10 & 0.00 & 5.16 & 4.10 \\
\hline$x^{\wedge} 2$ & & & 4.10 & & & 4.1 \\
\hline & $\begin{array}{c}14 \\
\text { :al }\end{array}$ & $\begin{array}{l}\text { Degr } \\
\text { lue o: }\end{array}$ & $\begin{array}{l}\text { Freedom } \\
\text { Square a }\end{array}$ & $\begin{array}{l}5-1 * 2-1=10 \\
.059 .49\end{array}$ & & \\
\hline
\end{tabular}

Given this situation, the sign test was used (Ferguson 1989 436). The median score for the package was used as the zero point (Ferguson 1989 229). For scores above the median a + was assigned to the cell. For scores at or below the median, a - was assigned to the cell. This 
created a matrix with two items and 5 samples (Table VI). In cases where the number of items is two, the Friedman rank test reverts to the sign test (Ferguson 1989 445). The sign test allows for empty cells.

The Chi square value from the data for the sign test was 4.101. The critical value at 0.05 was 9.49 with 4 degrees of freedom. The scores from the experts on these packages are from the same population (Ferguson 1989 216). This suggests that the panelists are consistent in their scoring.

\section{ANALYSIS OF THE MODEL AND PANELIST DATA}

This section contains a discussion of two statistical tests of the hypothesis with the combined data. The panelists provided a total number score from 0.0 to 1.00 which is the same range as the model.

A plot of the combined data is shown in Figure 24. The scores from the model and the four experts suggest a linear relationship but with 23 data points in a small band of the 0.5-1.0 range, it is difficult to determine. The correlation between the Total Score from the model and the expert score is .5633 . The $t$ value is 3.12 which is above the critical $t$ of 2.08 for the sample (with 21 degrees of freedom for a sample size of 23). The correlation between the Total Score from the model and the panelists is significant at the .05 level. Due to the lack of previous information, each variable has been equally weighted in the total model score. It is unclear if equal weighting is appropriate.

The significant correlation of the model scores with the panel scores and the visual plot (Figure 24) suggest a relationship between the model and the expert evaluation of quality in software user manuals. 
This suggests the model may be able to predict expert evaluation of user manual quality.

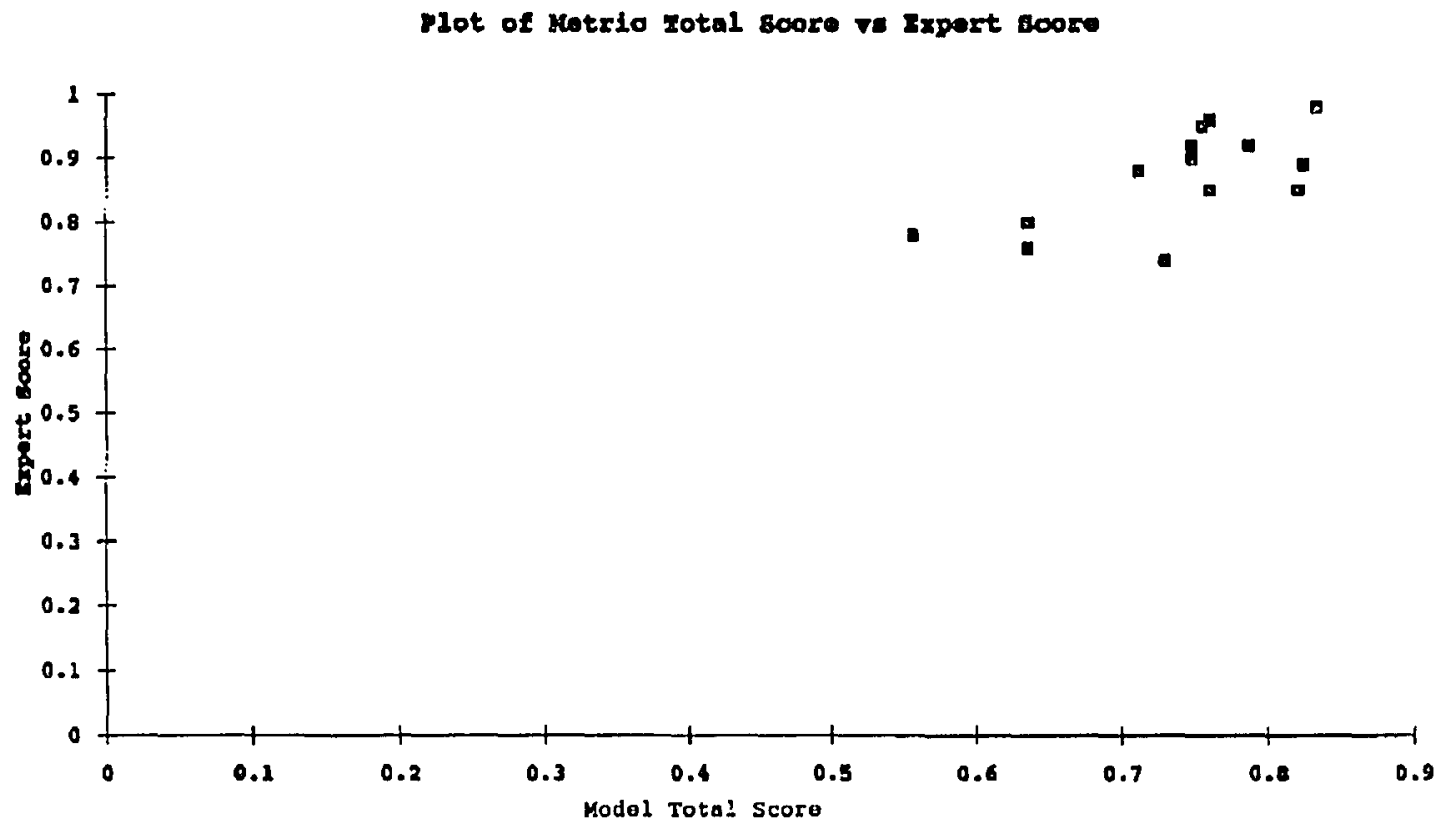

Figure 24. Plot of Expert and Model Scores.

\section{Statistical Tests of Hypothesis ${ }^{6}$}

This section tests the research hypothesis. The $\mathrm{F}$ test provides a statistical test of the differences between the model and the panel of experts. The F test for two samples outlined by Ferguson (1989 203) is shown in Table VII.

6 See page 47 for Hypothesis. 
TABLE VII

F TEST OF DATA FROM MODEL AND EXPERTS

$\begin{array}{lll} & \text { Model } & \text { Experts } \\ \text { mean } & 0.70 & 0.86 \\ \text { size } & 23 & 23 \\ \text { variance } & 0.0048 & 0.0054 \\ \text { F of samples } & 1.13 & \\ \text { Critical F } & 2.05 & \end{array}$

The value of $F$ is less than the critical value of $F$ for the sample. The null hypothesis that the variances are from the same population cannot be rejected. The variances are from the same population. That is, the differences in the Total Score from the model and the panelists varies in the same manner.

The $\mathrm{T}$ test examines the means of the items scored by the model and the panel to determine statistically if the means are nearly the same. The $T$ test of pooled variances from Ferguson (1989 188) is shown in Table VIII to test the model hypothesis.

The $T$ test indicates that the paired data differences from the model and the panel of experts are significant and therefore not from the same population. The null hypothesis is rejected. This tells us that the means from the model and the panel are not statistically the same. This may suggest that the model and the panel are measuring different dimensions. On the other hand it may suggest that the total score from the model and the panelists scores are merely shifted due to weighting differences of the component variables in the model. 
TABLE VIII

\section{T TEST PAIRED DATA FROM MODEL AND EXPERTS}

\begin{tabular}{|c|c|c|c|c|}
\hline & MODEL & EXPERTS & Difference & Diff ${ }^{\wedge} 2$ \\
\hline & 0.79 & 0.92 & 0.13 & 0.0169 \\
\hline & 0.56 & 0.78 & 0.22 & 0.0484 \\
\hline & 0.68 & 0.75 & 0.07 & 0.0049 \\
\hline & 0.83 & 0.89 & 0.06 & 0.0036 \\
\hline & 0.83 & 0.89 & 0.06 & 0.0035 \\
\hline & 0.64 & 0.76 & 0.12 & 0.0144 \\
\hline & 0.82 & 0.85 & 0.03 & 0.0009 \\
\hline & 0.82 & 0.85 & 0.03 & 0.0009 \\
\hline & 0.82 & 0.83 & 0.01 & 0.0001 \\
\hline & 0.83 & 0.98 & 0.15 & 0.0225 \\
\hline & 0.64 & 0.8 & 0.16 & 0.0256 \\
\hline & 0.71 & 0.88 & 0.17 & 0.0289 \\
\hline & 0.76 & 0.96 & 0.2 & 0.04 \\
\hline & 0.76 & 0.85 & 0.09 & 0.0081 \\
\hline & 0.76 & 0.95 & 0.19 & 0.0361 \\
\hline & 0.75 & 0.92 & 0.17 & 0.0289 \\
\hline & 0.75 & 0.91 & 0.16 & 0.0256 \\
\hline & 0.75 & 0.9 & 0.15 & 0.0225 \\
\hline & 0.75 & 0.8 & 0.05 & 0.0025 \\
\hline & 0.76 & 0.95 & 0.19 & 0.0361 \\
\hline & 0.76 & 0.95 & 0.19 & 0.0361 \\
\hline & 0.7 & 0.78 & 0.08 & 0.0064 \\
\hline & 0.73 & 0.74 & 0.01 & 0.0001 \\
\hline average & 0.747826 & 0.864783 & 0.116957 & \\
\hline sum & 17.2 & 19.89 & 2.69 & 0.4131 \\
\hline$N-1$ & 22 & & & \\
\hline$t$ & 8.38321 & & & \\
\hline $\begin{array}{l}\text { critical } t \\
\text { Not from } 8\end{array}$ & $\begin{array}{l}2.074 \\
\text { populati }\end{array}$ & & & \\
\hline
\end{tabular}

\section{Statistical Analysis of Combined Data}

A correlation matrix can show which features of the model and the panelists either by level or by model category, are statistically significant. A T test of the correlation will provide evidence if the relationships between the model dimensions, variables and the panelists are more than chance associations. A correlation matrix of the model 
category items and the Total Score from the panel of four experts is shown in Table IX. See Figure 7 page 34 for more explanation.

\begin{tabular}{|c|c|c|c|c|c|}
\hline & & TAB] & LE IX & & \\
\hline & & ELATION & OF CATE & RY ITEMS & \\
\hline & $\begin{array}{l}\text { Expert } \\
\text { Score }\end{array}$ & Text & Graphics & $\begin{array}{l}\text { Reference } \\
\text { Aids }\end{array}$ & Typographic \\
\hline Expert Score & 1.00 & & & & \\
\hline Text & 0.6268 & 1.00 & & & \\
\hline Graphics & 0.3045 & 0.2245 & 1.00 & & \\
\hline $\begin{array}{l}\text { Reference } \\
\text { Aids }\end{array}$ & 0.3202 & 0.2454 & 0.5568 & 1.00 & \\
\hline Typographic & 0.3427 & 0.4827 & 0.0601 & 0.3930 & 1.00 \\
\hline
\end{tabular}

As Table 9 illustrates the text category the only large correlations between the categories of measurement and the Total Score from the experts. The $\mathrm{T}$ test between each of the Category items and Expert Score resulted in $t$ values of $3.68,1.46,1.54$, and 1.74 . The critical value was 2.08 for 21 degrees of freedom (sample of 23). The text category of the model is significant at the .05 level. The remaining correlations between categories and expert scores are not significant at the 0.05 level. The intercorrelations between catagories (text, graphics, reference alds, typographic) are unique to the sample of 23 evaluated by the panel and not to the model sample of 82 packages.

This means that the panelists valued the text category over the other categories in the model.

Table X illustrates a similar pattern (one significant dimension and only one) between the levels of measurement and the expert score. The T test between the Levels (Figure 24 page 88 ) and the Expert Score resulted in $t$ values of $1.83,5.6,1.62$. The critical value of $t$ was 2.08 for 
21. degrees of freedom at 0.05. The Chapter Level 2 score is significant. Any values outside of the first column are model related and may be unique to the sample user manuals selected by the panel.

\begin{tabular}{lllll}
\multicolumn{5}{c}{ TABLE X } \\
& \multicolumn{5}{c}{ CORRELATION } & OF EXPERTS & AND DOCUMENT & LEVELS \\
& $\begin{array}{l}\text { Expert } \\
\text { Score } \\
\text { Document }\end{array}$ & $\begin{array}{l}\text { Devel } \\
\text { Levapter }\end{array}$ & $\begin{array}{l}\text { Sentence } \\
\text { Level }\end{array}$ & Level \\
$\begin{array}{l}\text { Expert } \\
\begin{array}{l}\text { Score } \\
\text { Document }\end{array}\end{array}$ & 0.3844 & 1.00 & & \\
$\begin{array}{l}\text { Level } \\
\text { Chapter }\end{array}$ & 0.7744 & 0.6903 & 1.00 & \\
$\begin{array}{l}\text { Level } \\
\text { Sentence } \\
\text { Level }\end{array}$ & 0.3269 & 0.2942 & 0.3752 & 1.00 \\
& & & &
\end{tabular}

The suggestion from the above discussion is that the panelists are focusing on text and its construction at the Chapter Level.

Since we can find the level and the category of the significant dimension on the model (Figure 7 page 75 ) finding the model variables which support the Chapter Level 2 and the text category would provide greater understanding of the scoring methods of the experts. In addition there may be some significant relationships between some of the more detalled model variable components and the panelists. A correlation of the detail model variables with the expert scores (see Appendix E) suggested fair relationships between the score of the experts and some detail items in the model. Values less than 0.00 mean a negative correlation between expert score and the model metric. The strongest correlations and the $\mathrm{T}$ test are shown in table $\mathrm{XI}$ in descending correlation order. 
TABLE XI

CORRELATION OF EXPERT SCORE AND VARIABLES

\begin{tabular}{lcc}
$\quad$ Data variable & Correlation & $t$ value \\
Procedures with Goals & 0.6833 & 4.28 \\
Pages in manual & 0.3936 & 1.96 \\
Indexes & 0.3934 & 1.96 \\
Price & 0.3709 & 1.83 \\
Typographic measures & 0.3427 & 1.67 \\
Task headings & 0.3349 & 1.63 \\
Reference aids & 0.3304 & 1.60 \\
Unnecessary Reference & 0.2936 & 1.41 \\
Agency- action & 0.2773 & 1.32 \\
Paragraph cohesion & 0.2405 & 1.13 \\
Data-ink & -0.3650 & -1.80 \\
Agency- equipment & -0.3417 & -1.67 \\
\multicolumn{1}{c}{ Critical $t$ value for 21 degrees of freedom .05 level 2.08}
\end{tabular}

Procedures with Goals is significant at the .05 level. The remaining $t$ values are below the critical value, suggesting no strong relations of significance between the variables and expert score. The suggestion is that the panelists regard a goal sentence at the beginning of each procedure as exhibiting quality in user manuals.

\section{Factor Analysis}

The preceding discussion has examined the groupings of the model and the component variables of the model but has not provided and insight into the dimensions the panel is using to determine quality in user manuals. This section examines the data with a technique that can provide some basis for interpreting how the panel measures quality in terms of the model variables.

Factor Analysis works best on large data sets with strong correlations between some of the variables. In this situation there is a 
small sample of data from the four experts and some strong (greater than .5) correlations among the independent variables, but fair correlation with the dependent variable (Expert Score). In order to derive some avenue for future research, the bounds of the factor analysis requirements were stretched, to say the least. A principal components analysis was done to verify the $\mathrm{T}$ test and look for basic dimensions of how the model and the Expert scores might be related. The exploratory factor analysis of the data (see Appendix E) suggested that 9 factors with eigenvalues greater than 1.0 are required to explain over $90 \%$ of the variance. A five factor model explains only $68 \%$ of the variance. This suggested that there was no simple explanation for the measurement of quality in end user documents with the data gathered. This further supports the notion that the scores from the model and the panel have no strong relations.

To further explore the dimensions the panelists used to determine quality a best relation model was built with certain variables. Using the existing data, the variables were examined using the Kalser-Meyer-Okin Measure, (KMO), (SPSS 1992 52) and measures of sampling adequacy from the anti-image correlation matrix (SPSS 1992 52) were examined to build a factor model with the best measures of the KMO statistic and the measures of sampling adequacy. This method follows the recommendation of Kim (1978 53-55) for determining if the data is sultable for factor analysis. The resulting factor model contained the following variables:

Expert Total Score - dependent variable Agency- action 
Agency- document

Agency- equipment

Captions

Glossary

Multistep procedures

Duck measure

Procedures with graphics

Procedures - user steps

The KMO statistic on a scale from zero to one was .6761 "mediocre" as described by Kaiser (SPSS 1992 53). The KMO statistic is sensitive to the number of data points and therefore can be improved with more panelists or the same panelists score more packages. The measures of sampling adequacy, measured on the same scale, ranged between 0.54 and 0.78 "mediocre." The resulting model created three factors with eigenvalues greater than 1.0 and could explain nearly $70 \%$ of the variance in the four expert's judgments of quality. The model was then rerun with a principal axis factoring and varimax rotation to create a model with the following major features:

Expert Score factor loadings

Factor $1 \quad 0.06$

Factor2 $\quad 0.40$

Factor3 $\quad 0.13$

Factor 1: high loading

Glossary $\quad 0.89$

Captions $\quad 0.63$

Agency Document. $\quad 0.84$ 
Procedures with graphics $\quad 0.37$

Procedures - user action $\quad-0.36$

Agency- equipment $\quad-0.40$

Agency- action $\quad-0.35$

Factor2: high loading

Agency- action $\quad 0.62$

Duck Measure $\quad 0.53$

Agency- document $\quad-0.27$

Agency- equipment $\quad-0.88$

Factor3: high loading

Duck measure $\quad 0.79$

Graphics in Procedures $\quad 0.61$

Procedures- user action $\quad-0.50$

The factors were rotated, (to concentrate the effect of the independent variables on certain factors). The rotation was othogonal to isolate the most independent factors. Given the stretch of the factor technique, oblique rotation was not considered with this data.

In order to give meaning to the statistical factors the following interpretation is offered.

Factor 1 suggests a dimension of finding and defining things; anthropomorphism and third person is unacceptable .

Factor2 suggests a dimension of active user participation in the document language. "The manual tells me what to do."

Factor3 suggests a dimension of visualization, "seeing what needs to be done". 
The factor model suggests that the panelists want to define and find things most importantly. Second in importance regarding quality, the panelists want to know what to do. Lastly the panelists want to see how to do it.

The analysis section has analyzed the model, the panelist scores of quality and has examined the relationship between the two. Finally some further analysis has suggested three factors which suggest how the panelists determine quality in user manuals. The conclusions form this section are:

There are no obvious relations between the model and descriptive features such as price, page count, applications category, and so forth.

- Weighting of the model groups and component variables can change the interpretation of the model score.

- The sampling method for the model provided consistent data. - Integration of Sentence Level 3 to Chapter level \& to Document level 1 shows declining quality scores.

- Commercial Windows software appears to have a minimum quality for sentence level text measures.

- The quality scores from the panel were consistent.

- There is a significant relation between the model and the quality evaluation of the panel. It is at the Chapter Level, in the text category, and is the Procedures with goals variable.

The scores from the model and the panel are not from the same population. 
- The panel appears to judge quality on finding and defining things, knowing what to do, and visualizing the process.

The following section provides observations that were gathered during the research process.

\section{OBSERVATIONS}

This section records some of the unforeseen happenings that occurred in the research. Since many important discoveries in research have been made by accident, these happenings are worth recording in hopes they may have some future value and interest. The observations begin with several sections regarding sample selection and data collection; they conclude with the observation regarding panel selection, scoring by the panel, and limitations of the graduate research process.

\section{Obtaining Evaluation Coples}

Initially it was very difficult to obtain evaluation copies of the latest Windows software. Many institutions, such as universities, do not have extensive suitable varietles of software, and colleagues are reluctant to relinquish their copies of private property. Two of the several large mail order software firms that were contacted granted access to their returns in warehcuses located in Washington state and New Jersey. While this was a very generous offer, it still made the research process difficult and costly. Many software development firms will not provide evaluation copies of products to individuals unless there is some connection with a reliable organization such as a university. The Business Manager and Purchasing Office at Portland State University authorized official 
requests for evaluation copies of software which substantially increased the number of software packages avallable. It is interesting to note that there is a appears to be a connection between the size of the firm and whether they participated in the research. The possible exceptions are Borland, and Aldus. Many firms offered to donate the software to the university after the research was completed. Within software development firms that had several packages, such as Microsoft, requests for some evaluation software were refused while others for different packages were approved. This state of affairs suggests that many companies have not developed a coherent policy toward educational research and support, but leave the decision to individual product line managers.

Volume of Material

The sample of software packages that were sent by the 82 software development firms covered a 25 sq. $\mathrm{ft}$.. wall area. The estirnated retall value of the sample was in excess of $\$ 25,000$. The sheer number of pages of total documentation and its variety dictated an efficient lean sampling method to reduce the data gathering phase to manageable proportions. The variety of formats, combinations, and other materials made the task of scoring the relevant samples even more challenging.

\section{Timing}

Many software developers sent packages within several days of the request for evaluation letter. Others took much longer. Additional delay was created answering questions for the developers, waiting for new versions to be released, etc. The consequence of the timing delay was 
that a few software packages were not included in the sample. Other reasons for not being included in the sample were that the software developer already had an entry in a particular category or there was no additional entries in the category to contrast the evaluation copy with. For example, the evaluation copy of OS/2 arrived late and other software developers such as Microsoft, Next, and Novell did not provide an evaluation copy to contrast the particular package with.

\section{Formats}

While at first the individual contributing variables seemed to offer the possibility to quantify the documents, there were many examples of situations where the procedure from NCR used by the model would not help. For example, many documents had tables with no reference to them. Many had procedures and in-line lists with no introductions. Many documents had different formatting options on how the manuals were put together. Some common themes were:

Common user and reference manuals Separate reference and user manuals Multiple user manuals (Getting Started, Tutorials, Tasks) Multiple combination manuals separated by function.

\section{- Writing Styles}

Several different writing styles were encouncered. The terse style of the educated engineer writing for professional engineers, the first person narrative, the second person narrative, and variations. It was common practice to bury instructions with one or two steps in text while identifying procedures with more steps of higher importance by 
headings, bold print, etc. In many user manuals, introductions were missing and section headings were required as part of the text in order to Identify what was happening. That is, the text under a section heading did not stand on its own.

In general it appeared that Windows user manuals used more complex language related to engineering than the Macintosh manuals. For example, "Flle Open dialog box" in a Windows manual and just "dialog box" in the Macintosh manual.

\section{Graphics}

Since Windows is a graphical interface, it was common practice to boldly show as many dialog boxes and screen shots as possible. One common practice was to use drop down menus as chapter headings, which appears to add little in the way of additional meaning compared to a chapter table of contests as suggested by Brockman (1990). From the large graphics count in many user manuals, it appears that dialog boxes were over used as surrogates for text and in many cases they may not have provided much additional meaning to the text. For example, in most instances, dialog boxes were used to present errors instead of providing an error message appendix. It was common practice not to identify dialog boxes with captions and referencing, such as a list of illustrations, or some other simple method.

\section{Presentation}

Most of the manuals had very high levels of typesetting quality as represented by the typographic scores (mean 0.89 , std. dev. 0.14 , See Table 2). In most cases, the quality of the presentation may have been 
superior to the material in the manual. One common fault was the failure to use the area on the left side of the page, which occurred by limiting the column width to 4.5 inches. A large portion of the manuals sampled still written in typewriter fashion (unable to switch fonts, type size, multiple columns, etc.) The material was [still] not clear and readable.

Style

The typographic measures addressed some elements of style by looking at layout. However, the actual writing style of procedures provided a wide uncharted territory of examples. Some of the issues suggested by the sample of documents are:

Should it be required to read a section heading as part of the follow-on sentences to insure meaning of procedures and Identify sections? Velotta (1992) suggests a wide latitude in acceptable variations in this area. The sample of documents suggests perhaps a more narrow vlew may be needed.

Should procedures be allowed in tables?

Should procedural tables be allowed as text?

If procedural tables are present, how should they be referenced? The sample of packages suggests that "not at all" is the current practice.

\section{Training Alds}

A few of the packages contained audio or video tapes to assist in learning more about the package other than reading the manuals and using the software. For those end users that find reading difficult, this 
media provides an alternative to reading manuals. Since these materials were outside the scope of the research, no data was collected on the quality or content of these materials. For reference purposes, video and audio tapes may not have much value due to the serial nature of the media and the lack of a uniform reference and access method for finding material on the media quickly.

Many of the sample software package also included advertisements for additional training materials from the developer and third parties as well as related goods and services. The question of dealing with and evaluating the usefulness of these generally unwelcome materials was not addressed in the research. By definition, the advertised goods and services did not accompany the software. However, it did appear that many of the advertised products could provide some additional training and reference material for the end user.

\section{$\underline{\text { Reference Alds }}$}

Many software packages contained keyboard templates to aid the user in using the software. However there were no standards for the function key assignments, many templates lacked instructions to press the shift key, Alt. key, Ctrl. key, etc. in addition to the function key. Therefore, some templates were not self-documenting. A person unfamiliar with the software would have to read the manual to understand the help template. In addition, the keyboard template could be found anywhere in the package with the rest of the materials. Some were in with the software disks, some with the user manual, and some were floating around in the box. 
Some software packages had reference cards of different sizes, shapes, and unique formats. If an end-user has several packages with reference cards, how do they store and use them? Reference cards cannot be stuck to the screen like post-it notes and cannot be easily left. on the desk.

In most of the packages, there were serial numbers to protect the developer against unauthorized copying and to assist the developer in identifying the purchaser. Serial numbers are typically used when loading the software onto the hard disk and providing proof of ownership to technical support personnel when calling the software developer. Should this information be readily avallable in the user manual? If the user never needs to call the developer, then maybe not. However, the serial numbers were scattered in different places and in several different forms for the user to find and keep track of in case it was needed to either use the software or to obtain technical support. Some of the more popular locations for displaying this information were:

Label of disk 1 of the software

On the outside of the box

On the cover of the User's manual or other manual Inside the cover of the user manual or other manual, or on the title page

On the registration card to mail to the developer

On a set of labels for the purchaser to place in assorted places In a similar vein, version numbers are needed when requesting technical support or making the decision to upgrade the software to a 
newer version. Version numbers were placed in locations similar to the serial numbers.

\section{$\underline{\text { Icons }}$}

In a graphical user interface, such as Microsoft Windows 3.1, the correct visual symbol can speed access through several layers of menus and perform common functions with greater ease than function keys and menus. If however, the visual symbol is confusing or requires constant learning, then the icon or button may revert to chart junk or ducks; ducks are described by Tuft (1983 107-121) in the glossary and in the literature search (page 27). Many packages used the Icon button paradigm to perform common functions such as bolding type faces, opening files, editing, and so forth. As one might suspect, there are no standards for designing the visual face of icons and buttons. Therefore, the user is faced with a confusing array, of buttons that may perform similar tasks in different software packages with different visual symbols. This in turn creates a steep learning curve and a lack of reference material readily at hand to remember what various buttons mean what from package to package. What is needed is a set of common symbols similar to international road signs that have a common meaning across software packages. Also missing was a keyboard template type reference guide for the meaning of each button. On-line help is not much use as it hides the button bar from view while the help text is on the screen. Secondly, the help screen rendition of the button lacked clarity in many cases. 
Product Depth

As a customer spends more money with a software developer, does the apparent quality of the product improve, stay constant, or decline from an end user document point of view? In the sample, several sets of software packages that work together (suites, office) were reviewed. The visual indication (size, shape, materials, organization) by examination of the end user documents was, that as a customer spends more money with a single developer, the quality of the products declines, suggesting a law of diminishing returns. That is, the sum of the total parts was not any greater than the sum of the components. There was no apparent synergy in the whole compared to its parts. This in turn suggests a strategy of picking the best packages from several software developers rather than focusing on a single software development house. The visual quality may be directly related to sales volume and therefore the marketing effort a software development house is willing to invest in slow moving products from version to version of the software. This creates a question of how complete a software developer should make a suite of software compared to the individual products. That is, should the quality of the suite be greater than the individual sum of its parts, or somewhat less?

In contrast however an integrated set of application manuals may have more consistent interfaces to ald in usability and reducing complexity in daily operations. An interesting question is, should the interfaces be more than the Windows 3.1 conventions? This question was beyond the scope of this research. 


\section{Completeness}

While the dissertation did not address the issue of completeness between the end user document and the software itself, several trials were conducted on an informal basis to test if this might be a major issue and a subject for future research. After the end user documents were scored, several of the software programs were loaded on a test machine and tested on a convenient basis to determine how well the user manual reflected the actual software. In many cases, the user manual provided instruction for areas in the software that did not clearly work in practice. These shortcomings were particularly evident in import and export procedures for changing file formats. In four cases, the software would not even install on the test machine according the user manual. The problems in this area naturally lead to some contact with the technical support departments of several software vendors.

\section{Software Support}

Again the area of software support was not included in the dissertation, so that the end user manual could stand on its own merit. But, as some of the trial tests of the software ended in fallure, calls were made to various vendors to resolve the problems encountered. This brings to mind the location of the technical support telephone number and the materials required. As with the serial numbers, the technical support telephone numbers could be anywhere in the packet if provided at all. In most cases it was a chore to find the correct phone number. In many cases technical support was not listed as an indexed item or spelled out in a table of contents. In most cases the technical support personnel were polite, but lacked program code specific knowledge to 
correct many problems, however they were able to provide solutions for minor problems. In many software packages there were unpublished conflicts between packages (memory, addressing, interrupts, Windows INI files, DLL files, etc.), rumor of unpublished conflicts, and lack of specific knowledge. Many solutions revolved around stripping down the system until the software worked. At this point, the vendor could claim the software performed as advertised. This area also suggests the opportunity for future research.

\section{Descriptive Statistics}

Many software packages had lower version numbers, user manuals of about 300 pages (mean), and were positioned at about $\$ 400$ in price. This suggested about $\$ 1.33$ in retail price per page of the user manual, but there was no relation between this notion and the Total Score of the manual. The highest frequency of software was in the utility category as It was easier to obtain evaluation copies and the retall purchase price was lower. Most software was for the Microsoft Windows 3.1 platform. The first year in the manual was usually 1992. Most manuals had less than 200 pages (by count). Most software was priced under $\$ 200$. It may have been easier to obtain lower price evaluation copies. The software showed a declining frequency by version number with version 1 or 2 being predominant. This suggests immature products, with a few packages with large page counts and many with lower page counts, and price point marketing in terms of retall price. 
CHAPTER VI

CONCLUSIONS AND IMPLICATIONS

This chapter includes the conclusion, implications of the research, and indications for future research

\section{CONCLUSIONS}

There is a significant correlation (.5633) between the total model score and the four expert panelists. The four experts scored the packages higher than the model. This means that the model could be used to predict expert opinion if appropriate weights were assigned to the model score. The accuracy of the prediction may be limited, however. There is a significant correlation $(.6268)$ between the overall text category from the model and the panelists. It appears that the experts valued the text category higher than graphics, reference aids, or typographic features. There is a significant correlation (.7744) between the Chapter Level 2 measures (Figure 7 page 88 from the model and the panelists. This suggests that particular groups of sentences are more important to the panelists than the overall Document Level 1 measures or the individual sentence structures. There is a significant correlation (.6833) between the procedures with goals variable and the scores from the four panelists. The panelists appear to value a goal statement at the beginning of procedure. There is no significant correlation between the panelist scores and the remaining model variables. There appears to be relationships between the model and the notion of overall quality. 
The dimensions from the factor analysis (define, instruct, and visualize) provide some indication of how the four experts evaluated the packages using the model variables. While the limited number of data points from the panel of experts and the limited range of documents used by the panel may be a consideration, the definite message is that more research is needed. This supports the conclusion of Duffy (1985) that more complex measures may be needed to capture the notion of quality In end user documents.

There are several alternative conclusions which support the results, and offer the possibility for future research. These are discussed briefly in the following sections regarding potential relationships that are more complex, intervening variables, and limiting values.

\section{Potential Relationships That are More Complex}

The factor analysis focused on direct relationships of the linear equation form $\mathrm{Y}=\mathrm{a}+\mathrm{bX} 1+\mathrm{cX} 2+\ldots$ It may be that the relationships are more complex, such as exponential, quadratic, or $x 1^{*} \mathrm{x} 2$.

\section{Intervening Variables}

It may be that the model provides the framework to judge quality, but that quality is judged by the subtle detalls within that framework. The metric measures may suggest the existence of intervening variables, but do not identify what they are.

\section{Limiting Values}

It may be that the model provides roughly proportional results until some threshold value is achieved. See Figure 25. Once the 
threshold is passed the correlation of the model with some of the variables is not measurable due to the flat slope. This pattern might be typified by a plot of $Y=1-e^{-X}$.

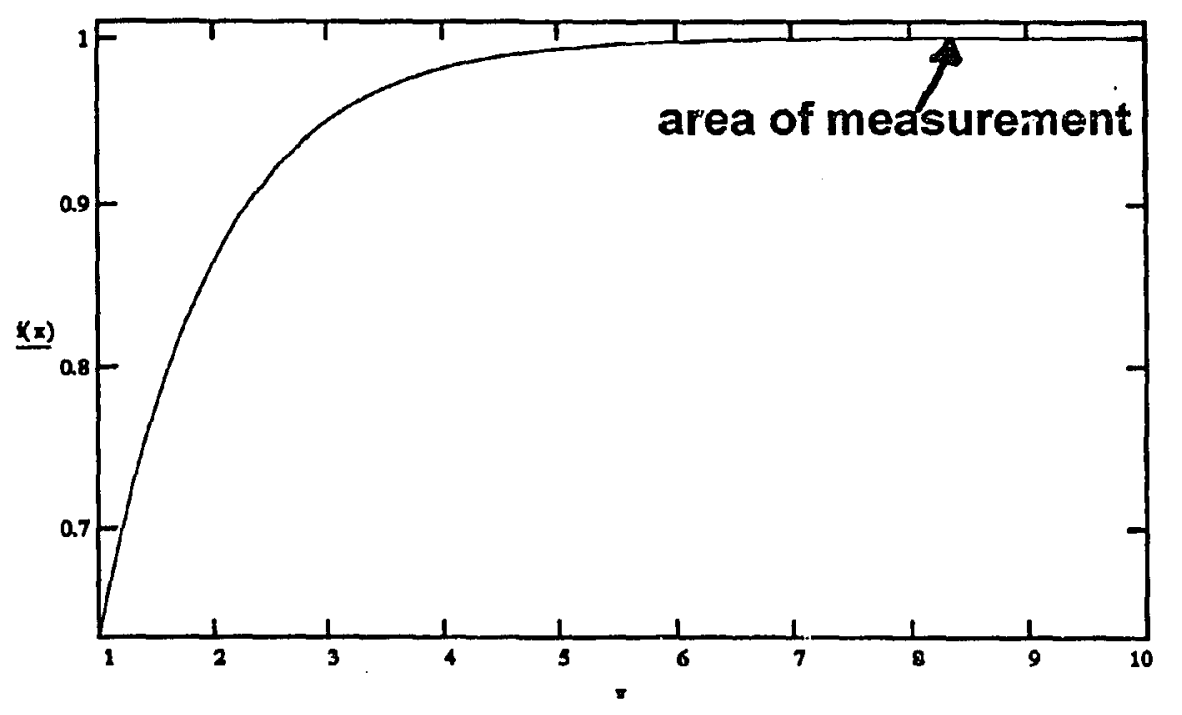

Figure 25. Plot of Exponential Function

It may well be that commercial end user documentation standards are above the threshold values of the model and the critical areas of judgment revolve around style and presentation issues not quantified by the model since the measurements fall in the far right area of the curve. This means that beyond a specific threshold value (unknown at this time) there is little measurable difference in document quality.

\section{IMPLICATIONS OF THE RESEARCH}

The process the human mind uses to develop notions of quality are not easily captured by the more simple measures of counting words, checking Chapter Level structure, and Document Level measures (Figure 2488 ). In measuring quality, the expert judges used subjective 
measures that may easily be expressed in language, but may be extremely difficult to capture and quantify. The four experts all rated most packages (Excel, Powerpoint, Word for Windows) from Microsoft very high. All four of the panelists had easy access to the Microsoft packages. The style of the Microsoft manuals, reputation, size of the company and experience with older DOS and windows software may have been major contributors to the expert scores. The model represents some of the most current methods of quantifying quality with respect to the variables that can be easily measured.

\section{INDICATIONS FOR FUTURE RESEARCH}

In the last ten years personal computer software has made great progress in terms of features, functionality and documentation. If the Word processors reviewed here were compared to the first versions of Wordstar and the spreadsheets compared to the first release of Visicalc, the improvement is nothing short of fantastic in the span of ten years. What has been lacking, however is a methodology to quantitatively measure the progress. Like quality, it can be seen and talked about and subjectively understood, but little has been done to quantify it. Several possible future research areas are outlined in the following sections.

\section{$\underline{\text { Range of Samples }}$}

The research resource constraints and the lack of private industry support restricted the samples to commercial software that was provided for evaluation. If the model applies to both internal and commercial user manuals then the sample range needs to be increased by including user 
manuals with lower scores. The resource constraints of this research restricted the ability to attract more experts to the panel, furnish sample user manuals, and obtain more expert scores from each panelist. Modifying the resource limitation could provide additional data with a wider range of scores.

\section{Analysis of the Converse Model}

If the model value has a low correlation with the opinion of experts, the converse question may be, is it possible to construct a high quality end user document in which all of the metric values score low? This would present absolute proof that the model does not measure or quantify quality.

\section{Improvement of the Model}

On the surface most of the model measures seem to be very narrow and strongly quantifiable. In practice many of the measures offer a wide degree of latitude for the document scoring person. This introduces more variability into the scoring process. Future research might focus on narrowing the fleld of some of the measures as well as developing other metrics that will account for more of the variation.

The measures of the panel of experts were very broad to determine if there was any correlation at all between the model and the panel of experts. Future improvement in the model might create more narrow criteria to define and quantify what items the expert judge uses in determining subjective quality. Unfortunately this study did not have the resources to hire experts for any length of time. 
Time Series Analysis of Documentation

The research took a single snapshot of documentation at a specific point in time. If the researcher has a useful model, it is possible take time series samples of specific software packages that have gone through several iterations of impairments over a long time period. For example Microsoft Word has a history of almost 8 years. The DOS operating system is an improvement of CPM/ 80 which has a history of nearly 13 years and spans two different software development firms (Digital, Research and Microsoft).

\section{Platform, Processor Studies (MAC,UNLX,OS/2,MVS,DEC)}

This research focused upon the Microsoft Windows 3.1 application platform. The few samples of Macintosh and DOS program applications suggest that the writing styles and presentation may be different for each hardware, operating system platform. In general, the Macintosh applications used less formal technical language, while the Windows 3.1 were more exact in the technical terminology. However, technical terminology may not have any greater meaning in many document settings. Other platforms may have more formal styles carried forward from historical development processes.

\section{$\underline{\text { Research on Completeness and Development of Metrics }}$}

This research did not address the issue of completeness. However many observations in the data suggest that the user documents present many features of the software that may not work in practice. The experiences in loading the software for the first time suggest that many problem areas are left for the end user to discover on his own. Being 
able to quantify the discrepancies between the end user document and the actual software would provide information in the pre sales stage when consumers are looking at the features and "quality" of competing products. Some focus in this area might also lessen the costs of maintaining technical support staffs.

\section{Evaluation of Additional Materials}

In many cases the package from the software developer included many advertising items to either introduce other services or products in order to maximize the marketing exposure of the particular media. An area of future research might be the evaluation of the value of the additional material out side of manuals, disks, and reference cards.

\section{BIAS of Expert Judges}

The literature search largely lgnored the issue of bias in document measurement. Since it is no doubt present, it has probably colored the research and the results. It may be worthwhlle to explore the issue of expert bias further in additional research to determine if its factors can be quantified and measured as part of the document evaluation process.

\section{Developrnent of End User Documents as a Computer Semiotic Register}

The notion of scoring certain linguistic constructs and paying special attention to certain symbols and forms suggests that a special language for user manuals is being developed. The material from linguistics and semiotics was not included in this research in order to more finely focus on the issue of quantitative metrics. Material from many technical writers such as Weiss, Brockman and others suggests 
certain styles and language uses. A review of Andersen (1990) and his studies of the Danish Post Office suggest that more research in this area could be done. 


\section{GLOSSARY}

Advance Organizers provide information regarding what follows, prepares the reader for future material, and provides guidance on how to follow the material.

Agency is the concept of using certain constructs as subjects of sentences, that make the sentence meaningful and readily understood such as: Click the left mouse button. In the example, the intended subject of the sentence is you and is readily understood.

Agency - Action is the condition where an action adverb statement is the subject of the sentence. For example, "Pressing the escape key exits the program."

Agency - Document is the condition where the document is the subject of the sentence. For example, "this chapter explains how to turn on the computer."

Agency - Equipment is the condition where the hardware or the program are the subject of the sentence. For example, "the computer will display the opening screen."

Agency - User is the condition where the user is the subject or implied subject of the sentence. For example, "Press any key to continue." The implied subject of the sentence is you. 
Captions below graphics provide clues as to why the graphic is in the text without requiring the reader to search through the text.

Chapter and Paragraph Level Cohesion measures determine how well sentences make up a unified thought pattern within the paragraph or section. For example, if a list of program steps begins without any statement of the purpose of the steps then the paragraph group does not follow a unified thought pattern. The reader is required to guess why the steps are there.

Chapter is a collection of paragraphs organdzed around a single major topic.

Data Ink Ratio refers to the amount of ink used to present the data vs the amount of ink used for other purposes. For example, an entire terminal screen display may be presented when only a small portion of the screen is relevant to the discussion in the text.

Document is a book composed of a table of contents, chapters, glossary and index.

Ducks are graphics that are put in the user manual purely for ornamentation and flavor. Ducks add nothing to the meaning of the text or the material in the text and may not even in fact be relevant. For example, the addition of a row of dots to the top of each page adds nothing to the meaning of the text. 
Factor - a dimension of a dependent variable composed of indepencient variables organized around an interpretation.

Glossaries are dictionaries of uncommon terms used in the manual.

Glossary - A place in the back of a book where we never look. That's why the terms in the text are not understood next. Looking here erases all fear that we don't know what they say.

Goals for Action provides a direction for the action to go and provide the user with a notion of why the action is taking place. For example, "pull the handle on the slot machine to begin play." In this example, the reader understands what the consequence of pulling the handle will be.

Graphics Used in Procedures counts if a one or more graphics are used as part of the procedure.

Incomplete Lists are those that elther miss or add items that the reader is not expecting.

Inconsistent Graphics are graphics that fail in providing meaning to the text or reference material outside of the text material.

Indexes list additional places in the text outside of the table of contents where information can be found.

Irrelevant Graphics are graphics that provide no additional meaning to the text. 
Jargon refers to words or groups of words that are outside the Intended users vocabulary or words that are common in certain fields such as: Ford F150 5.8 liter Extended Cab Stepside Long Bed Pickup.

Level - a group indication of certain variables in the model.

Lle Factors are due to misscaling in the graphic.

Logical Conditions provide the reader with paths to follow in the document. For example, "If you want to play the slot machine, then insert a coin and pull the handle."

Metric - The quantitative measure of a variable.

Model - An abstract a generalized hypothetical description based upon an analogy.

Multiple Steps make the directions of procedures more difficult to follow. For example, "type your name, dance in a circle, and press the enter key." In the previous example, the reader was given three instructions in the same sentence.

Nounstrings are groups of nouns that refer to a construct such as File Open Dialog Box; the long string of nouns makes the construct difficult to read and refer to.

Paragraph is a collection of sentences organized around a single thought.

Procedure Goals - Procedures are easier to follow if they begin with a statement of purpose or goal. Procedures are easier to understand if the steps are not buried in additional text that surrounds the steps necessary to 
accomplish the process. Procedures that have graphics often are better understood than those that have no visual clues to assist in following the text.

Reference Alds help the reader locate material within the document. For example, a table of contents with multiple levels, list of illustrations, index, a magic glossary, a reference card, and an error appendix.

Sentence is a collection of words composed of a subject, verb, and other modiflers expressing some communication.

Task Headings - In task-oriented manuals, headings that describe the task in the table of contents are easier to follow than those that leave the reader searching.

Typographic Items evaluate the visual context that surrounds and presents the written material. These items make the material in the document easy to follow, easy to read, and help keep the reader's attention.

Unnecessary References are references in the document that direct the reader to go some place else for small bits of information that could easily be placed in the text (and the reference omitted). For example, "See chapter 4 for instruction on how to click a mouse." The instructions in chapter 4 may be only one sentence. 


\section{REFERENCES}

Andersen, P.B. and K.H. Madsen. Design and Professional Languages. Aarhus Dennmark, Computer Science Department, 1988.

Andersen,P.B. A Theory of Computer Semiotics. New York, Cambridge University Press, 1990.

Andre, J. R. Furuta, and V. Quint ed. Structured Documents. New York, Cambridge University Press, 1989.

Andriole, Stephen J. Storyboard Prototyping: A New Approach to User Requirments Analysis. Wellesley, GED Informations Sciences Inc.,1989

Ayer, Steve J. and Frank S. Patrimostro. Software Development Planning \& Management Documents. Sunnyvale, Technical Communications Associates Inc., 1986.

Ayer, Steve J. and Frank S. Patrimostro. Software Development Analysis Documentation. Sunnyvale, Technical Communications Associates Inc., 1990.

Ayer, Steve J. and Frank S. Patrimostro. Software Program and Test Documentation. Sunnyvale, Technical Communications Associates Inc., 1986.

Babbie, Earl. Survey Research Methods. Belmont, Wadsworth Publishing Co., 1990.

Bailey, Robert W. Human Performance Engineering. Englewood Cliffs, Prentice Hall, Inc., 1982.

Barker, Richard. CASE Method: Tasks and Deliverables. New York, Addison Wesley, 1990.

Baroudi, Jack J. Margrethe H. Olson, and Blake Ives. "An Empirical Study of the Impact of User Involvement on System Usage and Information Satisfaction." Communications of the ACM, March 1986, pages 232-238.

Barrett, Edward, ed. Text, Context, and Hypertext. Cambridge, The MIT Press, 1988.

Berghel, H.L. and D.L. Sallach. "Measurement of Program Similarity in Identical Task Environments," SIGPLAN Notices, V19 \#8, August 1984. 
Berns, Gerald M. "Assesing Software Maintainability," Communications of the ACM. January 1984, pages 14-23.

Bethke, Frederick, Measuring the Usabllity of Software Manauals, Technical Communication, Second Quarter, 1983, pages 13-16.

Black, John B., John M. Carroll, and Stuart M. McGuigan, "What Kind of Minimal Instruction Manual is the Most Effective?" CHI'87 Proceedings, May 1987, pages 159-162 ACM.

Black, John M. and others, "Online Tutorials: What Kind of Inference Leads to the Most Effective Learning?" CHI'89 Proceedings, May 1989, pages 81-84, ACM.

Boehm, Barry W. "Software Engineering Economics," IEEE Transactions on Software Engineering. Vol SE-10, No. 1, January 1984.

Boehm, Barry W., John R. Brown, Hans Kaspar, Myron Lipow, Gordon J. MacLeod, and Michael J. Merritt. Characteristics of Software Quality. New York, North-Holland Publishing Co. 1978.

Boston, Bruce O. STET! Tricks of the Trade for Writers and Editors. Alexandria, Editorial Experts, Inc. 1986.

Brockman, J. Writing Better Computer User Documentation. New York, John Wiley \& Sons, 1990.

Brooks, Fredrick P. Jr. "No Silver Bullet, Essence and Accidents of Software Engineering," Computer. April 1987, pages 10-19.

Brown, Roger W., Irving M. Copl, Don E. Dulaney,William K Frankena, Paul Henle, and Charles L. Stevenson. Language Thought \& Culture. Ann Arbor, the University of Michigan Press, 1958.

Carroll, John M. ed. Interfacing Thought: Cognitive Aspects of HumanComputer Interaction. Cambridge, MIT Press, 1987.

Caroll, John M., Penny L Smith-Kerker, James R. Ford, and Sandra A. Mazur-Rimetz. "The Minimal Manual," Human Computer Interaction, vol 3, 1987-88, pages 123-153.

Caroll, John M. The Nurnberg Funnel: Designing Minimalist Instruction for Practical Computer Skill. Cambridge, The MIT Press, 1990.

Chikofsky, Elliot J. and James H. Cross II. "Reverse Engineering and Design Recovery: A Taxonomy," IEEE Software, January 1990.

Clark, I.A. "Software Simulation as a Tool for Usable Product Design." IBM Systems Journal, vol 20 no. 3, 1981.

Cooke, Adele. "Giving Documentation its Due," Training and Development Journal. August 1984 pages 64-65. 
Cohen, Jacob and Patricia Cohen. Applied Multiple

Regression/Correlation Analysis for the Behavioral Sciences.

Hillsdale, Lawrence Erlbaum Associates, 1983.

Comstock, Elizabeth M. and Elizabeth Ann clemens, "Perceptions of Computer Manuals: A View from the Field," Proceedings of the Human Factors Society 31 st Annual Meeting, 1987, pages 139143.

Covington Michael A. "Documentation that Works," PC Tech Journal, January, 1985, page 165.

Crosby, Philip. Quality Without Tears. New York, McGraw-Hill, 1984.

Crown, James. Effective Computer User Documentation. New York, Van Nostrand Reinhold, 1992.

Daiute, Collette. Writing \& Computers. Reading, Addison-Wesley Publising Company, 1985

De Roze, Barry C. and Thomas H. Nyman. "The Software Life Cycle - A Management and Technological Challenge in the Department of Defense," IEEE Transactions on Software Engineering. Vol SE-4, No. 4, July 1978, pages $309-318$.

Dickens, Mike. Cadre Corporation, Interview by author November 18 , 1992, Providence RI, by phone.

Dixon, Robert L. Winning With CASE. New York, McGraw-Hill Inc., 1992.

Downey, Lesli, Janice C. Redish, Ralph Thornburg, and Arthur G. Eiser. "The U-Metric Quesitonaire: A Tool for Assessing the Usability of Manuals." Proceedings 1992.

Duffy, Thomas M. and Robert Waller. Designing Usable Texts. New York, The Academic Press, 1985.

Duffy, Thomas M., Theodore Post, and Gregory Smith. "An Analysis of the Process of Developing Military Technical Manuals," Technical Communication, Second Quarter 1987, pages 70-78.

Dunsmore, H.E. "Designing An Interactive Facility for Nonprogrammers," ACM 0-89791-028, January 1980, pages 475-483.

Eco, Umberto. A Theory of Semiotics. Bloomington, Indiana University Press, 1979.

Ferguson, George A. and Yoshio Takane. Statistical Analysis in Psychology and Education. New York, McGraw-Hill, 1989. 
Fitzsimons, Ann and Tom Love. "A Review and Evaluation of Software Science," Computing Surveys, Vol 10, No 1, March 1978, pages 318.

Foss, D., M.B. Rosson, and P. Smith. :Reducing Manual Labor: an Experimental Analysis of Learning Alds for a Text Editor", Proceedings, Human Factors in Computer Systems, 1982, pages 332-36.

Girlill, T.R. and Carol G. Tull. "Comparative Access Rates for Online Documentation and Human Consultants." Proceeedings of the 51st ASIS Annual Meeting, Atlanta, Oct 23-27, 1988, pages 48-53.

Gould, John D., Lizette Alfaro, Vicent Barnes, Rich Finn Nancy Grischkowsky, and Angela Minuto. "Reading is Slower form CRT Displays than from Paper: Attempts to Isolate a single variable Explanation," Human Factors, 1987 29(3) pages 269-299.

Gray, Max and Keith R. London. Documentation Standards. New York, Brnadon/Systems Press, 1969.

Gullford, J.P. Psychometric Methods. New York,McGraw-Hill, 1954.

Halstead, Maurice H. Elements of Software Science. New York, North Holland, 1979.

Hansen, Marion. "Ten Steps to Usability Testing." Intel Corporation, 1992.

Hosier,William J. Phillp M. Rusens, Robert Krull and Christopher Velotta. "Basing Document Quality Standards on Research." Proceedings, 1992.

iBM, Business Systems Plannning; Information Systems Planning Guide. IBM Corporation, 1984.

Jonassen, David H. ed. The Technology of Text. Englewood Cliffs, Educational Technology Publications, 1982.

Juran, J.M. Juran on Leadership for Quality. New York, The Free Press, 1989.

Kim, Jae-On and charles W. Mueller. Factor Analysis: Statistical Methods and Practical Issues. Newbury Park, Sage Publications, 1978.

Landauer, Thomas K. "Let's Get Real: A Position Paper on the Role of Cognitive Psychology in the Design of Humanly Useful and Usable Systems,"

Layzell, Paul and Kathy Spurr editors. CASE Current Practice Future Prospects. New York, John Wiley \& Sons, 1992. 
Layzell, Paul and Kathy Spurr editors. CASE on Trial. New York, John Wiley \& Sons, 1990.

Li, H.F. and W.K. Cheung. "An Empirical Study of Software Metrics," IEEE Transactions on Software Engineering, Vol. SE-13, No. 6, June 1987, pages 697-708.

Loh, Marcus and R. Ryan Nelson. "Reaping CASE Harvests," Datamation. July 1, 1989 pages 31-34.

Minglone, Al. "Iteration, Key to Useful Documentation," Journal of Systems Managment. January 1983, pages 23-25.

McCabe, Thomas J. "A Complexity Measure," IEEE Transactions on Software Engineering. vol SE-2, No. 4, December 1976, pages 308320 .

Martin, James. Information Engineering. Englewood Cliffs, Prentice Hall, 1989.

Mayhew, Deborah J. Principles and Guidelines in Software User Interface Design. Englewood Cliffs, Prentice Hall, 1992.

McClure, Carma and James Martin. Structured Techniques: The Basis for CASE. Englewood Cliffs, Prentice Hall, 1988.

McClure, Carma, CASE is Software Automation. Englewood Cliffs, Prentice Hall, 1989

McClure, Carma. Three Rs of Software Automation, Re-engineering, Repository, Reusability. Englewood Cliffs, Prentice Hall, 1992.

Morrison, R. Interviews by author. Notes, Cannon Beach, Oregon

Mills, Harlan D. and Peter B. Dyson. "Using Metrics to Quantify Development," IEEE Software. March 1990, pages 15-24.

Moad, Jeff. "The Software Revolution," Datamation. February 1990, pages 22-30.

Moran, Thomas P. :An Applied Psychology of the User," Computing Surveys. vol 13 March 1981, pages 1-11.

Moranda, Paul B. "Software Quality Technology: (SAD) Status of: (Unapproached ) Limits to: (Manifold) Alternatives to," Computer, November 1978, pages 72-78.

Myers, Glenformd J. "An Extension to the Cyclomatic Measure," SIGPLAN Notices. October 1977, pages 61-64. 
Mynatt, Barbee T., Larua Marie Leventhal, Kelth Instone, John Farhat, and Dianae S. Robinson. "Hypertext or Book: Which is Better for Answering Questions," CHI'92 Proceedings, May 3-7, 1992. pages 19-25.

Norman, Ronald J. and Jay F. Nunamaker. "CASE Productivity Perceptions of Software Engineering Professionals," Communications of the ACM, September 1989, pages 1102-1108.

Oakland, J.S. Total Quality Management. Toronto, Heineman Ltd., 1990.

Parkins, John. Making CASE Work. Oxford, NCC Balckwell Ltd. 1991.

Pfaffenberger, Bryan. Democratizing Information. Boston, G.K. Hali \& Co., 1990.

Phillips, Bernard S. Social Research Strategy and Tactics. New York, Macmillan Publishing Co. Inc., 1976.

Polson, Peter G., Clayton Lewis, John Rieman, and Cathleen Wharton. "Cognitive Walkthroughs: a Method for Theory Based Evaluation of User Interfaces," International Journal Man-Machine Studies. (1992) 36 pages 741-743.

Rappoport, Anatol. General System Theory. Cambridge: Abacus Press, 1986. page 216 .

Rasmussen, Jens. Information Processing and Human-Machine Interaction. New York, North-Holland, 1986.

Redish, K.A. and W.F. Smith. "Program Style Analysis: A Natural ByProduct of Program Complilation," Communications of the ACM. Vol. 29, No. 2, February 1986, pages 126-133.

Reutter, John III. "Maintenance is a Management Problem and a Programmer's Opportunity," National Computer Conference, 1981, pages 343-347.

Rich, Charles and Richard C. Waters. "The Programmer's Apprentice," Computer, November 1988, pages 11-25.

Rightwriter User's Manual, Carmel, Que Software, 1991.

RobertShaw, Joseph, Stephen Mecca, and Mark Rerick. Problem Solving: A Systems Approach. New York: Petrocelli Book, 1978, pages 210212.

Robinson, John P. and James D. Graviss. Documentation Standards Manual for Computer Systems. Cleveland, Association for Systems Management, 1973. 
Roemer, Joan and Alphonse Chapnis "Learning Performance and Attitudes as a Function of the Reading Grade Level of a Computer Presented Tutorial," Proceedings of Human Factors in Computer Systems, Washington, DC Chapter of the ACM, 1982, pages 239244.

Rosenthall, Robert and Ralph Rosnow. Essentials of Behaviorial Research: Methods in Data Analysis. New York, Mcgraw-Hill, 1991, chapter 19.

Rowland, Lawrence R. and Evelyn L. Williams. "A computer Aided Method for assessing Accessibility of Information in Technical Documentation," Proceedings of the Human Factors Society 33rd Annual Meeting, 1989, pages 394-398.

Sadlin, Jag. Software Engineering, Methods Management and CASE Tools. New York, McGraw-Hill, 1989.

Scandinavian PC Systems. Readability Program for the IBM PC, XT, and AT. Rockville, Scandinavian PC Systems, 1987.

Schneider, Victor. "Prediction of Software Effort and Project Duration Four New Fromulas". The Areospace Corporation, 1978.

Schindler, Max. Computer Aided Systems Design. New York, John Wiley, 1990.

Scholtz, Jean and Marion Hansen. "Usability Testing a Minimal Manual for the Intel SatisFAXtion Board.", 1992.

Scholtz, Jean. Portland State University. Interview by author November 20, 1992, Portland, Oregon.

Scholtz, Jean, Emily Young, and Marybeth Olsted. An Invesitgation of the Effect of the Aesthetic Quality of Interfaces. Unpublished Article, Portland State University, 1992.

Shneiderman, Ben. Designing the User Interface: Stategies for Effective Human-Computer Interaction. Reading, Addison-Wesley, 1987.

Slegel, Martin A. Design and Evaluation of Computer/ Human Interfaces: Issues for Librarians and Information Scientists. Urbana, Graduate School of Library and Information Science, 1991.

Simon, Herbert. Sciences of the Artificial. Cambridge: MIT Press, 1988. pages 46-48.

Sohr, Dana. "Better Software Manuals," Byte. May 1983, page 286.

SPSS for Windows, Professional Statistics Release 5, Chicago, SPSS Inc., 1992. 
Swanson, E. " The Dimensions of Maintenance," Second International Conference on Software Engineering Proceedings (San Francisco, October 13-15, 1976), pp 492-497.

Swanson, E. Burton and Cynthia Mathis Beath. Maintaining Information Systems in Organizations. New York, John Wiley \& Sons, 1989.

Towner, Larry E. CASE Concepts and Implementation. New York, McGraw-Hill, 1989.

Tuft, Edward R. The Visual Display of Quantitative Information. Chesire, The Graphics Press, 1983.

Tuft, Edward R. The Envisioning of Information, Chesire, The Graphics Press, 1990.

Tullis, Thomas. "An Evaluation of Alphanumeric, Graphic, and Color Information Displays, " Human Factors, 1981, 23(5), pages 541550.

U.S. Department of Commerce. Computer Model Documentation: A Review and Approach. Washington, National Bureau of Standards publication 500-39, 1979.

Velotta, Christopher, Instructions for Document Coders, NCR Corporation, May 1992.

Weiss, Edmond, $\mathrm{H}$. How to Write a Usable User Manual. Philadelphia, ISI Press, 1985.

Weiss, Edmond, $\mathrm{H}$. The Writing System for Engineers and Scientists. Englewood Cliffs, Prentice Hall, Inc. 1982.

Whitten, Jeffery L., Lonnie D. Bentley, Victor M. Barlow. System Analysis \& Design Methods. Homewood, Irwin Press, 1989.

Williams, Patricia A. and Pamela S. Beason. Writing Effective Software Documentation. Glenview, Scott, Froesman and Company,1990

Zagare, Frank. Game Theory Concepts and Applications. Newbury Park: Sage Publications, 1984. page 51. 
APPENDIX A

FIRMS WHO SENT EVALUATION COPIES 


\section{Appendix A \\ Firms Who Sent Evaluation Copies \\ in Package Order}

\section{COMPANY}

Delorme Mapping Systems

Qualitas Inc.

Ace Software Corporation

Contact Software International

Wilson WindowWare

Adobe Systems Incorporated

Adobe Systems

Aldus Corporation

Aldus Corporation

Alpha Software Corp.

Franklin Quest Co.

Beyond Inc.

Manzanita Software Systems

ISICAD Inc.

Microcom Inc.

TouchStone Software Corporation

Information Management Services

Inc.

Corel Systems Corporation

Digital Communications Associates

Inc.

Decisioneering

Da Vinci Systems Corp.

DataEase International Inc.

DeltaPoint Inc.

DeScribe Inc.

Computervision

Halcyon Software

Applied Decision Analysis Inc.

Information Bullders Inc.

Microsoft Corp.

Frame Technology Corp.

NAG Inc.
PACKAGE

Street Atlas, Map Expert

386MAX and Blue Max

AceFlle for Windows

Act! for Windows

Address Manager Reminder and

Command Post

Adobe Illustrator and TypeAlign

Adobe Photoshop for Windows

Aldus Freehand for Windows

and PhotoStyler

Aldus Persuasion 2.0

AlphaFour

Ascend

Beyond Mail for Windows

BusinessWorks Accounting for

Windows

CADVANCE for Windows

Carbon Copy for Windows

Check It Pro

ClientWorks

CorelDRAW

Crosstalk for Windows

Crystal Ball

Da Vinci eMail for Windows

Dataease Express for Windows

DeltaGraph Professional for

Windows

DeScribe

Designview

DoDOT

DPL Decision Analysis Software Focus/EIS

Foxpro for Windows

Framemaker for Windows

Genstat 
Appendix A

Firms Who Sent Evaluation Coples

COMPANY

Hilgrave Inc.

Moon Valley Software

Advanced Software Inc.

Jetform Corporation

Lucid Corporation

Pacific Micro

Innovative Data Design Inc.

Fifth Generation Systems Inc.

Mainstay

Wolfram Research Inc.

Meta Software Corporation

Micro Planning International

KIDASA Software Inc.

Softklone

JSB Corporation

Symantec Corporation

MicroCal Inc.

IBM Corp. LAN Office Marketing

MD40-E2-03

Buttonware Inc.

Peachtree Software

RoseSoft Inc.

Quarterdeck Office Systems

Quarterdeck Office Systems

Qualisoft Corp.

Borland International Inc.

RFF Electronics

Que Software

University of British Columbia

Department of Econ

President

Hayes Microcomputer Products Inc.

SPSS Inc.

Manugistics Inc.

SynApps Software Inc.

FutureSoft Engineering Inc.

Sinper Corporation

Kaetron Software Corp.

Swifte International Ltd.

Automated Methods Inc.

Falrhaven Software Inc.

Ventura Software Inc.

Microcom Inc.
PACKAGE

HyperAccess for Windows

IconTamer Professional

Intouch

Jetform Design

Lightning for Windows

MAC-In-DOS for Windows

MacDraft for Windows

MACE Utilities and Direct

Access

MacSchedule and MacFlow

Mathematica

MetaDesign

Micro Planner for Windows

Milestones Etc.

Mirror

Multiview Desktop

On Target and Time Line for

Windows

Origin

OS/2 2.1

PC-FIle

Peachtree Accounting for

Windows

ProKey for Windows

QEMM-386

QEMM-386

QFD Designer

Quattro Pro for Windows

RFFlow

RightWriter

Shazam

Simply Accounting

Smartcom for Windows

SPSS for Windows

Statgraphics

Synergy

Terminal Plus-Faxit

TM/ 1 Perspectives

Topdown and Org Chart

Express

Typecase

Ultimate CAD Windows

Ultra Plus

Ventura Publisher

Virex for the PC 
Appendix A

Firms Who Sent Evaluation Copies

COMPANY

Shapeware Corporation

Mesonic USA Inc.

PC-Kwik Corporation

RIX Softworks Inc.

WordPerfect Corp.
PACKAGE

Visio

Win Line Quick

WinMaster and PC-KWIK Power Pak

Winrix

WordPerfect for Windows 
APPENDIX B

INSTRUCTIONS TO PANEL OF EXPERTS 
Appendix B - Instructions to Panel of Experts

Instructions for Panel of Experts

A few weeks ago, several of you provided a list of criteria that you were going to use to determine the quality of end user documentation. This is the final part of the research where you will be asked to evaluate at least one package from each of the following catagories and selected from the attached list:

1. Applications - Accounting, Project Management, Personal Informaiton Managers

2. Drawing - CAD, Presentations, Graphics

3. Quantitative - Spreadsheets, Addins, Math, Statistical

4. Systems - Databases, Operating systems, Networks

5. Textual - Word processing, Desktop Publishing, Forms Design

6. Misc. - Communications, Utilities

Each of these PC packages has been evaluated with a set of quantitative metrics. The research question is: Will the metrics provide any correlation with your expert evalaution of the same document?

In scoring the list of packages with the metrics, a random sampling technique was used to select chapters to score.

If you have trouble finding a copy of the documentation for a package please contact me and we will try to make some arrangement. You may leave message with Dr. Beverly Fuller at 503-725-3744.

INSTRUCTIONS

1. Evaluate one package from each catgory above. Evaluate only the

"User" Manual, Tutorial, training manual or similar.

2. Record your impressions, one page for each package on the attached sheets titled "Questions for Each Package."

3. After you evaluate your packages, please rank them from top to bottom (best to worst) relative to each other. Record your data on both the Questions sheet and the Score Sheet

4. Once the packages have been ranked, you need to place them on an absolute scale. Use a grading scale A,B,C,D with A being 90- 
100, B 80-89, C 70-79, D Below 70. Give each package a rough score on the ABCD scale. Record this data on both the Questions sheet and the score sheet.

5. Record any comments about the package on the back side of the form.

6. Please return Questions for each package and the Data and Score sheets as soon as possible.

Thank you for your participation and help. 
Questions for Bach Pachage

1. Package Name

2. Title of manual you evaluated

2. Do the chapters selected randomly for evaluation by the metric fairly evaluate the user manual?

3. If not, then why? What chapters would you select to score?

4. What chapters did you use for your most detail analysis?

5. What is the $\mathrm{ABCD}$ score for this document in these catagories:

Category

ABCD Score

TEXT

Sentence level - Readability

Remembering - goals for action, logical actions, multiple steps

Chapter level - cohesion, procedures

Document level - task headings, advance organizers

GRAPHICS

Text Graphic integration

Individual Graphics

REFERENCE AIDS

TYPOGRAPHIC PRESENTATION

Additonal areas, explain

OVERALL SCORE 70-100

Letter Score (ABCD)

RANK within your group. 
138

\begin{tabular}{|c|c|c|c|c|c|c|c|c|c|c|c|}
\hline & & & & Boftware & achage & - Dat & ta and & $18 c o r$ & Bheet & & \\
\hline & & & & & Model & chap & & & Complet & te Cols. & \\
\hline & & & Package & version & 1 & 2 & 3 & 4. & Rank & $\mathbf{A B C D}$ & score \\
\hline 1 & Appllo & cation & & & & & & & & & \\
\hline & 11. & Accou & inting & & & & & & & & \\
\hline & & & Business Works for Windows & 7.2 & 2 & 3 & 1 & 5 & & & \\
\hline & & & DAC Easy Accounting & 1.0 & 6 & 5 & 10 & 4 & & & \\
\hline & & & \begin{tabular}{|l} 
Windows \\
\end{tabular} & 5.0 & 6 & 2 & 9 & 3 & & & \\
\hline & & & & & & & & & & & \\
\hline & 12 & Projec & t Management & & & & & & & & \\
\hline & & & MicroPlanner & 6.24 & 5 & 3 & 2 & 4 & & & \\
\hline & & & Milestones & 3.1 & 8 & 11 & 10 & 5 & & & \\
\hline & & & Timeline & 1.0 & 2 & 3 & 6 & 4 & & & \\
\hline & & & & & & & & & & & \\
\hline & 13 . & Persol & nal Information Managers & & & & & & & & \\
\hline & & & Ascend & 4.0 & 15 & 20 & 19 & 12 & & & \\
\hline & & & In Touch MAC & 2.0 & 2 & 6 & 3 & 4 & & & \\
\hline & & & Lotus Organizer & 1.0 & 6 & 4 & 7 & 5 & & & \\
\hline & & & & & & & & & & & \\
\hline 2 & Draw & $\operatorname{lng}$ & & & & & & & & & \\
\hline & 21 & CAD & & & & & & & & & \\
\hline & & & CADVance & 5.0 & less & $3 \mathrm{D} \mathrm{hr} ?$ & Trk N & Util m & anu & & \\
\hline & & & Designvilew & 3.0 & 2 & 4 & 3 & 8 & & & \\
\hline & & & Ultimate CAD & 1.2 & 1 & 2 & 4 & 3 & & & \\
\hline & & & & & & & & & & & \\
\hline & 221 & Draw & & & & & & & & & \\
\hline & & & Mac Draft for Windows & 1.0 & 4 & 2 & 6 & 8 & & & \\
\hline & & & MetaDesign for Windows & 3.0 & 2 & 1 & 4 & 3 & & & \\
\hline & & & RFFLOW & 2.0 & 3 & 1 & 8 & 2 & & & \\
\hline & & & Top Down Flow Chart - MAC & 3.5 & 5 & 6 & 2 & 1 & & & \\
\hline & & & Vislo for Windows & 1.0 & 7 & 1 & 4 & 3 & & & \\
\hline & & & & & & & & & & & \\
\hline & 23 & Prese & atations & & & & & & & & \\
\hline & & & Delta Graph & 2.03 & 14 & 7 & 2 & 5 & & & \\
\hline & & & Freelance for Windows & 2.0 & 5 & 1 & 9 & 2 & & & \\
\hline & & & Persuation & 2.1 & welch & 6 & 4 & 5 & & & \\
\hline & & & Powerpolnt & 3.0 & 1 & 10 & 9 & 13 & & & \\
\hline & & & & & & & & & & & \\
\hline & 24 & Grapl & des & & & & & & & & \\
\hline & & & Aldus Photoshop & 2.5 & 7 & 2 & 4 & 10 & & & \\
\hline & & & Corel Draw & 3.0 & 24 & 28 & 46 & 33 & & & \\
\hline & & & Photosyler & 1.1 & 10 & 12 & 4 & 5 & & & \\
\hline & & & WinRlx & 1.2 & 1 & 3 & 2 & 4 & & & \\
\hline 3 & Quan & ntitati & & & & & & & & & \\
\hline & 31 & Oprea & dsheets & & & & & & & & \\
\hline & & & Excel & 4.0 & 13 & 14 & 4 & 12 & & & \\
\hline & & & Lotus 1-2-3 for Windows & 1.1 & 1 & 2 & 9 & 8 & & & \\
\hline & & & Lucid & & & & & & & & \\
\hline & & & Quattro Pro for Windows & 1.0 & 5 & 6 & 13 & 15 & & & \\
\hline
\end{tabular}


139

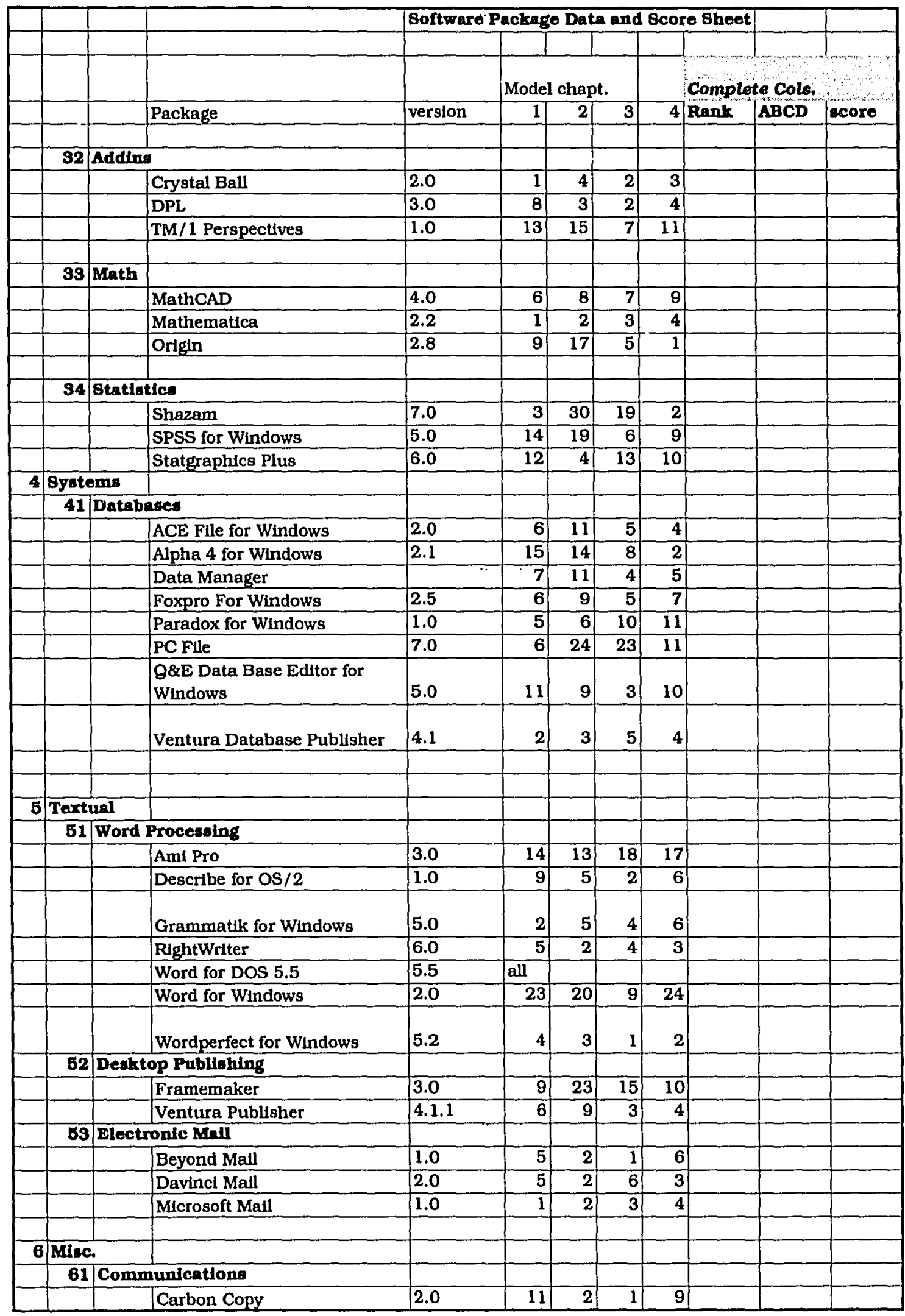







APPENDIX C

DETAIL SCORES FROM MODEL 
142

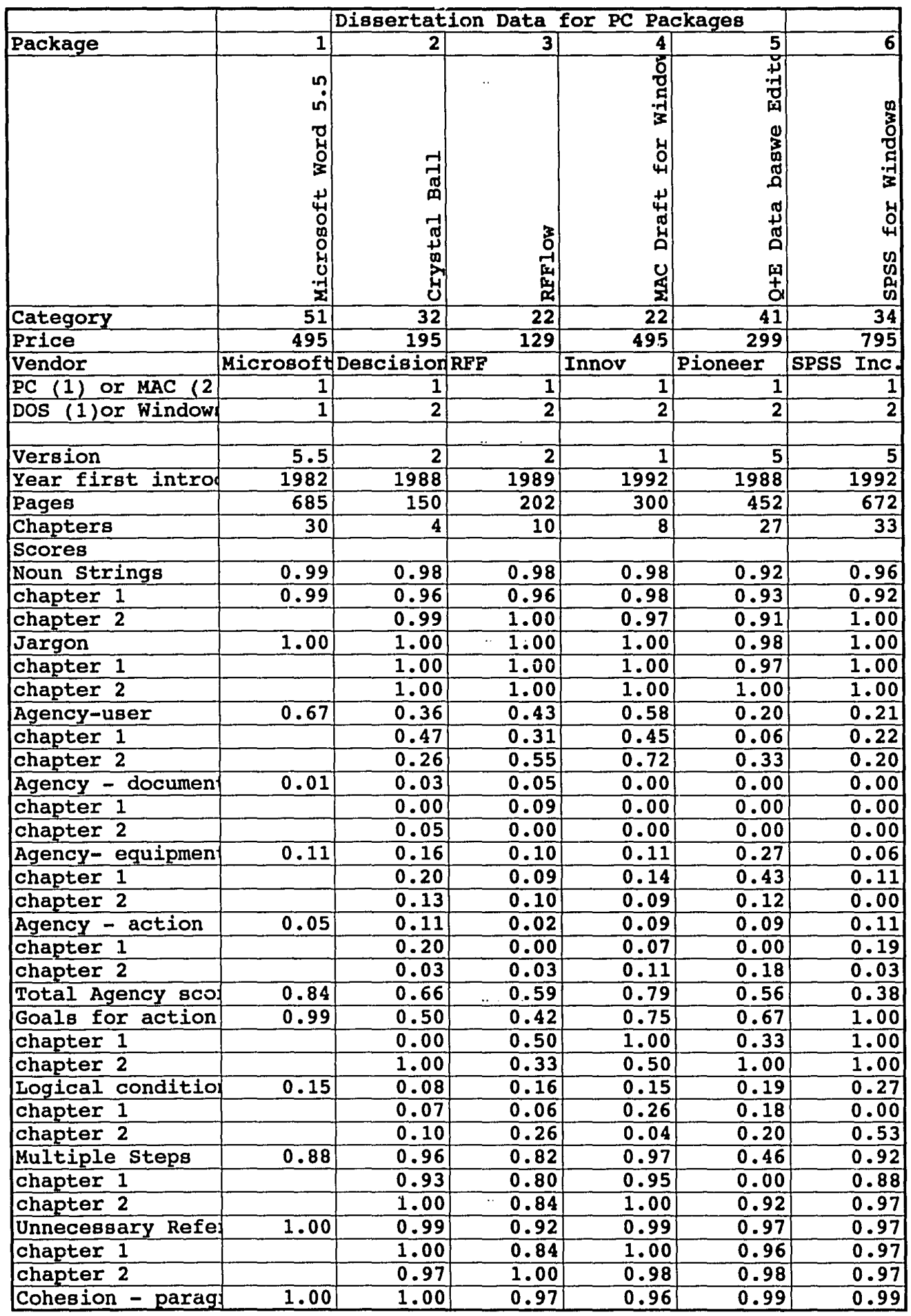




\begin{tabular}{|c|c|c|c|c|c|c|}
\hline & 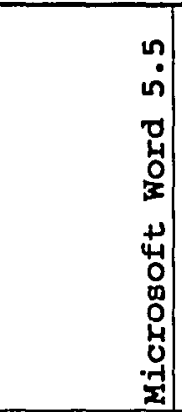 & 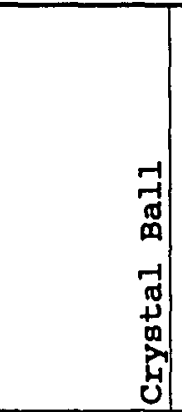 & 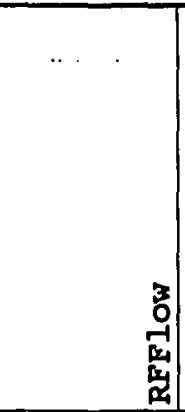 & 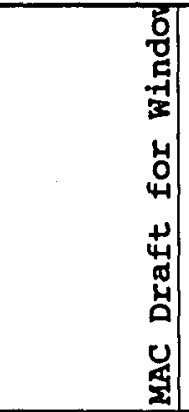 & 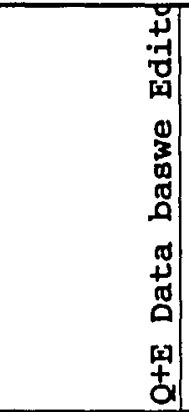 & 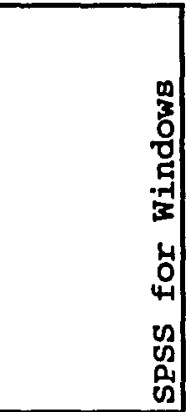 \\
\hline chapter 3 & 1.00 & 1.00 & 0.95 & 0.95 & 0.97 & 0.99 \\
\hline chapter 4 & 1.00 & 1.00 & 1.00 & 0.96 & 1.00 & 0.99 \\
\hline Cohesion - sectid & 0.97 & 1.00 & 1.00 & 0.98 & 1.00 & 0.96 \\
\hline chapter 3 & 1.00 & 1.00 & 1.00 & 0.96 & 1.00 & 1.00 \\
\hline chapter 4 & 0.93 & 1.00 & 1.00 & 1.00 & 1.00 & 0.92 \\
\hline Procedures - ove & 0.79 & 1.00 & 0.78 & 0.95 & 0.76 & 0.26 \\
\hline \begin{tabular}{|l|} 
chapter 3 \\
\end{tabular} & 0.58 & 1.00 & 0.56 & 0.96 & 0.73 & 0.19 \\
\hline chapter 4 & 1.00 & 1.00 & 1.00 & 0.93 & 0.80 & 0.33 \\
\hline Procedures - use & 0.67 & 0.44 & 0.28 & 0.42 & 0.52 & 0.13 \\
\hline chapter 3 & 0.69 & 0.59 & 0.33 & 0.35 & 0.51 & 0.13 \\
\hline chapter 4 & 0.64 & 0.29 & 0.24 & 0.49 & 0.54 & 0.13 \\
\hline Procedural graph & 0.13 & 1.50 & 0.59 & 0.21 & 0.85 & 0.62 \\
\hline chapter 3 & 0.08 & 1.00 & 0.19 & 0.36 & 0.91 & 0.58 \\
\hline Chapter 4 & 0.18 & 2.00 & 1.00 & 0.07 & 0.80 & 0.67 \\
\hline List consistency & 0.67 & 1.00 & 1.00 & 0.50 & 0.00 & 0.67 \\
\hline chapter 3 & 0.00 & 0.00 & 0.00 & 0.50 & 1.00 & 0.33 \\
\hline chapter 4 & 0.33 & 0.00 & 0.00 & 0.00 & 0.00 & 0.00 \\
\hline Advance Organize: & 0.57 & 0.44 & 0.50 & 0.81 & 0.30 & 0.26 \\
\hline chapter 3 & 0.47 & 0.67 & 0.00 & 0.92 & 0.35 & 0.03 \\
\hline chapter 4 & 0.67 & 0.21 & 1.00 & 0.71 & 0.24 & 0.50 \\
\hline Task Headings & 0.93 & 0.50 & 0.55 & 0.50 & 0.71 & 0.26 \\
\hline Informative capt & 0.01 & 1.00 & 0.68 & 0.00 & 0.00 & 1.00 \\
\hline NONIrrelevant gr: & 1.00 & 1.00 & 0.67 & 1.00 & 0.79 & 0.80 \\
\hline NONMisleading gr & 1.00 & 1.00 & 1.00 & 1.00 & 1.00 & 1.00 \\
\hline NON Lie factors & 1.00 & 1.00 & 1.00 & 1.00 & 1.00 & 1.00 \\
\hline NON Data ink & 1.00 & 1.00 & 1.00 & 1.00 & 1.00 & 1.00 \\
\hline NO Duck RATIO & 1.00 & 0.85 & 0.67 & 1.00 & 1.00 & 0.80 \\
\hline Reference Aids t & 0.56 & 0.44 & 0.44 & 0.44 & 0.33 & 0.44 \\
\hline Glossary to 28 & 0.00 & 1.00 & 0.00 & 0.00 & 0.00 & 0.00 \\
\hline Index to 5 per $p$ & 1.00 & 0.41 & 0.49 & 0.56 & 0.54 & 0.74 \\
\hline Typographic to 1 & 1.00 & 1.00 & 0.73 & 1.00 & 0.91 & 0.73 \\
\hline Text Category & 0.82 & 0.75 & 0.71 & 0.77 & 0.64 & 0.65 \\
\hline Graphics Category & 0.73 & 1.05 & 0.80 & 0.74 & 0.81 & 0.89 \\
\hline \begin{tabular}{|l|} 
Referencability \\
\end{tabular} & 0.52 & 0.62 & 0.31 & 0.33 & 0.29 & 0.39 \\
\hline Sentence Level sd & 0.88 & 0.80 & 0.76 & 0.86 & 0.78 & 0.83 \\
\hline Text & 0.84 & 0.74 & 0.70 & 0.80 & 0.68 & 0.79 \\
\hline Graphics & 1.00 & 0.95 & 0.89 & 1.00 & 1.00 & 0.93 \\
\hline Chapter Level Sco & 0.68 & 0.91 & 0.73 & 0.69 & 0.63 & 0.56 \\
\hline Document Level S & 0.69 & 0.79 & 0.57 & 0.56 & 0.53 & 0.62 \\
\hline \begin{tabular}{|l|} 
Total Score \\
\end{tabular} & 0.77 & 0.83 & 0.69 & 0.72 & 0.66 & 0.69 \\
\hline 2 score & 0.710691 & 1.410329 & -0.10701 & 0.204996 & -0.44966 & .13926 \\
\hline
\end{tabular}


144

\begin{tabular}{|c|c|c|c|c|c|c|}
\hline & & & & & & \\
\hline \multirow[t]{2}{*}{ Package } & 7 & 8 & 9 & 10 & 11 & 12 \\
\hline & 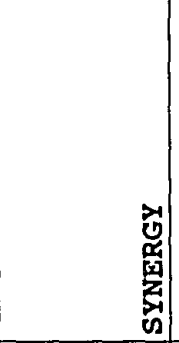 & 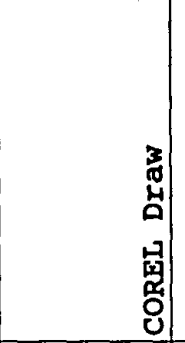 & 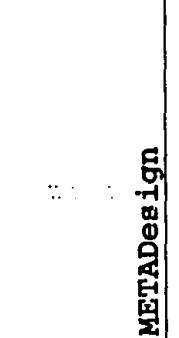 & 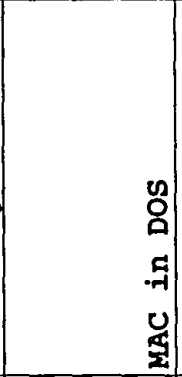 & 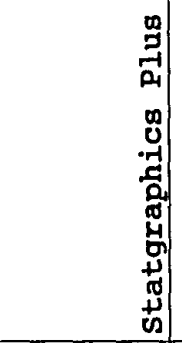 & 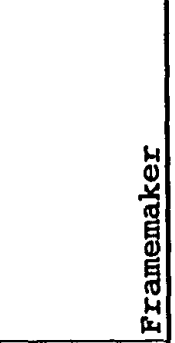 \\
\hline Category & 62 & 24 & 22 & 62 & 34 & 52 \\
\hline Price & 130 & 595 & 350 & 249 & 995 & 795 \\
\hline Vendor & SYNAPS & \multirow{2}{*}{ Corel } & META & Pacific & Manguisit & Frame \\
\hline PC (1) or MAC (2) & \multirow{2}{*}{\begin{tabular}{r|}
1 \\
2
\end{tabular}} & & 1 & 1 & \multirow{2}{*}{\begin{tabular}{|l|}
1 \\
\end{tabular}} & \\
\hline \multirow[t]{2}{*}{ DOS $(1)$ or Window } & & 2 & 2 & 2 & & $\frac{1}{2}$ \\
\hline & \multirow{2}{*}{1} & & & & \multirow[b]{2}{*}{6} & \\
\hline \multirow{3}{*}{$\begin{array}{l}\text { Version } \\
\text { Year first intro } \\
\text { Pages }\end{array}$} & & 3 & 3 & 2 & & \\
\hline & 1992 & 1986 & 1987 & 1990 & 1989 & 1986 \\
\hline & 239 & 522 & 147 & 26 & 485 & 620 \\
\hline Chapters & 21 & 48 & 4 & 6 & 14 & 24 \\
\hline Scores & & & & & & \\
\hline Noun Strings & 0.99 & 0.96 & 0.99 & 0.95 & 0.94 & 0.97 \\
\hline chapter 1 & 1.00 & 0.98 & 0.99 & 0.93 & 0.94 & 0.99 \\
\hline chapter 2 & 0.99 & 0.94 & 0.98 & 0.97 & 0.94 & 0.95 \\
\hline Jargon & 1.00 & 1.00 & 1.00 & 0.99 & 1.00 & 1.00 \\
\hline chapter 1 & 1.00 & 1.00 & 1.00 & 0.97 & 1.00 & 1.00 \\
\hline chapter 2 & 1.00 & 1.00 & 1.00 & 1.00 & 1.00 & 1.00 \\
\hline Agency-user & 0.41 & 0.42 & 0.47 & 0.39 & 0.38 & 0.33 \\
\hline chapter 1 & 0.24 & 0.31 & 0.65 & 0.37 & 0.48 & 0.29 \\
\hline chapter 2 & 0.58 & 0.53 & 0.29 & 0.42 & 0.27 & 0.38 \\
\hline Agency - documen & 0.00 & 0.00 & 0.01 & 0.12 & 0.07 & 0.02 \\
\hline chapter 1 & 0.00 & 0.00 & 0.02 & 0.20 & 0.02 & 0.04 \\
\hline chapter 2 & 0.00 & 0.00 & 0.00 & 0.04 & 0.13 & 0.00 \\
\hline Agency- equipmen & 0.34 & 0.27 & 0.22 & 0.30 & 0.36 & 0.40 \\
\hline chapter 1 & 0.52 & 0.37 & 0.17 & 0.33 & 0.39 & 0.52 \\
\hline Chapter 2 & 0.16 & 0.18 & 0.27 & 0.27 & 0.34 & 0.28 \\
\hline Agency - action & 0.04 & 0.17 & 0.15 & 0.04 & 0.05 & 0.17 \\
\hline chapter 1 & 0.05 & 0.21 & 0.06 & 0.00 & 0.10 & 0.11 \\
\hline chapter 2 & 0.02 & 0.13 & 0.25 & 0.08 & 0.00 & 0.23 \\
\hline Total Agency sco & 0.79 & 0.86 & 0.86 & 0.85 & 0.86 & 0.91 \\
\hline Goals for action & 1.00 & 0.48 & 0.56 & 0.75 & 0.70 & 0.58 \\
\hline Chapter 1 & 1.00 & 0.60 & 0.13 & 1.00 & 0.40 & 0.17 \\
\hline chapter 2 & 1.00 & 0.37 & 1.00 & 0.50 & 1.00 & 1.00 \\
\hline Logical conditiol & 0.33 & 0.12 & 0.13 & 0.09 & 0.17 & 0.11 \\
\hline chapter 1 & 0.29 & 0.14 & 0.10 & 0.07 & 0.16 & 0.20 \\
\hline chapter 2 & 0.37 & 0.10 & 0.17 & 0.12 & 0.19 & 0.03 \\
\hline Multiple Steps & 0.77 & 0.75 & 0.97 & 0.98 & 0.90 & 1.00 \\
\hline chapter 1 & 0.70 & 0.54 & 0.94 & 1.00 & 0.80 & 1.00 \\
\hline chapter 2 & 0.84 & 0.96 & 1.00 & 0.96 & 1.00 & 1.00 \\
\hline Unnecessary Refe: & 1.00 & 0.98 & 0.99 & 1.00 & 0.93 & 0.99 \\
\hline chapter 1 & 1.00 & 0.96 & 0.98 & 1.00 & 0.95 & 1.00 \\
\hline Chapter 2 & 1.00 & 1.00 & 1.00 & 1.00 & 0.90 & 0.98 \\
\hline Cohesion - parag & 0.99 & 1.00 & 0.99 & 1.00 & 0.76 & 1.00 \\
\hline
\end{tabular}




\begin{tabular}{|c|c|c|c|c|c|c|}
\hline & 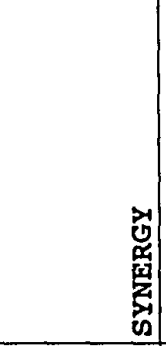 & 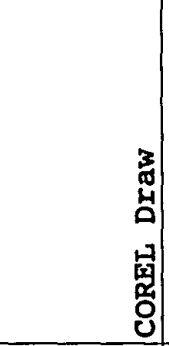 & 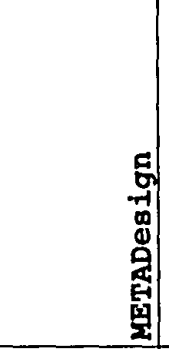 & 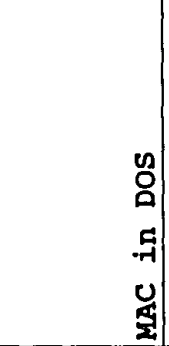 & 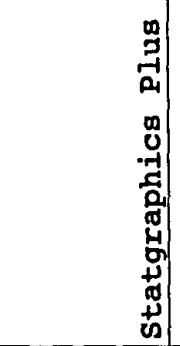 & 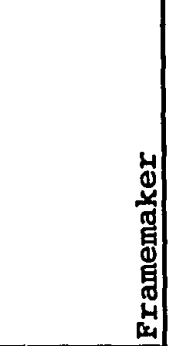 \\
\hline chapter: 3 & 0.98 & 1.00 & 0.98 & 1.00 & 0.81 & 1.00 \\
\hline chapter 4 & 1.00 & 1.00 & 1.00 & 1.00 & 0.71 & 1.00 \\
\hline Cohesion - sectid & 1.00 & 0.88 & 1.00 & 1.00 & 0.93 & 1.00 \\
\hline chapter: 3 & 1.00 & 1.00 & 1.00 & 1.00 & 0.91 & 1.00 \\
\hline chaptes: 4 & 1.00 & 0.75 & 1.00 & 1.00 & 0.94 & 1.00 \\
\hline Procedures - ove & 0.30 & 0.71 & 0.00 & 0.50 & 0.68 & 1.00 \\
\hline chapter 3 & 0.00 & 0.67 & 0.00 & 1.00 & 0.94 & 1.00 \\
\hline chapter 4 & 0.60 & 0.75 & 0.00 & 0.00 & 0.42 & 1.00 \\
\hline Procedures - use & 0.12 & 0.39 & 0.19 & 0.51 & 0.37 & 0.40 \\
\hline Chapter 3 & 0.09 & 0.36 & 0.39 & 0.52 & 0.30 & 0.46 \\
\hline chapter 4 & 0.15 & 0.42 & 0.00 & 0.50 & 0.44 & 0.35 \\
\hline Procedural graph & 0.30 & 0.51 & 0.10 & 1.00 & 0.08 & 0.68 \\
\hline chapter 3 & 0.00 & 0.27 & 0.21 & 1.00 & 0.00 & 0.60 \\
\hline chapter 4 & 0.60 & 0.75 & 0.00 & 1.00 & 0.17 & 0.75 \\
\hline List consistency & 1.00 & 0.00 & 1.00 & 1.00 & 1.00 & 1.00 \\
\hline chapter 3 & 0.00 & 0.00 & 0.00 & 0.00 & 0.00 & 0.00 \\
\hline chapter 4 & 0.00 & 1.00 & 0.00 & 0.00 & 0.00 & 0.00 \\
\hline Advance Organize & 0.50 & 0.13 & 0.00 & 0.50 & 0.76 & 0.57 \\
\hline Chapter 3 & 0.00 & 0.25 & 0.00 & 1.00 & 0.94 & 1.00 \\
\hline chapter 4 & 1.00 & 0.00 & 0.00 & 0.00 & 0.58 & 0.14 \\
\hline Task Hleadings & 0.32 & 0.56 & 0.43 & 0.37 & 0.70 & 0.82 \\
\hline Informative capt & 0.00 & 0.03 & 0.00 & 0.00 & 1.00 & 0.00 \\
\hline NONIrrelevant gr & 1.00 & 0.97 & 0.96 & 0.93 & 0.97 & 0.99 \\
\hline NONMigleading gr & 1.00 & 1.00 & 1.00 & 1.00 & 1.00 & 1.00 \\
\hline NON Lie factors & 1.00 & 1.00 & 1.00 & 0.00 & 1.00 & 1.00 \\
\hline NON Data ink & 1.00 & 1.00 & 1.00 & 1.00 & 1.00 & 1.00 \\
\hline NO Duck RATIO & 1.00 & 0.97 & 0.96 & 1.00 & 1.00 & 0.96 \\
\hline Reference Alds to & 0.33 & 1.00 & 0.44 & 0.22 & 0.78 & 0.67 \\
\hline Glosgary to 28 & 0.00 & 0.00 & 1.00 & 0.00 & 1.00 & 0.97 \\
\hline Index to 5 per pe & 0.32 & 1.00 & 0.46 & 0.00 & 0.24 & 1.00 \\
\hline Typoguraphic to 1 . & 0.82 & 1.00 & 0.91 & 0.36 & 0.91 & 1.00 \\
\hline Text Category & 0.72 & 0.63 & 0.65 & 0.75 & 0.76 & 0.81 \\
\hline Graphics Category & 0.76 & 0.78 & 0.72 & 0.70 & 0.86 & 0.80 \\
\hline Referencability & 0.22 & 0.67 & 0.64 & 0.07 & 0.67 & 0.88 \\
\hline Sentence Level so & 0.89 & 0.81 & 0.85 & 0.76 & 0.85 & 0.85 \\
\hline \begin{tabular}{|l|l|} 
Text & \\
\end{tabular} & 0.84 & 0.74 & 0.79 & 0.80 & 0.79 & 0.79 \\
\hline Graphics & 1.00 & 0.99 & 0.99 & 0.67 & 1.00 & 0.99 \\
\hline Chapter Ievel Sc & 0.60 & 0.52 & 0.47 & 0.79 & 0.65 & 0.81 \\
\hline Document Ievel so & 0.47 & 0.70 & 0.65 & 0.36 & 0.83 & 0.81 \\
\hline Total score & 0.68 & 0.69 & 0.68 & 0.64 & 0.79 & 0.82 \\
\hline 2 gcore & -0.26169 & -0.08117 & -0.23353 & -0.64342 & 0.947513 & 1.349385 \\
\hline
\end{tabular}


146

\begin{tabular}{|c|c|c|c|c|c|c|}
\hline & & & & & & \\
\hline \multirow[t]{2}{*}{ Package } & 13 & 14 & 15 & 16 & 17 & 18 \\
\hline & 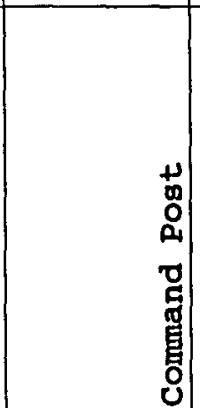 & 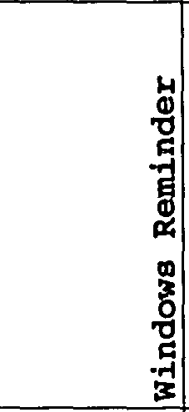 & 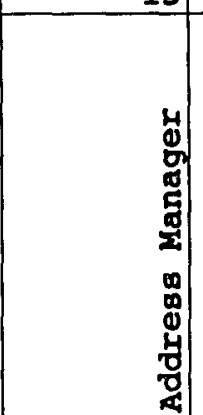 & $\begin{array}{l}0 \\
\mathbf{0} \\
\mathbf{c} \\
\mathbf{5} \\
\mathbf{5}\end{array}$ & 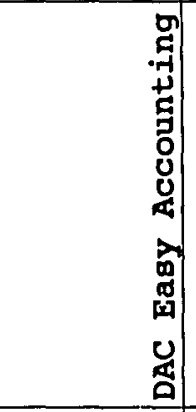 & 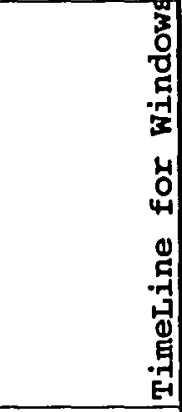 \\
\hline Category & 62 & 13 & 13 & 61 & 11 & 12 \\
\hline Price & 50 & 60 & 40 & 195 & 50 & 699 \\
\hline Vendor & Wilson & Wilson & Filson & $\mathrm{DCA}$ & DAC & Symantec \\
\hline PC (1) or MAC (2) & 1 & 1 & 1 & 1 & \multirow{2}{*}{$\frac{1}{3}$} & 1 \\
\hline \multirow[t]{2}{*}{ DOS (1)or Window } & 2 & 2 & 2 & 2 & & 2 \\
\hline & & & & & & \\
\hline \multirow{2}{*}{$\begin{array}{l}\text { Version } \\
\text { Year first intro }\end{array}$} & 7 & & & 2 & 1 & 1 \\
\hline & 1988 & & & 1991 & 1992 & 1992 \\
\hline Pages & 42 & 0 & 70 & 195 & 317 & 425 \\
\hline Chapters & 6 & 0 & 18 & 10 & 11 & 10 \\
\hline \multicolumn{7}{|l|}{ Scores } \\
\hline Noun Strings & 0.94 & 0.00 & 0.97 & 0.95 & 0.98 & 0.95 \\
\hline chapter 1 & 0.96 & 0.00 & 0.98 & 0.96 & 0.98 & 0.93 \\
\hline chapter 2 & 0.93 & 0.00 & 0.96 & 0.94 & 0.98 & 0.96 \\
\hline Jargon & 0.98 & 0.00 & 1.00 & 1.00 & 1.00 & 1.00 \\
\hline chapter 1 & 0.99 & 0.00 & 1.00 & 1.00 & 1.00 & 0.99 \\
\hline chapter 2 & 0.97 & 0.00 & 1.00 & 1.00 & 1.00 & 1.00 \\
\hline Agency-user & 0.17 & 0.00 & 0.31 & 0.60 & 0.48 & 0.22 \\
\hline chapter 1 & 0.30 & 0.00 & 0.11 & 0.54 & 0.45 & 0.07 \\
\hline chapter 2 & 0.05 & 0.00 & 0.50 & 0.67 & 0.50 & C.36 \\
\hline Agency - documen & 0.00 & 0.00 & 0.00 & 0.10 & 0.03 & 0.04 \\
\hline chapter 1 & 0.00 & 0.00 & 0.00 & 0.13 & 0.03 & 0.04 \\
\hline chapter 2 & 0.00 & 0.00 & 0.00 & 0.07 & 0.04 & 0.04 \\
\hline Agency- equipmen & 0.43 & 0.00 & 0.30 & 0.19 & 0.34 & 0.38 \\
\hline chapter 1 & 0.60 & 0.00 & 0.14 & 0.17 & 0.30 & 0.36 \\
\hline chapter 2 & 0.27 & 0.00 & 0.46 & 0.22 & 0.37 & 0.40 \\
\hline Agency - action & 0.00 & 0.00 & 0.19 & 0.06 & 0.02 & 0.02 \\
\hline chapter 1 & 0.00 & 0.00 & 0.39 & 0.08 & 0.00 & 0.04 \\
\hline chapter 2 & 0.00 & 0.00 & 0.00 & 0.03 & 0.04 & 0.00 \\
\hline Total Agency scos & 0.61 & 0.00 & 0.80 & 0.95 & 0.87 & 0.65 \\
\hline Goals for action & 0.00 & 0.00 & 0.03 & 1.00 & 0.30 & 1.00 \\
\hline chapter 1 & 0.00 & 0.00 & 0.07 & 1.00 & 0.20 & 1.00 \\
\hline chapter 2 & 0.00 & 0.00 & 0.00 & 1.00 & 0.40 & 1.00 \\
\hline Logical conditiol & 0.10 & 0.00 & 0.17 & 0.06 & 0.10 & 0.12 \\
\hline chapter 1 & 0.00 & 0.00 & 0.00 & 0.00 & 0.06 & 0.07 \\
\hline chapter 2 & 0.20 & 0.00 & 0.35 & 0.12 & 0.15 & 0.16 \\
\hline Multiple steps & 0.83 & 0.00 & 0.82 & 1.00 & 1.00 & 1.00 \\
\hline chapter 1 & 0.67 & 0.00 & 0.75 & 1.00 & 1.00 & 1.00 \\
\hline chapter 2 & 1.00 & 0.00 & 0.88 & 1.00 & 1.00 & 1.00 \\
\hline Unnecessary Refe & 1.00 & 0.00 & 0.93 & 0.98 & 0.98 & 1.00 \\
\hline chapter 1 & 1.00 & 0.00 & 0.86 & 1.00 & 1.00 & 1.00 \\
\hline chapter 2 & 1.00 & 0.00 & 1.00 & 0.97 & 0.96 & 1.00 \\
\hline Cohesion - parag & 0.99 & 0.00 & 1.00 & 1.00 & 0.98 & 0.93 \\
\hline
\end{tabular}


147

\begin{tabular}{|c|c|c|c|c|c|c|}
\hline & 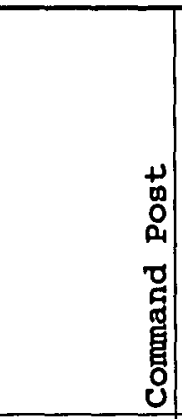 & 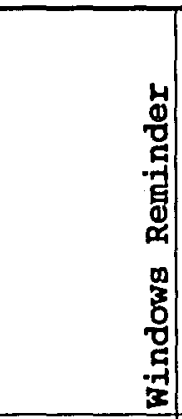 & 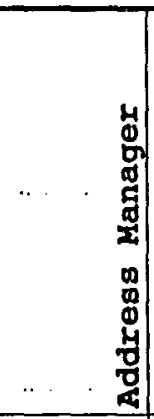 & 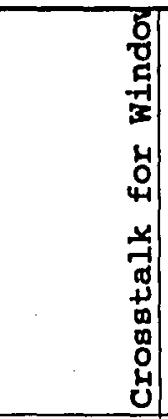 & 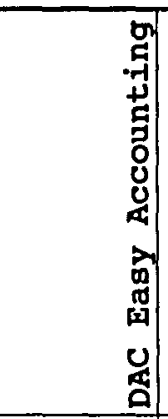 & 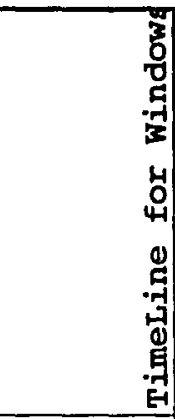 \\
\hline chapter 3 & 0.97 & 0.00 & 1.00 & 1.00 & 0.98 & 0.98 \\
\hline chapter 4 & 1.00 & 0.00 & 1.00 & 1.00 & 0.98 & 0.89 \\
\hline Cohesion - sectid & 0.91 & 0.00 & 1.00 & 1.00 & 1.00 & 0.87 \\
\hline chapter 3 & 1.00 & 0.00 & 1.00 & 1.00 & 1.00 & 0.86 \\
\hline chapter 4 & 0.82 & 0.00 & 1.00 & 1.00 & 1.00 & 0.88 \\
\hline Procedures - ove & 0.00 & 0.00 & 1.00 & 0.94 & 0.00 & 1.00 \\
\hline chapter 3 & 0.00 & 0.00 & 1.00 & 1.00 & 0.00 & 1.00 \\
\hline chapter 4 & 0.00 & 0.00 & 1.00 & 0.88 & 0.00 & 1.00 \\
\hline Procedures - use & 0.26 & 0.00 & 0.41 & 0.44 & 0.82 & 0.43 \\
\hline chapter 3 & 0.00 & 0.00 & 0.42 & 0.44 & 1.00 & 0.38 \\
\hline chapter 4 & 0.52 & 0.00 & 0.41 & 0.44 & 0.64 & 0.49 \\
\hline Procedural graph & 0.00 & 0.00 & 0.00 & 0.22 & 0.39 & 0.91 \\
\hline chapter 3 & 0.00 & 0.00 & 0.00 & 0.00 & 0.00 & 1.00 \\
\hline chapter 4 & 0.00 & 0.00 & 0.00 & 0.44 & 0.79 & 0.82 \\
\hline List consistency & 1.00 & 1.00 & 1.00 & 1.00 & 0.50 & 1.00 \\
\hline chapter 3 & 0.00 & 0.00 & 0.00 & 0.00 & 0.50 & 0.00 \\
\hline chapter 4 & 0.00 & 0.00 & 0.00 & 0.00 & 0.50 & $0 . \overline{00}$ \\
\hline Advance Organize & 0.05 & 0.00 & 0.00 & 0.80 & 0.08 & 0.04 \\
\hline chapter 3 & 0.00 & 0.00 & 0.00 & 1.00 & 0.16 & 0.00 \\
\hline chapter 4 & 0.09 & 0.00 & 0.00 & 0.61 & 0.00 & 0.08 \\
\hline Task Headings & 0.10 & 0.00 & 0.39 & 0.58 & 0.30 & 0.60 \\
\hline Informative capt & 0.00 & 0.00 & 0.00 & 1.00 & 0.00 & 0.82 \\
\hline NONIrrelevant gr & 0.00 & 0.00 & 1.00 & 1.00 & 0.55 & 0.98 \\
\hline NONMisleading gr & 1.00 & 1.00 & 1.00 & 1.00 & 0.47 & 1.00 \\
\hline NON Lie factors & 1.00 & 1.00 & 1.00 & 1.00 & 0.47 & 1.00 \\
\hline NON Data ink & 1.00 & 1.00 & 1.00 & 1.00 & 1.00 & 0.99 \\
\hline NO DuCK RATIO & 1.00 & 1.00 & 1.00 & 0.73 & 0.55 & 0.95 \\
\hline Reference Aids $t$ & 0.00 & 0.00 & 0.33 & 0.67 & 0.33 & 0.67 \\
\hline Glossary to 28 & 0.00 & 0.00 & 0.00 & 0.00 & 0.00 & 0.88 \\
\hline Index to 5 per $p$ & 0.00 & 0.00 & 0.15 & 0.48 & 0.24 & 0.90 \\
\hline Typographic to 1 & 0.73 & 0.00 & 0.73 & 0.91 & 1.00 & 1.00 \\
\hline Text Category & 0.55 & 0.07 & 0.68 & 0.84 & 0.64 & 0.76 \\
\hline Graphics Category & 0.57 & 0.57 & 0.71 & 0.85 & 0.49 & 0.95 \\
\hline Referencability & 0.00 & 0.00 & 0.16 & 0.38 & 0.19 & 0.82 \\
\hline Sentence Level S & 0.75 & 0.30 & 0.77 & 0.87 & 0.73 & 0.86 \\
\hline Text & 0.64 & 0.00 & 0.67 & 0.85 & 0.75 & 0.82 \\
\hline Graphics & 1.00 & 1.00 & 1.00 & 0.91 & 0.67 & 0.98 \\
\hline Chapter Level Sce & 0.46 & 0.14 & 0.63 & 0.77 & 0.54 & 0.74 \\
\hline Document Level S & 0.23 & 0.12 & 0.45 & 0.70 & 0.36 & 0.86 \\
\hline Total Score & 0.50 & 0.20 & 0.63 & 0.79 & 0.56 & 0.83 \\
\hline 2 score & -2.15955 & -5.39504 & -0.757 & 0.95458 & -1.5404 & .372749 \\
\hline
\end{tabular}




\begin{tabular}{|c|c|c|c|c|c|c|}
\hline Package & 19 & 20 & 21 & 22 & 23 & 24 \\
\hline & $\begin{array}{l}0 \\
0 \\
0 \\
5 \\
0 \\
0 \\
0 \\
0\end{array}$ & 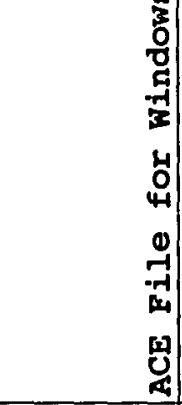 & 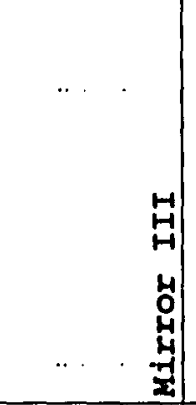 & 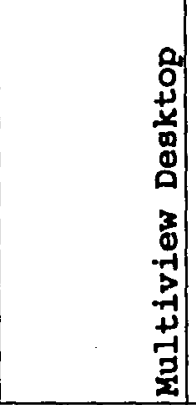 & $\begin{array}{l}\mathbf{d} \\
0 \\
0 \\
0 \\
\mathbf{D} \\
\end{array}$ & 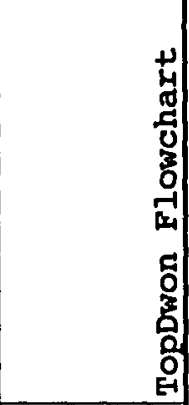 \\
\hline Category & 61 & 41 & 61 & $\overline{61}$ & 13 & 22 \\
\hline Price & 199 & 295 & 149 & 445 & 299 & 295 \\
\hline Vendor & Micorcom & $\overline{\mathrm{ACE}}$ & Softklone & JSB & Franklin & Kaetron \\
\hline PC (1) Or MAC (2) & 1 & 1 & \begin{tabular}{r|}
1 \\
\end{tabular} & 1 & 1 & 2 \\
\hline DOS (1)or Window & 2 & 2 & 1 & 2 & 2 & 0 \\
\hline Version & 2 & 2 & 2.5 & 3.15 & 4 & 3.5 \\
\hline Year first intro & 1992 & 1992 & 1984 & 1992 & 1991 & 1988 \\
\hline Pages & 206 & 480 & 311 & 70 & 335 & 181 \\
\hline Chapters & 14 & 18 & 13 & 10 & 30 & 7 \\
\hline Scores & & & & & & \\
\hline Noun Strings & 0.94 & 0.96 & 0.99 & 0.98 & 0.95 & 0.99 \\
\hline chapter 1 & 0.96 & 0.94 & 0.99 & 0.98 & 0.97 & 0.99 \\
\hline chapter 2 & 0.91 & 0.97 & 1.00 & 0.98 & 0.93 & 0.98 \\
\hline Jargon & 1.00 & 1.00 & 0.99 & 1.00 & 1.00 & 0.99 \\
\hline chapter 1 & 1.00 & 1.00 & 0.99 & 1.00 & 1.00 & 1.00 \\
\hline Chapter 2 & 0.99 & 1.00 & 1.00 & 1.00 & 1.00 & 0.98 \\
\hline Agency-user & 0.50 & 0.19 & 0.26 & 0.42 & 0.25 & 0.34 \\
\hline chapter 1 & 0.40 & 0.23 & 0.13 & 0.31 & $0 . \overline{31}$ & 0.44 \\
\hline chapter 2 & 0.60 & 0.16 & 0.40 & 0.53 & 0.18 & 0.25 \\
\hline Agency - documen & 0.04 & 0.00 & 0.11 & 0.03 & 0.00 & 0.03 \\
\hline chapter 1 & 0.04 & 0.00 & 0.19 & 0.00 & 0.00 & 0.00 \\
\hline chapter 2 & 0.04 & 0.00 & 0.03 & 0.05 & 0.00 & 0.06 \\
\hline Agency- equipmen & 0.30 & 0.46 & 0.31 & 0.39 & 0.57 & 0.43 \\
\hline chapter 1 & 0.30 & 0.51 & 0.21 & 0.52 & 0.50 & 0.36 \\
\hline chapter 2 & 0.30 & 0.40 & 0.42 & 0.26 & 0.64 & 0.50 \\
\hline Agency - action & 0.10 & 0.10 & 0.09 & 0.03 & 0.09 & 0.09 \\
\hline chapter 1 & 0.17 & 0.14 & 0.13 & 0.00 & 0.19 & 0.09 \\
\hline chapter 2 & 0.02 & 0.05 & 0.05 & 0.05 & 0.00 & 0.09 \\
\hline Total Agency sco: & 0.94 & 0.75 & 0.78 & 0.86 & 0.91 & 0.90 \\
\hline Goals for action & 0.61 & 1.00 & 0.32 & 0.83 & 1.00 & 0.90 \\
\hline chapter 1 & 0.46 & 1.00 & 0.31 & 1.00 & 1.00 & 1.00 \\
\hline chapter 2 & 0.75 & 1.00 & 0.33 & 0.67 & 1.00 & 0.80 \\
\hline Logical conditiol & 0.21 & 0.12 & 0.07 & 0.10 & 0.05 & 0.16 \\
\hline chapter 1 & 0.21 & 0.11 & 0.06 & 0.14 & 0.00 & 0.20 \\
\hline chapter 2 & 0.20 & 0.12 & 0.09 & 0.05 & 0.09 & 0.13 \\
\hline Multiple Steps & 0.80 & 1.00 & 0.99 & 1.00 & 1.00 & 1.00 \\
\hline chapter 1 & 0.68 & 1.00 & 1.00 & 1.00 & 1.00 & 1.00 \\
\hline Chapter 2 & 0.92 & 1.00 & 0.99 & 1.00 & 1.00 & 1.00 \\
\hline Unnecesgary Refe & 0.96 & 0.95 & 0.99 & 1.00 & 1.00 & 1.00 \\
\hline chapter 1 & 0.96 & 1.00 & 1.00 & 1.00 & 1.00 & 1.00 \\
\hline chapter 2 & 0.96 & 0.89 & 0.99 & 1.00 & 1.00 & 1.00 \\
\hline Cohegion - parag & 0.95 & 0.96 & 1.00 & 1.00 & 0.98 & 0.88 \\
\hline
\end{tabular}




\begin{tabular}{|c|c|c|c|c|c|c|}
\hline & $\begin{array}{l}0 \\
0 \\
0 \\
5 \\
0 \\
0 \\
0 \\
0\end{array}$ & 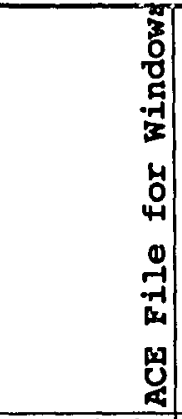 & 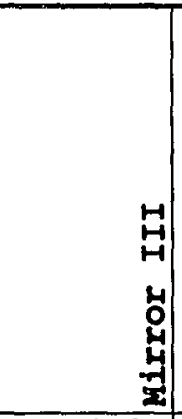 & 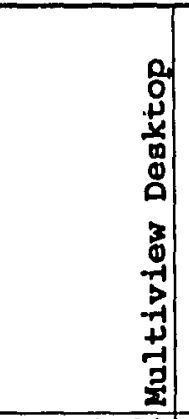 & 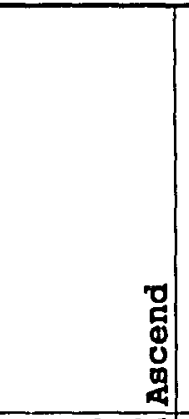 & 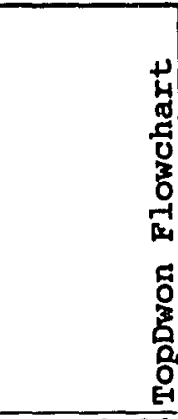 \\
\hline chapter 3 & 0.99 & 1.00 & 1.00 & 1.00 & 0.96 & 1.00 \\
\hline chapter 4 & 0.92 & 0.93 & 1.00 & 1.00 & 1.00 & 0.76 \\
\hline Cohesion - sectis & 0.94 & 0.96 & 0.96 & 0.75 & 0.96 & 0.94 \\
\hline chapter 3 & 0.89 & 0.92 & 1.00 & 1.00 & 1.00 & 0.89 \\
\hline chapter 4 & 1.00 & 1.00 & 0.92 & 0.50 & 0.92 & 1.00 \\
\hline Procedures - ove & 0.50 & 0.75 & 0.46 & 0.63 & 0.70 & 0.46 \\
\hline Chapter 3 & 0.00 & 0.93 & 0.67 & 1.00 & 1.00 & 0.67 \\
\hline chapter 4 & 1.00 & 0.57 & 0.25 & 0.25 & 0.41 & 0.25 \\
\hline Procedures - use & 0.18 & 0.50 & 0.21 & 0.38 & 0.47 & 0.56 \\
\hline chapter 3 & 0.00 & 0.41 & 0.29 & 0.63 & 0.64 & 0.48 \\
\hline chapter 4 & 0.37 & 0.59 & 0.14 & 0.14 & 0.30 & 0.64 \\
\hline Procedural graph & 0.18 & 0.41 & 0.25 & 0.39 & 1.00 & 0.54 \\
\hline chapter 3 & 0.00 & 0.43 & 0.00 & 0.29 & 1.00 & 0.33 \\
\hline chapter 4 & 0.36 & 0.39 & 0.50 & 0.50 & 1.00 & 0.75 \\
\hline List consistency & 0.67 & 1.00 & 1.00 & 1.00 & 1.00 & 0.75 \\
\hline chapter 3 & 0.33 & 0.00 & 0.00 & 0.00 & 0.00 & 0.25 \\
\hline chapter 4 & 0.00 & 0.00 & 0.00 & 0.00 & 0.00 & 0.00 \\
\hline Advance Organize & 0.16 & 0.00 & 0.15 & 0.22 & 0.04 & 0.22 \\
\hline Chapter 3 & 0.22 & 0.00 & 0.13 & 0.25 & 0.00 & 0.33 \\
\hline chapter 4 & 0.11 & 0.00 & 0.18 & 0.18 & 0.09 & 0.11 \\
\hline Task Headings & 0.35 & 0.55 & 0.19 & 0.19 & 0.24 & 0.36 \\
\hline Informative capt & 0.00 & 0.00 & 0.00 & 0.00 & 0.00 & 0.79 \\
\hline NONIrrelevant gr & 0.78 & 0.50 & 1.00 & 1.00 & 1.00 & 0.77 \\
\hline NONMigleading gr & 1.00 & 1.00 & 1.00 & 1.00 & 1.00 & 1.00 \\
\hline NON Lie factors & 1.00 & 1.00 & 1.00 & 1.00 & 1.00 & 1.00 \\
\hline NON Data ink & 1.00 & 1.00 & 1.00 & 1.00 & 1.00 & 1.00 \\
\hline NO Duck RATIO & 1.00 & 1.00 & 1.00 & 1.00 & 1.00 & 0.83 \\
\hline Reference Aids ts & 0.44 & 0.22 & 0.22 & 0.22 & 0.11 & 0.56 \\
\hline Glossary to 28 & 1.00 & 0.00 & 0.00 & 0.00 & 0.00 & 1.00 \\
\hline Index to 5 per p & 0.49 & 0.39 & 0.88 & 1.00 & 0.34 & 0.46 \\
\hline Typographic to 1 & 1.00 & 0.82 & 0.82 & 0.82 & 0.82 & 0.91 \\
\hline Text Category & 0.66 & 0.75 & 0.65 & 0.71 & 0.74 & 0.72 \\
\hline Graphics Category & 0.71 & 0.70 & 0.75 & 0.77 & 0.86 & 0.85 \\
\hline Referencability & 0.64 & 0.20 & 0.37 & 0.41 & 0.15 & 0.67 \\
\hline Sentence Level s & 0.84 & 0.88 & 0.81 & 0.88 & 0.89 & 0.88 \\
\hline Text & 0.78 & 0.82 & 0.74 & 0.82 & 0.84 & 0.85 \\
\hline Graphics & 1.00 & 1.00 & 1.00 & 1.00 & 1.00 & 0.94 \\
\hline Chapter Level Sc & 0.51 & 0.65 & 0.58 & 0.62 & 0.74 & 0.62 \\
\hline Document Level S & 0.63 & 0.44 & 0.51 & 0.53 & 0.44 & 0.73 \\
\hline Total Score & 0.68 & 0.67 & 0.65 & 0.69 & 0.70 & 0.76 \\
\hline 2 score & -0.16928 & -0.28246 & -0.51682 & -0.05645 & 0.034053 & 643682 \\
\hline
\end{tabular}


150

\begin{tabular}{|c|c|c|c|c|c|c|}
\hline & & & & & & \\
\hline Package & 25 & 26 & 27 & 28 & 29 & 30 \\
\hline & 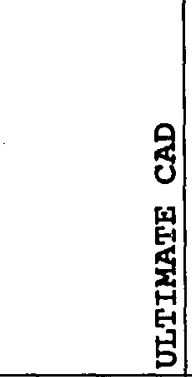 & 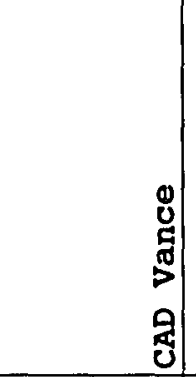 & 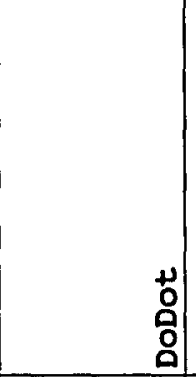 & $\begin{array}{l}3 \\
7 \\
1 \\
4 \\
0 \\
0 \\
0\end{array}$ & 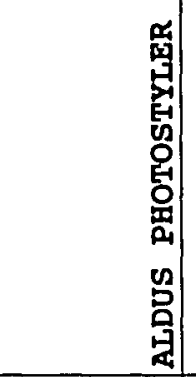 & 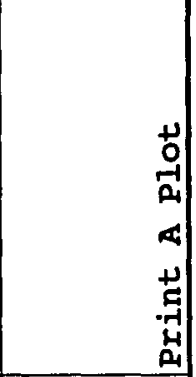 \\
\hline Category & 21 & 21 & 62 & 62 & 24 & 62 \\
\hline Price & 695 & 1995 & 189 & 195 & 795 & 295 \\
\hline Vendor & Automated & ISICAD & Halcyon & Columbia & Aldus & Insight \\
\hline PC (1) or MAC (2) & 1 & 1 & 1 & 1 & 1 & 1 \\
\hline DOS (1)or Window & 2 & 2 & 2 & 1 & 2 & $\overline{1}$ \\
\hline & & & & & & \\
\hline Version & 1.2 & 5 & 4 & 1 & 1.1 & 3.1 \\
\hline Year first introd. & 1988 & 1987 & 1992 & 1992 & 1992 & 1988 \\
\hline \begin{tabular}{|l|l|} 
Pages \\
\end{tabular} & 146 & 875 & 204 & 91 & 402 & 125 \\
\hline Chapters & 8 & 54 & 25 & 5 & 14 & 9 \\
\hline Scores & & & & & & \\
\hline Noun Strings & 0.99 & 0.99 & 0.93 & 0.99 & 0.97 & 0.98 \\
\hline chapter 1 & 0.98 & 0.97 & 0.88 & 0.99 & 0.98 & 0.95 \\
\hline chapter 2 & 1.00 & 1.00 & 0.98 & 1.00 & 0.96 & 1.00 \\
\hline Jargon & 1.00 & 1.00 & 1.00 & 1.00 & 1.00 & 1.00 \\
\hline chapter 1 & 1.00 & 1.00 & 1.00 & 1.00 & 1.00 & 1.00 \\
\hline chapter 2 & 1.00 & 1.00 & 1.00 & 1.00 & 1.00 & 0.99 \\
\hline Agency-user & 0.12 & 0.49 & 0.44 & 0.52 & 0.45 & 0.60 \\
\hline chapter 1 & 0.20 & 0.69 & 0.34 & 0.38 & 0.32 & 0.49 \\
\hline chapter 2 & 0.04 & 0.29 & 0.53 & 0.67 & 0.59 & 0.71 \\
\hline Agency - documen & 0.09 & 0.05 & 0.00 & 0.05 & 0.00 & 0.05 \\
\hline chapter 1 & 0.14 & 0.06 & 0.00 & 0.07 & 0.00 & 0.10 \\
\hline chapter 2 & 0.04 & 0.04 & 0.00 & 0.03 & 0.00 & 0.00 \\
\hline Agency- equipmen & 0.42 & 0.38 & 0.50 & 0.30 & 0.35 & 0.20 \\
\hline chapter 1 & 0.57 & 0.25 & 0.59 & 0.34 & 0.42 & 0.14 \\
\hline chapter 2 & 0.27 & 0.50 & 0.41 & 0.25 & 0.28 & 0.27 \\
\hline Agency - action & 0.02 & 0.00 & $0: 05$ & 0.00 & 0.13 & 0.03 \\
\hline chapter 1 & 0.00 & 0.00 & 0.03 & 0.00 & 0.18 & 0.02 \\
\hline \begin{tabular}{|l|} 
chapter 2 \\
\end{tabular} & 0.04 & 0.00 & 0.06 & 0.00 & 0.09 & 0.04 \\
\hline Total Agency sco & 0.65 & 0.92 & 0.98 & 0.87 & 0.94 & 0.88 \\
\hline Goals for action & 0.67 & 0.94 & 0.75 & 1.00 & 0.66 & 0.75 \\
\hline chapter 1 & 1.00 & 0.88 & 0.50 & 1.00 & 0.92 & 0.78 \\
\hline chapter 2 & 0.33 & 1.00 & 1.00 & 1.00 & 0.40 & 0.71 \\
\hline Logical conditiol & 0.05 & 0.06 & 0.22 & 0.42 & 0.11 & 0.33 \\
\hline chapter 1 & 0.02 & 0.08 & 0.14 & 0.59 & 0.19 & 0.24 \\
\hline chapter 2 & 0.08 & 0.04 & 0.29 & 0.25 & 0.03 & 0.43 \\
\hline Multiple Steps & 1.00 & 0.98 & 0.92 & 0.99 & 1.00 & 1.00 \\
\hline chapter 1 & 1.00 & 0.97 & 0.90 & 1.00 & 1.00 & 1.00 \\
\hline chapter 2 & 1.00 & 1.00 & 0.94 & 0.97 & 1.00 & 1.00 \\
\hline Unnecessary Refe & 0.97 & 1.00 & 1.00 & 1.00 & 1.00 & 1.00 \\
\hline chapter 1 & 0.98 & 1.00 & 1.00 & 1.00 & 1.00 & 1.00 \\
\hline chapter 2 & 0.96 & 1.00 & 1.00 & 1.00 & 1.00 & 1.00 \\
\hline Cohesion - parag & 1.00 & 0.86 & 0.45 & 1.00 & 0.98 & 0.98 \\
\hline
\end{tabular}


151

\begin{tabular}{|c|c|c|c|c|c|c|}
\hline & 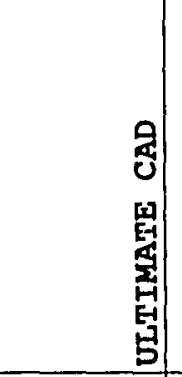 & 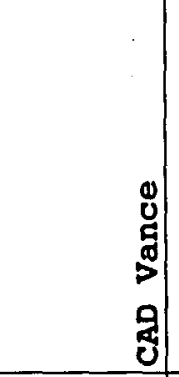 & $\begin{array}{r}\text { · } \\
\text { o } \\
\text { o } \\
\end{array}$ & $\begin{array}{l}3 \\
1 \\
\text { 岁 } \\
0\end{array}$ & 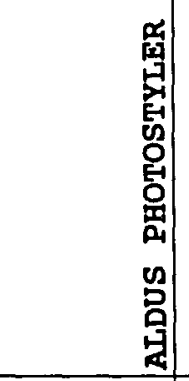 & 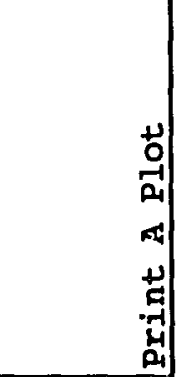 \\
\hline chapter 3 & 1.00 & 0.90 & 0.00 & 1.00 & 0.96 & 1.00 \\
\hline chapter 4 & 1.00 & 0.83 & 0.90 & 1.00 & 1.00 & 0.97 \\
\hline Cohesion - sectis & 1.00 & 0.57 & 1.00 & 1.00 & 1.00 & 1.00 \\
\hline chapter 3 & 1.00 & 0.14 & 1.00 & 1.00 & 1.00 & 1.00 \\
\hline chapter 4 & 1.00 & 1.00 & 1.00 & 1.00 & 1.00 & 1.00 \\
\hline Procedures - ove & 0.33 & 0.93 & 0.62 & 0.00 & 1.00 & 0.50 \\
\hline chapter 3 & 0.00 & 0.86 & 0.67 & 0.00 & 1.00 & 0.00 \\
\hline chapter 4 & 0.67 & 1.00 & 0.57 & 0.00 & 1.00 & 1.00 \\
\hline Procedures - uge: & 0.26 & 0.38 & 0.43 & 0.00 & 0.36 & 0.12 \\
\hline chapter 3 & 0.24 & 0.42 & 0.32 & 0.00 & 0.38 & 0.00 \\
\hline chapter 4 & 0.27 & 0.35 & 0.55 & 0.00 & 0.34 & 0.24 \\
\hline Procedural graph & 1.00 & 0.79 & 0.79 & 0.00 & 1.00 & 0.00 \\
\hline chapter 3 & 1.00 & 1.00 & 1.00 & 0.00 & 1.00 & 0.00 \\
\hline chapter 4 & 1.00 & 0.57 & 0.57 & 0.00 & 1.00 & 0.00 \\
\hline ist consistency & 1.00 & 0.75 & 0.75 & 0.50 & 1.00 & 1.00 \\
\hline chapter 3 & 0.00 & 0.25 & 0.00 & 0.00 & 0.00 & 0.00 \\
\hline chapter 4 & 0.00 & 0.00 & 0.25 & 0.50 & 0.00 & 0.00 \\
\hline Advance Organize & 0.24 & 0.25 & 0.41 & 0.00 & 0.10 & 0.38 \\
\hline chapter 3 & 0.20 & 0.50 & 0.25 & 0.00 & 0.16 & 0.00 \\
\hline chapter 4 & 0.27 & 0.00 & 0.57 & 0.00 & 0.04 & 0.75 \\
\hline Task Headings & 0.48 & 0.10 & 0.11 & 0.18 & 0.69 & 0.93 \\
\hline Informative capt & 0.00 & 0.00 & 0.00 & 0.67 & 0.08 & 1.00 \\
\hline NONIrrelevant gr & 0.98 & 0.92 & 0.94 & 1.00 & 0.90 & 0.68 \\
\hline NONMisleading gr & 1.00 & 1.00 & 1.00 & 1.00 & 1.00 & 1.00 \\
\hline NON Lie factors & 1.00 & 1.00 & 0.99 & 1.00 & 1.00 & 1.00 \\
\hline NON Data ink & 0.57 & 0.95 & 1.00 & 1.00 & 1.00 & 1.00 \\
\hline NO DuCk RATIO & 1.00 & 0.97 & 1.00 & 1.00 & 1.00 & 0.68 \\
\hline Reference Aids to & 0.22 & 0.44 & 0.33 & 0.22 & 0.44 & 0.67 \\
\hline Glossary to 28 & 0.00 & 0.00 & 0.00 & 0.00 & 0.75 & 0.00 \\
\hline Index to 5 per $p$ & 0.00 & 0.13 & 0.96 & 0.00 & 0.64 & 0.43 \\
\hline Typographic to 1 . & 0.73 & 0.91 & 0.82 & 0.82 & 1.00 & 0.82 \\
\hline Text Category & 0.69 & 0.70 & 0.68 & 0.64 & 0.77 & 0.77 \\
\hline Graphics Category & 0.79 & 0.80 & 0.82 & 0.81 & 0.85 & 0.77 \\
\hline Referencability & 0.07 & 0.19 & 0.43 & 0.07 & 0.61 & 0.36 \\
\hline Sentence Level S & 0.79 & 0.88 & 0.88 & 0.93 & 0.87 & 0.86 \\
\hline Text & 0.76 & 0.84 & 0.83 & 0.89 & 0.81 & 0.85 \\
\hline Graphics & 0.86 & 0.97 & 1.00 & 1.00 & 1.00 & 0.89 \\
\hline Chapter Level Sc & 0.69 & 0.65 & 0.64 & 0.36 & 0.78 & 0.57 \\
\hline Document Level s & 0.43 & 0.44 & 0.52 & 0.49 & 0.69 & 0.69 \\
\hline \begin{tabular}{|l|} 
Total Score \\
\end{tabular} & 0.65 & 0.67 & 0.70 & 0.63 & 0.78 & 0.72 \\
\hline Z score & -0.58905 & -0.27583 & -0.03869 & -0.79513 & 0.920604 & 0.268257 \\
\hline
\end{tabular}


152

\begin{tabular}{|c|c|c|c|c|c|c|}
\hline & & & & & & \\
\hline Package & 31 & 32 & 33 & 34 & 35 & 36 \\
\hline & 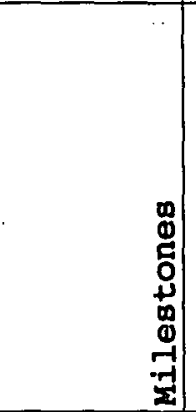 & 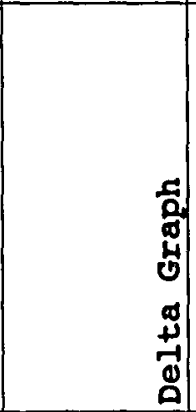 & 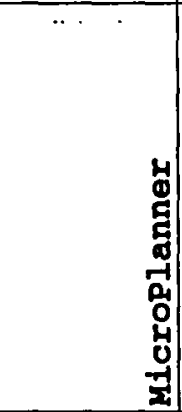 & $\begin{array}{l}\mathbf{y} \\
\mathbf{y} \\
\mathbf{x} \\
\mathbf{x} \\
\mathbf{x} \\
\mathbf{0} \\
\mathbf{H}\end{array}$ & $\begin{array}{l}0 \\
\mathbf{4} \\
\mathbf{3} \\
4 \\
0 \\
4 \\
0 \\
0 \\
4 \\
0 \\
0 \\
4 \\
4 \\
4 \\
0 \\
0 \\
0\end{array}$ & 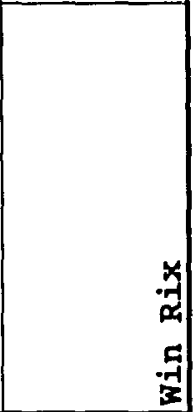 \\
\hline Category & 12 & 23 & 12 & 62 & 31 & 22 \\
\hline Price & 189 & 495 & 595 & 100 & 495 & 395 \\
\hline Vendor & \begin{tabular}{|l|l} 
Kidsa &
\end{tabular} & Delta Pt. & Microcon & Hoon & Borland & Computer \\
\hline PC (1) Or MAC (2) & 1 & 1 & 1 & 1 & 1 & \\
\hline DOS (1)or Window & 2 & 2 & 2 & 2 & 2 & 2 \\
\hline & & & & & & \\
\hline Version & 3.1 & 2.03 & 6.24 & 1 & 1 & 1.2 \\
\hline Year first introd & 1992 & 1992 & 1988 & 1992 & 1992 & 1991 \\
\hline \begin{tabular}{|l|} 
Pages \\
\end{tabular} & 145 & 460 & 228 & 148 & 447 & 170 \\
\hline Chapters & 15 & 16 & 7 & 5 & 16 & 6 \\
\hline Scores & & & & & & \\
\hline Noun Strings & 0.97 & 0.99 & 0.96 & 0.96 & 0.98 & 0.99 \\
\hline chapter 1 & 0.95 & 0.98 & 0.94 & 0.96 & 0.98 & 0.98 \\
\hline chapter 2 & 0.99 & 1.00 & 0.98 & 0.95 & 0.99 & 1.00 \\
\hline Jargon & 0.97 & 1.00 & 1.00 & 1.00 & 1.00 & 1.00 \\
\hline chapter 1 & 0.95 & 1.00 & 1.00 & 1.00 & 1.00 & 1.00 \\
\hline chapter 2 & 1.00 & 1.00 & 1.00 & 1.00 & 1.00 & 1.00 \\
\hline Agency-user & 0.43 & 0.44 & 0.60 & 0.30 & 0.43 & 0.15 \\
\hline chapter 1 & 0.38 & 0.40 & 0.69 & 0.36 & 0.27 & 0.27 \\
\hline chaptex 2 & 0.48 & 0.48 & 0.51 & 0.25 & 0.59 & 0.02 \\
\hline Agency - documen & 0.03 & 0.04 & 0.04 & 0.25 & 0.12 & 0.12 \\
\hline chapter 1 & 0.03 & 0.08 & 0.08 & 0.17 & 0.24 & 0.24 \\
\hline chaptex 2 & 0.03 & 0.00 & 0.00 & 0.33 & 0.00 & 0.00 \\
\hline Agency- equipmen & 0.34 & 0.32 & 0.24 & 0.33 & 0.27 & 0.45 \\
\hline chapter 1 & 0.30 & 0.35 & 0.22 & 0.36 & 0.29 & 0.29 \\
\hline chapter 2 & 0.38 & 0.29 & 0.26 & 0.31 & 0.24 & 0.61 \\
\hline Agency - action & 0.06 & 0.12 & 0.03 & 0.10 & 0.03 & 0.00 \\
\hline chapter 1 & 0.05 & 0.13 & 0.00 & 0.10 & 0.00 & 0.00 \\
\hline chapter 2 & 0.07 & 0.11 & 0.05 & 0.10 & 0.05 & 0.00 \\
\hline Total Agency sco & 0.86 & 0.92 & 0.91 & 0.99 & 0.84 & 0.72 \\
\hline Goals for action & 0.65 & 0.44 & 0.75 & 0.90 & 0.78 & 0.88 \\
\hline chapter 1 & 0.75 & 0.33 & 1.00 & 0.88 & 0.75 & 0.75 \\
\hline chapter 2 & 0.56 & 0.54 & 0.50 & 0.92 & 0.81 & 1.00 \\
\hline Logical conditiol & 0.20 & 0.22 & 0.20 & 0.16 & 0.15 & 0.11 \\
\hline chapter 1 & 0.19 & 0.18 & 0.14 & 0.26 & 0.14 & 0.14 \\
\hline chapter 2 & 0.21 & 0.26 & 0.26 & 0.06 & 0.16 & 0.09 \\
\hline Multiple Steps & 0.89 & 1.00 & 1.00 & 1.00 & 0.93 & 1.00 \\
\hline chapter 1 & 0.79 & 1.00 & 1.00 & 1.00 & 0.86 & 1.00 \\
\hline chapter 2 & 1.00 & 1.00 & 1.00 & 1.00 & 1.00 & 1.00 \\
\hline Unnecessary Refe: & 1.00 & 0.98 & 1.00 & 0.86 & 0.99 & 1.00 \\
\hline chapter 1 & 1.00 & 0.95 & 1.00 & 0.71 & 1.00 & 1.00 \\
\hline chapter 2 & 1.00 & 1.00 & 1.00 & 1.00 & 0.98 & 1.00 \\
\hline Cohesion - parag & 1.00 & 0.84 & 0.99 & 1.00 & 0.99 & 1.00 \\
\hline
\end{tabular}


153

\begin{tabular}{|c|c|c|c|c|c|c|}
\hline & 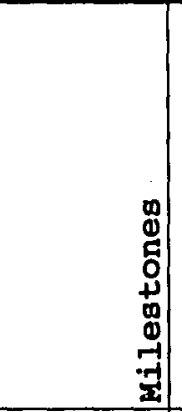 & 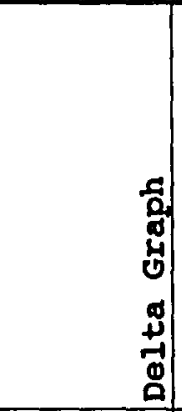 & 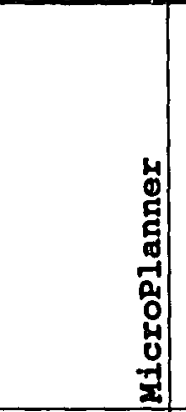 & 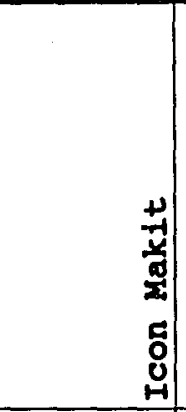 & 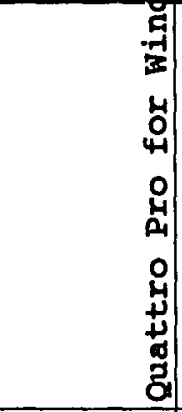 & $\begin{array}{r}7 \\
.7 \\
7 \\
7\end{array}$ \\
\hline chapter 3 & 1.00 & 0.79 & 0.99 & 1.00 & 0.98 & 1.00 \\
\hline chapter 4 & 1.00 & 0.90 & 0.99 & 1.00 & 1.00 & 1.00 \\
\hline Cohesion - sectid & 1.00 & 1.00 & 1.00 & 1.00 & 1.00 & 1.00 \\
\hline chapter 3 & 1.00 & 1.00 & 1.00 & 1.00 & 1.00 & 1.00 \\
\hline chapter 4 & 1.00 & 1.00 & 1.00 & 1.00 & 1.00 & 1.00 \\
\hline Procedures - ove & 0.45 & 0.83 & 0.59 & 0.39 & 1.00 & 0.37 \\
\hline chapter 3 & 0.43 & 1.00 & 0.56 & 0.63 & 1.00 & 0.15 \\
\hline chapter 4 & 0.48 & 0.67 & 0.63 & 0.15 & 1.00 & 0.58 \\
\hline Procedures - use & 0.53 & 0.40 & 0.47 & 0.19 & 0.42 & 0.06 \\
\hline chapter 3 & 0.70 & 0.35 & 0.53 & 0.33 & 0.40 & 0.00 \\
\hline chapter 4 & 0.36 & 0.44 & 0.40 & 0.06 & 0.43 & 0.12 \\
\hline Procedural graph & 0.50 & 0.67 & 1.00 & 0.52 & 0.75 & 0.96 \\
\hline chapter 3 & 0.00 & 1.00 & 1.00 & 1.00 & 0.75 & 0.92 \\
\hline chapter 4 & 1.00 & 0.33 & 1.00 & 0.04 & 0.75 & 1.00 \\
\hline List consistency & 1.00 & 1.00 & 1.00 & 1.00 & 1.00 & 1.00 \\
\hline chapter 3 & 0.00 & 0.00 & 0.00 & 0.00 & 0.00 & 0.00 \\
\hline chapter 4 & 0.00 & 0.00 & 0.00 & 0.00 & 0.00 & 0.00 \\
\hline Advance Organize & 0.00 & 0.16 & 0.06 & 0.06 & 0.11 & 0.00 \\
\hline chapter 3 & 0.00 & 0.24 & 0.08 & 0.10 & 0.12 & 0.00 \\
\hline chapter 4 & 0.00 & 0.07 & 0.04 & 0.02 & 0.11 & 0.00 \\
\hline Task Headings & 0.41 & 0.71 & 0.18 & 0.42 & 0.56 & 0.25 \\
\hline Informative capt & 0.00 & 0.32 & 0.00 & 0.19 & 0.57 & 0.01 \\
\hline NONIrrelevant gr & 0.00 & 1.00 & 0.95 & 1.00 & 0.90 & 0.90 \\
\hline NONMisleading gri & 1.00 & 1.00 & 1.00 & 1.00 & 1.00 & 0.54 \\
\hline NON Lie factors & 1.00 & 1.00 & 1.00 & 1.00 & 1.00 & 0.54 \\
\hline NON Data ink & 1.00 & 1.00 & 1.00 & 1.00 & 1.00 & 1.00 \\
\hline NO DuCK RATIO & 1.00 & 1.00 & 0.91 & 0.93 & 1.00 & 0.96 \\
\hline Reference Aids th & 0.22 & 0.33 & 0.33 & 0.33 & 0.78 & 0.33 \\
\hline Glossary to 28 & 0.00 & 0.00 & 1.00 & 0.00 & 1.00 & 0.00 \\
\hline Index to 5 per $p$ & 0.38 & 0.77 & 0.68 & 0.70 & 1.00 & 0.35 \\
\hline Typographic to 1 & 0.82 & 1.00 & 0.91 & 0.82 & 0.82 & 0.91 \\
\hline Text Category & 0.71 & 0.75 & 0.72 & 0.71 & 0.77 & 0.67 \\
\hline Graphics Category & 0.64 & 0.86 & 0.84 & 0.81 & 0.89 & 0.70 \\
\hline Referencability & 0.20 & 0.37 & 0.67 & 0.34 & 0.93 & 0.23 \\
\hline Sentence Level S & 0.86 & 0.85 & 0.87 & 0.88 & 0.87 & 0.82 \\
\hline Text & 0.79 & 0.79 & 0.83 & 0.84 & 0.81 & 0.81 \\
\hline Graphice & 1.00 & 1.00 & 0.97 & 0.98 & 1.00 & 0.83 \\
\hline Chapter Level Scd & 0.64 & 0.70 & 0.73 & 0.59 & 0.75 & 0.63 \\
\hline Document Level so & 0.35 & 0.64 & 0.63 & 0.56 & 0.83 & 0.41 \\
\hline Total Score & 0.63 & 0.74 & 0.76 & 0.70 & 0.82 & 0.63 \\
\hline z score & -0.70465 & 0.467847 & 0.603903 & -0.03388 & 1.334351 & -0.6999 \\
\hline
\end{tabular}


154

\begin{tabular}{|c|c|c|c|c|c|c|}
\hline & & & & & & \\
\hline Pack.age & 37 & 38 & 39 & 40 & 41 & 42 \\
\hline & 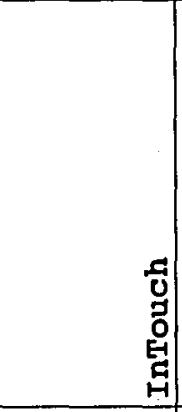 & 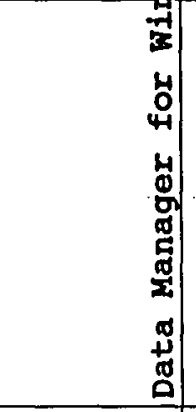 & 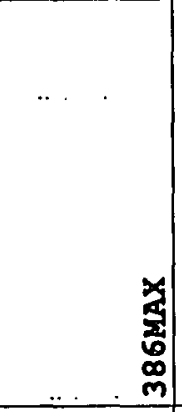 & 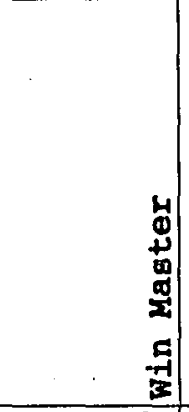 & $\begin{array}{l}5 \\
0 \\
0 \\
0 \\
5 \\
5 \\
0 \\
5 \\
5 \\
0 \\
5 \\
0 \\
0 \\
0 \\
0\end{array}$ & $\begin{array}{l}\text {. } \\
\text { ⿹े口 } \\
\text { : }\end{array}$ \\
\hline Category & 13 & 41 & 62 & 62 & 32 & 11 \\
\hline Price & 100 & 100 & 100 & 130 & 395 & 100 \\
\hline \begin{tabular}{l|l} 
Vendor & \\
\end{tabular} & Advance & Timeworka & 2uanitas & PCKWIK & ADA DeC & Peachtree \\
\hline PC (1) or MAC (2) & 2 & 1 & 1 & 1 & 1 & \\
\hline DOS (1)or Window & 0 & 2 & 2 & 2 & 2 & 2 \\
\hline & & & & & & \\
\hline Version & 2 & & 6 & 1.5 & 3. & 5 \\
\hline Year first intro & 1990 & 1992 & 1987 & 1992 & 1992 & 1992 \\
\hline \begin{tabular}{|l|l|} 
Pages & \\
\end{tabular} & 69 & 189 & 40 & 150 & 255 & 307 \\
\hline Chapters & 11 & 12 & 4 & 7 & 8 & 10 \\
\hline Scores & & & & & & \\
\hline Noun Strings & 0.98 & 0.95 & 0.99 & 0.97 & 0.97 & 0.98 \\
\hline chapter 1 & 0.97 & 0.97 & 0.99 & 0.98 & 0.96 & 1.00 \\
\hline chapter 2 & 0.99 & 0.93 & 0.99 & 0.97 & 0.99 & 0.96 \\
\hline Jargon & 1.00 & 1.00 & 1.00 & 1.00 & 1.00 & 1.00 \\
\hline chapter 1 & 1.00 & 1.00 & 1.00 & 1.00 & 1.00 & 1.00 \\
\hline chapter 2 & 1.00 & 1.00 & 1.00 & 1.00 & 0.99 & 1.00 \\
\hline Agency-user & 0.43 & 0.47 & 0.28 & 0.30 & 0.41 & 0.22 \\
\hline chapter 1 & 0.48 & 0.47 & 0.23 & 0.32 & 0.43 & 0.43 \\
\hline chapter 2 & 0.38 & 0.48 & 0.34 & 0.29 & 0.39 & 0.00 \\
\hline Agency - documen & 0.13 & 0.00 & 0.06 & 0.14 & 0.00 & 0.01 \\
\hline chapter 1 & 0.24 & 0.00 & 0.11 & 0.28 & 0.00 & 0.02 \\
\hline chapter 2 & 0.02 & 0.00 & 0.01 & 0.00 & 0.00 & 0.00 \\
\hline Agency- equipmen & 0.22 & 0.38 & 0.46 & 0.45 & 0.41 & 0.63 \\
\hline chapter 1 & 0.00 & 0.41 & 0.45 & 0.25 & 0.35 & 0.38 \\
\hline chapter 2 & 0.44 & 0.34 & 0.47 & 0.65 & 0.46 & 0.89 \\
\hline Agency - action & 0.10 & 0.04 & 0.04 & 0.00 & 0.00 & 0.04 \\
\hline chapter 1 & 0.10 & 0.04 & 0.00 & 0.00 & 0.00 & $0 . \overline{03}$ \\
\hline chapter 2 & 0.09 & 0.05 & 0.07 & 0.00 & 0.00 & 0.04 \\
\hline Total Agency sco & 0.88 & 0.89 & 0.84 & 0.89 & 0.82 & 0.89 \\
\hline Goals for action & 0.64 & 0.73 & 0.75 & 1.00 & 1.00 & 1.00 \\
\hline chapter 1 & 0.67 & 0.80 & 1.00 & 1.00 & 1.00 & 1.00 \\
\hline chapter 2 & 0.62 & 0.67 & 0.50 & 1.00 & 1.00 & 1.00 \\
\hline Logical conditiol & 0.31 & 0.21 & 0.09 & 0.16 & 0.31 & 0.29 \\
\hline chapter 1 & 0.48 & 0.25 & 0.07 & 0.12 & 0.17 & 0.16 \\
\hline chapter 2 & 0.15 & 0.16 & 0.11 & 0.19 & 0.44 & $0 . \overline{43}$ \\
\hline Multiple steps & 0.95 & 0.98 & 1.00 & 1.00 & 1.00 & 1.00 \\
\hline chapter 1 & 0.93 & 1.00 & 1.00 & 1.00 & 1.00 & 1.00 \\
\hline chapter 2 & 0.96 & 0.95 & 1.00 & 1.00 & 1.00 & 1.00 \\
\hline Unnecessary Refe: & 0.99 & 1.00 & 0.99 & 1.00 & 1.00 & 1.00 \\
\hline chapter 1 & 1.00 & 1.00 & 1.00 & 1.00 & 1.00 & 1.00 \\
\hline chapter 2 & 0.98 & 1.00 & 0.97 & 1.00 & 1.00 & 1.00 \\
\hline Cohesion - parag & 1.00 & 1.00 & 1.00 & 0.94 & 1.00 & 0.94 \\
\hline
\end{tabular}


155

\begin{tabular}{|c|c|c|c|c|c|c|}
\hline & 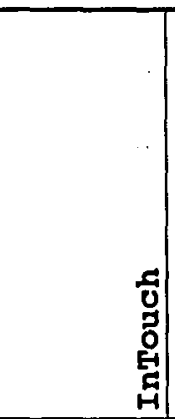 & 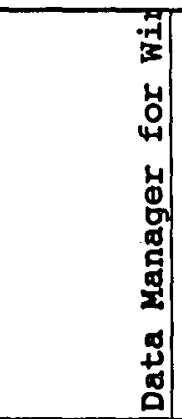 & 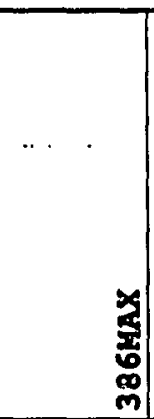 & $\begin{array}{l}4 \\
0 \\
+ \\
0 \\
\mathbf{g} \\
\mathbf{2} \\
\mathbf{z}\end{array}$ & 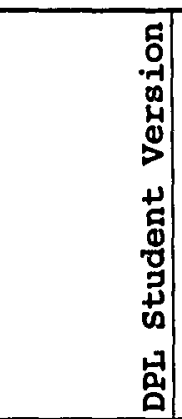 & 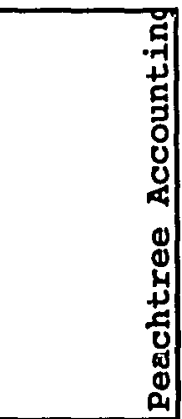 \\
\hline chapter 3 & 1.00 & 1.00 & 1.00 & 0.89 & 1.00 & 1.00 \\
\hline chapter 4 & 1.00 & 1.00 & 1.00 & 1.00 & 1.00 & 0.88 \\
\hline Cohesion - sectil & 1.00 & 1.00 & 1.00 & 0.50 & 1.00 & 1.00 \\
\hline chapter 3 & 1.00 & 1.00 & 1.00 & 1.00 & 1.00 & 1.00 \\
\hline chapter 4 & 1.00 & 1.00 & 1.00 & 0.00 & 1.00 & 1.00 \\
\hline Procedures - ove & 0.00 & 1.00 & 1.00 & 0.50 & 0.00 & 0.08 \\
\hline chapter 3 & 0.00 & 1.00 & 1.00 & 0.00 & 0.00 & 0.00 \\
\hline chapter 4 & 0.00 & 1.00 & 1.00 & 1.00 & 0.00 & 0.17 \\
\hline Procedures - use & 0.25 & 0.21 & 0.31 & 0.11 & 0.25 & 0.62 \\
\hline chapter 3 & 0.16 & 0.25 & 0.38 & 0.00 & 0.00 & 0.54 \\
\hline chapter 4 & 0.33 & 0.18 & 0.25 & 0.22 & 0.50 & 0.70 \\
\hline Procedural graph & 1.00 & 1.00 & 0.50 & 0.00 & 1.00 & 0.50 \\
\hline chapter 3 & 1.00 & 1.00 & 1.00 & 0.00 & 1.00 & 0.00 \\
\hline chapter 4 & 1.00 & 1.00 & 0.00 & 0.00 & 1.00 & 1.00 \\
\hline List consistency & 1.00 & 0.50 & 1.00 & 1.00 & 1.00 & 1.00 \\
\hline chapter 3 & 0.00 & 0.00 & 0.00 & 0.00 & 0.00 & 0.00 \\
\hline chapter 4 & 0.00 & 0.50 & 0.00 & 0.00 & 0.00 & 0.00 \\
\hline Advance Organize & 0.00 & 0.03 & 0.03 & 0.00 & 0.05 & 0.00 \\
\hline chapter 3 & 0.00 & 0.06 & 0.06 & 0.00 & 0.07 & 0.00 \\
\hline chapter 4 & 0.00 & 0.00 & 0.00 & 0.00 & 0.04 & 0.00 \\
\hline Task Headings & 0.38 & 0.55 & 0.06 & 0.27 & 0.33 & 0.11 \\
\hline Informative capt & 0.00 & 0.00 & 0.00 & 0.00 & 0.50 & 0.00 \\
\hline NONIrrelevant gr & 1.00 & 1.00 & 1.00 & 0.96 & 0.95 & 0.33 \\
\hline NONMisleading gr & 1.00 & 1.00 & 1.00 & 1.00 & 0.98 & 0.97 \\
\hline NON Lie factors & 1.00 & 1.00 & 1.00 & 1.00 & 1.00 & 1.00 \\
\hline NON Data ink & 1.00 & 1.00 & 1.00 & 1.00 & 1.00 & 1.00 \\
\hline NO Duck RATIO & 1.00 & -1.59 & 0.86 & 1.00 & 0.50 & 0.67 \\
\hline Reference Aids t & 0.22 & 0.33 & 0.33 & 0.44 & 0.44 & 0.44 \\
\hline Glosiary to 28 & 0.00 & 0.00 & 0.00 & 1.00 & 0.00 & $0 . \overline{65}$ \\
\hline Index to 5 per p & 0.70 & 0.86 & 0.57 & 0.52 & 0.92 & 0.30 \\
\hline Typographic to 1 & 0.82 & 0.91 & 1.00 & 1.00 & 0.91 & 1.00 \\
\hline Text Category & 0.67 & 0.72 & 0.72 & 0.67 & 0.69 & 0.71 \\
\hline Graphics Category & 0.86 & 0.49 & 0.77 & 0.71 & 0.85 & 0.64 \\
\hline Referencability & 0.31 & 0.40 & 0.30 & 0.66 & 0.46 & 0.47 \\
\hline Sentence Level S & 0.87 & 0.62 & 0.85 & 0.90 & 0.86 & 0.88 \\
\hline \begin{tabular}{|l|l|} 
Text \\
\end{tabular} & 0.82 & 0.82 & 0.81 & 0.86 & 0.87 & 0.88 \\
\hline Graphics & 1.00 & 0.14 & 0.95 & 1.00 & 0.83 & 0.89 \\
\hline Chapter Level Scd & 0.61 & 0.68 & 0.69 & 0.44 & 0.61 & 0.59 \\
\hline Document Level S & 0.51 & 0.58 & 0.50 & 0.65 & 0.63 & 0.48 \\
\hline Total score & 0.68 & 0.62 & 0.69 & 0.69 & 0.72 & 0.67 \\
\hline z score & -0.16487 & -0.83041 & -0.0719 & -0.09634 & 0.188497 & -0.30793 \\
\hline
\end{tabular}


156

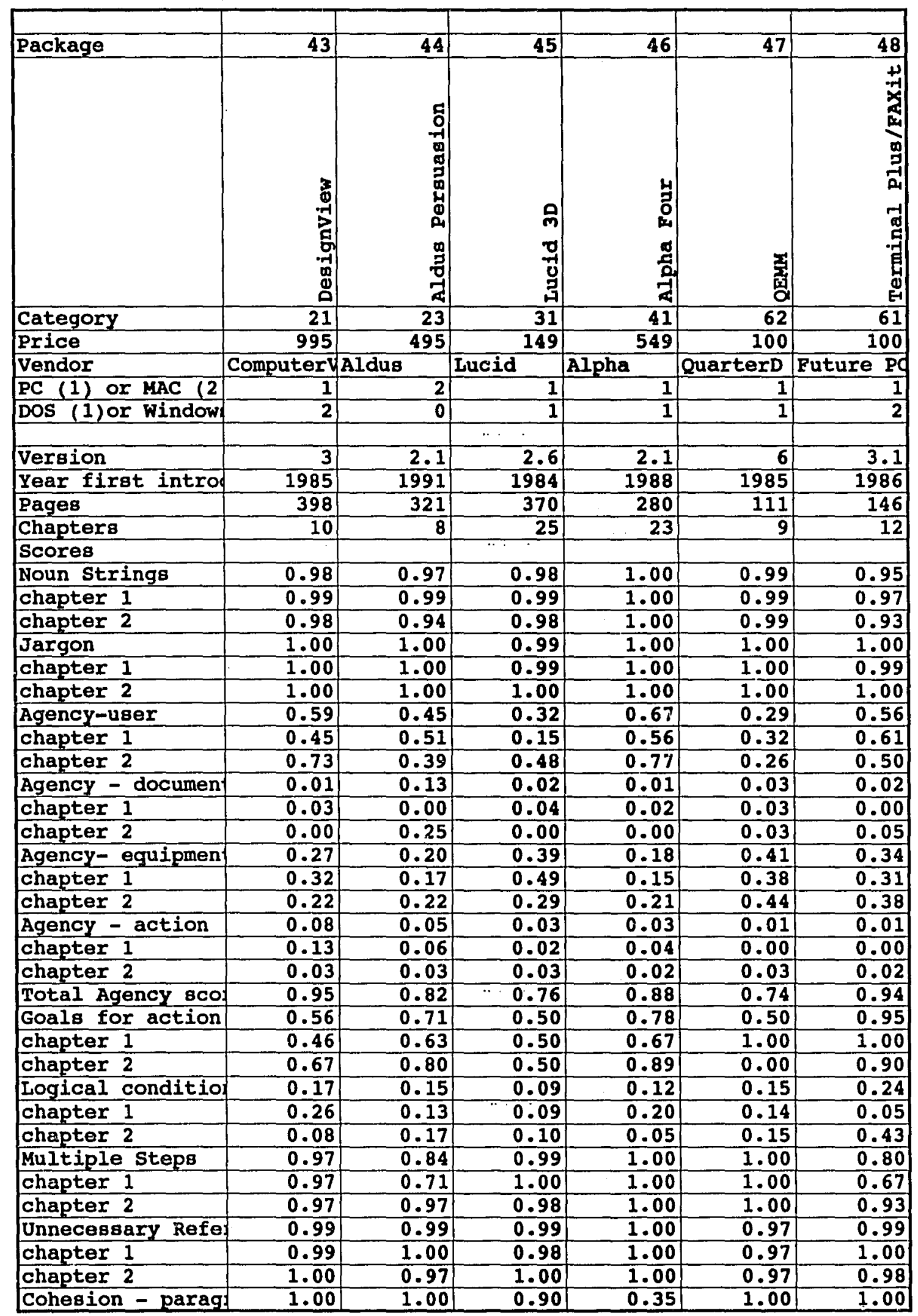




\begin{tabular}{|c|c|c|c|c|c|c|}
\hline & $\begin{array}{r}3 \\
\vdots \\
\vdots \\
\vdots \\
-1 \\
0 \\
0 \\
0\end{array}$ & 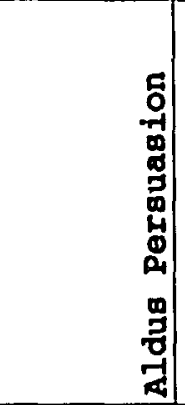 & 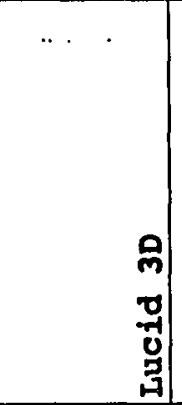 & $\begin{array}{l}4 \\
0 \\
0 \\
0 \\
0 \\
0 \\
0 \\
0 \\
0\end{array}$ & 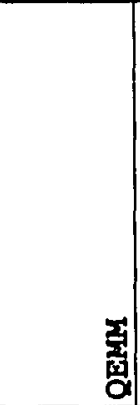 & 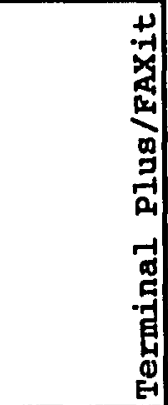 \\
\hline chapter 3 & 1.00 & 1.00 & 0.90 & 0.94 & 1.00 & 1.00 \\
\hline chapter 4 & 1.00 & 1.00 & 0.90 & -0.25 & 0.99 & 1.00 \\
\hline Cohesion - sectio & 1.00 & 1.00 & 0.97 & 1.00 & 1.00 & 1.00 \\
\hline chapter 3 & 1.00 & 1.00 & $\because 0.94$ & 1.00 & 1.00 & 1.00 \\
\hline chapter 4 & 1.00 & 1.00 & 1.00 & 1.00 & 1.00 & 1.00 \\
\hline Procedures - ove: & 0.93 & 1.00 & 0.17 & 0.54 & 0.42 & 0.50 \\
\hline chapter 3 & 0.88 & 1.00 & 0.33 & 0.75 & 0.33 & 1.00 \\
\hline chapter 4 & 0.97 & 1.00 & 0.00 & 0.33 & 0.50 & 0.00 \\
\hline Procedures - use & 0.46 & 0.46 & 0.58 & 0.31 & 0.37 & 0.19 \\
\hline chapter 3 & 0.42 & 0.44 & 0.52 & 0.35 & 0.29 & 0.38 \\
\hline chapter 4 & 0.51 & 0.49 & 0.64 & 0.28 & 0.44 & 0.00 \\
\hline Procedural graph & 0.69 & 0.67 & 0.58 & 0.58 & 0.00 & 0.50 \\
\hline chapter 3 & 1.00 & 0.50 & 0.33 & 0.50 & 0.00 & 1.00 \\
\hline chapter 4 & 0.37 & 0.83 & 0.83 & 0.67 & 0.00 & 0.00 \\
\hline List consistency & 1.00 & 1.00 & $1: 00$ & 1.00 & 1.00 & 0.67 \\
\hline chapter 3 & 0.00 & 0.00 & 0.00 & 0.00 & 0.00 & 0.33 \\
\hline chapter 4 & 0.00 & 0.00 & 0.00 & 0.00 & 0.00 & 0.00 \\
\hline Advance Organize & 0.47 & 0.03 & 0.00 & 0.15 & 0.06 & 0.02 \\
\hline chapter 3 & 0.84 & 0.06 & 0.00 & 0.14 & 0.13 & 0.04 \\
\hline chapter 4 & 0.11 & 0.00 & 0.00 & 0.17 & 0.00 & 0.00 \\
\hline Task Headings & 0.43 & 0.94 & 0.48 & 0.47 & 0.25 & 0.32 \\
\hline Informative capt & 0.00 & 0.44 & 0.01 & 1.00 & 0.00 & 0.60 \\
\hline NONIrrelevant gr & 0.90 & 1.00 & 0.90 & 1.00 & 1.00 & 1.00 \\
\hline NONMIBleading gr & 1.00 & 1.00 & 1.00 & 1.00 & 1.00 & 1.00 \\
\hline NON Iie factors & 1.00 & 1.00 & 1.00 & 1.00 & 1.00 & 0.00 \\
\hline NON Data ink & 1.00 & 1.00 & 1.00 & 1.00 & 1.00 & 1.00 \\
\hline NO Duck RATIO & 0.99 & 0.96 & 1.00 & 0.72 & 0.50 & 0.77 \\
\hline Reference Aids $t$ & 0.56 & 0.67 & $0: 33$ & 0.44 & 0.22 & 0.44 \\
\hline Glogsary to 28 & 0.00 & 1.00 & 0.00 & 0.00 & 0.00 & 0.00 \\
\hline Index to 5 per $p$ & 0.30 & 1.00 & 0.23 & 0.00 & 0.93 & 0.26 \\
\hline Typographic to 1 & 0.91 & 1.00 & 0.82 & 1.00 & 0.82 & 0.82 \\
\hline Text Categony & 0.78 & 0.78 & 0.67 & 0.69 & 0.67 & 0.68 \\
\hline Graphias Category & 0.80 & 0.87 & 0.78 & 0.90 & 0.64 & 0.70 \\
\hline Referencability & 0.29 & 0.89 & 0.19 & 0.15 & 0.38 & 0.23 \\
\hline Sentence Level S & 0.86 & 0.84 & 0.83 & 0.85 & 0.79 & 0.76 \\
\hline Text & 0.80 & 0.78 & 0.76 & 0.83 & 0.76 & 0.84 \\
\hline Graphics & 1.00 & 0.99 & 1.00 & 0.91 & 0.83 & 0.59 \\
\hline Chapter Leve1 Sc & 0.79 & 0.74 & 0.60 & 0.56 & 0.55 & 0.55 \\
\hline Document Level s & 0.51 & 0.88 & 0.47 & 0.61 & 0.53 & 0.55 \\
\hline Total score & 0.73 & 0.83 & 0.65 & 0.69 & 0.64 & 0.64 \\
\hline 2 score & 0.333711 & 1.354802 & -0.52391 & -0.06129 & -0.683 & 0.6712 \\
\hline
\end{tabular}


158

\begin{tabular}{|c|c|c|c|c|c|c|}
\hline & & & & & & \\
\hline Package & 49 & 50 & 5.1 & 52 & 53 & 54 \\
\hline & 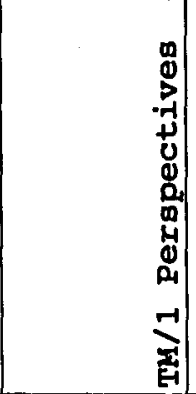 & 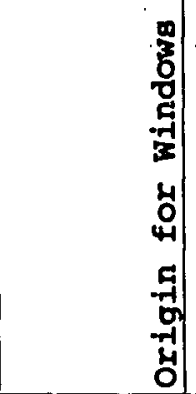 & 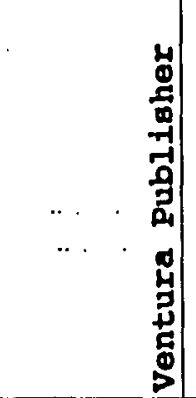 & 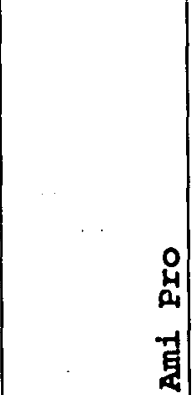 & 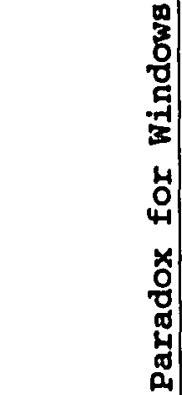 & 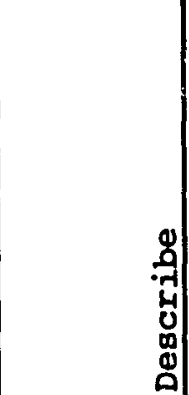 \\
\hline Category & 32 & 33 & 52 & 51 & 41 & 51 \\
\hline Price & 495 & 545 & 795 & 495 & 795 & 495 \\
\hline Vendor & Sniper & Microcal & Ventura & Lotus & Bor land & Describe \\
\hline PC (1) or MAC (2) & $+2-e^{2}$ & 1 & 1 & 1 & 1 & 1 \\
\hline DOS (1)or Windowt & $\frac{2}{2}$ & 2 & $\overline{2}$ & 2 & 2 & 4 \\
\hline & & & & & & \\
\hline Version & 1 & 2.8 & 4.1 & 3 & 1 & 1 \\
\hline Year first intro & 1993 & 1992 & 1986 & 1989 & 1993 & 1992 \\
\hline Pages & 196 & 238 & 244 & 621 & 641 & 243 \\
\hline Chapters & 18 & 22 & 11 & 32 & 15 & 11 \\
\hline Scores & & & & & & \\
\hline Noun Stringg & 0.99 & 0.94 & 0.95 & 1.00 & 0.96 & 1.00 \\
\hline chapter 1 & 0.99 & 0.97 & 0.95 & 1.00 & 0.98 & 1.00 \\
\hline chapter 2 & 0.99 & 0.92 & 0.96 & 1.00 & 0.95 & 0.99 \\
\hline Jargon & 1.00 & 1.00 & 1.00 & 1.00 & 1.00 & 1.00 \\
\hline chapter 1 & 1.00 & 1.00 & 1.00 & 1.00 & 1.00 & 1.00 \\
\hline chapter 2 & 0.99 & 1.00 & 1.00 & 1.00 & 0.99 & 1.00 \\
\hline Agency-user & 0.19 & 0.41 & 0.47 & 0.60 & 0.56 & 0.52 \\
\hline chapter 1 & 0.16 & 0.35 & 0.34 & 0.65 & 0.56 & 0.51 \\
\hline chapter 2 & 0.23 & 0.47 & 0.59 & 0.55 & 0.56 & 0.54 \\
\hline Agency - doctumen & 0.00 & 0.03 & 0.02 & 0.03 & 0.09 & 0.02 \\
\hline chapter 1 & 0.00 & 0.04 & 0.02 & 0.07 & 0.15 & 0.03 \\
\hline chapter 2 & 0.00 & 0.03 & 0.02 & 0.00 & 0.04 & 0.00 \\
\hline Agency- equipmen & 0.59 & 0.40 & 0.36 & 0.18 & 0.27 & 0.34 \\
\hline chapter 1 & 0.66 & 0.42 & 0.43 & 0.20 & 0.19 & 0.37 \\
\hline chapter 2 & 0.51 & 0.39 & 0.29 & 0.17 & 0.35 & 0.32 \\
\hline Agency - action & 0.15 & 0.00 & 0.02 & 0.01 & 0.05 & 0.00 \\
\hline chapter 1 & 0.09 & 0.00 & 0.03 & 0.02 & 0.08 & 0.00 \\
\hline chapter 2 & 0.20 & 0.00 & 0.00 & 0.00 & 0.02 & 0.00 \\
\hline Total Agency sco & 0.92 & 0.84 & 0.86 & 0.83 & 0.97 & 0.88 \\
\hline Goals for action & 0.43 & 1.00 & 0.88 & 0.38 & 0.55 & 1.00 \\
\hline chapter 1 & 0.40 & 1.00 & 0.75 & 0.75 & 0.60 & 1.00 \\
\hline chapter 2 & 0.46 & 1.00 & 1.00 & 0.00 & 0.50 & 1.00 \\
\hline Logical conditiol & 0.12 & 0.07 & 0.05 & 0.10 & 0.26 & 0.05 \\
\hline chapter 1 & 0.09 & 0.09 & 0.07 & 0.08 & 0.25 & 0.02 \\
\hline chapter 2 & 0.14 & 0.06 & 0.04 & 0.11 & 0.27 & 0.08 \\
\hline Multiple steps & 1.00 & 0.95 & 0.98 & 1.00 & 0.96 & 0.98 \\
\hline chapter 1 & 1.00 & 0.89 & 0.95 & 1.00 & 0.96 & 0.97 \\
\hline chapter 2 & 1.00 & 1.00 & 1.00 & 1.00 & 0.96 & 1.00 \\
\hline Unnecessary Refe & 1.00 & 1.00 & 1.00 & 1.00 & 0.96 & 1.00 \\
\hline chapter 1 & 1.00 & 1.00 & 1.00 & 1.00 & 0.96 & 1.00 \\
\hline chapter 2 & 1.00 & 1.00 & 1.00 & 1.00 & 0.96 & 1.00 \\
\hline Cohesion - parag & 0.46 & 1.00 & 0.91 & 1.00 & 0.99 & 1.00 \\
\hline
\end{tabular}


159

\begin{tabular}{|c|c|c|c|c|c|c|}
\hline & 㗊 & 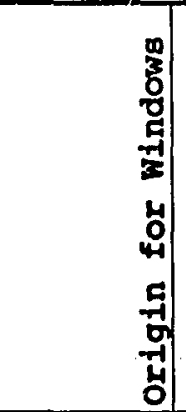 & 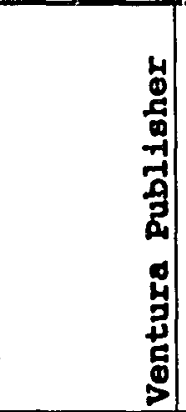 & 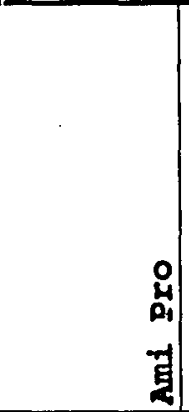 & 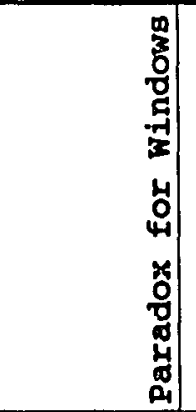 & 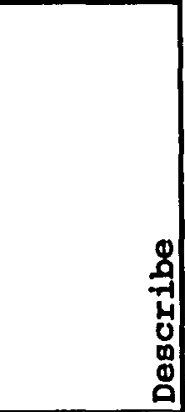 \\
\hline chapter 3 & 0.93 & 1.00 & 0.91 & 1.00 & 0.98 & 1.00 \\
\hline chapter 4 & 0.00 & 1.00 & 0.91 & 1.00 & 1.00 & 1.00 \\
\hline Cohesion - sectid & 0.50 & 1.00 & 1.00 & 1.00 & 1.00 & 1.00 \\
\hline chapter 3 & 1.00 & 1.00 & 1.00 & 1.00 & 1.00 & 1.00 \\
\hline chapter 4 & 0.00 & 1.00 & 1.00 & 1.00 & 1.00 & 1.00 \\
\hline Procedures - ove & 0.30 & 0.89 & 0.83 & 0.97 & 0.83 & 0.54 \\
\hline chapter 3 & 0.60 & 1.00 & 0.82 & 1.00 & 1.00 & 0.09 \\
\hline chapter 4 & 0.00 & 0.79 & 0.83 & 0.94 & 0.67 & 1.00 \\
\hline Procedures - use & 0.28 & 0.35 & 0.44 & 0.46 & 0.26 & 0.46 \\
\hline chapter 3 & 0.56 & 0.38 & 0.36 & 0.39 & 0.08 & 0.45 \\
\hline chapter 4 & 0.00 & 0.32 & 0.51 & 0.54 & 0.43 & 0.46 \\
\hline Procedural graph & 0.25 & 0.62 & 0.86 & 0.54 & 0.83 & 0.08 \\
\hline chapter 3 & 0.50 & 0.60 & 0.88 & 0.56 & 0.67 & 0.04 \\
\hline chapter 4 & 0.00 & 0.64 & $0: 83$ & 0.52 & 1.00 & 0.11 \\
\hline List consistency & 1.00 & 1.00 & 1.00 & 1.00 & 1.00 & 1.00 \\
\hline chapter 3 & 0.00 & 0.00 & 0.00 & 0.00 & 0.00 & 0.00 \\
\hline chapter 4 & 0.00 & 0.00 & 0.00 & 0.00 & 0.00 & 0.00 \\
\hline Advance Organize & 0.38 & 0.52 & 0.21 & 0.00 & 0.05 & 0.06 \\
\hline \begin{tabular}{|l|} 
chapter 3 \\
\end{tabular} & 0.67 & 0.33 & 0.08 & 0.00 & 0.07 & 0.05 \\
\hline chapter 4 & 0.10 & 0.71 & 0.33 & 0.00 & 0.02 & 0.07 \\
\hline Task Headings & 0.41 & 0.60 & 0.66 & 0.94 & 0.61 & 0.04 \\
\hline Informative capt & 0.00 & 0.00 & 0.00 & 0.00 & 0.72 & 0.00 \\
\hline NONIrrelevant gr: & 0.91 & 0.90 & 1.00 & 0.65 & 0.90 & 1.00 \\
\hline NONMisleading gr & 0.91 & 1.00 & 1.00 & 1.00 & 1.00 & 1.00 \\
\hline NON Lie factors & 1.00 & 1.00 & 0.99 & 1.00 & 1.00 & 1.00 \\
\hline NON Data ink & 1.00 & 0.90 & 0.90 & 0.09 & 1.00 & 1.00 \\
\hline NO Duck RATIO & 1.00 & 1.00 & 0.98 & 0.14 & 1.00 & 1.00 \\
\hline Reference Alds t & 0.44 & 0.56 & 0.44 & 0.44 & 0.67 & 0.44 \\
\hline Glossary to 28 & 0.00 & 0.00 & 0.00 & 0.00 & 1.00 & 0.00 \\
\hline Index to 5 per $p$ & 0.47 & 0.25 & 0.42 & 1.00 & 1.00 & 0.81 \\
\hline Typographic to 1 . & 0.91 & 1.00 & 0.91 & 1.00 & 1.00 & 0.91 \\
\hline Text Category & 0.63 & 0.80 & 0.77 & 0.76 & 0.74 & 0.72 \\
\hline Graphics Category & 0.72 & 0.77 & 0.82 & 0.49 & 0.92 & 0.73 \\
\hline Referencability & 0.31 & 0.27 & 0.29 & 0.48 & 0.89 & 0.42 \\
\hline Sentence Level S & 0.85 & 0.87 & 0.86 & 0.65 & 0.87 & 0.89 \\
\hline Text & 0.78 & 0.83 & 0.82 & 0.76 & 0.81 & 0.84 \\
\hline Graphics & 1.00 & 0.97 & 0.96 & 0.41 & 1.00 & 1.00 \\
\hline Chapter Level Sc & 0.45 & 0.77 & 0.75 & 0.71 & 0.71 & 0.59 \\
\hline Locument Level s & 0.51 & 0.54 & 0.55 & 0.63 & 0.86 & 0.53 \\
\hline Total Score & 0.63 & 0.74 & 0.73 & 0.66 & 0.82 & 0.69 \\
\hline 2 score & -0.77739 & 0.392446 & 0.335276 & -0.41555 & 1.313287 & -0.10077 \\
\hline
\end{tabular}


160

\begin{tabular}{|c|c|c|c|c|c|c|}
\hline Package & 55 & 56 & 57 & 58 & 53 & 60 \\
\hline & 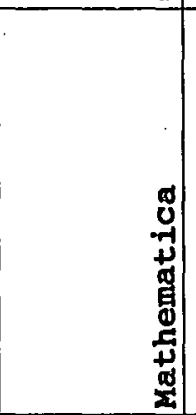 & 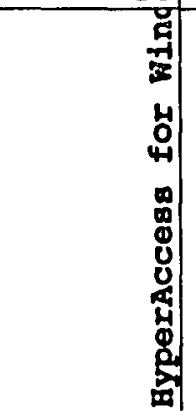 & 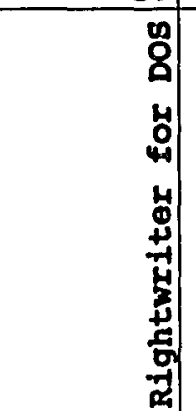 & 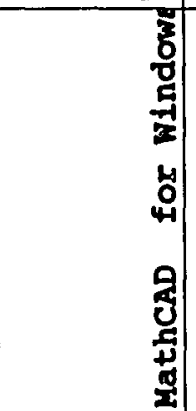 & 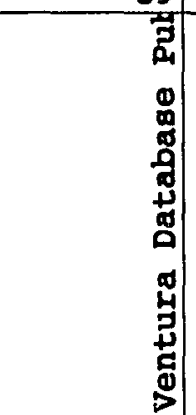 & 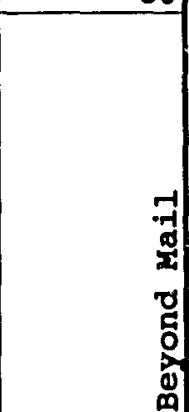 \\
\hline Category & 33 & 61 & 51 & 33 & 41 & 53 \\
\hline Price & 995 & 199 & 99 & 495 & 295 & 995 \\
\hline \begin{tabular}{|l|l} 
Vendor & \\
\end{tabular} & Woflram & Hilgrave & Que & Mathsoft & Ventura & Beyond In \\
\hline PC (1) or MAC (2) & 1 & 1 & 1 & 1 & 1 & \begin{tabular}{|l|} 
\\
1
\end{tabular} \\
\hline DOS (1)or Window: & 2 & 2 & 1 & 2 & 2 & 2 \\
\hline Version & 2.2 & 1 & 6 & 4 & 4.1 .1 & \\
\hline Year first intro & 1992 & 1993 & 1986 & 1991 & 1988 & 1989 \\
\hline \begin{tabular}{|l|l|} 
Pages \\
\end{tabular} & 118 & 265 & $\therefore 151$ & 454 & 105 & 192 \\
\hline Chapters & 6 & 8 & 9 & 21 & 5 & 9 \\
\hline Scores & & & & & & \\
\hline Noun Strings & 0.97 & 0.98 & 0.99 & 1.00 & 0.95 & 0.99 \\
\hline chapter 1 & 1.00 & 0.99 & 0.98 & 1.00 & 0.95 & 1.00 \\
\hline chapter 2 & 0.95 & 0.97 & 0.99 & 0.99 & 0.96 & 0.97 \\
\hline Jargon & 1.00 & 1.00 & 1.00 & 1.00 & 1.00 & 1.00 \\
\hline chapter 1 & 1.00 & 1.00 & 1.00 & 1.00 & 1.00 & 1.00 \\
\hline chapter 2 & 1.00 & 1.00 & 1.00 & 1.00 & 1.00 & 1.00 \\
\hline Agency-user & 0.32 & 0.35 & 0.17 & 0.36 & 0.39 & 0.49 \\
\hline chapter 1 & 0.44 & 0.31 & 0.25 & 0.30 & 0.33 & 0.66 \\
\hline chapter 2 & 0.20 & 0.38 & 0.09 & 0.42 & 0.45 & 0.33 \\
\hline Agency - documen & 0.02 & 0.24 & 0.37 & 0.09 & 0.03 & 0.04 \\
\hline chapter 1 & 0.03 & 0.48 & 0.08 & 0.11 & 0.02 & 0.07 \\
\hline chapter 2 & 0.00 & 0.00 & 0.67 & 0.06 & 0.05 & 0.00 \\
\hline Agency- equipmen & 0.44 & 0.23 & 0.27 & 0.36 & 0.39 & 0.35 \\
\hline chapter 1 & 0.44 & 0.13 & 0.45 & 0.36 & 0.40 & 0.16 \\
\hline chapter 2 & 0.43 & 0.33 & 0.09 & 0.35 & 0.39 & 0.54 \\
\hline Agency - action & 0.03 & 0.04 & 0.10 & 0.04 & 0.09 & 0.04 \\
\hline chapter 1 & 0.07 & 0.00 & 0.20 & 0.06 & 0.19 & 0.01 \\
\hline chapter 2 & 0.00 & 0.08 & 0.00 & 0.02 & 0.00 & 0.07 \\
\hline Total Agency sco: & 0.81 & 0.86 & 0.91 & 0.84 & 0.91 & 0.92 \\
\hline Goals for action & 0.28 & 0.75 & 0.00 & 0.60 & 0.67 & 0.75 \\
\hline chapter 1 & 0.56 & 1.00 & 0.00 & 0.33 & 0.33 & 0.80 \\
\hline chapter 2 & 0.00 & 0.50 & $\therefore 0.00$ & 0.86 & 1.00 & 0.70 \\
\hline Logical conditiol & 0.19 & 0.11 & 0.17 & 0.15 & 0.03 & 0.11 \\
\hline chapter 1 & 0.07 & 0.10 & 0.14 & 0.08 & 0.05 & 0.07 \\
\hline chapter 2 & 0.31 & 0.12 & 0.21 & 0.23 & 0.02 & 0.15 \\
\hline Multiple Steps & 1.00 & 1.00 & 1.00 & 0.98 & 1.00 & 0.97 \\
\hline chapter 1 & 1.00 & 1.00 & 1.00 & 1.00 & 1.00 & 0.98 \\
\hline chapter 2 & 1.00 & 1.00 & 1.00 & 0.96 & 1.00 & 0.96 \\
\hline Unnecessary Refe: & 1.00 & 1.00 & 1.00 & 1.00 & 1.00 & 1.00 \\
\hline chapter 1 & 1.00 & 1.00 & 1.00 & 1.00 & 1.00 & 1.00 \\
\hline chapter 2 & 1.00 & 1.00 & 1.00 & 1.00 & 1.00 & 1.00 \\
\hline Cohesion - parag & 1.00 & 1.00 & 1.00 & 1.00 & 0.98 & 1.00 \\
\hline
\end{tabular}


161

\begin{tabular}{|c|c|c|c|c|c|c|}
\hline & 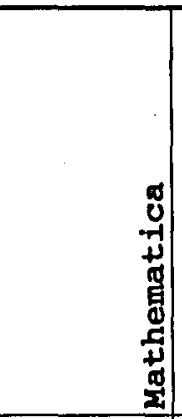 & 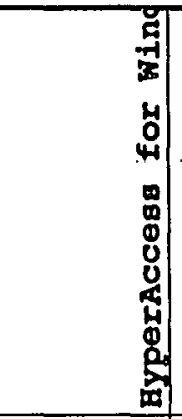 & 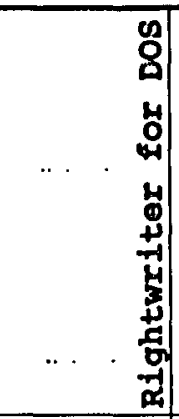 & 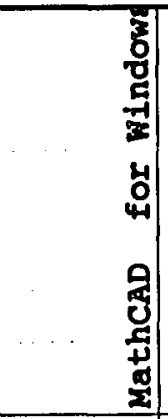 & 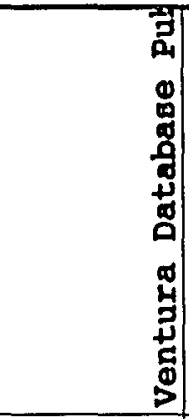 & 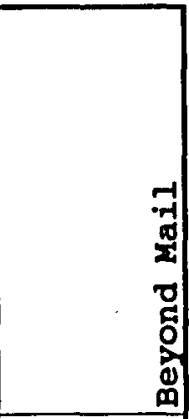 \\
\hline chapter 3 & 1.00 & 1.00 & 1.00 & 1.00 & 0.96 & 1.00 \\
\hline chapter 4 & 1.00 & 1.00 & 1.00 & 1.00 & 1.00 & 1.00 \\
\hline Cohesion - sectil & 1.00 & 1.00 & 1.00 & 1.00 & 0.95 & 1.00 \\
\hline chapter 3 & 1.00 & 1.00 & 1.00 & 1.00 & 0.89 & 1.00 \\
\hline chapter 4 & 1.00 & 1.00 & 1.00 & 1.00 & 1.00 & 1.00 \\
\hline Procedures - ove & 1.00 & 1.00 & 0.50 & 1.00 & 0.00 & 0.00 \\
\hline chapter 3 & 1.00 & 1.00 & 0.00 & 1.00 & 0.00 & 0.00 \\
\hline chapter 4 & 1.00 & 1.00 & 1.00 & 1.00 & 0.00 & 0.00 \\
\hline Procedures - use & 0.45 & 0.37 & 0.05 & 0.27 & 0.56 & 0.20 \\
\hline chapter 3 & 0.40 & 0.35 & 0.00 & 0.19 & 0.54 & 0.00 \\
\hline chapter 4 & 0.50 & 0.38 & 0.11 & 0.35 & 0.58 & 0.40 \\
\hline Procedural graph & 0.30 & 1.00 & 0.00 & 0.43 & 0.50 & 0.50 \\
\hline chapter 3 & 0.40 & 1.00 & 0.00 & 0.00 & 0.50 & 0.00 \\
\hline chapter 4 & 0.20 & 1.00 & 0.00 & 0.86 & 0.50 & 1.00 \\
\hline List consistency & 1.00 & 1.00 & 1.00 & 1.00 & 1.00 & 1.00 \\
\hline chapter 3 & 0.00 & 0.00 & 0.00 & 0.00 & 0.00 & 0.00 \\
\hline chapter 4 & 0.00 & 0.00 & 0.00 & 0.00 & 0.00 & 0.00 \\
\hline Advance Organize & 0.04 & 0.31 & 0.25 & 0.20 & 0.09 & 0.08 \\
\hline chapter 3 & 0.00 & 0.43 & 0.25 & 0.27 & 0.04 & 0.17 \\
\hline chapter 4 & 0.07 & 0.20 & 0.25 & 0.12 & 0.14 & 0.00 \\
\hline Task Headings & 0.30 & 0.24 & 0.62 & 0.29 & 0.15 & 0.34 \\
\hline Informative capt. & 0.00 & 1.00 & 0.00 & 0.67 & 0.00 & 0.00 \\
\hline NONIrrelevant gr & 0.93 & 0.97 & $\cdots 0.97$ & 1.00 & 1.00 & 0.95 \\
\hline NONMirleading gr & 1.00 & 1.00 & 1.00 & 1.00 & 1.00 & 1.00 \\
\hline NON Lie factors & 1.00 & 1.00 & 1.00 & 1.00 & 1.00 & 1.00 \\
\hline NON Data ink & 1.00 & 1.00 & 0.94 & 0.90 & 1.00 & 0.94 \\
\hline NO Duck RATIO & 0.86 & 1.00 & 1.00 & 1.00 & 1.00 & 1.00 \\
\hline Reference Aids ts & 0.33 & 0.56 & 0.56 & 0.33 & 0.22 & 0.33 \\
\hline Glossary to 28 & 0.00 & 1.00 & 1.00 & 0.00 & 0.00 & 0.00 \\
\hline Index to 5 per $p$ & 1.00 & 0.72 & 0.63 & 0.68 & 0.00 & 0.59 \\
\hline Typographic to 1 & 0.91 & 1.00 & 0.91 & 1.00 & 0.91 & 1.00 \\
\hline Text Category & 0.72 & 0.76 & 0.68 & 0.74 & 0.66 & 0.67 \\
\hline Graphics Category & 0.73 & 1.00 & 0.70 & 0.86 & 0.79 & 0.77 \\
\hline Referencability & 0.44 & 0.76 & 0.73 & 0.34 & 0.07 & 0.31 \\
\hline Sentence Level S & 0.81 & 0.87 & 0.80 & 0.85 & 0.86 & 0.87 \\
\hline Text & 0.75 & 0.81 & 0.73 & 0.79 & 0.79 & 0.82 \\
\hline Graphics & 0.95 & 1.00 & 0.98 & 0.97 & 1.00 & 0.98 \\
\hline Chapter Level Sce & 0.68 & 0.81 & 0.54 & 0.70 & 0.58 & 0.54 \\
\hline Document Level so & 0.56 & 0.81 & 0.71 & 0.62 & 0.41 & 0.53 \\
\hline Total Score & 0.69 & 0.83 & 0.70 & 0.73 & 0.64 & 0.67 \\
\hline 2 score & -0.05572 & 1.453962 & 0.004663 & 0.35916 & -0.67957 & -0.34931 \\
\hline
\end{tabular}


162

\begin{tabular}{|c|c|c|c|c|c|c|}
\hline & & & & & & \\
\hline Package & 61 & 62 & 63 & 64 & 65 & 66 \\
\hline & $\begin{array}{l}\stackrel{0}{-1} \\
-7 \\
0 \\
0 \\
\infty\end{array}$ & 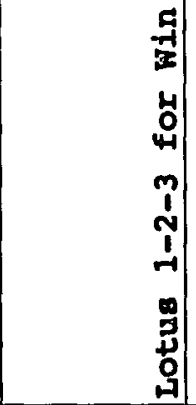 & 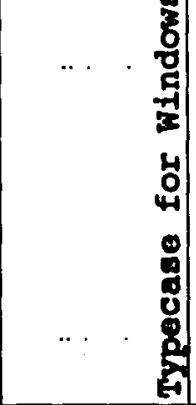 & 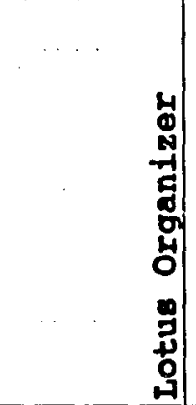 & $\begin{array}{l}0 \\
-1 \\
0 \\
5\end{array}$ & 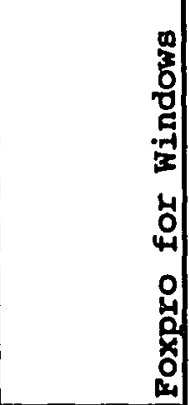 \\
\hline Category & 41 & 31 & 62 & 13 & 22 & 41 \\
\hline Price & 150 & 595 & 99 & 149 & 199 & 495 \\
\hline Vendor & Buttonway & Lotus & Swifte & Iotus & SHAPE & Microsoft \\
\hline PC (1) or MAC (2) & 1 & 1 & 1 & 1 & 1 & 1 \\
\hline DOS (1)or Windowl & 1 & 2 & 2 & 2 & 2 & 2 \\
\hline & & & & & & \\
\hline Version & 7 & 1.1 & 1 & 1 & 1 & 2.5 \\
\hline Year first intro & 1982 & 1991 & 1992 & 1992 & 1992 & 1989 \\
\hline Pages & 681 & 398 & 2 & 44 & 360 & 487 \\
\hline Chapterg & 28 & 18 & 1 & 7 & 8 & 14 \\
\hline Scores & & & & & & \\
\hline Noun Strings & 1.00 & 0.95 & 0.48 & 0.99 & 0.99 & 0.99 \\
\hline chapter 1 & 1.00 & 0.95 & 0.96 & 0.99 & 1.00 & 0.99 \\
\hline chapter 2 & 1.00 & 0.94 & 0.00 & 0.99 & 0.99 & 0.98 \\
\hline Jargon & 1.00 & 0.99 & 0.50 & 1.00 & 1.00 & 1.00 \\
\hline chapter 1 & 1.00 & 0.99 & 1.00 & 1.00 & 1.00 & 1.00 \\
\hline chapter 2 & 1.00 & 1.00 & 0.00 & 1.00 & 1.00 & 1.00 \\
\hline Agency-user & 0.55 & 0.52 & 0.38 & 0.57 & 0.45 & 0.40 \\
\hline chapter 1 & 0.57 & 0.40 & 0.76 & 0.60 & 0.31 & 0.63 \\
\hline chapter 2 & 0.54 & 0.64 & 0.00 & 0.55 & 0.60 & 0.17 \\
\hline Agency - documen & 0.01 & 0.03 & 0.00 & 0.04 & 0.02 & 0.01 \\
\hline chapter 1 & 0.02 & 0.06 & 0.00 & 0.03 & 0.02 & 0.00 \\
\hline chapter 2 & 0.00 & 0.00 & 0.00 & 0.04 & 0.02 & 0.02 \\
\hline Agency- equipmen & 0.20 & 0.37 & 0.06 & 0.27 & 0.32 & 0.43 \\
\hline chapter 1 & 0.15 & 0.38 & 0.12 & 0.23 & 0.44 & 0.33 \\
\hline Chapter 2 & 0.26 & 0.36 & 0.00 & 0.31 & 0.19 & 0.54 \\
\hline Agency - action & 0.08 & 0.01 & 0.00 & 0.02 & 0.15 & 0.01 \\
\hline chapter 1 & 0.13 & 0.02 & 0.00 & 0.02 & 0.13 & 0.00 \\
\hline chapter 2 & $0 . \overline{02}$ & 0.00 & 0.00 & 0.02 & 0.16 & 0.02 \\
\hline Total Agency sco & 0.84 & 0.92 & 0.44 & 0.90 & 0.94 & 0.85 \\
\hline Goals for action & 0.54 & 0.92 & 0.50 & 0.83 & 0.48 & 0.83 \\
\hline chapter 1 & 0.27 & 0.83 & 1.00 & 0.83 & 0.33 & 1.00 \\
\hline chapter 2 & 0.80 & 1.00 & 0.00 & 0.83 & 0.63 & 0.67 \\
\hline Logical conditiol & 0.07 & 0.12 & 0.03 & 0.04 & 0.24 & 0.23 \\
\hline chapter 1 & 0.03 & 0.11 & 0.06 & 0.05 & 0.20 & 0.28 \\
\hline chapter 2 & 0.11 & 0.14 & 0.00 & 0.04 & 0.28 & 0.19 \\
\hline Multiple Steps & 1.00 & 0.98 & 0.46 & 0.99 & 1.00 & 1.00 \\
\hline chapter 1 & 1.00 & 0.95 & 0.92 & 1.00 & 1.00 & 1.00 \\
\hline chapter 2 & 1.00 & 1.00 & 0.00 & 0.98 & 1.00 & 1.00 \\
\hline Unnecessary Refe & 1.00 & 1.00 & 0.50 & 1.00 & 1.00 & 1.00 \\
\hline chapter 1 & 1.00 & 1.00 & 1.00 & 1.00 & 1.00 & 1.00 \\
\hline chapter 2 & 1.00 & 1.00 & 0.00 & 1.00 & 1.00 & 1.00 \\
\hline Cohesion - paragt & 1.00 & 1.00 & 0.00 & 0.96 & 0.50 & 1.00 \\
\hline
\end{tabular}


163

\begin{tabular}{|c|c|c|c|c|c|c|}
\hline & 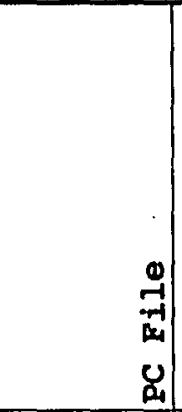 & 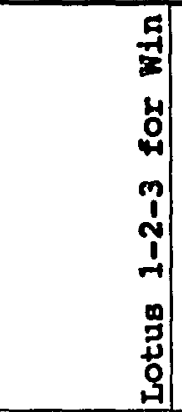 & 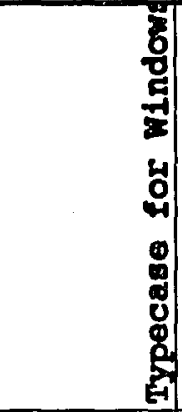 & 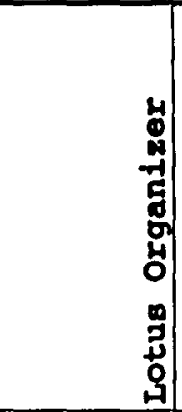 & $\begin{array}{r}0 \\
-7 \\
m \\
-1\end{array}$ & 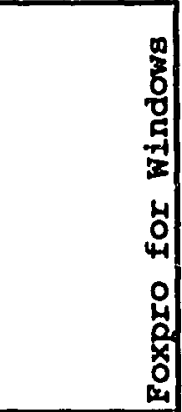 \\
\hline chapter 3 & 1.00 & 1.00 & 0.00 & 1.00 & 1.00 & 1.00 \\
\hline chapter 4 & 1.00 & 1.00 & 0.00 & 0.93 & 0.00 & 1.00 \\
\hline Cohesion - sectid & 1.00 & 1.00 & 0.33 & 1.00 & 1.00 & 1.00 \\
\hline chapter 3 & 1.00 & 1.00 & 0.67 & 1.00 & 1.00 & 1.00 \\
\hline chapter 4 & 1.00 & 1.00 & 0.00 & 1.00 & 1.00 & 1.00 \\
\hline Procedures - ove & 1.00 & 1.00 & 0.50 & 0.42 & 1.00 & 0.50 \\
\hline chapter 3 & 1.00 & 1.00 & 1.00 & 0.17 & 1.00 & 0.00 \\
\hline chapter 4 & 1.00 & 1.00 & 0.00 & 0.67 & 1.00 & 1.00 \\
\hline Procedures - use & 0.53 & 0.52 & $0: 36$ & 0.56 & 0.62 & 0.17 \\
\hline chapter 3 & 0.41 & 0.57 & 0.73 & 0.51 & 0.46 & 0.00 \\
\hline chapter 4 & 0.66 & 0.47 & 0.00 & 0.62 & 0.77 & 0.33 \\
\hline Procedural graph & 0.10 & 0.76 & 0.00 & 0.50 & 0.51 & 0.00 \\
\hline chapter 3 & 0.04 & 0.78 & 0.00 & 0.67 & 0.38 & 0.00 \\
\hline chapter 4 & 0.17 & 0.75 & 0.00 & 0.33 & 0.64 & 0.00 \\
\hline List consistency & 1.00 & 1.00 & 1.00 & 1.00 & 1.00 & 0.83 \\
\hline chapter 3 & 0.00 & 0.00 & 0.00 & 0.00 & 0.00 & 0.00 \\
\hline chapter 4 & 0.00 & 0.00 & 0.00 & 0.00 & 0.00 & 0.17 \\
\hline Advance Organize & 0.02 & 0.20 & 0.00 & 0.47 & 0.20 & 0.00 \\
\hline chapter 3 & 0.00 & 0.20 & 0.00 & 0.14 & 0.26 & 0.00 \\
\hline chapter 4 & 0.04 & 0.20 & 0.00 & 0.80 & 0.14 & 0.00 \\
\hline Task Headings & 0.35 & 0.71 & 0.00 & 0.93 & 0.66 & 0.31 \\
\hline Informative capt & 1.00 & 0.00 & 0.00 & 0.00 & 0.07 & 0.90 \\
\hline NONIrrelevant gr & 1.00 & 0.90 & 0.00 & 1.00 & 1.00 & 1.00 \\
\hline NONMIsleading gr & 1.00 & 1.00 & 1.00 & 1.00 & 1.00 & 1.00 \\
\hline NON Lie factors & 1.00 & 1.00 & 1.00 & 1.00 & 1.00 & 1.00 \\
\hline NON Data ink & 1.00 & 1.00 & 1.00 & 1.00 & 1.00 & 1.00 \\
\hline NO Duck RATIO & 1.00 & 1.00 & 0.00 & 1.00 & 0.95 & 1.00 \\
\hline Reference Aidg $t$ & 0.67 & 0.44 & 0.00 & 0.22 & 0.67 & 0.78 \\
\hline Glossary to 28 & 0.00 & 0.00 & 0.00 & 0.00 & 1.00 & 0.00 \\
\hline Index to 5 per $p$ & 0.24 & 1.00 & 0.00 & 0.00 & 1.00 & 0.50 \\
\hline Typographic to 1 & 1.00 & 1.00 & 0.91 & 1.00 & 0.91 & 1.00 \\
\hline Text Category & 0.74 & 0.81 & 0.36 & 0.79 & 0.76 & 0.69 \\
\hline Graphics Category & 0.87 & 0.81 & $0: 43$ & 0.79 & 0.79 & 0.84 \\
\hline Referencability & 0.30 & 0.48 & 0.00 & 0.07 & 0.89 & 0.43 \\
\hline Sentence Level st & 0.84 & 0.89 & 0.49 & 0.88 & 0.86 & 0.89 \\
\hline Text & 0.78 & 0.84 & 0.42 & 0.82 & 0.81 & 0.84 \\
\hline Graphics & 1.00 & 1.00 & 0.67 & 1.00 & 0.98 & 1.00 \\
\hline Chapter Level Sc. & 0.67 & 0.78 & 0.31 & 0.70 & 0.69 & 0.50 \\
\hline Document Level s & 0.66 & 0.63 & 0.24 & 0.52 & 0.79 & 0.69 \\
\hline Total Score & 0.73 & 0.78 & 0.36 & 0.71 & 0.79 & 0.72 \\
\hline z score & 0.376981 & 0.832708 & -3.65949 & 0.142208 & 0.965022 & 0.173446 \\
\hline
\end{tabular}


164

\begin{tabular}{|c|c|c|c|c|c|c|}
\hline Package & 67 & 68 & 69 & 70 & 71 & 72 \\
\hline & 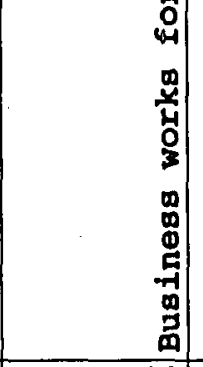 & 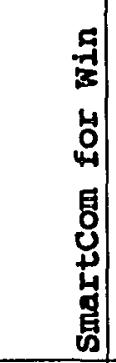 & 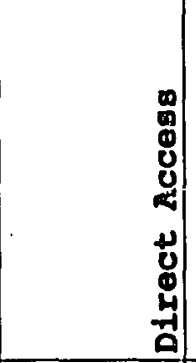 & 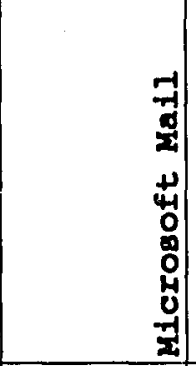 & 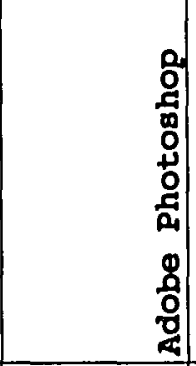 & 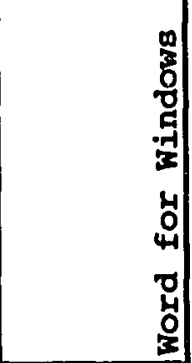 \\
\hline Category & 11 & 61 & 62 & 53 & 24 & 51 \\
\hline Price & \begin{tabular}{|l|}
795 \\
\end{tabular} & 149 & 99 & \begin{tabular}{|l|}
$\cdots 99$ \\
\end{tabular} & \begin{tabular}{|l|}
795 \\
\end{tabular} & 495 \\
\hline Vendor & \multicolumn{2}{|c|}{ Manzanita Hayes } & Fifth & \multicolumn{2}{|c|}{ Microsoft Adobe } & Microsoft \\
\hline PC (1) or MAC (2) & $\begin{array}{r}1 \\
\end{array}$ & 1 & 1 & 1 & 1 & 1 \\
\hline DOS (1)or Window & 2 & 2 & 3 & 2 & 2 & 2 \\
\hline Version & 7.2 & 1 & 5.1 & 1 & 2.5 & \\
\hline Year first intro & 1988 & 1993 & 1984 & 1992 & 1993 & 1989 \\
\hline \begin{tabular}{|l|} 
Pages \\
\end{tabular} & 84 & 103 & 133 & 35 & 191 & 848 \\
\hline Chapters & 5 & 4 & 6 & 4 & 15 & 42 \\
\hline \multicolumn{7}{|l|}{ ScoreB } \\
\hline Noun Stringg & 0.99 & 0.92 & 1.00 & 0.97 & 0.97 & 0.98 \\
\hline chapter 1 & 0.98 & 0.96 & 1.00 & 0.97 & 0.98 & 0.98 \\
\hline chapter 2 & 1.00 & 0.88 & 0.99 & 0.98 & 0.97 & 0.97 \\
\hline Jargon & 1.00 & 0.99 & 1.00 & 1.00 & 1.00 & 1.00 \\
\hline chapter 1 & 1.00 & 1.00 & 1.00 & 1.00 & 1.00 & 1.00 \\
\hline chapter 2 & 1.00 & 0.99 & 1.00 & 1.00 & 1.00 & 1.00 \\
\hline Agency-user & 0.65 & 0.54 & 0.19 & 0.47 & 0.27 & 0.70 \\
\hline chapter 1 & 0.65 & 0.47 & 0.15 & 0.47 & 0.45 & 0.64 \\
\hline chapter 2 & 0.65 & 0.61 & 0.24 & 0.47 & 0.09 & 0.76 \\
\hline Agency - documen & 0.12 & 0.11 & 0.02 & 0.03 & 0.01 & 0.00 \\
\hline chapter 1 & 0.22 & 0.03 & 0.04 & 0.05 & 0.00 & 0.00 \\
\hline chapter 2 & 0.03 & 0.18 & 0.00 & 0.01 & 0.03 & 0.00 \\
\hline Agency-eguipmen & 0.18 & 0.31 & 0.52 & 0.38 & 0.25 & 0.17 \\
\hline chapter 1 & 0.11 & 0.43 & 0.55 & 0.37 & 0.39 & 0.28 \\
\hline chapter 2 & 0.25 & 0.18 & 0.48 & 0.39 & 0.10 & 0.07 \\
\hline Agency - action & 0.01 & 0.02 & 0.10 & 0.07 & 0.05 & 0.12 \\
\hline chapter 1 & 0.00 & 0.03 & 0.04 & 0.08 & 0.09 & 0.08 \\
\hline chapter 2 & 0.02 & 0.00 & 0.15 & 0.06 & 0.01 & 0.15 \\
\hline Total Agency sco: & 0.96 & 0.97 & 0.83 & 0.96 & 0.58 & 0.99 \\
\hline Goals for action & 0.90 & 0.83 & 0.44 & 0.70 & 0.84 & 0.71 \\
\hline chapter 1 & 1.00 & 0.67 & 0.50 & 0.40 & 0.69 & 0.71 \\
\hline chapter 2 & 0.80 & 1.00 & 0.38 & 1.00 & 1.00 & 0.71 \\
\hline Logical conditiol & 0.15 & 0.13 & 0.19 & 0.30 & 0.06 & 0.14 \\
\hline chapter 1 & 0.11 & 0.23 & 0.19 & 0.32 & 0.07 & 0.15 \\
\hline chapter 2 & 0.18 & 0.03 & 0.19 & 0.29 & 0.05 & 0.13 \\
\hline Multiple Steps & 1.00 & 1.00 & 1.00 & 1.00 & 1.00 & 1.00 \\
\hline chapter 1 & 1.00 & 1.00 & 1.00 & 1.00 & 1.00 & 1.00 \\
\hline chapter 2 & 1.00 & 1.00 & 1.00 & 1.00 & 1.00 & 1.00 \\
\hline Unnecessary Refe & 1.00 & 0.98 & 0.99 & 1.00 & 1.00 & 1.00 \\
\hline chapter 1 & 1.00 & 0.97 & 1.00 & 1.00 & 1.00 & 1.00 \\
\hline chapter 2 & 1.00 & 1.00 & 0.98 & 1.00 & 1.00 & 1.00 \\
\hline Cohesion - parag & 0.49 & 0.99 & 1.00 & 1.00 & 1.00 & 1.00 \\
\hline
\end{tabular}


165

\begin{tabular}{|c|c|c|c|c|c|c|}
\hline & 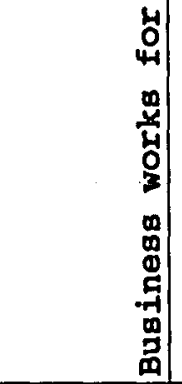 & 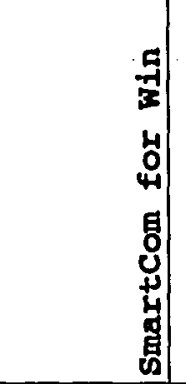 & 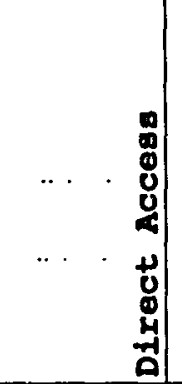 & $\begin{array}{l}7 \\
7 \\
2 \\
2 \\
4 \\
4 \\
0 \\
0 \\
0 \\
0 \\
\frac{1}{2}\end{array}$ & 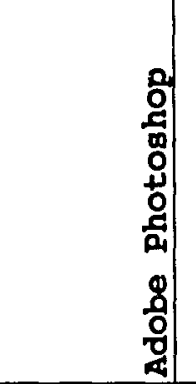 & 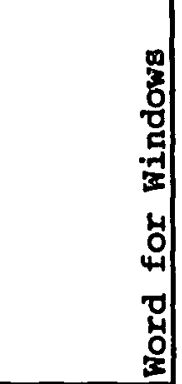 \\
\hline chapter 3 & 0.00 & 0.99 & 1.00 & 1.00 & 1.00 & 1.00 \\
\hline chapter 4 & 0.98 & 0.99 & 1.00 & 1.00 & 1.00 & 1.00 \\
\hline Cohesion - sectil & 1.00 & 1.00 & 1.00 & 1.00 & 1.00 & 1.00 \\
\hline chapter 3 & 1.00 & 1.00 & 1.00 & 1.00 & 1.00 & 1.00 \\
\hline chapter 4 & 1.00 & 1.00 & 1.00 & 1.00 & 1.00 & 1.00 \\
\hline Procedures - ove & 0.00 & 1.00 & 1.00 & 0.50 & 1.00 & 1.00 \\
\hline chapter 3 & 0.00 & 1.00 & 1.00 & 1.00 & 1.00 & 1.00 \\
\hline chapter 4 & 0.00 & 1.00 & 1.00 & 0.00 & 1.00 & 1.00 \\
\hline Procedures - use & 0.30 & 0.40 & 0.54 & 0.16 & 0.38 & 0.61 \\
\hline chapter 3 & 0.00 & 0.32 & 0.50 & 0.31 & 0.33 & 0.66 \\
\hline chapter 4 & 0.60 & 0.48 & 0.57 & 0.00 & 0.42 & 0.55 \\
\hline Procedural graph & 0.50 & 0.90 & 0.00 & 0.25 & 0.50 & 0.58 \\
\hline chapter 3 & 0.00 & 0.80 & 0.00 & 0.50 & 0.00 & 0.75 \\
\hline chapter 4 & 1.00 & 1.00 & 0.00 & 0.00 & 1.00 & 0.40 \\
\hline Ligt consistency & 1.00 & 1.00 & 1.00 & 1.00 & 1.00 & 1.00 \\
\hline chapter 3 & 0.00 & 0.00 & 0.00 & 0.00 & 0.00 & 0.00 \\
\hline chapter 4 & 0.00 & 0.00 & 0.00 & 0.00 & 0.00 & 0.00 \\
\hline Advance Organize & 0.05 & 0.15 & 0.03 & 0.19 & 0.20 & 0.00 \\
\hline chapter 3 & 0.06 & 0.23 & 0.07 & 0.29 & 0.14 & 0.00 \\
\hline chapter 4 & 0.04 & 0.06 & 0.00 & 0.09 & 0.25 & 0.00 \\
\hline Task Headings & 0.07 & 0.44 & $\ldots 0.09$ & 0.65 & 0.57 & 0.52 \\
\hline Informative capt. & 0.00 & 0.00 & 1.00 & 0.00 & 0.48 & 0.27 \\
\hline NONIrrelevant gr & 1.00 & 0.93 & 1.00 & 0.95 & 0.94 & 1.00 \\
\hline NONMisleading gr & 1.00 & 1.00 & 1.00 & 1.00 & 1.00 & 1.00 \\
\hline NON Lie factors & 1.00 & 1.00 & 1.00 & 1.00 & 1.00 & 1.00 \\
\hline NON Data ink & 1.00 & 1.00 & 1.00 & 1.00 & 1.00 & 1.00 \\
\hline NO Duck RATIO & 1.00 & 1.00 & 1.00 & 1.00 & 0.90 & 1.00 \\
\hline Reference Aids t & 0.67 & 0.44 & 0.67 & 0.33 & 0.67 & 0.33 \\
\hline Glossary to 28 & 1.00 & 0.00 & 0.00 & 0.00 & 1.00 & 0.00 \\
\hline Index to 5 per $\mathrm{p}$ & 0.38 & 0.47 & 0.92 & 0.82 & 1.00 & 1.00 \\
\hline Typographic to 1 & 0.91 & 0.82 & 0.91 & 1.00 & 0.82 & 0.91 \\
\hline Text Category & 0.64 & 0.77 & 0.72 & 0.74 & 0.76 & 0.78 \\
\hline Graphics Category & 0.79 & 0.83 & 0.86 & 0.74 & 0.83 & 0.83 \\
\hline Referencability & 0.68 & 0.30 & 0.53 & 0.39 & 0.89 & 0.44 \\
\hline Sentence Level S & 0.90 & 0.88 & 0.84 & 0.89 & 0.84 & 0.88 \\
\hline \begin{tabular}{|l|l|} 
Text \\
\end{tabular} & 0.86 & 0.83 & 0.78 & 0.85 & 0.78 & 0.83 \\
\hline Graphics & 1.00 & 1.00 & 1.00 & 1.00 & 0.97 & 1.00 \\
\hline Chapter Level Sce & 0.48 & 0.78 & 0.65 & 0.58 & 0.72 & 0.74 \\
\hline Document Level s & 0.63 & 0.51 & 0.70 & 0.60 & 0.81 & 0.63 \\
\hline Total Score & 0.69 & 0.73 & 0.74 & 0.71 & 0.80 & 0.76 \\
\hline 2 score & -0.05889 & 0.378861 & 0.480328 & 0.128401 & 1.044077 & 0.663536 \\
\hline
\end{tabular}


166

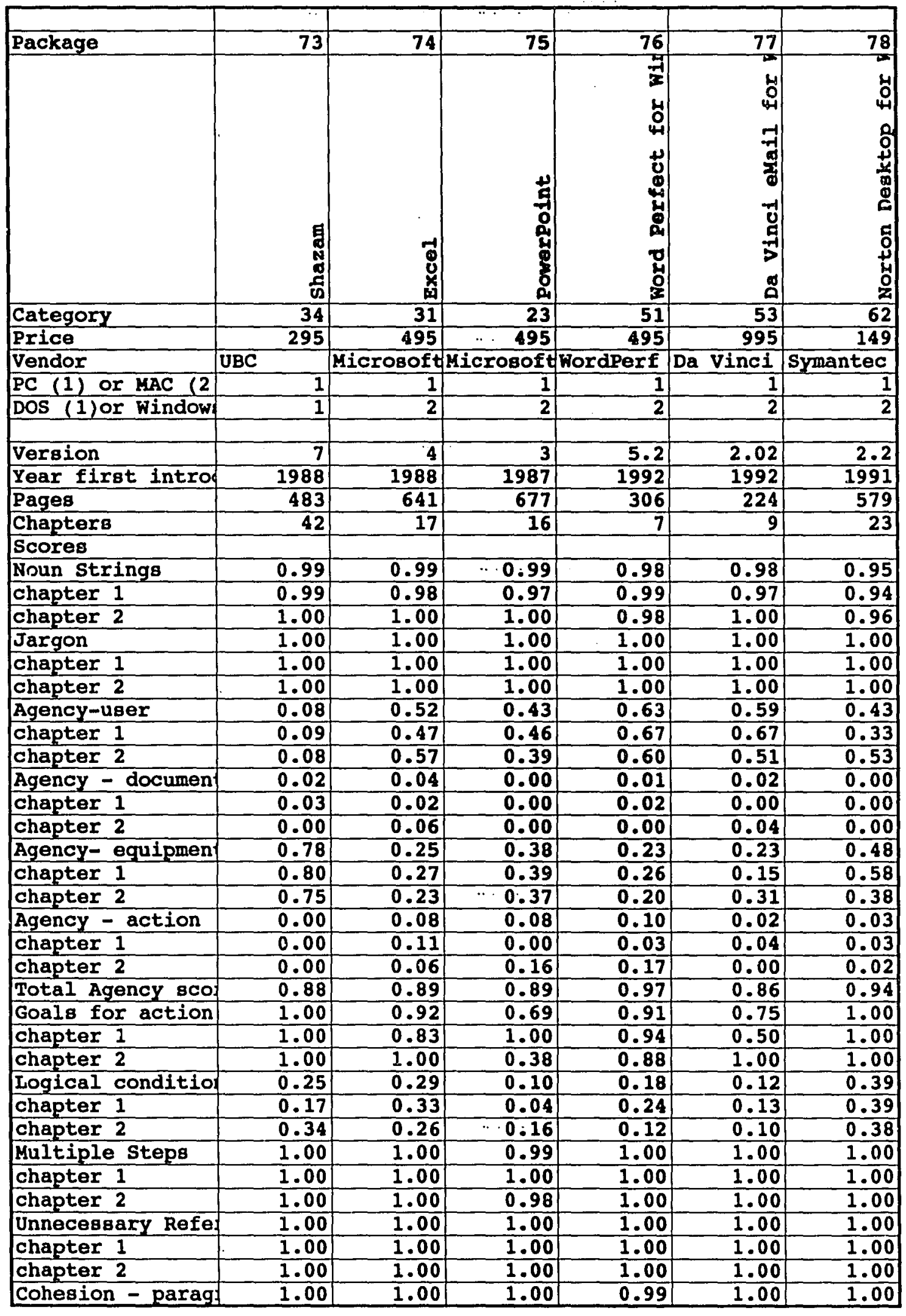




\begin{tabular}{|c|c|c|c|c|c|c|}
\hline & 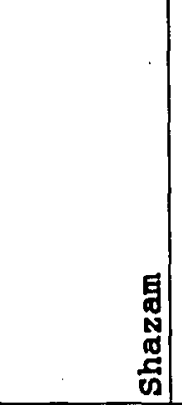 & 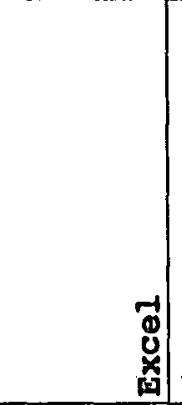 & 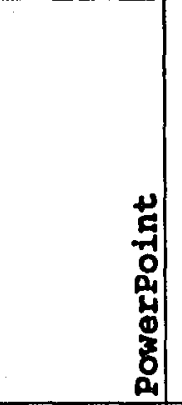 & 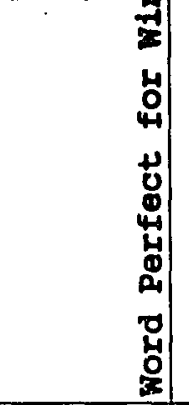 & 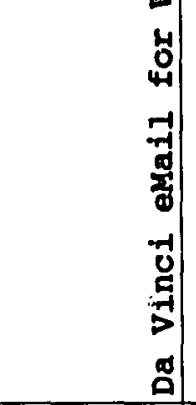 & 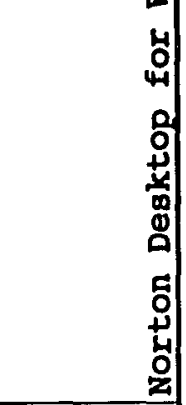 \\
\hline chapter 3 & 1.00 & 1.00 & 1.00 & 0.99 & 1.00 & 1.00 \\
\hline chaptex 4 & 1.00 & 1.00 & 1.00 & 0.99 & 1.00 & 1.00 \\
\hline Cohesion - sectil & 1.00 & 1.00 & 1.00 & 1.00 & 1.00 & 1.00 \\
\hline chapter 3 & 1.00 & 1.00 & 1.00 & 1.00 & 1.00 & 1.00 \\
\hline chapter 4 & 1.00 & 1.00 & $\cdots 1.00$ & 1.00 & 1.00 & 1.00 \\
\hline Procedures - ove & 0.50 & 1.00 & 1.00 & 0.72 & 0.25 & 1.00 \\
\hline chapter 3 & 0.00 & 1.00 & 1.00 & 0.72 & 0.50 & 1.00 \\
\hline chapter 4 & 1.00 & 1.00 & 1.00 & 0.71 & 0.00 & 1.00 \\
\hline Procedures - use: & 0.04 & 0.49 & 0.33 & 0.48 & 0.25 & 0.47 \\
\hline chapter 3 & 0.00 & 0.52 & 0.40 & 0.49 & 0.22 & 0.48 \\
\hline chapter 4 & 0.07 & 0.46 & 0.25 & 0.48 & 0.29 & 0.47 \\
\hline Procedural graph & 0.00 & 0.03 & 0.81 & 0.62 & 0.54 & 0.70 \\
\hline chapter 3 & 0.00 & 0.00 & 0.63 & 0.62 & 0.50 & 1.00 \\
\hline chapter 4 & 0.00 & 0.07 & 1.00 & 0.63 & 0.59 & 0.40 \\
\hline List consistency & 1.00 & 1.00 & 1.00 & 1.00 & 1.00 & 1.00 \\
\hline chapter 3 & 0.00 & 0.00 & 0.00 & 0.00 & 0.00 & 0.00 \\
\hline chapter 4 & 0.00 & 0.00 & 0.00 & 0.00 & 0.00 & 0.00 \\
\hline Advance Organize: & 0.50 & 0.00 & 0.03 & 0.14 & 0.00 & 0.08 \\
\hline chapter 3 & 0.00 & 0.00 & 0.05 & 0.17 & 0.00 & 0.10 \\
\hline chapter 4 & 1.00 & 0.00 & 0.00 & 0.11 & 0.00 & 0.06 \\
\hline Task Headings & 0.10 & 0.80 & 0.76 & 0.01 & 0.62 & 0.63 \\
\hline Informative capt & 0.00 & 0.00 & 0.00 & 0.00 & 0.00 & 0.00 \\
\hline NONIrrelevant gr & 1.00 & 1.00 & 0.90 & 0.90 & 1.00 & 1.00 \\
\hline NONMisleading gr & 1.00 & 1.00 & 1.00 & 1.00 & 1.00 & 1.00 \\
\hline NON Lie factors & 1.00 & 1.00 & 1.00 & 1.00 & 1.00 & 1.00 \\
\hline NON Data ink & 1.00 & 1.00 & 0.97 & 0.96 & 0.80 & 1.00 \\
\hline NO DuCK RATIO & 1.00 & 0.86 & $\overline{1.00}$ & 1.00 & 1.00 & 1.00 \\
\hline Reference Aids $t$ & 0.33 & 0.44 & 0.44 & 0.14 & 0.56 & 0.67 \\
\hline Glossary to 28 & 0.00 & 0.00 & 0.00 & 1.00 & 0.00 & 0.86 \\
\hline Index to 5 per pi & 1.00 & 1.00 & 1.00 & 0.58 & 0.30 & 0.38 \\
\hline Typographic to 1 & 0.82 & 1.00 & 1.00 & 0.91 & 0.82 & 1.00 \\
\hline Text Category & 0.73 & 0.81 & 0.77 & 0.74 & 0.70 & 0.82 \\
\hline Graphics Category & 0.71 & 0.70 & 0.81 & 0.78 & 0.76 & 0.81 \\
\hline Referencability & 0.44 & 0.48 & 0.48 & 0.68 & 0.28 & 0.64 \\
\hline Sentence Level s & 0.91 & 0.90 & 0.86 & 0.90 & 0.85 & 0.93 \\
\hline \begin{tabular}{|l|} 
Text \\
\end{tabular} & 0.87 & 0.87 & 0.81 & 0.86 & 0.82 & 0.90 \\
\hline Graphics & 1.00 & 0.95 & 0.99 & 0.99 & 0.93 & 1.00 \\
\hline Chapter Level Sco & 0.58 & 0.65 & 0.74 & 0.71 & 0.58 & 0.75 \\
\hline Document Level s & 0.53 & 0.66 & 0.64 & 0.61 & 0.54 & 0.69 \\
\hline Total score & 0.70 & 0.75 & 0.76 & 0.75 & 0.67 & 0.80 \\
\hline 2 score & -0.03334 & 0.530273 & 0.607617 & 0.564714 & -0.27943 & 112341 \\
\hline
\end{tabular}


168

\begin{tabular}{|c|c|c|c|c|c|c|}
\hline & & & & & & \\
\hline Package & 79 & 80 & 81 & 82 & & \\
\hline & 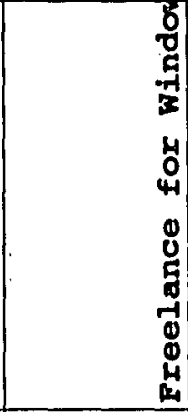 & 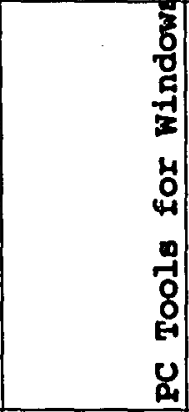 & 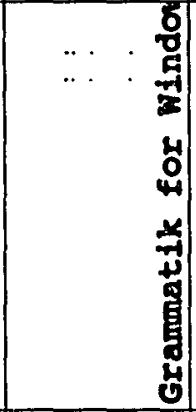 & $\begin{array}{l}\text { : } \\
\text { : } \\
\text { : } \\
\text { : }\end{array}$ & & 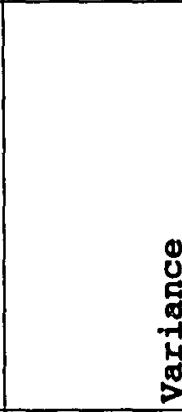 \\
\hline Category & 24 & 62 & 51 & 62 & & \\
\hline Price & 495 & 179 & 99 & 99 & 398.2561 & 106466.6 \\
\hline Vendor & Lotus & Central & Reference & HP & & \\
\hline PC (1) or MAC (2) & 1 & 1 & 1 & 1 & & \\
\hline DOS (1)or Windowe & 2 & 2 & 2 & $\overline{2}$ & & \\
\hline & & & & & & \\
\hline Version & 2 & 1 & 5 & 1 & 2.883846 & 3.361027 \\
\hline Year first intro of & 1991 & 1992 & 1992 & 1992 & & \\
\hline Pages & 243 & 772 & 188 & 56 & 295.2683 & 45171.53 \\
\hline Chapters & 14 & 39 & 11 & 4 & 14.58537 & 118.2951 \\
\hline Scores & & & & & & \\
\hline Noun Strings & 0.96 & 0.90 & 1.00 & 0.95 & 0.954009 & 0.014761 \\
\hline chapter 1 & 0.95 & 0.90 & 1.00 & 0.91 & 0.959765 & 0.012108 \\
\hline chapter 2 & 0.96 & 0.90 & 0.99 & 1.00 & 0.947762 & 0.023778 \\
\hline Jargon & 1.00 & 0.99 & 1.00 & 1.00 & 0.979624 & 0.015036 \\
\hline chapter 1 & 0.99 & 1.00 & 1.00 & 1.00 & 0.985055 & 0.01234 \\
\hline chapter 2 & 1.00 & 0.98 & 1.00 & 1.00 & 0.97369 & 0.024322 \\
\hline Agency-user & 0.53 & 0.58 & 0.55 & 0.67 & 0.41626 & 0.023616 \\
\hline chapter 1 & 0.54 & 0.60 & 0.74 & 0.63 & 0.408578 & 0.030864 \\
\hline chapter 2 & 0.51 & 0.55 & 0.36 & 0.71 & 0.41777 & 0.039948 \\
\hline Agency - documen & 0.07 & 0.03 & 0.04 & 0.00 & 0.044788 & 0.003853 \\
\hline chapter 1 & 0.11 & 0.03 & 0.03 & 0.00 & 0.056271 & 0.006896 \\
\hline chapter 2 & 0.03 & 0.03 & 0.06 & 0.00 & 0.034252 & 0.007804 \\
\hline Agency- equipmen & 0.22 & 0.28 & 0.31 & 0.20 & 0.320288 & 0.017099 \\
\hline chapter 1 & 0.29 & 0.20 & 0.26 & 0.27 & 0.326852 & 0.02356 \\
\hline chapter 2 & 0.16 & 0.37 & 0.36 & 0.14 & 0.318853 & 0.026644 \\
\hline Agency - action & 0.00 & 0.00 & 0.09 & 0.01 & 0.054161 & 0.002342 \\
\hline chapter 1 & 0.00 & 0.00 & 0.00 & 0.00 & 0.058496 & 0.005226 \\
\hline chapter 2 & 0.00 & 0.00 & 0.18 & 0.03 & 0.049917 & 0.003583 \\
\hline Total Agency sco: & 0.82 & 0.89 & 1.00 & 0.89 & 0.835497 & 0.022642 \\
\hline Goals for action & 1.00 & 1.00 & 0.52 & 0.75 & 746 & 0.065375 \\
\hline chapter 1 & 1.00 & 1.00 & 1.00 & 1.00 & 0.709242 & 0.100001 \\
\hline chapter 2 & 1.00 & 1.00 & 0.04 & 0.50 & 0.698776 & 0.110335 \\
\hline Logical conditiol & 0.16 & 0.22 & 0.15 & 0.19 & 0.157332 & 0.007213 \\
\hline chapter 1 & 0.29 & 0.11 & 0.17 & 0.23 & 0.145822 & 0.011649 \\
\hline chapter 2 & 0.03 & 0.32 & 0.12 & 0.14 & 0.168926 & 0.013523 \\
\hline Multiple Steps & 1.00 & 1.00 & 0.96 & 1.00 & 0.942387 & 0.020891 \\
\hline chapter 1 & 1.00 & 1.00 & 0.92 & 1.00 & 0.925621 & 0.031756 \\
\hline chapter 2 & 1.00 & 1.00 & $\because 1.00$ & 1.00 & 0.960607 & 0.024714 \\
\hline Unnecessary Refe: & 1.00 & 1.00 & 1.00 & 1.00 & 0.971358 & 0.015216 \\
\hline chapter 1 & 1.00 & 1.00 & 1.00 & 1.00 & 0.975198 & 0.013639 \\
\hline chapter 2 & 1.00 & 1.00 & 1.00 & 1.00 & 0.966811 & 0.024324 \\
\hline Cohesion - parag & 0.97 & 0.99 & 1.00 & 1.00 & 0.924437 & 0.039672 \\
\hline
\end{tabular}




\begin{tabular}{|c|c|c|c|c|c|c|}
\hline & 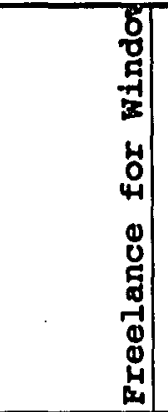 & 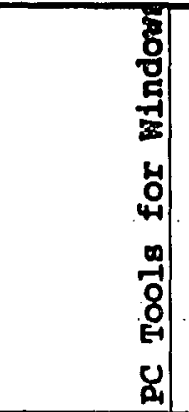 & 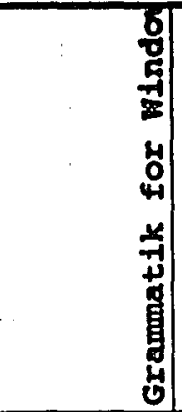 & 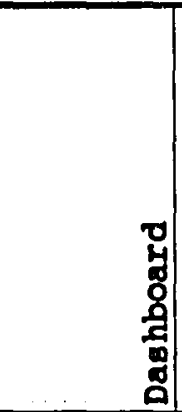 & 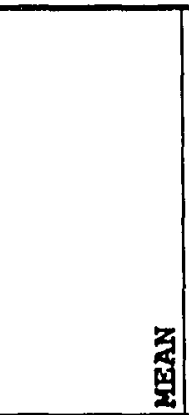 & 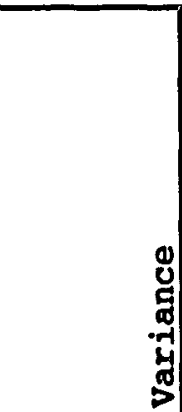 \\
\hline chapter 3 & 1.00 & 1.00 & $1: 00$ & 1.00 & 0.934329 & 0.046805 \\
\hline chapter 4 & 0.95 & 0.98 & 1.00 & 1.00 & 0.914544 & 0.064411 \\
\hline Coherion-sectis & 1.00 & 1.00 & 1.00 & 1.00 & 0.949028 & 0.025221 \\
\hline chapter 3 & 1.00 & 1.00 & 1.00 & 1.00 & 0.964283 & 0.02243 \\
\hline chapter 4 & 1.00 & 1.00 & 1.00 & 1.00 & 0.933773 & 0.049753 \\
\hline Procedures - ovef & 0.65 & 0.08 & 0.83 & 0.25 & 0.614431 & 0.121232 \\
\hline chapter 3 & 0.83 & 0.00 & 0.67 & 0.00 & 0.608436 & 0.179197 \\
\hline chapter 4 & 0.47 & 0.17 & 1.00 & 0.50 & 0.620426 & 0.162944 \\
\hline Procedures - use: & 0.51 & 0.45 & 0.47 & 0.20 & 0.363737 & 0.027392 \\
\hline chapter 3 & 0.52 & 0.41 & 0.60 & 0.00 & 0.35255 & 0.045871 \\
\hline chapter 4 & 0.50 & 0.49 & 0.34 & 0.39 & 0.374924 & 0.036365 \\
\hline Procedural graph & 0.88 & 0.63 & 0.00 & 0.50 & 0.501142 & 0.120847 \\
\hline chapter 3 & 1.00 & 1.00 & 0.00 & 0.00 & 0.464054 & 0.170084 \\
\hline chapter 4 & 0.76 & 0.25 & 0.00 & 1.00 & 0.53823 & 0.17571 \\
\hline Tist consigtency & 1.00 & 1.00 & 1.00 & 1.00 & 0.92378 & 0.039301 \\
\hline chapter 3 & 0.00 & 0.00 & 0.00 & 0.00 & 0.042663 & 0.022334 \\
\hline chapter 4 & 0.00 & 0.00 & 0.00 & 0.00 & 0.039634 & 0.022501 \\
\hline Advance Organize & 0.19 & 0.03 & 0.15 & 0.00 & 0.177185 & 0.0419 \\
\hline chapter 3 & 0.29 & 0.06 & 0.14 & 0.00 & 0.186681 & 0.068655 \\
\hline \begin{tabular}{|l|} 
chapter 4 \\
\end{tabular} & 0.09 & 0.00 & 0.17 & 0.00 & 0.167689 & 0.067464 \\
\hline Task Headings & 0.00 & 0.47 & 0.67 & 0.77 & 0.431889 & 3783 \\
\hline Informative capt: & 0.00 & 0.00 & 0.86 & 0.00 & 0.227691 & 0.136416 \\
\hline NONIrrelevant gr & 0.93 & 1.00 & 0.92 & 0.91 & 0.88 & 0.05495 \\
\hline NONMisleading gr & 1.00 & 1.00 & 1.00 & 1.00 & 0.986232 & 0.006035 \\
\hline NON Lie factors & 1.00 & 1.00 & 1.00 & 1.00 & 0.96329 & 0.029441 \\
\hline NON Data ink & 1.00 & 1.00 & 1.00 & 1.00 & 0.974435 & 0.012813 \\
\hline NO DuCk RATIO & 1.00 & 0.97 & 1.00 & 0.98 & 0.887052 & 0.108822 \\
\hline Reference Aids to & 0.44 & 0.44 & 0.33 & 0.22 & 0.426829 & 0.034894 \\
\hline Glogsary to 28 & 0.00 & 0.00 & 0.00 & 0.00 & 0.245261 & 0.179131 \\
\hline Index to 5 per $P$ & 1.00 & 0.46 & 0.38 & 1.00 & 0.56978 & 0.111911 \\
\hline Typographic to 1 & 1.00 & 0.91 & 1.00 & 1.00 & 0.894678 & 0.02091 \\
\hline Text Categony & 0.73 & 0.72 & 0.77 & 0.71 & 0.71 & 0.01 \\
\hline Graphics Category & 0.83 & 0.80 & 0.83 & 0.77 & 0.77 & 0.01 \\
\hline Referencability & 0.48 & 0.30 & 0.24 & 0.41 & 0.41 & 0.05 \\
\hline Sentence Level S & 0.89 & 0.90 & 0.86 & 0.88 & 0.84 & 0.01 \\
\hline Text & 0.85 & 0.86 & 0.80 & 0.83 & 0.79 & 0.01 \\
\hline Graphics & 1.00 & 0.99 & 1.00 & 0.99 & 0.94 & 0.02 \\
\hline Chapter Level Sc & 0.74 & 0.60 & 0.64 & 0.56 & 0.64 & 0.01 \\
\hline Document Lavel S & 0.55 & 0.54 & 0.65 & 0.61 & 0.58 & 0.02 \\
\hline Total Score & 0.74 & 0.70 & 0.73 & 0.70 & 0.70 & 0.01 \\
\hline 2 score & 0.43839 & -0.02675 & 328782 & 0.050493 & & \\
\hline
\end{tabular}




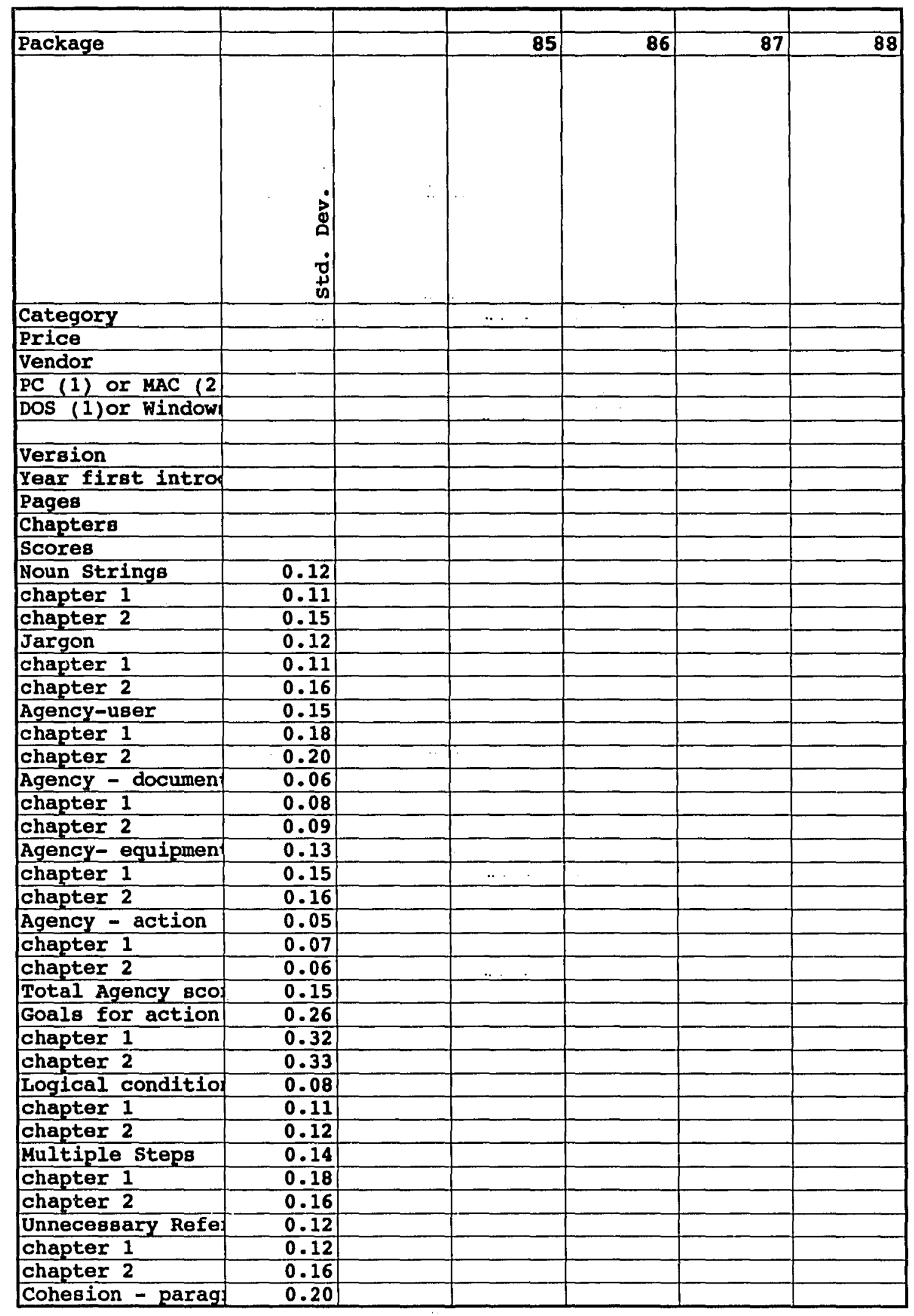




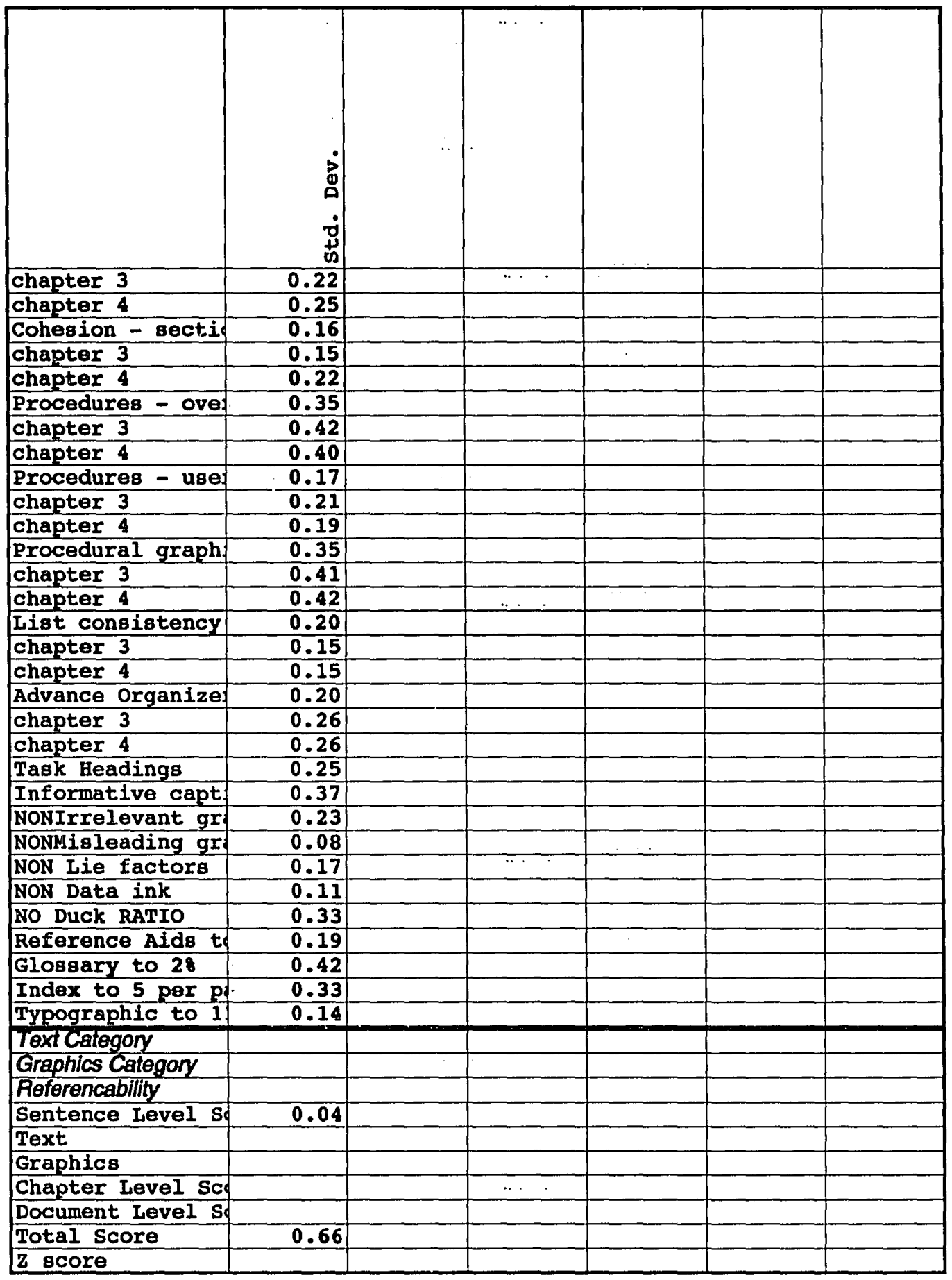




\section{APPENDIX D}

\section{DETAIL DATA FROM PANEL OF EXPERTS}




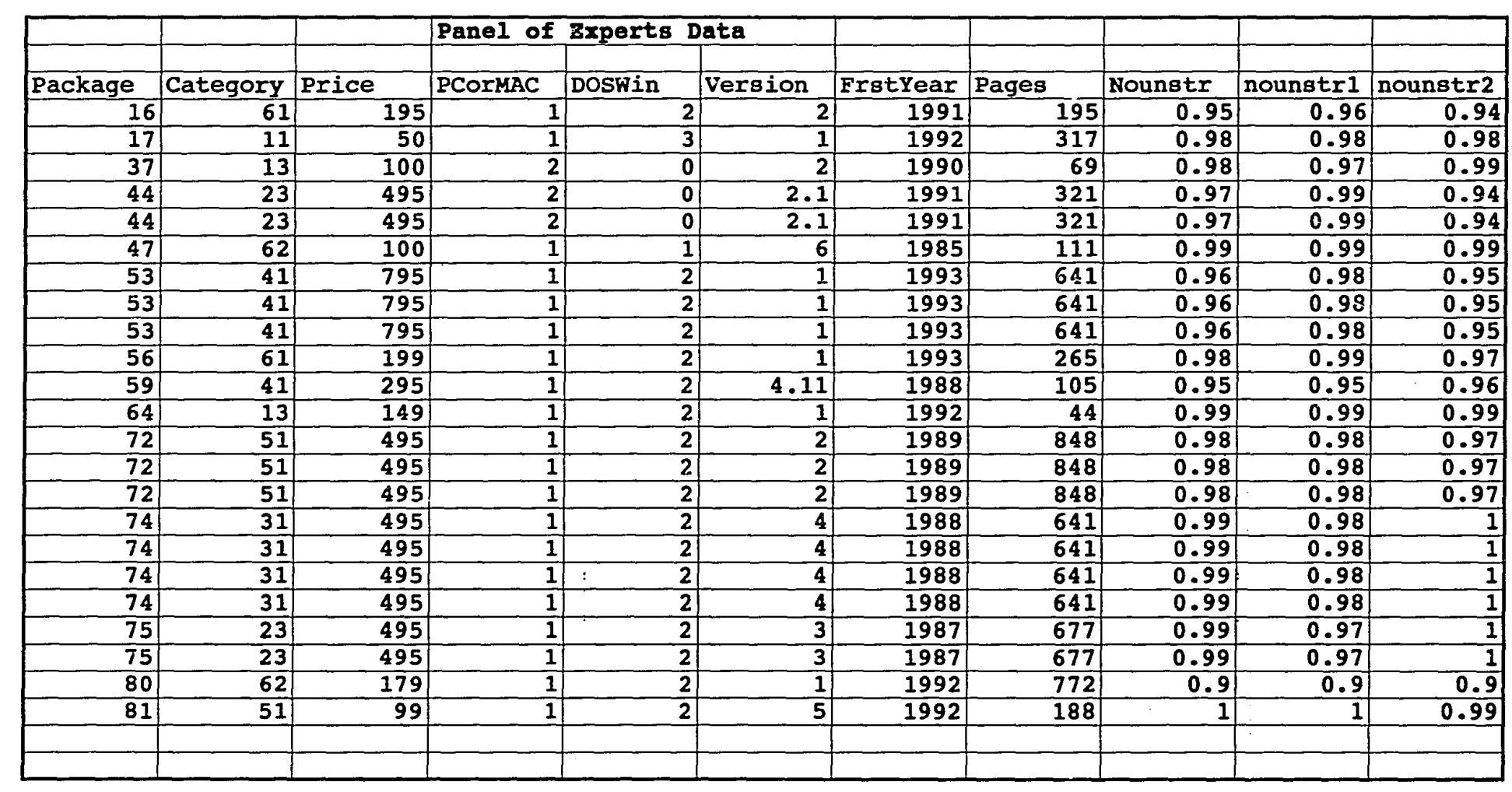




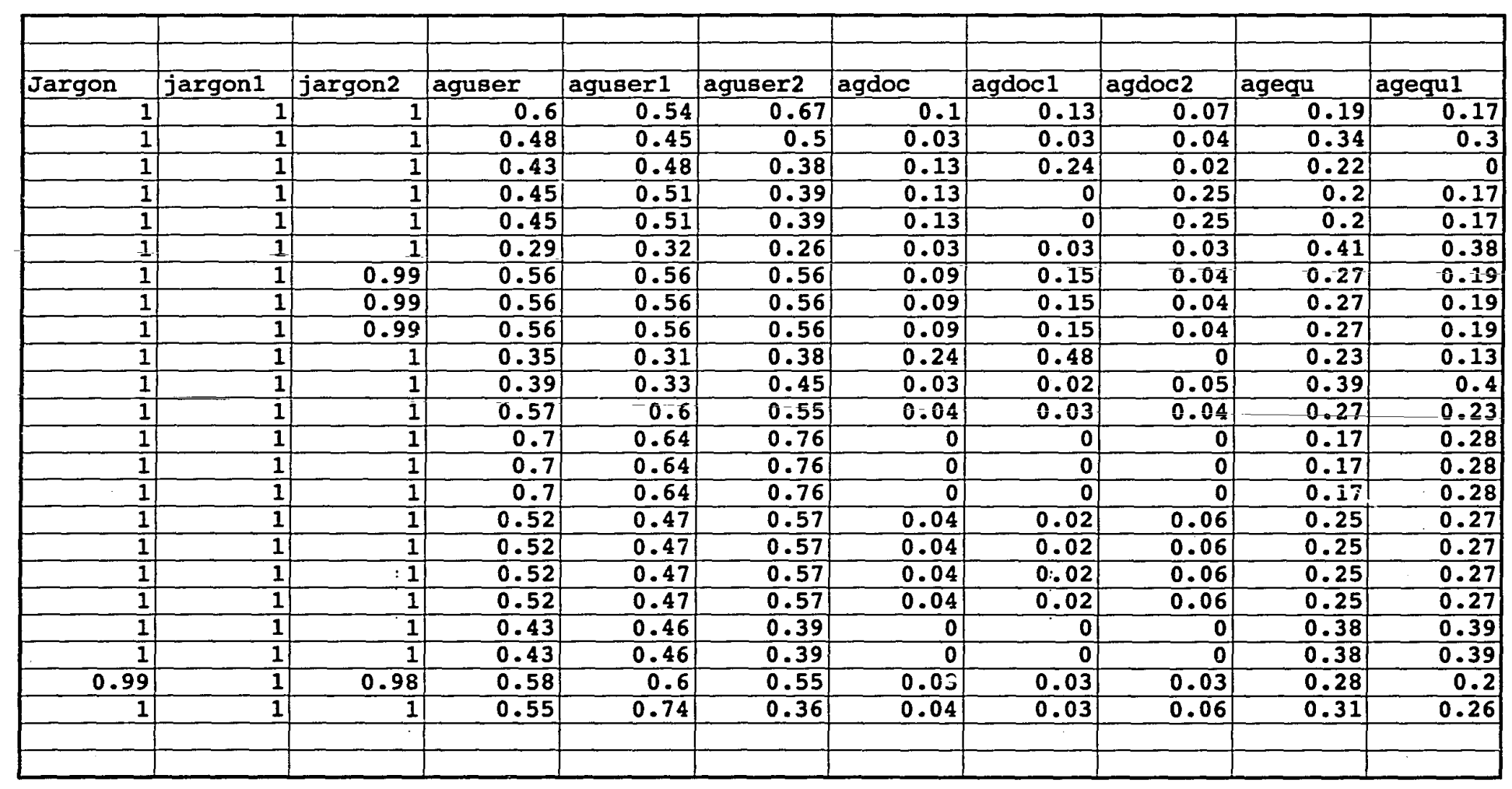




\begin{tabular}{|c|c|c|c|c|c|c|c|c|c|c|}
\hline agequ2 & agact & agact 1 & agact2 & agtotal & goalsa & goalsi & goals2 & logical & $\operatorname{logil}$ & $\operatorname{logi2}$ \\
\hline 0.22 & 0.06 & 0.08 & 0.03 & 0.95 & 1 & 1 & 1 & 0.06 & 0 & 0.12 \\
\hline 0.37 & 0.02 & 0 & 0.04 & 0.87 & 0.3 & 0.2 & 0.4 & 0.1 & 0.06 & 0.15 \\
\hline 0.44 & 0.1 & 0.1 & 0.09 & 0.88 & 0.64 & 0.67 & 0.62 & 0.31 & 0.48 & 0.15 \\
\hline 0.22 & 0.05 & 0.06 & 0.03 & 0.82 & 0.71 & 0.63 & 0.8 & 0.15 & 0.13 & 0.17 \\
\hline 0.22 & 0.05 & 0.06 & 0.03 & 0.82 & 0.71 & 0.63 & 0.8 & 0.15 & 0.13 & 0.17 \\
\hline 0.44 & 0.01 & 0 & 0.03 & 0.74 & 0.5 & 1 & 0 & 0.15 & 0.14 & 0.15 \\
\hline 0.35 & 0.05 & 0.08 & 0.02 & 0.97 & 0.55 & 0.6 & 0.5 & 0.26 & 0.25 & 0.27 \\
\hline 0.35 & 0.05 & 0.08 & 0.02 & 0.97 & 0.55 & 0.6 & 0.5 & 0.26 & 0.25 & 0.27 \\
\hline 0.35 & 0.05 & 0.08 & 0.02 & 0.97 & 0.55 & 0.6 & 0.5 & 0.26 & 0.25 & 0.27 \\
\hline 0.33 & 0.04 & 0 & 0.08 & 0.86 & 0.75 & 1 & 0.5 & 0.11 & 0.1 & 0.12 \\
\hline 0.39 & 0.09 & 0.19 & 0 & 0.91 & 0.67 & 0.33 & 1 & 0.03 & 0.05 & 0.02 \\
\hline 0.31 & 0.02 & 0.02 & 0.02 & 0.9 & 0.83 & 0.83 & 0.83 & 0.04 & 0.05 & 0.04 \\
\hline 0.07 & 0.12 & 0.08 & 0.15 & 0.99 & 0.71 & 0.71 & 0.71 & 0.14 & 0.15 & 0.13 \\
\hline 0.07 & 0.12 & 0.08 & 0.15 & 0.99 & 0.71 & 0.71 & 0.71 & 0.14 & 0.15 & 0.13 \\
\hline 0.07 & 0.12 & 0.08 & 0.15 & 0.99 & 0.71 & 0.71 & 0.71 & 0.14 & 0.15 & 0.13 \\
\hline 0.23 & 0.08 & 0.11 & 0.06 & 0.89 & 0.92 & 0.83 & 1 & 0.29 & 0.33 & 0.26 \\
\hline 0.23 & 0.08 & 0.11 & 0.06 & 0.89 & 0.92 & 0.83 & 1 & 0.29 & 0.33 & 0.26 \\
\hline 0.23 & $: 0.08$ & 0.11 & 0.06 & 0.89 & 0.92 & 0.83 & 1 & 0.29 & 0.33 & 0.26 \\
\hline 0.23 & 0.08 & 0.11 & 0.06 & 0.89 & $0 . \overline{92}$ & 0.83 & 1 & 0.29 & 0.33 & 0.26 \\
\hline 0.37 & 0.08 & 0 & 0.16 & 0.89 & 0.69 & 1 & 0.38 & 0.1 & 0.04 & 0.16 \\
\hline 0.37 & 0.08 & 0 & 0.16 & 0.89 & 0.69 & 1 & 0.38 & 0.1 & 0.04 & 0.16 \\
\hline 0.37 & 0 & 0 & 0 & 0.89 & 1 & 1 & 1 & 0.22 & 0.11 & 0.32 \\
\hline 0.36 & 0.09 & 0 & 0.18 & 1 & 0.52 & 1 & 0.04 & 0.15 & 0.17 & 0.12 \\
\hline & & & & & & & & & & \\
\hline & & & & & & & & & & \\
\hline
\end{tabular}




\begin{tabular}{|c|c|c|c|c|c|c|c|c|c|c|}
\hline multistp & multil & multi2 & unref & unref1 & unref2 & cchesp & cohesp3 & cohesp4 & Cohess & cohess 3 \\
\hline 1 & 1 & 1 & 0.98 & 1 & 0.97 & 1 & 1 & 1 & 1 & 1 \\
\hline 1 & 1 & 1 & 0.98 & 1 & 0.96 & 0.98 & 0.98 & 0.98 & 1 & 1 \\
\hline 0.95 & 0.93 & 0.96 & 0.99 & 1 & 0.98 & 1 & 1 & 1 & 1 & 1 \\
\hline 0.84 & 0.71 & 0.97 & 0.99 & 1 & 0.97 & 1 & 1 & 1 & 1 & 1 \\
\hline 0.84 & 0.71 & 0.97 & 0.99 & 1 & 0.97 & 1 & 1 & 1 & 1 & 1 \\
\hline 1 & 1 & 1 & 0.97 & 0.97 & 0.97 & 1 & 1 & 0.99 & 1 & 1 \\
\hline 0.96 & 0.96 & 0.96 & 0.96 & 0.96 & 0.96 & 0.99 & 0.98 & 1 & 1 & 1 \\
\hline 0.96 & 0.96 & 0.96 & 0.96 & 0.96 & 0.96 & 0.99 & 0.98 & 1 & 1 & 1 \\
\hline 0.96 & 0.96 & 0.96 & 0.96 & 0.96 & 0.96 & 0.99 & 0.98 & 1 & 1 & 1 \\
\hline 1 & 1 & 1 & 1 & 1 & 1 & 1 & 1 & 1 & 1 & 1 \\
\hline 1 & 1 & 1 & 1 & 1 & 1 & 0.98 & 0.96 & 1 & 0.95 & 0.89 \\
\hline 0.99 & 1 & 0.98 & 1 & 1 & 1 & 0.96 & 1 & 0.93 & 1 & 1 \\
\hline 1 & 1 & 1 & 1 & 1 & 1 & 1 & 1 & 1 & 1 & 1 \\
\hline 1 & 1 & 1 & 1 & 1 & 1 & 1 & 1 & 1 & 1 & 1 \\
\hline 1 & 1 & 1 & 1 & 1 & 1 & 1 & 1 & 1 & 1 & 1 \\
\hline 1 & 1 & 1 & 1 & 1 & 1 & 1 & 1 & 1 & 1 & 1 \\
\hline 1 & 1 & 1 & 1 & 1 & 1 & 1 & 1 & 1 & 1 & 1 \\
\hline 1 & 1 & 1 & 1 & 1 & 1 & 1 & 1 & 1 & $: 1$ & 1 \\
\hline 1 & 1 & 1 & 1 & 1 & 1 & 1 & 1 & 1 & 1 & 1 \\
\hline 0.99 & 1 & 0.98 & 1 & $i$ & 1 & 1 & 1 & 1 & 1 & 1 \\
\hline 0.99 & 1 & 0.98 & 1 & 1 & 1 & 1 & 1 & 1 & 1 & 1 \\
\hline 1 & 1 & 1 & 1 & $I$ & 1 & 0.99 & 1 & 0.98 & 1 & 1 \\
\hline 0.96 & 0.92 & 1 & 1 & 1 & 1 & 1 & 1 & 1 & 1 & 1 \\
\hline & & & & & & & & & & \\
\hline & & & & & & & & & & \\
\hline
\end{tabular}




\begin{tabular}{|c|c|c|c|c|c|c|c|c|c|c|}
\hline Cohess4 & proc & proc3 & proc4 & procu & procu 3 & procu4 & procg & procg 3 & procg4 & ListConsi \\
\hline 1 & 0.94 & 1 & 0.88 & 0.44 & 0.44 & 0.44 & 0.22 & 0 & 0.44 & 1 \\
\hline 1 & 0 & n & 0 & 0.82 & 1 & 0.64 & 0.39 & 0 & 0.79 & 0.5 \\
\hline 1 & 0 & 0 & 0 & 0.25 & 0.16 & 0.33 & 1 & 1 & 1 & 1 \\
\hline 1 & 1 & 1 & 1 & 0.46 & 0.44 & 0.49 & 0.67 & 0.5 & 0.83 & 1 \\
\hline 1 & 1 & 1 & 1 & 0.46 & 0.44 & 0.49 & 0.67 & 0.5 & 0.83 & 1 \\
\hline 1 & 0.42 & 0.33 & 0.5 & 0.37 & 0.29 & 0.44 & 0 & 0 & 0 & 1 \\
\hline 1 & 0.83 & 1 & 0.67 & 0.26 & 0.08 & 0.43 & 0.83 & 0.67 & 1 & 1 \\
\hline 1 & 0.83 & 1 & 0.67 & 0.26 & 0.08 & 0.43 & 0.83 & 0.67 & 1 & 1 \\
\hline 1 & 0.83 & 1 & 0.67 & 0.26 & 0.08 & 0.43 & 0.83 & 0.67 & 1 & 1 \\
\hline 1 & 1 & 1 & 1 & 0.37 & 0.35 & 0.38 & 1 & 1 & 1 & 1 \\
\hline 1 & 0 & 0 & 0 & 0.56 & 0.54 & 0.58 & 0.5 & 0.5 & 0.5 & 1 \\
\hline 1 & 0.42 & 0.17 & 0.67 & 0.56 & 0.51 & 0.62 & 0.5 & 0.67 & 0.33 & 1 \\
\hline 1 & 1 & 1 & 1 & 0.61 & 0.66 & 0.55 & 0.58 & 0.75 & 0.4 & 1 \\
\hline 1 & 1 & 1 & 1 & 0.61 & 0.66 & 0.55 & 0.58 & 0.75 & 0.4 & 1 \\
\hline 1 & 1 & 1 & 1 & 0.61 & 0.66 & 0.55 & 0.58 & 0.75 & 0.4 & 1 \\
\hline 1 & 1 & 1 & 1 & 0.49 & 0.52 & 0.46 & 0.03 & 0 & 0.07 & 1 \\
\hline 1 & 1 & 1 & 1 & 0.49 & 0.52 & 0.46 & 0.03 & 0 & 0.07 & 1 \\
\hline 1 & 1 & 1 & 1 & 0.49 & 0.52 & 0.46 & 0.03 & 0 & 0.07 & 1 \\
\hline 1 & 1 & 1 & 1 & 0.49 & 0.52 & 0.46 & 0.03 & 0 & 0.07 & 1 \\
\hline 1 & 1 & 1 & 1 & 0.33 & 0.4 & 0.25 & 0.81 & 0.63 & 1 & 1 \\
\hline 1 & 1 & 1 & 1 & 0.33 & 0.4 & 0.25 & 0.81 & 0.63 & 1 & 1 \\
\hline 1 & 0.08 & 0 & 0.17 & 0.45 & 0.41 & 0.49 & 0.63 & 1 & 0.25 & 1 \\
\hline 1 & 0.83 & 0.67 & 1 & 0.47 & 0.6 & 0.34 & 0 & 0 & 0 & 1 \\
\hline & & & & & & & & & & \\
\hline & & & & & & & & & & \\
\hline
\end{tabular}




\begin{tabular}{|c|c|c|c|c|c|c|c|c|c|c|}
\hline list 3 & list 4 & advorg & advorg3 & advorg4 & taskhead & captions & irevgrph & mislead & Iiefact & data ink \\
\hline 0 & 0 & 0.8 & 1 & 0.61 & 0.58 & 1 & 1 & 1 & 1 & 1 \\
\hline 0.5 & 0.5 & 0.08 & 0.16 & 0 & 0.3 & 0 & 0.55 & 0.47 & 0.47 & 1 \\
\hline 0 & 0 & 0 & 0 & 0 & 0.38 & 0 & 1 & 1 & 1 & 1 \\
\hline 0 & 0 & 0.03 & 0.06 & 0 & 0.94 & 0.44 & 1 & 1 & 1 & 1 \\
\hline 0 & 0 & 0.03 & 0.06 & 0 & 0.94 & 0.44 & 1 & 1 & 1 & 1 \\
\hline 0 & 0 & 0.06 & 0.13 & 0 & 0.25 & 0 & 1 & 1 & 1 & 1 \\
\hline 0 & 0 & 0.05 & 0.07 & 0.02 & 0.61 & 0.72 & 0.9 & 1 & 1 & 1 \\
\hline 0 & 0 & 0.05 & 0.07 & 0.02 & 0.61 & 0.72 & 0.9 & 1 & 1 & 1 \\
\hline 0 & 0 & 0.05 & 0.07 & 0.02 & 0.61 & 0.72 & 0.9 & 1 & 1 & 1 \\
\hline 0 & 0 & 0.31 & 0.43 & 0.2 & 0.24 & 1 & 0.97 & 1 & 1 & 1 \\
\hline 0 & 0 & 0.09 & 0.04 & 0.14 & 0.15 & 0 & 1 & 1 & 1 & 1 \\
\hline 0 & 0 & 0.47 & 0.14 & 0.8 & 0.93 & 0 & 1 & 1 & 1 & 1 \\
\hline 0 & 0 & 0 & 0 & 0 & 0.52 & 0.27 & 1 & 1 & 1 & 1 \\
\hline 0 & 0 & 0 & 0 & 0 & 0.52 & 0.27 & 1 & 1 & 1 & 1 \\
\hline 0 & 0 & 0 & 0 & 0 & 0.52 & 0.27 & 1 & 1 & 1 & 1 \\
\hline 0 & 0 & 0 & 0 & 0 & 0.8 & 0 & 1 & 1 & 1 & 1 \\
\hline 0 & 0 & 0 & 0 & 0 & 0.8 & 0 & 1 & 1 & 1 & 1 \\
\hline 0 & 0 & 0 & 0 & 0 & 0.8 & 0 & 1 & 1 & 1 & 1 \\
\hline 0 & 0 & 0 & 0 & 0 & 0.8 & 0 & 1 & 1 & 1 & 1 \\
\hline 0 & 0 & 0.03 & 0.05 & 0 & 0.76 & 0 & 0.9 & 1 & 1 & 0.97 \\
\hline 0 & 0 & 0.03 & 0.05 & 0 & 0.76 & D & 0.9 & 1 & 1 & 0.97 \\
\hline 0 & 0 & 0.03 & 0.06 & 0 & 0.47 & 0 & 1 & 1 & 1 & 1 \\
\hline 0 & 0 & 0.15 & 0.14 & 0.17 & 0.67 & 0.86 & 0.92 & 1 & 1 & 1 \\
\hline & & & & & & & & & & \\
\hline & & & & & & & & & & \\
\hline
\end{tabular}




\begin{tabular}{|c|c|c|c|c|c|c|c|c|c|c|}
\hline No Duck & Refaid & gloвsary & index & typogrph & Textcat & Graphcat & Refabil & Sentence & text $8 \mathrm{cr}$ & graphscr \\
\hline 0.73 & 0.67 & 0 & 0.48 & 0.91 & 0.84 & 0.85 & 0.38 & 0.87 & 0.85 & 0.91 \\
\hline 0.55 & 0.33 & 0 & 0.24 & 1 & 0.64 & 0.49 & 0.19 & 0.73 & 0.75 & 0.67 \\
\hline 1 & 0.22 & 0 & 0.7 & 0.82 & 0.67 & 0.86 & 0.31 & 0.87 & 0.82 & 1.00 \\
\hline 0.96 & 0.67 & 1 & 1 & 1 & 0.78 & 0.87 & 0.89 & 0.84 & 0.78 & 0.99 \\
\hline 0.96 & 0.67 & 1 & 1 & 1 & 0.78 & 0.87 & 0.89 & 0.84 & 0.78 & 0.99 \\
\hline 0.5 & 0.22 & 0 & 0.93 & 0.82 & 0.67 & 0.64 & 0.38 & 0.79 & 0.76 & 0.83 \\
\hline 1 & 0.67 & 1 & 1 & 1 & 0.74 & 0.92 & 0.89 & 0.87 & 0.81 & 1.00 \\
\hline 1 & 0.67 & 1 & 1 & 1 & 0.74 & 0.92 & 0.89 & 0.87 & 0.81 & 1.00 \\
\hline 1 & 0.67 & 1 & 1 & 1 & 0.74 & 0.92 & 0.89 & 0.87 & 0.81 & 1.00 \\
\hline 1 & 0.56 & 1 & 0.72 & 1 & 0.76 & 1.00 & 0.76 & 0.87 & 0.81 & 1.00 \\
\hline 1 & 0.22 & 0 & 0 & 0.91 & 0.66 & 0.79 & 0.07 & 0.86 & 0.79 & 1.00 \\
\hline 1 & 0.22 & 0 & 0 & 1 & 0.79 & 0.79 & 0.07 & 0.88 & 0.82 & 1.00 \\
\hline 1 & 0.33 & 0 & 1 & 0.91 & 0.78 & 0.83 & 0.44 & 0.88 & 0.83 & 1.00 \\
\hline 1 & 0.33 & 0 & 1 & 0.91 & 0.78 & 0.83 & 0.44 & 0.88 & 0.83 & 1.00 \\
\hline 1 & 0.33 & 0 & 1 & 0.91 & 0.78 & 0.83 & 0.44 & 0.88 & 0.83 & 1.00 \\
\hline 0.86 & 0.44 & 0 & 1 & $\therefore \quad 1$ & 0.81 & 0.70 & 0.48 & 0.90 & 0.87 & 0.95 \\
\hline 0.86 & 0.44 & 0 & 1 & 1 & 0.81 & 0.70 & 0.48 & 0.90 & 0.87 & 0.95 \\
\hline 0.86 & 0.44 & 0 & 1 & 1 & 0.81 & 0.70 & 0.48 & 0.90 & 0.87 & 0.95 \\
\hline 0.86 & 0.44 & 0 & 1 & 1 & 0.81 & 0.70 & 0.48 & 0.90 & 0.87 & 0.95 \\
\hline 1 & 0.44 & 0 & 1 & 1 & 0.77 & 0.81 & 0.48 & 0.86 & 0.81 & 0.99 \\
\hline 1 & 0.44 & 0 & 1 & 1 & 0.77 & 0.81 & 0.48 & 0.86 & 0.81 & 0.99 \\
\hline 0.97 & 0.44 & 0 & 0.46 & 0.91 & 0.72 & 0.80 & 0.30 & 0.90 & 0.86 & 0.99 \\
\hline 1 & 0.33 & 0 & 0.38 & 1 & 0.77 & 0.83 & 0.24 & 0.86 & 0.80 & 1.00 \\
\hline & & & & & & & & & & \\
\hline & & & & & & & & & & \\
\hline
\end{tabular}




\begin{tabular}{|c|c|c|c|c|c|c|c|c|c|c|}
\hline Chapter & Document & TOTSCORE & Expert & Exsenten & Exgraph & Exrefer & Extypo & Exother & EXTOTAL & \\
\hline 0.77 & 0.70 & 0.79 & 3 & 0.85 & 0.95 & 0.95 & 0.95 & & 0.92 & \\
\hline 0.54 & 0.36 & 0.56 & 1 & 0.85 & 0.75 & 0.85 & 0.75 & 0.75 & 0.78 & \\
\hline 0.61 & 0.51 & 0.68 & 4 & 0.75 & 0.8 & 0.8 & 0.8 & 0.6 & 0.75 & \\
\hline 0.74 & 0.88 & 0.83 & 2 & 0.85 & 0.95 & 0.95 & 0.85 & & 0.89 & \\
\hline 0.74 & 0.88 & 0.83 & 4 & 0.9 & 0.9 & 0.8 & 0.9 & 0.95 & 0.89 & \\
\hline 0.55 & 0.53 & 0.64 & 2 & 0.65 & 0.75 & 0.85 & 0.85 & & 0.76 & \\
\hline 0.71 & 0.86 & 0.82 & 1 & 0.85 & 0.95 & 0.95 & 0.95 & 0.85 & 0.85 & \\
\hline 0.71 & $0 . \overline{86}$ & 0.82 & 2 & 0.75 & 0.95 & 0.85 & 0.85 & & 0.85 & \\
\hline 0.71 & 0.86 & 0.82 & 4 & 0.9 & 0.75 & 0.9 & 0.9 & 0.7 & 0.83 & \\
\hline 0.81 & 0.81 & 0.83 & 1 & 0.95 & 0.95 & 0.95 & 0.95 & 0.95 & 0.98 & \\
\hline 0.58 & 0.41 & 0.64 & 3 & 0.85 & 0.85 & 0.75 & 0.75 & & 0.8 & \\
\hline 0.70 & 0.52 & 0.71 & 2 & 0.95 & 0.85 & 0.85 & 0.95 & & 0.88 & \\
\hline 0.74 & 0.63 & 0.76 & 1 & 0.95 & 0.95 & 0.95 & 0.95 & & 0.96 & \\
\hline 0.74 & 0.63 & 0.76 & 3 & 0.85 & 0.85 & 0.85 & 0.85 & & 0.85 & \\
\hline 0.74 & 0.63 & 0.76 & 4 & 0.95 & 0.9 & 0.95 & 0.95 & 0.98 & 0.95 & \\
\hline 0.65 & 0.66 & 0.75 & 1 & 0.95 & 0.95 & 0.95 & 0.95 & 0.75 & 0.92 & \\
\hline 0.65 & 0.66 & 0.75 & 2 & 0.85 & 0.95 & 0.85 & 0.95 & & 0.91 & \\
\hline 0.65 & 0.66 & 0.75 & 3 & 0.85 & 0.95 & 0.85 & 0.85 & & 0.9 & \\
\hline 0.65 & 0.66 & 0.75 & 4 & 0.8 & 0.8 & 0.7 & 0.9 & & 0.8 & \\
\hline 0.74 & 0.64 & 0.76 & 1 & 0.95 & 0.95 & 0.95 & 0.95 & 0.75 & 0.95 & \\
\hline 0.74 & 0.64 & 0.76 & 3 & 0.95 & 0.95 & 0.85 & 0.95 & & 0.95 & \\
\hline 0.60 & 0.54 & 0.70 & 4 & 0.7 & 0.85 & 0.7 & 0.9 & & 0.78 & \\
\hline \multirow[t]{3}{*}{0.64} & 0.65 & 0.73 & 2 & 0.85 & 0.75 & 0.75 & 0.75 & & 0.74 & \\
\hline & & & & & & & & & 0.864783 & MEAN \\
\hline & & & & & & & & & 0.005426 & VARIANCE \\
\hline
\end{tabular}




\section{APPENDIX E}

STATISTICAL ANALYSIS OF DETAIL DATA 
Appendix $\mathrm{E}$

Statistical Analysis of Detall Data
1. Data Name Description Index
2. Reliability Analyois of Combined Hetric Data
184
3. Correlation Matrix of Combined Data
194
4. Ractor Analysis of All Variables
202
5. Custom Factor Model using KMO statistic
207 


\section{Data Name Description Index}

Data name Description

\begin{tabular}{|c|c|}
\hline $\begin{array}{l}\text { ADVORG } \\
\text { AGACT } \\
\text { AGDOC } \\
\text { AGEQU } \\
\text { AGTOTAL } \\
\text { AGUSER } \\
\text { CAPTIONS } \\
\text { CATEGORY } \\
\text { CHAPTER } \\
\text { COHESP } \\
\text { COHESS } \\
\text { DATA INK } \\
\text { DOCUMENT } \\
\text { DOSWIN } \\
\text { FRSTYEAR } \\
\text { GLOSSARY } \\
\text { GOALSA } \\
\text { GRAPHSCR } \\
\text { INDEX } \\
\text { IREVGRPH } \\
\text { JARGON } \\
\text { LIEFACT } \\
\text { LISTCONS } \\
\text { LOGICAL } \\
\text { MISLEAD } \\
\text { MULTISTP } \\
\text { NO DUCK } \\
\text { PACKAGE } \\
\text { PAGES } \\
\text { PCORMAC } \\
\text { PRICE } \\
\text { PROC } \\
\text { PROCU } \\
\text { REFAID } \\
\text { SENTENCE } \\
\text { TASKHEAD } \\
\text { TEXT SCR } \\
\text { TOTSCORE } \\
\text { TYPOGRPH } \\
\text { UNREF } \\
\text { VERSION }\end{array}$ & $\begin{array}{l}\text { Advance Organizers Score } \\
\text { Agency - Action Score } \\
\text { Agency - Document Score } \\
\text { Agency - Equipment Score } \\
\text { Total Agency Score } \\
\text { Agency - Uber Score } \\
\text { Informative Captions Score } \\
\text { Category } \\
\text { Chapter Level Score } \\
\text { Cohesion - Paragraph Score } \\
\text { Cohesion - Section Score } \\
\text { NON-Data Ink Graphics Score } \\
\text { Document Level Score } \\
\text { DoS, Windows, Both, or Syetem } 7 \\
\text { First Year in Manual } \\
\text { Glossary to 28 Pages Score } \\
\text { Goals for Action Score } \\
\text { Total Graphics Score } \\
\text { Index to } 5 \text { per Page Score } \\
\text { NON-Irrelevant Graphics Score } \\
\text { Jargon Score } \\
\text { NON-Lie factors Graphics Score } \\
\text { List Consistency } \\
\text { Logical Conditions Score } \\
\text { NON-Misleading Graphics Score } \\
\text { Multiple Steps Score } \\
\text { No Duck RATIO Score } \\
\text { Package } \\
\text { Pages in Manual } \\
\text { PC or MacIntosh } \\
\text { Retail Price } \\
\text { Procedures - With Goals Score } \\
\text { Procedures - User Act1on Score } \\
\text { Reference Aids to } 9 \text { Score } \\
\text { Total Sentence Level Score } \\
\text { Task Headings Score } \\
\text { Total Text Score } \\
\text { Total Score for Manual } \\
\text { Typographic to 11 count score } \\
\text { Unnecessary References Score } \\
\text { Version }\end{array}$ \\
\hline
\end{tabular}


SPSS STATISTICAT PACKAGE

COMBINED FOR ATL FOUR SAMPLES

RE I I A B I L I T Y A A I I S I S - SCAIE (AI P B A)

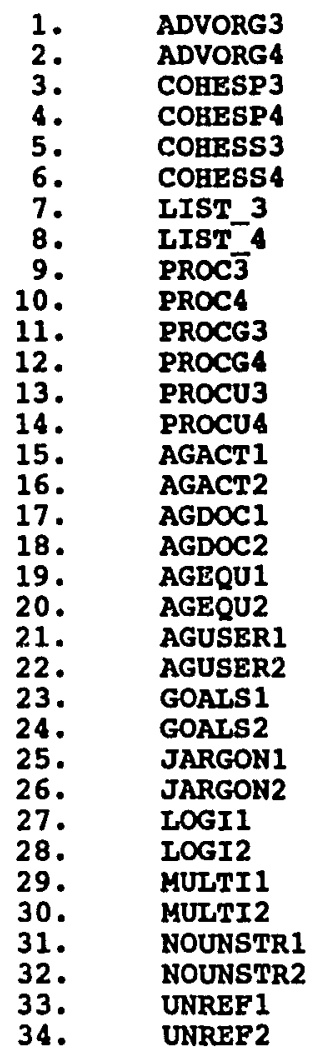

chapter 3 advance organlzer Bcore chapter 4 advance organizer score chapter 3 paragraph cohesion score chapter 4 paragraph cohesion score chapter 3 section cohesion score chapter 4 section cohesion score chapter 3 list consistency score chapter ilet consistency score chapter 3 proceuure with goals score chapter 4 procedure with goals acore chapter 3 graphics procedures score chapter 4 graphics procedures score chapter 3 user action in procedure chapter 4 user action in procedure chapter 1 action agency ecore chapter 2 action agency Bcore chapter 1 document agency acore chapter 2 document agency acore chapter 1 equipment agency Bcore chapter 2 equipment agency score chapter 1 user agency score chapter 2 usex agency score chapter 1 goals for action 8core chapter 2 goals for action score chapter 1 Jargon score chapter 2 jargon score

chapter 1 logical conditlons score chapter 2 logical conditions score chapter 1 multiple steps score chapter 2 multiple ateps score chapter 1 noun string score chapter 2 noun string score chapter 1 unnecessary references score chapter 2 unnecessary references score 
R B I A B I I I T A A LYBIB- BCAIB (A I P A ) Covarlance Matrix

$\begin{array}{lccccc} & \text { ADVORG3 } & \text { ADVORG4 } & \text { COHESP3 } & \text { COHESP4 } & \text { COHESS3 } \\ \text { ADVORG3 } & & & & & \\ \text { ADVORG4 } & .0685 & & & & \\ \text { COHESP3 } & .0142 & .0652 & & & \\ \text { COBESP4 } & .0032 & -.0006 & .0473 & .0651 & \\ \text { COHESS3 } & -.0051 & .0032 & .0240 & .0164 & .0227 \\ \text { COHESS4 } & -.0009 & .0043 & .0157 & .0164 \\ \text { LIST_3 } & .0008 & .0069 & .0232 & .0321 & .0145 \\ \text { LIST-4 } & .0069 & .0033 & .0018 & .0018 & -.0021 \\ \text { PROC3 } & -.0014 & -.0061 & -.0008 & .0027 & .0013 \\ \text { PROC4 } & .0388 & -.0104 & .0085 & -.0052 & .0036 \\ \text { PROCG3 } & .0106 & .0226 & .0242 & .0240 & .0069 \\ \text { PROCG4 } & .0171 & -.0146 & .0099 & .0114 & .0027 \\ \text { PROCU3 } & .0109 & -.0054 & .0088 & .0170 & .0088 \\ \text { PROCU4 } & .0111 & -.0083 & .0043 & -.0052 & .0019 \\ \text { AGACT1 } & .0046 & -.0048 & .0039 & .0074 & .0050 \\ \text { AGACT2 } & .0024 & -.0010 & .0023 & .0004 & .0012 \\ \text { AGDOC1 } & .0039 & -.0017 & .0016 & -.0012 & .0015 \\ \text { AGDOC2 } & .0018 & -.0010 & .0001 & .0037 & .0012 \\ \text { AGEQU1 } & .0021 & .0000 & .0014 & .0018 & .0004 \\ \text { AGEQU2 } & .0028 & .0045 & .0057 & .0032 & .0053 \\ \text { AGUSER1 } & -.0065 & -.0057 & .0073 & .0071 & .0029 \\ \text { AGUSER2 } & -.0004 & -.0079 & -.0011 & .0023 & .0016 \\ \text { GOALS1 } & .0062 & .0058 & .0061 & .0061 & .0086 \\ \text { GOALS2 } & -.0107 & .0061 & .0062 & .0139 & .0059 \\ \text { JARGON1 } & .0095 & .0146 & .0114 & .0147 & .0069 \\ \text { JARGON2 } & .0022 & .0022 & .0115 & .0112 & .0120 \\ \text { LOGI1 } & .0047 & .0040 & .0233 & .0228 & .0157 \\ \text { LOGI2 } & -.0001 & -.0016 & .0038 & .0021 & .0030 \\ \text { MULTI1 } & -.0083 & .0052 & .0028 & .0051 & .0045 \\ \text { MULTI2 } & .0012 & -.0032 & .0111 & .0083 & .0111 \\ \text { NOUNSTR1 } & .0052 & .0011 & .0233 & .0218 & .0153 \\ \text { NOUNSTR2 } & .0018 & .0012 & .0125 & .0104 & .0119 \\ \text { UNREF1 } & .0032 & .0044 & .0223 & .0215 & .0152 \\ \text { UNREF2 } & .0027 & .0011 & .0112 & .0106 & .0117 \\ & .0032 & .0036 & .0230 & .0226 & .0157\end{array}$


R E I I B I I T X A A I Y I I - B C I E (A I P B A)

Covarlance Matrix

\begin{tabular}{|c|c|c|c|c|c|}
\hline & COAESS4 & IIST_3 & II8T_4 & RROC3 & PROC4 \\
\hline $\begin{array}{l}\text { COBESS4 } \\
\text { IIST_3 } \\
\text { IIST 4 } \\
\text { PROC3 } \\
\text { PROC4 } \\
\text { PROCG3 } \\
\text { PROCG4 } \\
\text { PROCU3 } \\
\text { PROCU4 } \\
\text { AGACT1 } \\
\text { AGACT2 } \\
\text { AGDOC1 } \\
\text { AGDOC2 } \\
\text { AGEQU1 } \\
\text { AGEQU2 } \\
\text { AGUSER1 } \\
\text { AGUSER2 } \\
\text { GOALS1 } \\
\text { GOALS2 } \\
\text { JARGON1 } \\
\text { JARGON2 } \\
\text { IOGI1 } \\
\text { IOGI2 } \\
\text { MULTI1 } \\
\text { MULTI2 } \\
\text { NOUNSTR1 } \\
\text { NOUNSTR2 } \\
\text { UNREF1 } \\
\text { UNREF2 }\end{array}$ & $\begin{array}{l}.0504 \\
.0026 \\
-.0007 \\
.0083 \\
.0220 \\
.0194 \\
.0273 \\
.0003 \\
.0172 \\
.0014 \\
.0000 \\
.0000 \\
.0018 \\
.0017 \\
.0021 \\
.0072 \\
.0149 \\
.0052 \\
.0186 \\
.0116 \\
.0234 \\
.0047 \\
.0050 \\
.0110 \\
.0225 \\
.0112 \\
.0228 \\
.0110 \\
.0229\end{array}$ & $\begin{array}{r}.0226 \\
.0016 \\
-.0018 \\
-.0016 \\
.0038 \\
.0000 \\
.0045 \\
.0027 \\
-.0003 \\
.0015 \\
-.0019 \\
-.0006 \\
-.0013 \\
-.0037 \\
-.0028 \\
.0006 \\
-.0032 \\
.0042 \\
.0002 \\
.0011 \\
-.0001 \\
.0016 \\
-.0129 \\
.0000 \\
-.0001 \\
.0002 \\
.0003 \\
.0004\end{array}$ & $\begin{array}{r}.0217 \\
-.0055 \\
-.0030 \\
-.0044 \\
.0025 \\
.0006 \\
-.0007 \\
.0009 \\
.0005 \\
-.0014 \\
-.0008 \\
.0018 \\
-.0010 \\
-.0005 \\
.0037 \\
-.0022 \\
-.0034 \\
.0005 \\
.0009 \\
.0031 \\
-.0001 \\
-.0034 \\
.0003 \\
.0004 \\
.0005 \\
.0005 \\
.0010\end{array}$ & $\begin{array}{r}.1814 \\
.0724 \\
.0630 \\
.0221 \\
.0449 \\
.0117 \\
.0063 \\
.0044 \\
-.0022 \\
-.0019 \\
.0052 \\
-.0121 \\
.0010 \\
.0174 \\
-.0003 \\
.0007 \\
.0076 \\
.0032 \\
-.0029 \\
-.0111 \\
.0075 \\
.0036 \\
.0078 \\
.0000 \\
.0070 \\
.0019\end{array}$ & $\begin{array}{r}.1632 \\
.0098 \\
.0068 \\
.0026 \\
.0162 \\
.0042 \\
.0008 \\
.0006 \\
.0022 \\
.0073 \\
-.0057 \\
-.0059 \\
.0147 \\
.0051 \\
-.0018 \\
.0081 \\
.0158 \\
-.0001 \\
-.0017 \\
.0051 \\
.0147 \\
.0091 \\
.0145 \\
.0079 \\
.0154\end{array}$ \\
\hline
\end{tabular}


REI I A B I I I Y ANAIYSIS- 6 CAIB (A L P A A) Covariance Matrix

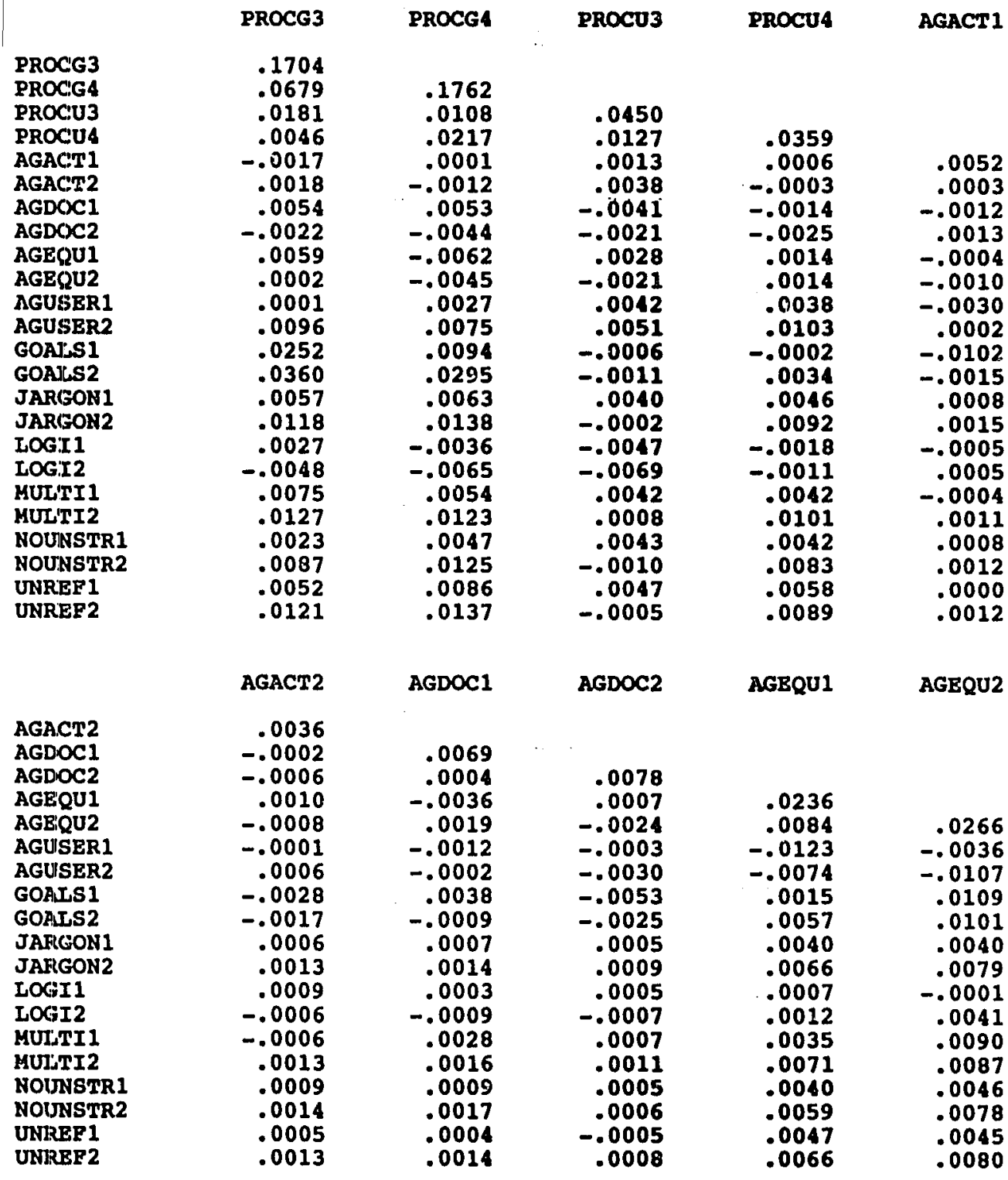

RE L I A B I L I T Y A N A I Y I S - S CAIE (A L P B A)

Covariance Matrix

AGUSER1 AGUSER2 GOALS1 GOALS2 JARGON1

$\begin{array}{llllll}\text { AGUSER1 } & .0309 & & & & \\ \text { AGUSER2 } & .0108 & .0399 & & & \\ \text { GOALS1 } & .0141 & .0068 & .1000 & \\ \text { GOALS2 } & .0051 & .0126 & .0252 & .1103 & \\ \text { JARGON1 } & .0054 & .0052 & .0089 & .0088 & .0123 \\ \text { JARGON2 } & .0007 & .0105 & .0054 & .0176 & .0121 \\ \text { LOGI1 } & .0025 & .0069 & .0060 & .0080 & .0018\end{array}$




\begin{tabular}{|c|c|c|c|c|c|}
\hline \multirow[t]{2}{*}{$\begin{array}{l}\text { LOGI2 } \\
\text { MULTI1 } \\
\text { MULTI2 } \\
\text { NOUNSTR1 } \\
\text { NOUNSTR2 } \\
\text { UNREF1 } \\
\text { UNRER2 }\end{array}$} & $\begin{array}{r}-.0017 \\
.0104 \\
.0018 \\
.0051 \\
.0008 \\
.0062 \\
.0010\end{array}$ & $\begin{array}{l}.0002 \\
.0052 \\
.0093 \\
.0046 \\
.0099 \\
.0054 \\
.0110\end{array}$ & $\begin{array}{l}.0023 \\
.0189 \\
.0065 \\
.0078 \\
.0053 \\
.0106 \\
.0055\end{array}$ & $\begin{array}{l}.0038 \\
.0091 \\
.0181 \\
.0065 \\
.0153 \\
.0100 \\
.0169\end{array}$ & $\begin{array}{l}.0021 \\
.0120 \\
.0120 \\
.0120 \\
.0118 \\
.0122 \\
.0120\end{array}$ \\
\hline & JARGON2 & IOGI 1 & LOGI2 & MULTI1 & MULTI2 \\
\hline \multirow[t]{2}{*}{$\begin{array}{l}\text { JARGON2 } \\
\text { LOGI1 } \\
\text { LOGI2 } \\
\text { MULTI1 } \\
\text { HULTI2 } \\
\text { NOUNSTR1 } \\
\text { NOUNSTR2 } \\
\text { UNREF1 } \\
\text { UNREF2 }\end{array}$} & $\begin{array}{l}.0243 \\
.0029 \\
.0041 \\
.0117 \\
.0240 \\
.0120 \\
.0237 \\
.0119 \\
.0241\end{array}$ & $\begin{array}{l}.0116 \\
.0020 \\
.0023 \\
.0028 \\
.0018 \\
.0029 \\
.0017 \\
.0030\end{array}$ & $\begin{array}{r}.0135 \\
-.0008 \\
.0029 \\
.0015 \\
.0043 \\
.0019 \\
.0042\end{array}$ & $\begin{array}{l}.0318 \\
.0140 \\
.0120 \\
.0128 \\
.0125 \\
.0120\end{array}$ & $\begin{array}{l}.0247 \\
.0119 \\
.0234 \\
.0122 \\
.0238\end{array}$ \\
\hline & NOUNSTR1 & NOUNSTR2 & UTREP I & UKREE2 & \\
\hline $\begin{array}{l}\text { NOUNSTR1 } \\
\text { NOUNSTR2 } \\
\text { UNREF1 } \\
\text { UNREF2 }\end{array}$ & $\begin{array}{l}.0122 \\
.0118 \\
.0119 \\
.0120\end{array}$ & $\begin{array}{l}.0238 \\
.0117 \\
.0236\end{array}$ & $\begin{array}{l}.0136 \\
.0118\end{array}$ & .0243 & \\
\hline
\end{tabular}


R B I I A B I L I T Y A N A I S I S - S C A I B (A I P A A) Correlation Matrix

\begin{tabular}{|c|c|c|c|c|c|}
\hline & ADVORG3 & ADVORG4 & CORBSP 3 & COABSP4 & COHBSS3 \\
\hline $\begin{array}{l}\text { ADVORG3 } \\
\text { ADVORG4 } \\
\text { COHESP3 } \\
\text { COHESP4 } \\
\text { COHESS3 } \\
\text { CORESS4 } \\
\text { LIST_3 } \\
\text { LIST 4 } \\
\text { PROC5 } \\
\text { PROC4 } \\
\text { PROCG3 } \\
\text { PROCG4 } \\
\text { PROCU3 } \\
\text { PROCU4 } \\
\text { AGACT1 } \\
\text { AGACT2 } \\
\text { AGDOC1 } \\
\text { AGDOC2 } \\
\text { AGEQU1 } \\
\text { AGEQU2 } \\
\text { AGUSER1 } \\
\text { AGUSER2 } \\
\text { GOALS1 } \\
\text { GOALS2 } \\
\text { JARGON1 } \\
\text { JARGON2 } \\
\text { LOGI1 } \\
\text { LOGI2 } \\
\text { MULTI1 } \\
\text { MULTI2 } \\
\text { NOUNSTR1 } \\
\text { NOUNSTR2 } \\
\text { UNREF1 } \\
\text { UNREF2 }\end{array}$ & $\begin{array}{r}1.0000 \\
.2120 \\
.0566 \\
-.0758 \\
-.0239 \\
.0129 \\
.1753 \\
-.0373 \\
.3483 \\
.0999 \\
.1587 \\
.0989 \\
.2003 \\
.0934 \\
.1282 \\
.2500 \\
.0813 \\
.0891 \\
.0697 \\
-.1513 \\
-.0086 \\
.1181 \\
-.1291 \\
.1091 \\
.0746 \\
.1145 \\
-.0038 \\
-.2736 \\
.0264 \\
.1273 \\
.0626 \\
.0801 \\
.0891 \\
.0791\end{array}$ & $\begin{array}{r}1.0000 \\
-.0106 \\
.0493 \\
.1115 \\
.1201 \\
.0851 \\
-.1091 \\
-.0960 \\
.2196 \\
-.1382 \\
-.0505 \\
-.1531 \\
-.0995 \\
-.0527 \\
-.1112 \\
-.0485 \\
-.0011 \\
.1149 \\
-.1369 \\
-.1754 \\
.1132 \\
.0750 \\
.1727 \\
.0777 \\
.1013 \\
-.0583 \\
.1752 \\
-.0711 \\
.0270 \\
.0436 \\
.1115 \\
.0385 \\
.0911\end{array}$ & $\begin{array}{r}1.0000 \\
.4316 \\
.4805 \\
.4745 \\
.0536 \\
-.0254 \\
.0920 \\
.2756 \\
.1107 \\
.0961 \\
.0922 \\
.0942 \\
.1471 \\
.1200 \\
.0041 \\
.0741 \\
.1716 \\
.2049 \\
. .0281 \\
.1401 \\
.0903 \\
.1579 \\
.4775 \\
.6853 \\
.1603 \\
.1090 \\
.2850 \\
.6811 \\
.5205 \\
.6632 \\
.4425 \\
.6793\end{array}$ & $\begin{array}{r}1.0000 \\
.4271 \\
.5603 \\
.0463 \\
.0725 \\
-.0482 \\
.2330 \\
.1080 \\
.1588 \\
-.0963 \\
.1536 \\
.0193 \\
-.0818 \\
.1726 \\
.0806 \\
.0822 \\
.1706 \\
.0506 \\
.1190 \\
.1723 \\
.1730 \\
.3960 \\
.5737 \\
.0747 \\
.1728 \\
.1828 \\
.5422 \\
.3679 \\
.5453 \\
.3572 \\
.5681\end{array}$ & $\begin{array}{r}1.0000 \\
.4297 \\
-.0948 \\
.0594 \\
.0557 \\
.1126 \\
.0432 \\
.1395 \\
.0590 \\
.1752 \\
.1075 \\
.1707 \\
.0947 \\
.0294 \\
.2309 \\
.1194 \\
.0598 \\
.2844 \\
.1236 \\
.1378 \\
.7155 \\
.6697 \\
.1822 \\
.2595 \\
.4137 \\
.6481 \\
.7129 \\
.6524 \\
.6662 \\
.6695\end{array}$ \\
\hline
\end{tabular}


R E I I A B I I I T Y A Y A I Y S I S - S C A L B (A I P H A) Correlation Matrix

\begin{tabular}{|c|c|c|c|c|c|}
\hline & COHBSS4 & IIST_3 & IIIST_A & PROC3 & PROC4 \\
\hline $\begin{array}{l}\text { COHESS4 } \\
\text { IIST 3 } \\
\text { LIST14 } \\
\text { PROC3 } \\
\text { PROC4 } \\
\text { PROCG3 } \\
\text { PROCG4 } \\
\text { PROCU3 } \\
\text { PROCU4 } \\
\text { AGACT1 } \\
\text { AGACT2 } \\
\text { AGDOC1 } \\
\text { AGDOC2 } \\
\text { AGEQU1 } \\
\text { AGEQU2 } \\
\text { AGUSER1 } \\
\text { AGUSER2 } \\
\text { GOALS1 } \\
\text { GOALS2 } \\
\text { JARGOH1 } \\
\text { JARGON2 } \\
\text { LOGI1 } \\
\text { LOGI2 } \\
\text { MULTI1 } \\
\text { MULTI2 } \\
\text { NOUNSTR1 } \\
\text { NOUNSTR2 } \\
\text { UNREF1 } \\
\text { UNREF2 }\end{array}$ & $\begin{array}{r}1.0000 \\
.0757 \\
-.0215 \\
.0870 \\
.2425 \\
.2092 \\
.2895 \\
.0058 \\
.4039 \\
.0876 \\
.0023 \\
. .0001 \\
.0900 \\
.0505 \\
.0574 \\
.1824 \\
.3318 \\
.0731 \\
.2489 \\
.4648 \\
.6681 \\
.1955 \\
.1912 \\
.2738 \\
.6385 \\
.4509 \\
.6579 \\
.4202 \\
.6541\end{array}$ & $\begin{array}{r}1.0000 \\
.0700 \\
-.0279 \\
-.0270 \\
.0617 \\
.0001 \\
.1403 \\
.0951 \\
-.0285 \\
.1721 \\
-.1522 \\
-.0434 \\
-.0544 \\
-.1491 \\
-.1043 \\
.0203 \\
-.0683 \\
.0845 \\
.0126 \\
.0450 \\
-.0051 \\
.0927 \\
-.4803 \\
-.0010 \\
-.0057 \\
.0083 \\
.0161 \\
.0187\end{array}$ & $\begin{array}{r}1.0000 \\
-.0881 \\
-.0497 \\
-.0721 \\
.0410 \\
.0202 \\
-.0262 \\
.0844 \\
.0586 \\
-.1170 \\
-.0615 \\
.0809 \\
-.0414 \\
-0.0189 \\
.1244 \\
-.0475 \\
-.0703 \\
.0315 \\
.0413 \\
.1961 \\
-.0083 \\
-.1284 \\
.0131 \\
.0238 \\
.0228 \\
.0266 \\
.0426\end{array}$ & $\begin{array}{r}1.0000 \\
.4208 \\
.3581 \\
.1238 \\
.4967 \\
.1452 \\
.2049 \\
.1730 \\
-.0623 \\
-.0513 \\
.0800 \\
-.1744 \\
.0132 \\
.2042 \\
-.0620 \\
.0053 \\
.1596 \\
.0474 \\
-.0624 \\
-.2235 \\
.0989 \\
.0539 \\
.1655 \\
.0003 \\
.1406 \\
.0282\end{array}$ & $\begin{array}{r}1.0000 \\
.0588 \\
.0404 \\
.0305 \\
.2113 \\
.1453 \\
.0313 \\
.0190 \\
.0627 \\
.1182 \\
-.0861 \\
-.0831 \\
.1815 \\
.0399 \\
-.0133 \\
.1813 \\
.2503 \\
-.0026 \\
-.0368 \\
.0715 \\
.2314 \\
.2035 \\
.2328 \\
.1668 \\
.2439\end{array}$ \\
\hline
\end{tabular}


R E I I A B I I I T Y A A I Y I I - 8 C A I E (A I R A )

Correlation Matrix

\begin{tabular}{|c|c|c|c|c|c|}
\hline & PROCG3 & PROCG 4 & PROCU3 & PROCO4 & AGACT1 \\
\hline \multirow[t]{2}{*}{$\begin{array}{l}\text { PROCG3 } \\
\text { PROCG4 } \\
\text { PROCU3 } \\
\text { PROCU4 } \\
\text { AGACT1 } \\
\text { AGACT2 } \\
\text { AGDOC1 } \\
\text { AGDOC2 } \\
\text { AGEQU1 } \\
\text { AGEQU2 } \\
\text { AGUSER1 } \\
\text { AGUSER2 } \\
\text { GOALS1 } \\
\text { GOALS2 } \\
\text { JARGON1 } \\
\text { JARGON2 } \\
\text { IOGI1 } \\
\text { LOGI2 } \\
\text { HULTI1 } \\
\text { MULTI2 } \\
\text { NOUNSTR1 } \\
\text { NOUNSTR2 } \\
\text { UNREF1 } \\
\text { UNREF2 }\end{array}$} & $\begin{array}{r}1.0000 \\
.3919 \\
.2064 \\
.0586 \\
-.0560 \\
.0736 \\
.1568 \\
-.0607 \\
.0936 \\
.0027 \\
.0011 \\
.1166 \\
.1927 \\
.2626 \\
.1250 \\
.1837 \\
.0597 \\
-.0993 \\
.1014 \\
.1965 \\
.0512 \\
.1369 \\
.1071 \\
.1882\end{array}$ & $\begin{array}{r}1.0000 \\
.1212 \\
.2724 \\
.0021 \\
-.0484 \\
.1525 \\
-.1179 \\
-.0955 \\
-.0658 \\
.0364 \\
.0895 \\
.0710 \\
.2118 \\
.1346 \\
.2104 \\
-.0801 \\
-.1324 \\
.0727 \\
.1862 \\
.1011 \\
.1938 \\
.1746 \\
.2096\end{array}$ & $\begin{array}{r}1.0000 \\
.3159 \\
.0819 \\
.2953 \\
-.2304 \\
-.1109 \\
.0856 \\
-.0614 \\
.1123 \\
.1201 \\
-.0093 \\
-.0156 \\
.1703 \\
-.0053 \\
-.2046 \\
-.2780 \\
.1108 \\
.0240 \\
.1814 \\
-.0304 \\
.1887 \\
-.0145\end{array}$ & $\begin{array}{r}1.0000 \\
.0470 \\
-.0221 \\
-.0865 \\
-.1507 \\
.0496 \\
.0454 \\
.1127 \\
.2709 \\
-.0036 \\
.0538 \\
.2166 \\
.3113 \\
-.0873 \\
-.0498 \\
.1235 \\
.3382 \\
.2010 \\
.2839 \\
.2605 \\
.3016\end{array}$ & $\begin{array}{r}1.0000 \\
.0780 \\
-.1995 \\
1937 \\
-.0400 \\
-.0812 \\
-.2393 \\
.0115 \\
-.4455 \\
-.0636 \\
.0985 \\
.1292 \\
-.0687 \\
.0644 \\
-.0273 \\
.0924 \\
.1010 \\
.1113 \\
-.0044 \\
.1086\end{array}$ \\
\hline & AGACT2 & AGDOC1 & AGDOC2 & MGBQU1 & AGEQU2 \\
\hline $\begin{array}{l}\text { AGACT2 } \\
\text { AGDOC1 } \\
\text { AGDOC2 } \\
\text { AGEQU1 } \\
\text { AGEQU2 } \\
\text { AGUSER1 } \\
\text { AGUSER2 } \\
\text { GOALS1 } \\
\text { GOALS2 } \\
\text { JARGON1 } \\
\text { JARGON2 } \\
\text { LOGI1 } \\
\text { LOGI2 } \\
\text { MULTI1 } \\
\text { MULTI2 } \\
\text { NOUNSTR1 } \\
\text { NOUNSTR2 } \\
\text { UNREF1 } \\
\text { UNREF2 }\end{array}$ & $\begin{array}{r}1.0000 \\
-.0492 \\
-.1139 \\
.1036 \\
-.0812 \\
-.0105 \\
.0532 \\
-.1454 \\
-.0875 \\
.0891 \\
.1371 \\
.1448 \\
-.0827 \\
-.0565 \\
.1397 \\
.1361 \\
.1477 \\
.0686 \\
.1339\end{array}$ & $\begin{array}{r}1.0000 \\
.0566 \\
-.2807 \\
.1415 \\
-.0801 \\
-.0137 \\
.1457 \\
-.0319 \\
.0735 \\
.1118 \\
.0389 \\
-.0935 \\
.1904 \\
.1196 \\
.0933 \\
.1302 \\
.0403 \\
.1115\end{array}$ & $\begin{array}{r}1.0000 \\
.0491 \\
-.1644 \\
-.0185 \\
-.01676 \\
-.1914 \\
-.0863 \\
.0461 \\
.0629 \\
.0508 \\
-.0654 \\
.0464 \\
.0790 \\
.0485 \\
.0435 \\
-.0528 \\
.0545\end{array}$ & $\begin{array}{r}1.0000 \\
.3366 \\
-.4570 \\
-.2402 \\
.0319 \\
.1121 \\
.2358 \\
.2771 \\
.0436 \\
.0683 \\
.1262 \\
.2962 \\
.2336 \\
.2497 \\
.2599 \\
.2741\end{array}$ & $\begin{array}{r}1.0000 \\
-.1270 \\
-.3288 \\
.2111 \\
.1871 \\
.2224 \\
.3113 \\
-.0082 \\
.2151 \\
.3101 \\
.3391 \\
.2519 \\
.3087 \\
.2377 \\
.3161\end{array}$ \\
\hline
\end{tabular}


R E I I A B I I I T Y A A I Y S I S - - S C A I B (A I P B A) Correlation Hatrix

\begin{tabular}{|c|c|c|c|c|c|}
\hline & AGUSERI & AGUSBR2 & COALS1 & Gonss2 & JARGOH 1 \\
\hline \multirow[t]{2}{*}{$\begin{array}{l}\text { AGUSER1 } \\
\text { AGUSER2 } \\
\text { GOALS1 } \\
\text { GOALS2 } \\
\text { JARGON1 } \\
\text { JARGON2 } \\
\text { LOGI1 } \\
\text { LOGI2 } \\
\text { MULTI1 } \\
\text { MULTI2 } \\
\text { NOUNSTR1 } \\
\text { NOUNSTR2 } \\
\text { UNREF1 } \\
\text { UNREP2 }\end{array}$} & $\begin{array}{r}1.0000 \\
.3086 \\
.2532 \\
.0867 \\
.2760 \\
.0245 \\
.1339 \\
-.0821 \\
.3332 \\
.0639 \\
.2636 \\
.0292 \\
.3038 \\
.0379\end{array}$ & $\begin{array}{r}1.0000 \\
.1079 \\
.1897 \\
.2339 \\
.3382 \\
.3211 \\
.0078 \\
.1448 \\
.2946 \\
.2078 \\
.3223 \\
.2323 \\
.3538\end{array}$ & $\begin{array}{r}1.0000 \\
.2403 \\
.2543 \\
.1092 \\
.1752 \\
.0626 \\
.3355 \\
.1305 \\
.2216 \\
.1090 \\
.2871 \\
.1121\end{array}$ & $\begin{array}{r}1.0000 \\
.2387 \\
.3403 \\
.2218 \\
.0977 \\
.1532 \\
.3457 \\
.1772 \\
.2992 \\
.2573 \\
.3270\end{array}$ & $\begin{array}{r}1.0000 \\
.6988 \\
.1536 \\
.1613 \\
.6070 \\
.6857 \\
.9773 \\
.6894 \\
.9373 \\
.6934\end{array}$ \\
\hline & JARGON2 & LOGII & IOGI2 & MULTI1 & MULTI2 \\
\hline \multirow[t]{2}{*}{$\begin{array}{l}\text { JARGON2 } \\
\text { LOGI1 } \\
\text { LOGI2 } \\
\text { MULTI1 } \\
\text { MULTI2 } \\
\text { NOUNSTR1 } \\
\text { NOUNSTR2 } \\
\text { UNREF1 } \\
\text { UNREF2 }\end{array}$} & $\begin{array}{r}1.0000 \\
.1743 \\
.2271 \\
.4200 \\
.9780 \\
.6942 \\
.9853 \\
.6512 \\
.9919\end{array}$ & $\begin{array}{r}1.0000 \\
.1610 \\
.1206 \\
.1643 \\
.1542 \\
.1772 \\
.1385 \\
.1801\end{array}$ & $\begin{array}{r}1.0000 \\
-.0381 \\
.1592 \\
.1179 \\
.2404 \\
.1390 \\
.2306\end{array}$ & $\begin{array}{r}1.0000 \\
.4991 \\
.6083 \\
.4646 \\
.6028 \\
.4305\end{array}$ & $\begin{array}{r}1.0000 \\
.6825 \\
.9659 \\
.6627 \\
.9710\end{array}$ \\
\hline & NOUNSTR1 & NOUNSTR2 & UARBP1 & URRBP2 & \\
\hline $\begin{array}{l}\text { NOUNSTR1 } \\
\text { NOUNSTR2 } \\
\text { UNREF1 } \\
\text { UNREF2 }\end{array}$ & $\begin{array}{r}1.0000 \\
.6943 \\
.9217 \\
.6929\end{array}$ & $\begin{array}{r}1.0000 \\
.6492 \\
.9799\end{array}$ & $\begin{array}{r}1.0000 \\
.6484\end{array}$ & 1.0000 & \\
\hline
\end{tabular}




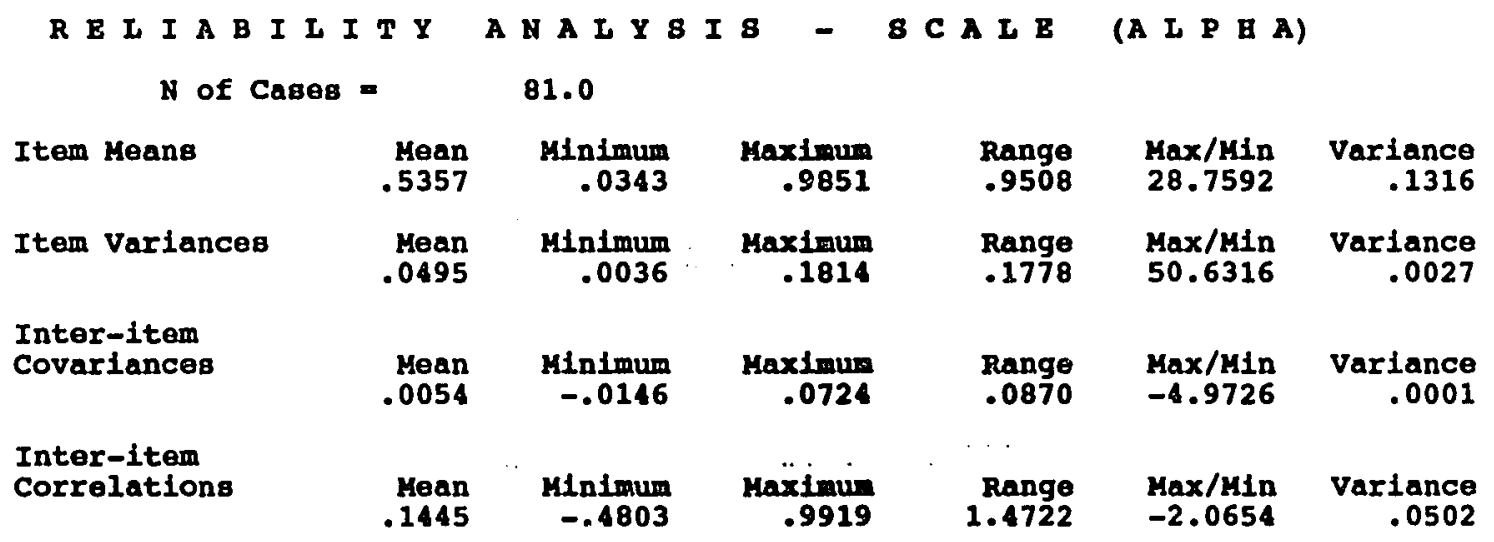

Analysis of variance

$\begin{array}{cccrrr}\text { Source of Variation } & \text { Sum of Sq. } & \text { DF } & \text { Mean square } & \text { F } & \text { Prob. } \\ \text { Between People } & 18.1737 & 80 & .2272 & & \\ \text { Within People } & 468.0846 & 2673 & .1751 & \\ \text { Between Measures } & 351.6360 & 33 & 10.6556 & 241.5732 & .0000 \\ \text { Residual } & 116.4487 & 2640 & .0441 & & \\ \text { Total Grand Hean } & .5357 & 2753 & .1766 & & \end{array}$

\footnotetext{
Rellability Coefficients

34 items

Alpha $=.8058$

Standardized Item alpha $=.8517$
} 
Correlation Analyois of Combined Variablea - Correlation coefficients - -

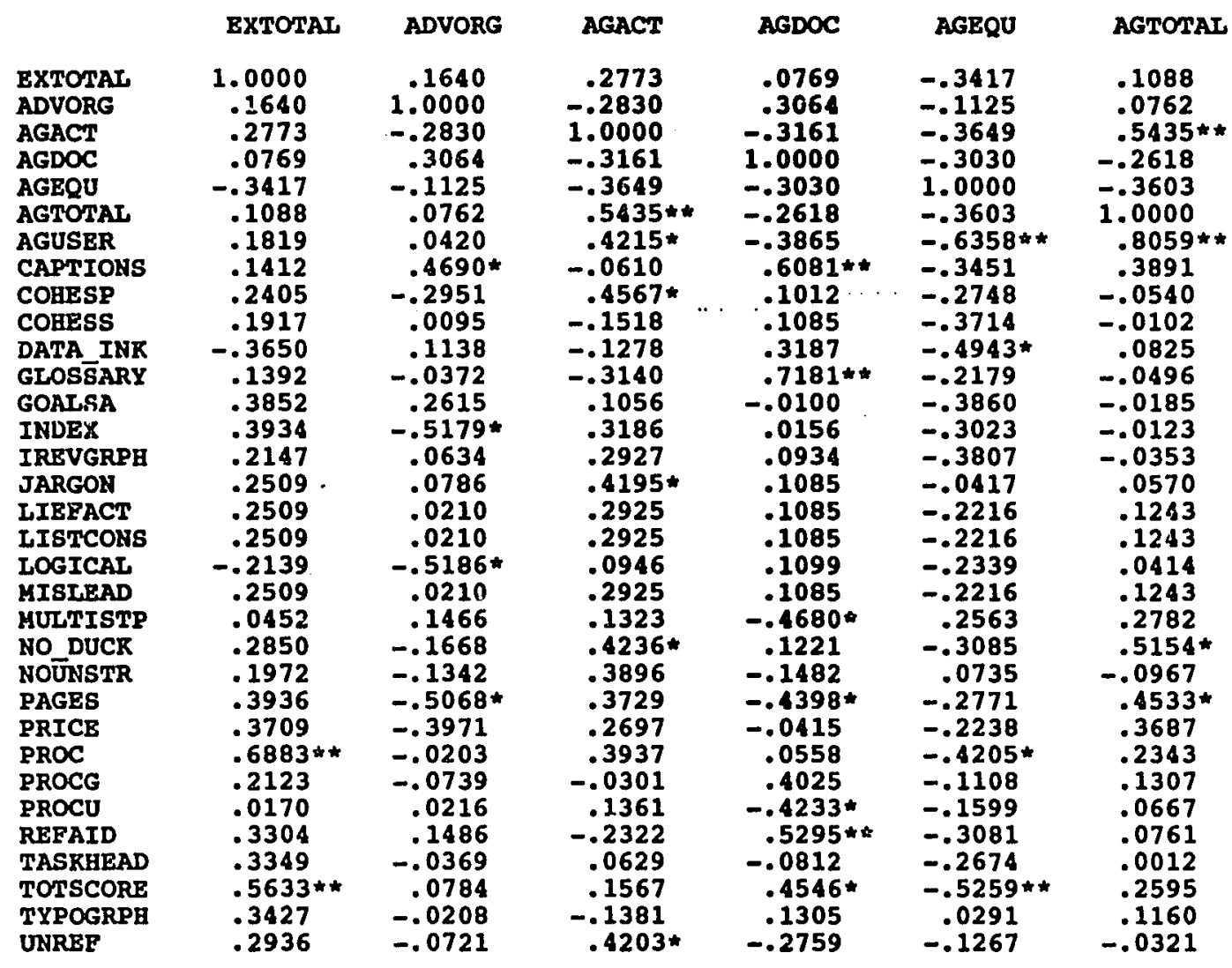

*-signif. LE .05 * - signif. IE .01 (2-tailed)

" " is printed if a coefficient cannot be computed 
- Correlation coefficients - -

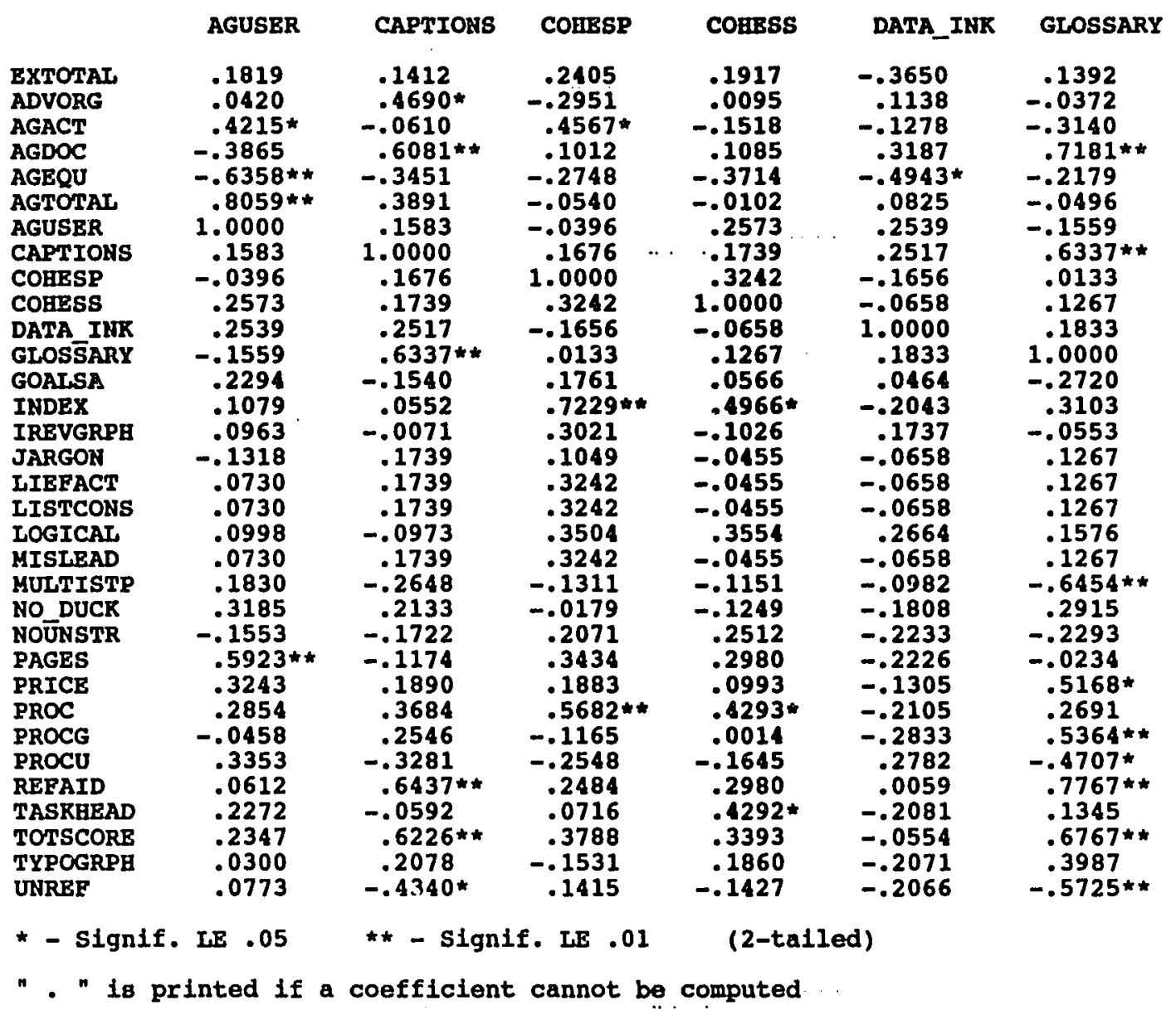




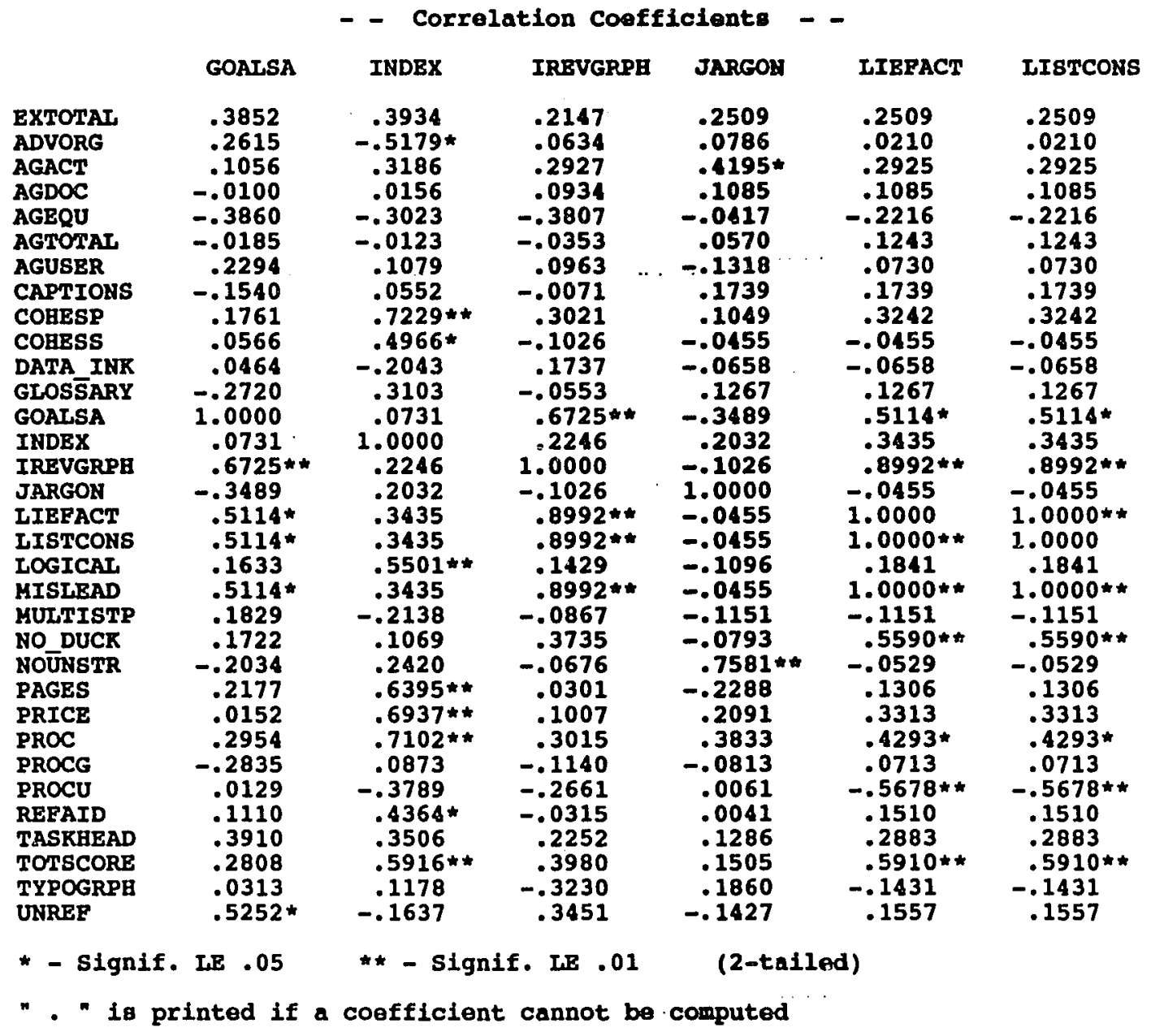




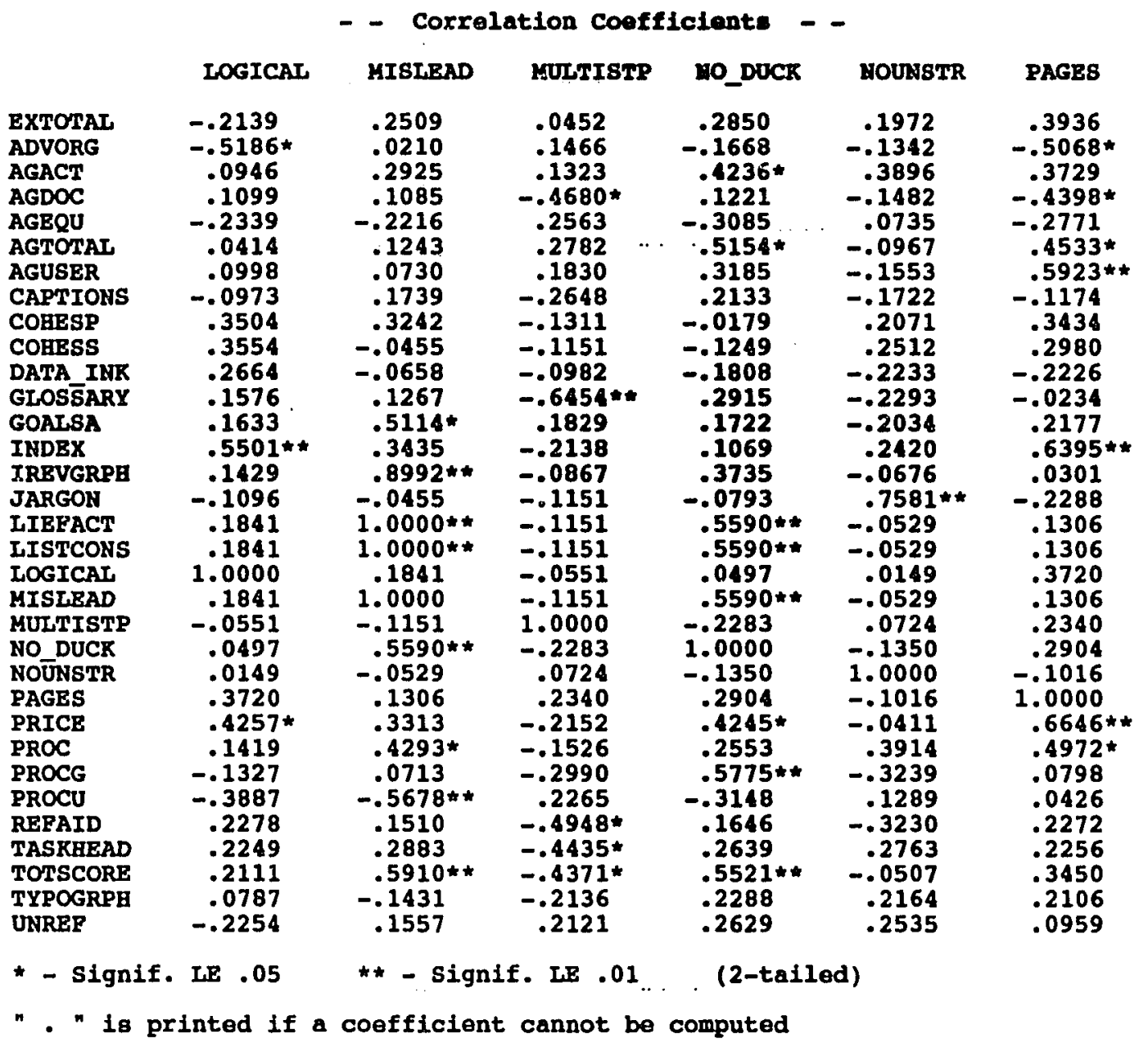


- Correlation Coefficients - -

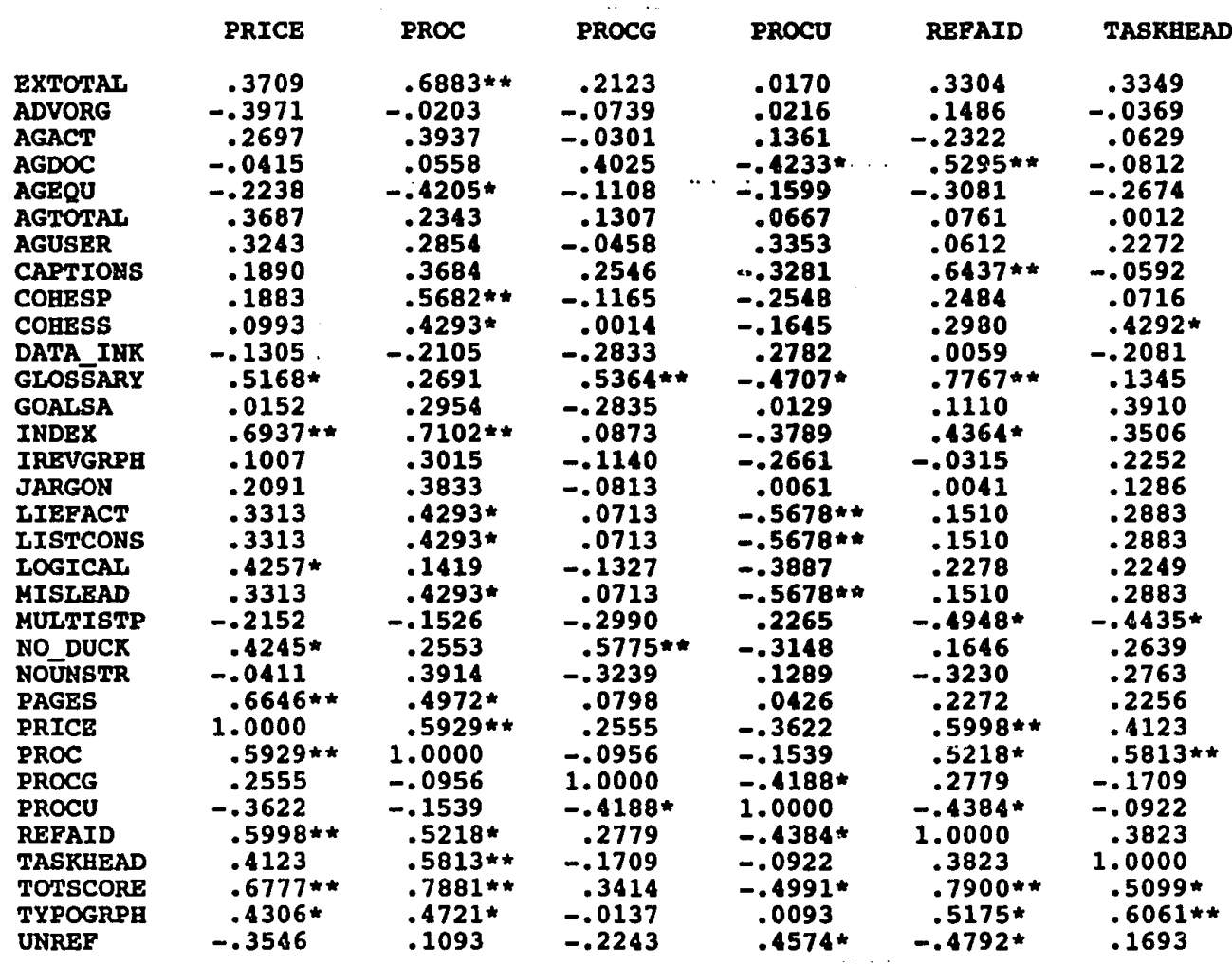

* - Signif. LE .05 ** - signif. Le .01”' (2-tailed)

". " is printed if a coefficient cannot be computed 


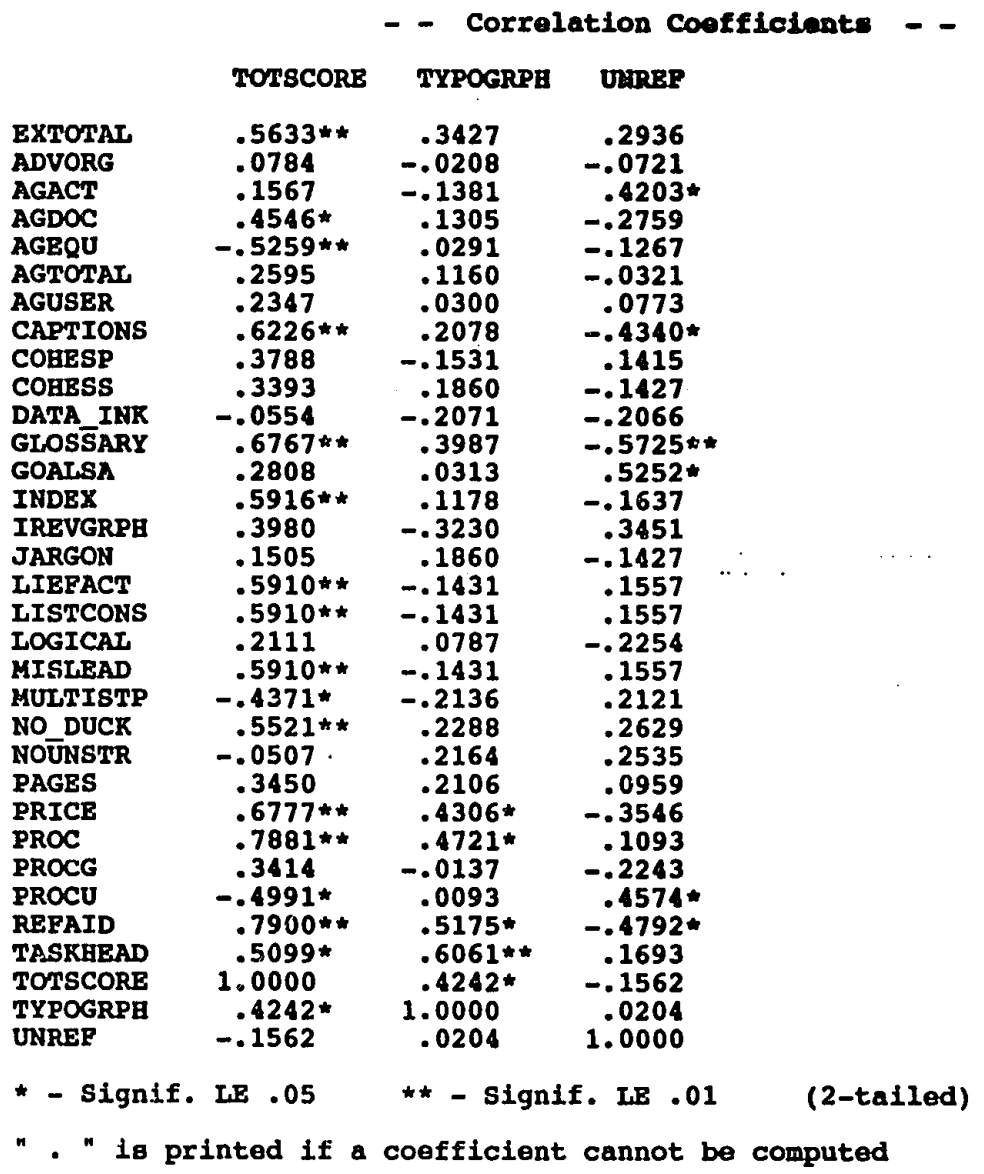




\section{- - Correlation Coefficients - -}

EXTOTAL DOCUMENT CHAPTER SENTEMTE TEXT_SCR

GRAPHSCR

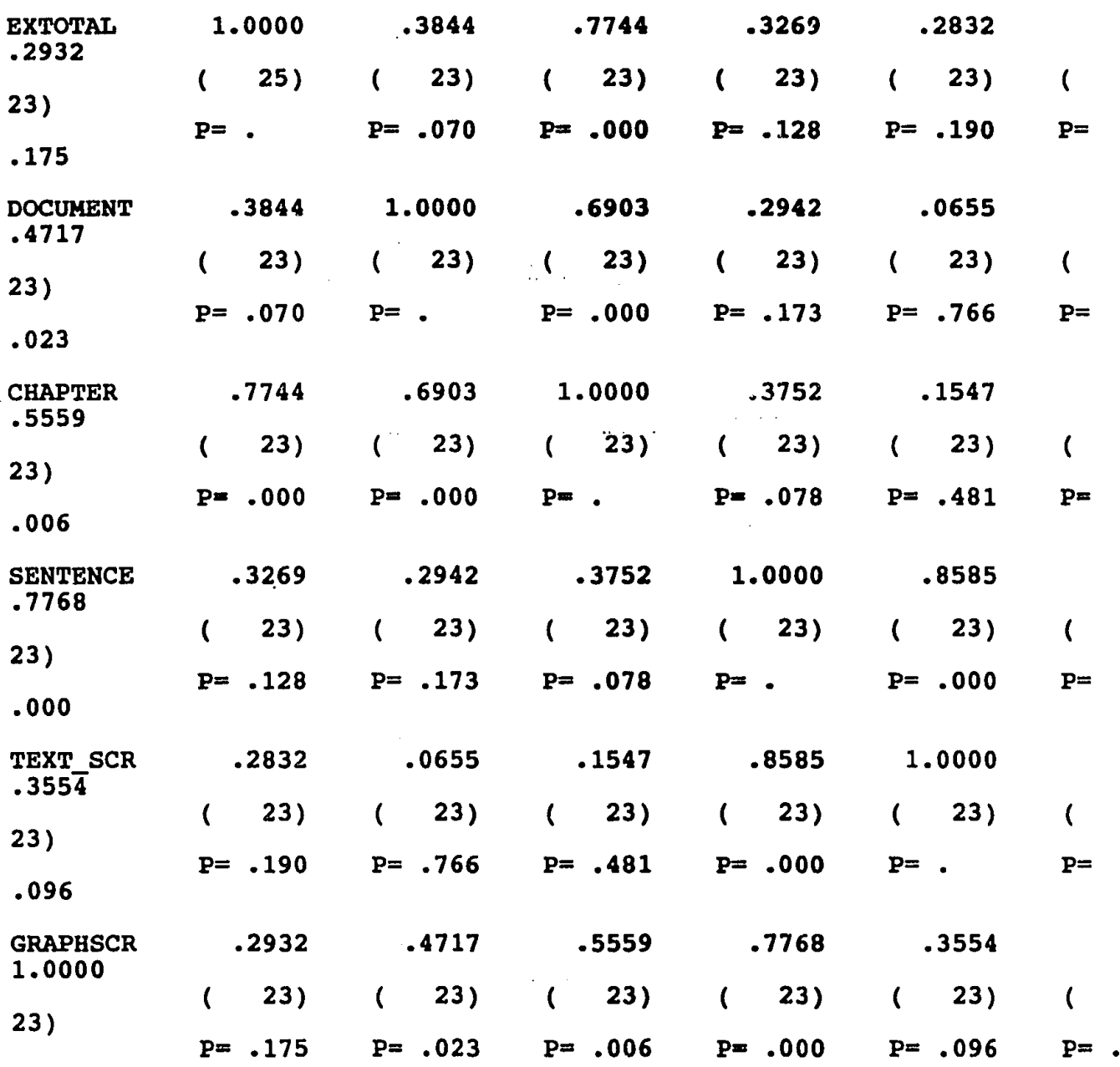

(Coefficient / (Cases) /.2-tailed significance)

" " is printed if a coefficient cannot be computed 


\begin{tabular}{|c|c|c|c|c|c|}
\hline & \multirow[b]{2}{*}{ EXTOTAL } & \multicolumn{3}{|c|}{$\begin{array}{c}\text { Correlation Coefficients } \\
\text { by Category }\end{array}$} & \multirow[b]{2}{*}{ YPOGRPE } \\
\hline & & TEXTCAT & GRAPHCAT & REFABIL & \\
\hline EXTOTAL & $\begin{array}{l}1.0000 \\
\left(\begin{array}{l}1.05 \\
\mathrm{P}=\end{array}\right.\end{array}$ & $\begin{array}{r}.6268 \\
\left(\begin{array}{r}23 \\
P\end{array}=.001\right.\end{array}$ & $\begin{array}{r}.3045 \\
\left(\begin{array}{r}23 \\
(\mathrm{P}\end{array}\right. \\
.158\end{array}$ & 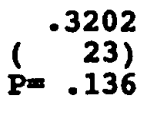 & 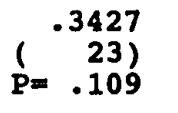 \\
\hline TEXTCAT & 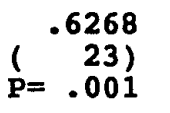 & $\begin{array}{r}1.0000 \\
\left(\begin{array}{r}23 \\
\mathrm{p}=.\end{array}\right.\end{array}$ & 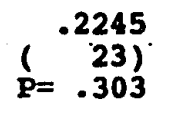 & 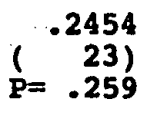 & 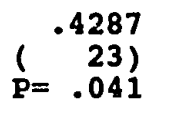 \\
\hline GRAPHCAT & 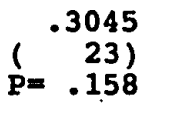 & 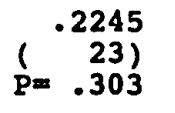 & $\begin{array}{r}1.0000 \\
\left(\begin{array}{r}23 \\
P=\end{array}\right.\end{array}$ & 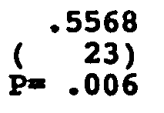 & $\begin{array}{r}.0601 \\
\left(\begin{array}{r}23 \\
\mathrm{p}= \\
.785\end{array}\right)\end{array}$ \\
\hline REFABIL & 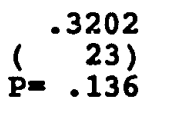 & 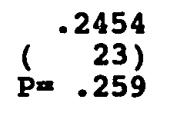 & 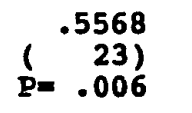 & $\begin{array}{l}1.0000 \\
\left(\begin{array}{l}23 \\
P=\end{array}\right.\end{array}$ & 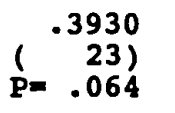 \\
\hline TYPOGRPH & 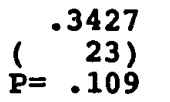 & 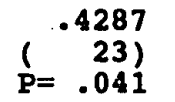 & 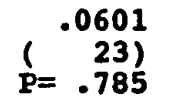 & $\begin{array}{r}.3930 \\
\left(\begin{array}{r}23 \\
P\end{array}\right) .064\end{array}$ & $\begin{array}{r}1.0000 \\
\left(\begin{array}{l}23) \\
p=\end{array}\right.\end{array}$ \\
\hline
\end{tabular}

(Coefficient / (Cases) / 2-tailed significance)

" " is printed if a coefficient cannot be computed 


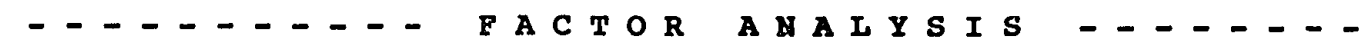
$\cdots$

Analysis number 1 Listwise deletion of cases with missing values

Extraction 1 for analysis 1, Principal components Analysis (PC)

Initial statigtics:

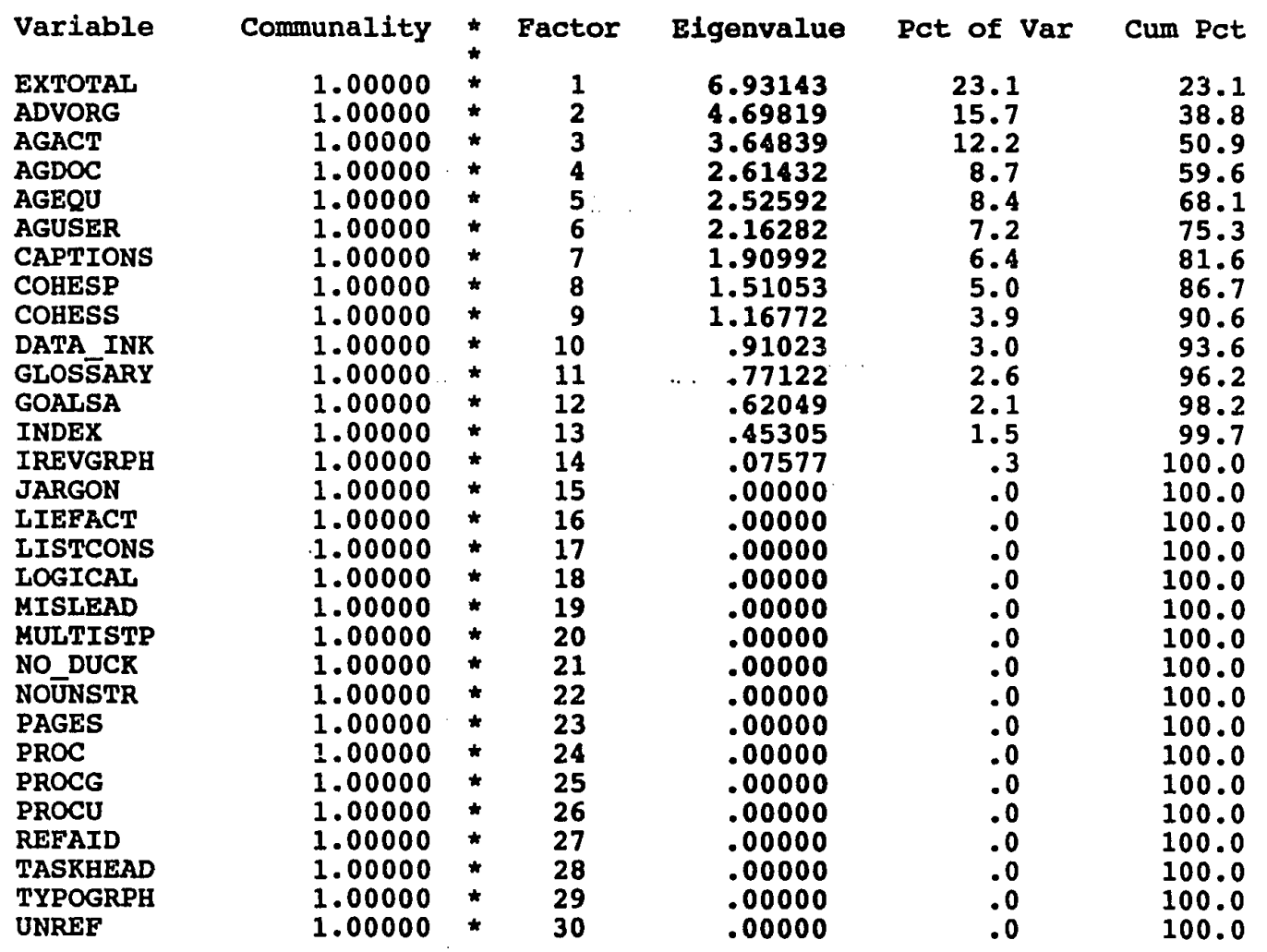




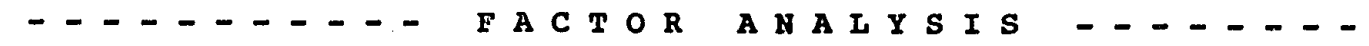

Hi-Res Chart \# 1: Factor scree plot

PC extracted 9 factors.

Factor Matrix:

Factor 5

Factor 1 Factor 2 Factor 3 Factor 4

EXTOTAL

.40797

ADVORG

.50238

AGACT

.11273

AGDOC

.16410

AGEOU

.18587

AGUSER

.34191

CAPTIONS

.16423

COHESP

.12895

COHESS

.20935

DATA INK

$.338 \overline{2} 7$

GLOSSARY

.02375

GOALSA

.02105

INDEX

.26910

IREVGRPH

.04226

JARGON

.62977

IIEFACT

.08135

LISTCONS

.08135

LOGICAI

.63504

MISLEAD

.08135

MULTISTP

.06768

NO DUCK

$.0 \overline{5} 345$

NOUNSTR

.54188

PAGES

.50666

$$
\begin{aligned}
& .53627 \\
& -.09867 \\
& .37773 \\
& .25208 \\
& -.54229 \\
& .26563 \\
& .35498 \\
& .55232 \\
& .32367 \\
& -.09680 \\
& .39537 \\
& .47058 \\
& .70045 \\
& .65507 \\
& .08977 \\
& .79012 \\
& .79012 \\
& .36906 \\
& .79012 \\
& -.31726 \\
& .58564 \\
& .04449 \\
& .44306
\end{aligned}
$$$$
.12523
$$$$
.28841
$$$$
.23612
$$$$
-.20498
$$$$
-.34129
$$$$
.55566
$$$$
.56917
$$$$
.18942
$$$$
-.06955
$$$$
-.74060
$$$$
-.25069
$$$$
.08926
$$$$
-.00515
$$$$
-.07815
$$$$
-.62415
$$$$
.30817
$$$$
.20586
$$$$
.63654
$$$$
-.63814
$$$$
-.07142
$$$$
.31886
$$$$
.15149
$$$$
.23617
$$$$
-.28983
$$$$
-.14750
$$$$
.49927
$$$$
.13234
$$$$
-.17653
$$$$
-.24607
$$$$
.48476
$$$$
-.85865
$$$$
.03238
$$$$
-.01520
$$$$
.44849
$$$$
-.29719
$$$$
.39992
$$$$
-.00029
$$$$
.47516
$$$$
-.34407
$$$$
.37016
$$$$
-.57839
$$$$
.01773
$$$$
-.07544
$$$$
.39606
$$$$
-.19387
$$$$
.20257
$$$$
-.51062
$$$$
-.17031
$$$$
.20257
$$$$
-.51062
$$$$
-.17031
$$$$
-.03161
$$$$
.17891
$$$$
-.23808
$$$$
.20257
$$$$
-.51062
$$$$
-.17031
$$$$
.54741
$$$$
-.02446
$$$$
.06485
$$$$
.02983
$$$$
-.22736
$$$$
.02954
$$$$
.28832
$$$$
.52487
$$$$
-.29511
$$$$
.32468
$$$$
.46683
$$$$
.06085
$$ 
204

PROC
.25391
PROCG
.03690
PROCU
.05923
REFAID
.07520
TASKHEAD
.17925
TYPOGRPH
.27895
UNREF
.27660

$$
\begin{array}{r}
.79080 \\
.18919 \\
-.50676 \\
.54778 \\
.54119 \\
.21272
\end{array}
$$

Factor 6

Factor 7

EXTOTAL

ADVORG

AGACT

AGDOC

AGEQU

$-.28688$

.13931

.02171

.23608

$-.23351$

.00134
-.15442
.61759
.05744
-.033473

Pactor 8

Factor 9

$$
\begin{array}{r}
.28794 \\
.39487 \\
-.07103 \\
-.04481 \\
.12962
\end{array}
$$




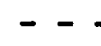

- -
F A T O R

Factor 6

AGUSER

CAPTIONS

COHESP

COHESS

DATA INR

GLOSSARY

GOALSA

INDEX

IREVGRPH

JARGON

LIEFACT

IISTCONS

LOGICAI

MISLBAD

MULTISTP

NO DUCK

NOŪNSTR

PAGES

PROC

PROCG

PROCU

REEAID

TASKHEAD

TYPOGRPH

UNREF
A N A I Y I S

$\begin{array}{rr}\text { Ractor } 8 & \text { Factor } \\ .02081 & .34671 \\ .28345 & .17590 \\ .29649 & -.39358 \\ .20152 & -.08002 \\ -.29523 & .08433 \\ -.15406 & -.01113 \\ .05248 & -.18619 \\ .13852 & -.09769 \\ -.09381 & -.05435 \\ -.08153 & .21931 \\ .00304 & .16253 \\ .00304 & .16253 \\ -.20962 & .10500 \\ .00304 & .16253 \\ .55236 & .25210 \\ -.31537 & .08209 \\ -.14630 & .08273 \\ .18568 & .07609 \\ .15058 & .06045 \\ .04897 & -.22849 \\ -.19760 & -.17619 \\ .12401 & .00451 \\ -.42217 & .14333 \\ -.28482 & .17783 \\ -.21681 & -.43871\end{array}$

Final Statistics:

$\begin{array}{lrcrrrr}\text { Variable } & \text { Communality } & * & \text { Factor } & \text { Eigenvalue } & \text { Pct of Var } & \text { Cum Pct } \\ \text { EXTOTAI } & .83119 * & 1 & 6.93143 & 23.1 & 23.1 \\ \text { ADVORG } & .94471 * & 2 & . .4 .69819 & 15.7 & 38.8 \\ \text { AGACT } & .90789 & \star & 3 & 3.64839 & 12.2 & 50.9 \\ \text { AGDOC } & .89834 * & 4 & 2.61432 & 8.7 & 59.6 \\ \text { AGEQU } & .95375 * & 5 & 2.52592 & 8.4 & 68.1 \\ \text { AGUSER } & .95939 * & 6 & 2.16282 & 7.2 & 75.3 \\ \text { CAPTIONS } & .87023 * & 7 & 1.90992 & 6.4 & 81.6 \\ \text { COHESP } & .86389 * * & 8 & 1.51053 & 5.0 & 86.7 \\ \text { COHESS } & .60110 * & 9 & 1.16772 & 3.9 & 90.6\end{array}$




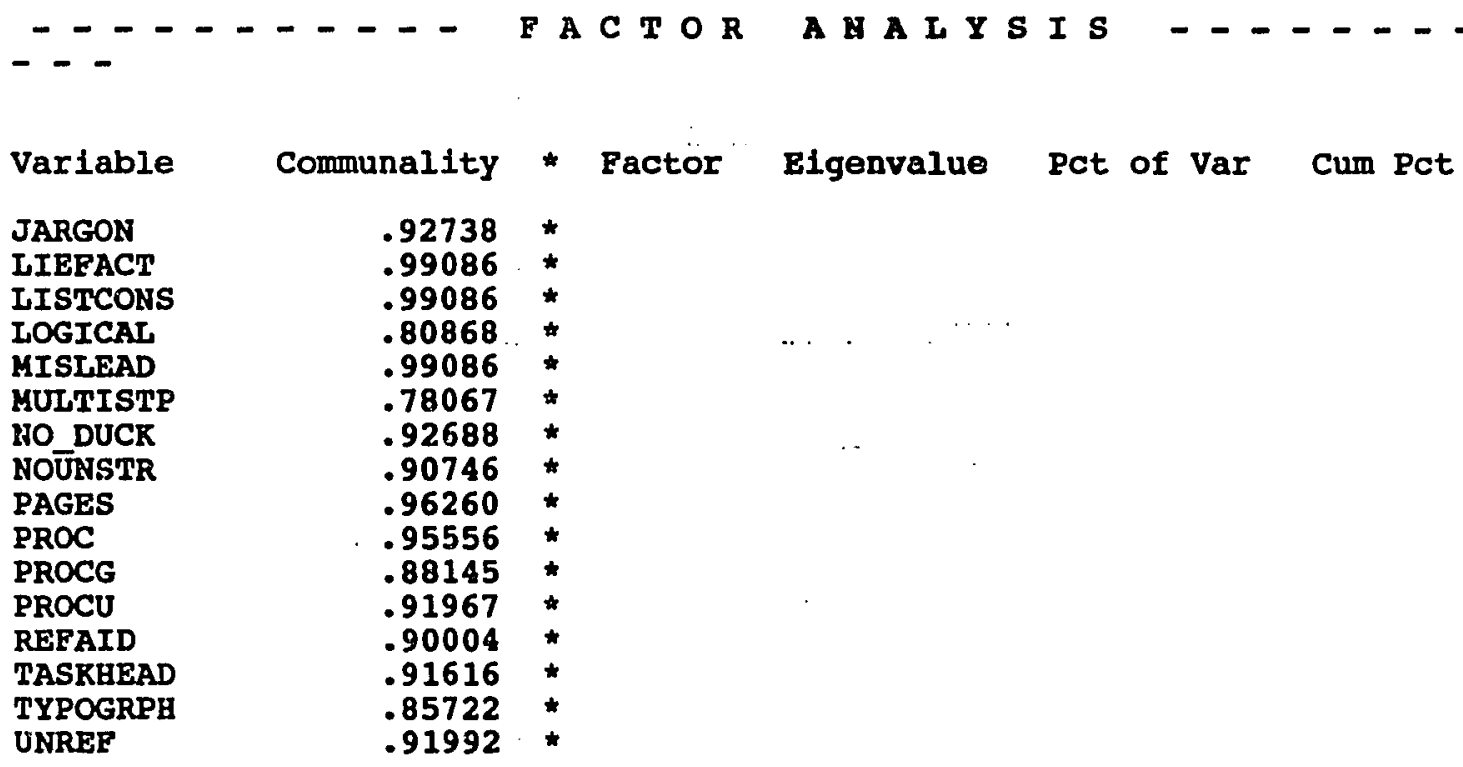

Skipping rotation 1 for extraction 1 in analysis 1 


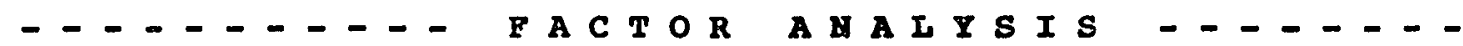
$--$

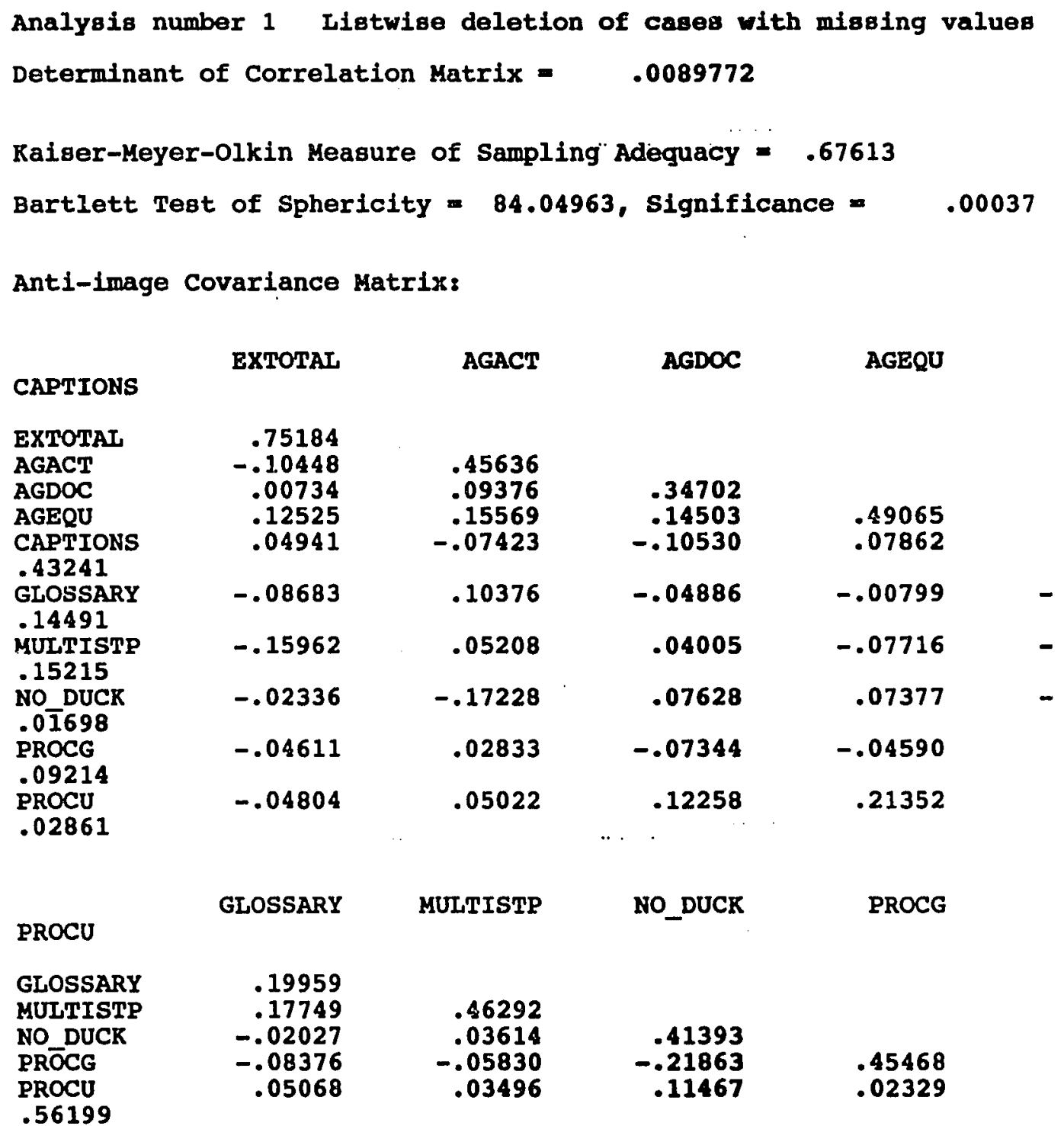

Anti-image Correlation Matrix:

\begin{tabular}{|c|c|c|c|c|c|c|}
\hline MULTISTP & EXTOTAL & AGACT & AGDOC & AGEQU & CAPTIONS & GLOSSARY \\
\hline $\begin{array}{l}\text { EXTOTAL } \\
\text { AGACT } \\
\text { AGDOC } \\
\text { AGEQU }\end{array}$ & $\begin{array}{r}.62666 \\
-.17836 \\
.01437 \\
.20621\end{array}$ & $\begin{array}{r}.54475 \\
.23562 \\
.32903\end{array}$ & $\begin{array}{l}.78680 \\
.35149\end{array}$ & .57069 & & \\
\hline
\end{tabular}




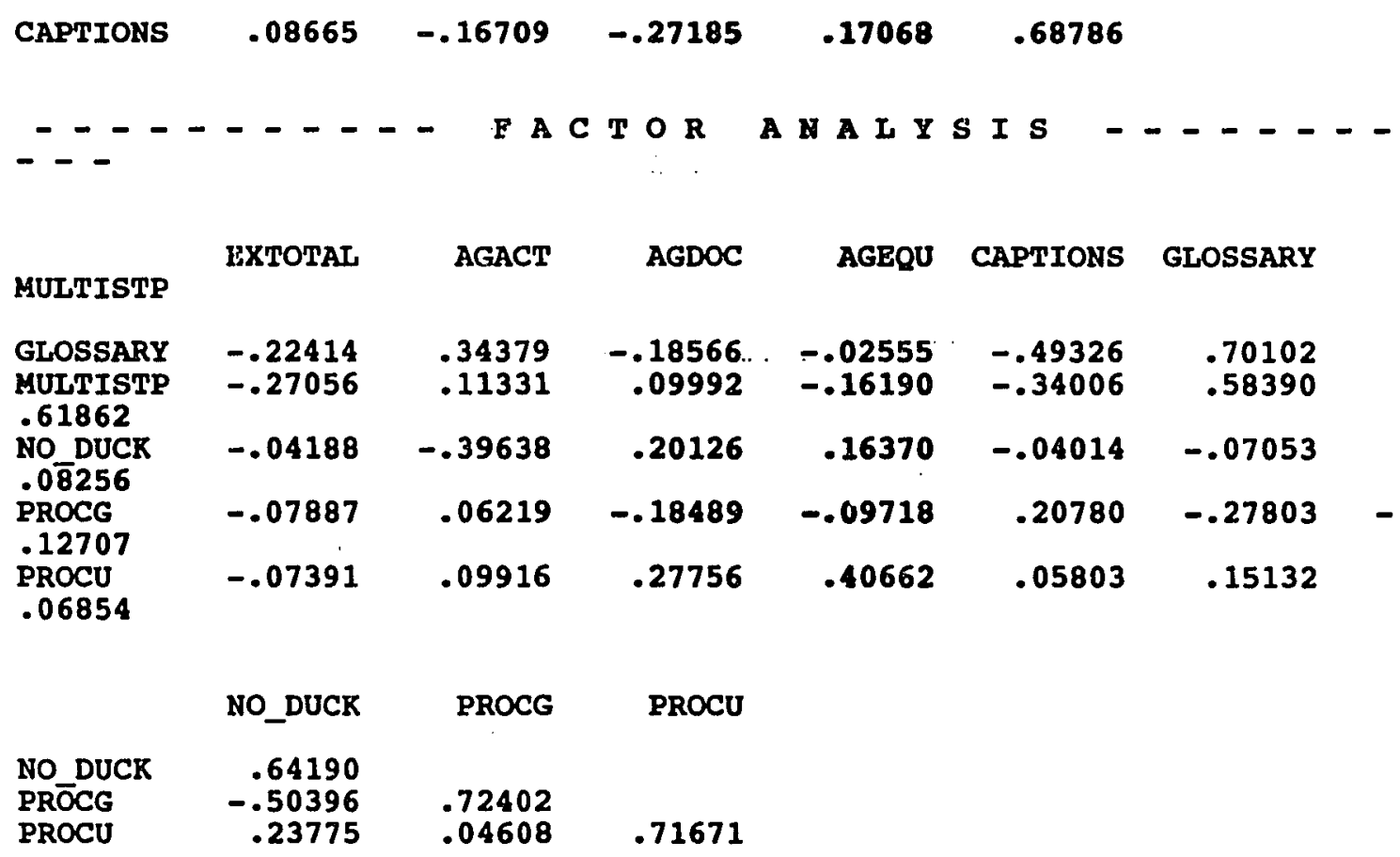

Measures of Sampling Adequacy (MSA) are printed on the diagonal.

Extraction 1 for analysis 1, Principal Axis Factoring (PAF)

Initial Statistics:

$\begin{array}{lrlrrrr}\text { Variable } & \text { Communality } & * & \text { Factor } & \text { Eigenvalue } & \text { Pct of var } & \text { Cum Pct } \\ \text { EXTOTAL } & .24816 & * & 1 & 3.65541 & 36.6 & 36.6 \\ \text { AGACT } & .54364 & * & 2 & 1.98186 & 19.8 & 56.4 \\ \text { AGDOC } & .65298 & * & 3 & 1.24993 & 12.5 & 68.9 \\ \text { AGEQU } & .50935 & * & 4 & .86274 & 8.6 & 77.5 \\ \text { CAPTIONS } & .56759 & * & 5 & .73013 & 7.3 & 84.8 \\ \text { GLOSSARY } & .80041 & * & 6 & .50561 & 5.1 & 89.9 \\ \text { MULTISTP } & .53708 & * & 7 & .39175 & 3.9 & 93.8 \\ \text { NODUCK } & .58607 & * & 8 & .27073 & 2.7 & 96.5 \\ \text { PROCG } & .54532 & * & 9 & .21588 & 2.2 & 98.6 \\ \text { PROCU } & .43801 & * & 10 & .13595 & 1.4 & 100.0\end{array}$

PAF extracted 3 factors. 42 iterations required.

Factor Matrix:

EXTOTAL

Factor 1 Factor 2 Factor 3

$.20529 \quad .37687 \quad-.02489$




\section{$-\infty-$

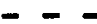

A 8 \& $I$ I 8 I 8 -

Factor 1 Factor 2 | Factor 3

$\begin{array}{lrrr}\text { AGACT } & -.10644 & .72198 & .08403 \\ \text { AGDOC } & .77695 & -.26981 & -.22666 \\ \text { AGEQU } & -.42218 & -.65624 & .62137 \\ \text { CAPTIONS } & .63246 & -.03979 & -.18923 \\ \text { GLOSSARY } & .91643 & -.26922 & -.05230 \\ \text { MULTISTP } & -.55508 & .10652 & .08766 \\ \text { NODDUCR } & .53473 & .59842 & .51393 \\ \text { PROCG } & .62527 & .08124 & .35606 \\ \text { PROCU } & -.50592 & .21291 & -.33860\end{array}$

Final Statistics:

$\begin{array}{lrccccr}\text { Variable } & \text { Communality } & * & \text { Factor } & \text { Eigenvalue } & \text { PCt of Var } & \text { Cum PCt } \\ \text { EXTOTAL } & .18480 & * & 1 & 3.31619 & 33.2 & 33.2 \\ \text { AGACT } & .53965 & * & 2 & 1.66218 & 16.6 & 49.8 \\ \text { AGDOC } & .72783 & * & 3 & .99694 & 10.0 & 59.8 \\ \text { AGEQU } & .99499 & * & & & & \\ \text { CAPTIONS } & .43739 & * & & & & \\ \text { GLOSSARY } & .91506 & \star & & & & \\ \text { MULTISTP } & .32715 & * & & & & \\ \text { NO DUCR } & .90817 & * & & & & \\ \text { PROCG } & .52434 & * & & & & \\ \text { PROCU } & .41593 & * & & & & \end{array}$

VARIMAX rotation 1 for extraction, 1 in analysis 1 - Kaiser Normalization.

VARIMAX converged in 9 iterations.

Rotated Factor Matrix:

$\begin{array}{lccc} & \text { Factor } 1 & \text { Factor } 2 & \text { Pactor } 3 \\ \text { EXTOTAL } & .06392 & .40425 & .13149 \\ \text { AGACT } & -.35880 & .62658 & .13530 \\ \text { AGDOC } & .84441 & -.01577 & .12061 \\ \text { AGEQU } & -.39709 & -.88150 & .24548 \\ \text { CAPTIONS } & .63096 & .15635 & .12178 \\ \text { GLOSSARY } & .89445 & -.03358 & .33749\end{array}$


$-$ $--$

$\begin{array}{lrrr} & \text { Factor } 1 & \text { Factor } 2 & \text { Pactor } 3 \\ \text { MULTISTP } & -.54574 & -.04825 & -.16428 \\ \text { NO DUCK } & .06016 & .53181 & .78850 \\ \text { PROCG } & .36836 & .11372 & .61296 \\ \text { PROCU } & -.36824 & .18233 & -.49708\end{array}$

Factor Transformation Matrix:

Factor 1 Factor 2 Factor 3

Factor 1

.85807
-.32411

$-.39834$
.46334

.87267
.15414 